University of Nebraska - Lincoln

DigitalCommons@University of Nebraska - Lincoln

Dissertations, Theses, \& Student Research in Food Science and Technology

Food Science and Technology Department

$5-2012$

\title{
Characterization of IgG and IgE Binding to Parvalbumin Derived from Commercially Important Fish Species
}

Poi-Wah Lee

University of Nebraska-Lincoln, leepoiwah@yahoo.com

Follow this and additional works at: https://digitalcommons.unl.edu/foodscidiss

Part of the Food Science Commons

Lee, Poi-Wah, "Characterization of IgG and IgE Binding to Parvalbumin Derived from Commercially Important Fish Species" (2012). Dissertations, Theses, \& Student Research in Food Science and Technology. 23.

https://digitalcommons.unl.edu/foodscidiss/23

This Article is brought to you for free and open access by the Food Science and Technology Department at DigitalCommons@University of Nebraska - Lincoln. It has been accepted for inclusion in Dissertations, Theses, \& Student Research in Food Science and Technology by an authorized administrator of DigitalCommons@University of Nebraska - Lincoln. 
CHARACTERIZATION OF IgG AND IgE BINDING TO PARVALBUMIN DERIVED

FROM COMMERCIALLY IMPORTANT FISH SPECIES

by

Poi-Wah Lee

\section{A DISSERTATION}

Presented to the Faculty of

The Graduate College at the University of Nebraska

In Partial Fulfillment of Requirements

For the Degree of Doctor of Philosophy

Major: Food Science and Technology

Under the Supervision of Professor Steve L. Taylor

Lincoln, Nebraska

May, 2012 


\title{
CHARACTERIZATION OF IgG AND IgE BINDING TO PARVALBUMIN DERIVED FROM COMMERCIALLY IMPORTANT FISH SPECIES
}

\author{
Poi-Wah Lee, Ph.D. \\ University of Nebraska, 2012
}

Adviser: Steve L. Taylor

Parvalbumin is a calcium-binding muscle protein that is present in all vertebrates. Despite being a pan-allergen in fish and frog, fish-specific IgE and antiparvalbumin IgG antibodies displayed varying cross-reactivity among fish species. In this research, the parvalbumin-binding characteristics of several antibodies were investigated, including 3 IgG antibodies against frog, carp, and cod parvalbumins, and human IgE.

By immunoassay and IgG-immunoblotting, 3 antiparvalbumin antibodies revealed inconsistent specificity among 29 raw fish muscle extracts, which may be partially attributed to the decreased levels of fish muscle parvalbumin from anterior to posterior positions. Parvalbumin-binding by antibodies was unaffected in 112 days of frozenstored fish muscles. Anticod parvalbumin polyclonal antibody (anticod PoAb) was the most suitable for detecting parvalbumins as it reacted to the widest range, but not all fish species.

IgE-immunoblotting demonstrated intra- and inter-individual diversity in IgEbinding to fish and frog proteins. Of 39 fish-allergic individuals, $>50 \%$ subjects bound to purified cod and carp parvalbumins, and proteins corresponding to parvalbumins in 21 
fish extracts, whereas $<13 \%$ had IgE-binding to parvalbumins in mahi-mahi, swordfish, and frog extracts. The IgE-reactive spots on two-dimensional gel electrophoresis were identified by mass spectrometry as $\alpha$ - and $\beta$-actin, desmin, glyceraldehyde 3 -phosphate dehydrogenase, fast myosin light chain, enolase, and creatine kinase besides parvalbumins.

Heating, calcium-depletion and Maillard reactions affected the 3 antiparvalbumin IgG antibodies binding to fish muscle extracts and cod parvalbumin, although anticod PoAb was less affected. Both Maillard and heat treatments reduced IgE binding to cod parvalbumin and these effects were more pronounced without calcium.

Parvalbumins among fish revealed higher sequence identity than non-fish species. Both calcium-binding loops representing Gad c 1 epitopes were conserved among fish and non-fish, whereas low homology in $\mathrm{AB}$ domain and $\mathrm{AB} / \mathrm{CD}$ inter-domain junction of fish parvalbumins may contribute to variable cross-reactivity among fish. Phylogenetic analysis showed that all fish parvalbumins but zebrafish and pike were closely related. Teleost $\beta$-parvalbumins were closely related to $\beta$-parvalbumins of amphibians and reptiles, but divergent from $\alpha$-parvalbumin in mammals and non-mammals. 


\section{ACKNOWLEDGEMENTS}

I would like to express gratitude to those who have assisted me in various aspects of this research and throughout my PhD studies.

First and foremost, I wish to express my sincere appreciation and deepest gratitude to my adviser, Dr. Steve Taylor, for providing the guidance and support when I needed them the most. Thank you for beliving in me and giving me the opportunity to pursue a $\mathrm{PhD}$. His mentoring, patience, and great flexibility that he offered are invaluable in my research skills development. Also, he encouraged and provided me the opportunity to attend national and international conferences for my professional development. I would like to thank him for all his valuable time in reviewing and editing my dissertation and manuscripts. Without his supervision, this research would have not been successful. Appreciation is also expressed to my committee members, Dr. Stef Koppelman, Dr. Rick Goodman, Dr. Vicki Schlegel, Dr. Jens Walter, and Dr. John Markwell for their continual scientific guidance, suggestions, and interest in this project.

Special thanks are given to Dr. Joe Baumert for lending his expertise to this project and sharing his professional advice and inputs. I am indebted to Julie Nordlee for her patience and time training me with the laboratory techniques. She has provided continuous support and guidance and was excellent to work with and learn from. I appreciated all her advice on both professional and personal levels. Also, the fishing trip that she took to help expand the list of fish species for this project was greatly appreciated. A great deal of gratitude also goes to all colleagues and friends in the FARRP lab, especially Lynn Niemann, Debra Lambrecht, Ferdelie Gaskin, Pat Gergen, and Jamie Kabourek for their great support and for creating a pleasant working 
environment. I owe my thanks to my labmates and friends, Rakhi Panda, Pei Wen Lim, Afua Ofori-Anti, Pramod Siddanakoppalu, Melanie Downs, Ben Remington, Jelena Spiric, Brigitta Santha, Kaye Ivens, Denise Tran, Plaimein Amnuaycheewa, Fulei Luan, Kwame Andoh, and Joey Lim for their friendship and unconditional support.

I would like to thank FARRP for providing the financial support for this project. I would also like to acknowledge Allergy, Asthma and Immunology Associates (Lincoln and Omaha, NE), University Hospital (Zurich Switzerland), University Medical Center (Utrecht, The Netherlands), and John Hopkins University Dermatology Allergy and Clinical Immunology Reference Laboratory (Baltimore, MD) for providing the human sera. A sincere thank you is extended to Martha R. Wiberg (Gorton's Inc.), Richard Norland (Norland Products Inc.), Dr. Yi-Cheng Su (Oregon State University), and Tony Korth (Nebraska Game and Parks Commission) for their generous donation of the fish samples, and Monte Conrad (Surf and Turf) for his help in getting the tuna sample. I am grateful to E. Pearce Smith (Eurofins GeneScan, Inc.) for his technical assistance in fish authentication and Roger Powell (National Jewish Health) for his assistance in the mass spectrometry analysis. I also thank John Wise for his useful help in bioinformatics and Dr. Devin Rose, Nyambe Lisulo Mkandawire, and Junyi Yang for use of the freeze dryer and their technical assistance.

Finally, a heartfelt thanks goes to my family, who have provided me with unending love, support and understanding, and have encouraged me to work hard and chase my ambitions in life. 
TABLE OF CONTENTS

ABSTRACT

CHAPTER 1: LITERATURE REVIEW .......................................... 1

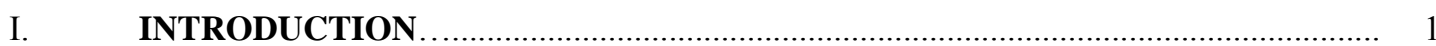

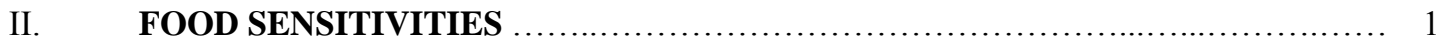

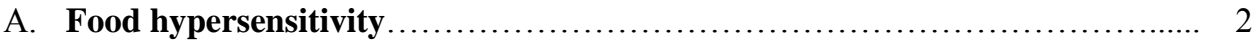

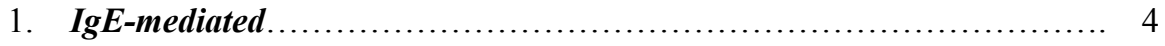

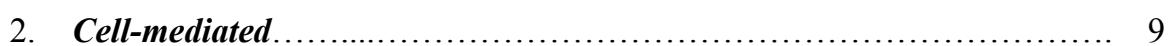

B. Food Intolerance.................................................................. 11

1. Anaphylactoid reactions......................................... 11

2. Metabolic disorders................................................ 12

3. Idiosyncratic reactions............................................. 13

4. Pharmacological reactions.................................................. 13

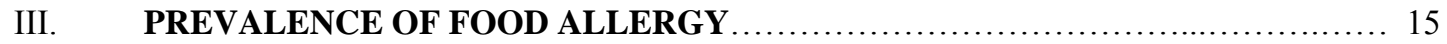

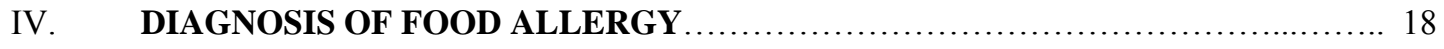

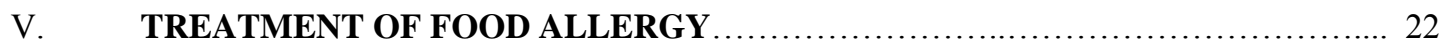

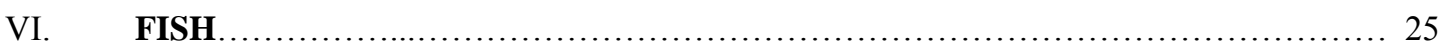

A. Fish classification, composition, and uses.............................. 26

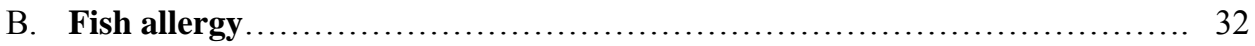

1. Prevalence ......................................................... 33

2. Diagnosis............................................................ 34

3. Threshold .......................................................... 36

4. Cross-reactivity among fish species................................ 37

5. Fish allergens................................................ 39

a. Parvalbumin ................................................... 39

b. Minor allergens.................................................. 43

C. Detection methods for fish....................................................... 46

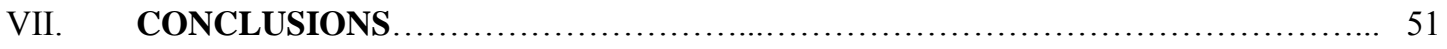

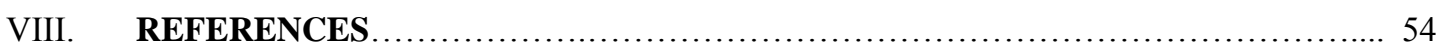


CHAPTER 2: EVALUATION AND COMPARISON OF THE SPECIESSPECIFICITY OF 3 ANTI-PARVALBUMIN IgG ANTIBODIES .73

CHAPTER 3: MEASURING PARVALBUMIN LEVELS IN FISH MUSCLE TISSUE: RELEVANCE OF MUSCLE LOCATIONS AND STORAGE CONDITIONS

CHAPTER 4: SEROLOGICAL SCREENING OF IgE BINDING TO PURIFIED PARVALBUMINS AND MUSCLE PROTEINS OF 26 FISH AND FROG SPECIES BY IMMUNOBLOTTING.

CHAPTER 5: IDENTIFICATION OF POTENTIAL ALLERGENS IN COD, CUSK, HERRING, PILCHARD, AND TROUT BY PROTEOMIC APPROACHES.

CHAPTER 6: EFFECTS OF HEATING, CALCIUM, AND MAILLARD REACTIONS ON THE IgE AND IgG BINDING TO FISH PARVALBUMINS

CHAPTER 7: EVALUATION OF THE EVOLUTIONARY RELATIONSHIP OF PARVALBUMINS 


\section{LIST OF TABLES}

PAGE

\section{CHAPTER 1}

Table 1.

Symptoms of IgE-mediated food allergies

Table 2.

Proximate composition of edible parts of raw cod, tuna, and salmon. ...

\section{CHAPTER 2}

Table 1.

Scientific names and sources of fish and frog samples.

\section{CHAPTER 4}

Table 1.

Characteristics of fish-allergic subjects and in vitro diagnosis

Table 2.

Scientific names and sources of fish and frog samples

Table 3.

Immunoblot recognition of fish and frog proteins of different MW ranges by sera IgE from 39 fish-allergic subjects

\section{CHAPTER 5}

Table 1.

Clinical and serological characteristics of the fish-allergic subjects.

Table 2. Identification of IgE-reactive spots excised from 2-DE by LC$\mathrm{MS} / \mathrm{MS}$ analysis.

Table 3. Summary of peptides identified for IgE-reactive spots by LC$\mathrm{MS} / \mathrm{MS}$ analysis.

Table 4. Sequence homology shared between IgE-reactive proteins identified by LC-MS/MS and known allergens, as determined by FASTA search. 


\section{LIST OF TABLES (cont.)}

PAGE

\section{CHAPTER 6}

Table 1.

Characteristics of fish-allergic subjects and in vitro diagnosis......

Table 2.

Experimental conditions for competitive-inhibition IgG-ELISA....

\section{CHAPTER 7}

Table 1.

Detailed information on the parvalbumin sequences from fish and non-fish species, including biological classifications for the source organisms of the parvalbumin sequences, sequence identification numbers (GI), and protein names.................

Table 2. Comparisons of the \% ID of parvalbumin sequences among fish species in the class of Actinopterygii, and non-fish species, specifically human $\alpha$ - or $\beta$-parvalbumin...................... 


\section{LIST OF FIGURES}

PAGE

\section{CHAPTER 1}

Figure 1.

Classifications of various types of food sensitivities

2

Figure 2. Mechanism involved in IgE-mediated reaction

6

\section{CHAPTER 2}

Figure 1. SDS-PAGE profiles of the raw muscle protein extracts of frog and fish species. Five micrograms of crude fish extract and $1 \mu \mathrm{g}$ of the purified cod and carp parvalbumin were separated under reducing condition. The family and order of the species were represented by bold and italic characters, respectively......................

Figure 2. Reactivity of anti-frog, anti-carp, and anti-cod parvalbumin antibodies with the raw muscle extracts of frog and fish species, as determined by the indirect ELISA. Each column and error bars represents the mean absorbance values and standard error of the mean of 18 readings, respectively

Figure 3. IgG-immunoblot analysis of the anti-frog MoAb reactivity with the raw muscle protein extracts of frog and fish species.

Figure 4. IgG-immunoblot analysis of the anti-carp MoAb reactivity with the raw muscle protein extracts of frog and fish species.

Figure 5. IgG-immunoblot analysis of the anti-cod PoAb reactivity with the raw muscle protein extracts of frog and fish species 


\section{LIST OF FIGURES (cont.)}

PAGE

\section{CHAPTER 3}

Figure 1

Stability of parvalbumin during frozen storage of carp, catfish, chub mackerel, sardine, chinook salmon, and albacore tuna, as determined by the indirect ELISA using anti-frog MAb, anti-carp $\mathrm{MAb}$, and anti-cod PAb.

Figure 2. SDS-PAGE profiles of the raw muscles obtained from 6 different body positions of 2 carp (Carp A and B), 2 catfish (Catfish A and B), one albacore tuna, and one mahi-mahi.

Figure 3. Band intensity ratio of parvalbumin to total proteins (expressed as a percentage) in 6 body positions of 2 carp (Carp A and B), 2 catfish (Catfish A and B), one albacore tuna, and one mahi-mahi, as determined by the densitometry analysis of stained SDS-PAGE gels

Figure 4. Reactivity of anti-frog MAb, anti-carp MAb, and anti-cod PAb with the raw muscle extracts obtained from 6 different body positions of 2 carp (Carp A and B), 2 catfish (Catfish A and B), one albacore tuna, and one mahi-mahi, as determined by the indirect ELISA.

\section{CHAPTER 4}

Figure 1.

SDS-PAGE profiles of purified cod and carp parvalbumin, and raw muscle protein extracts of frog and fish species.

Figure 2. Immunoblot analysis of purified cod and carp parvalbumins, and crude extracts of fish and frog muscles with sera IgE from fishallergic Subject no. 24 and 27 .

Figure 3. Frequency and mean IgE-binding intensity of sera from 39 fishallergic subjects to fish and frog proteins at $10-13 \mathrm{kDa}$ on immunoblots 


\section{LIST OF FIGURES (cont.)}

PAGE

\section{CHAPTER 5}

Figure 1. Colloidal-stained 1-D SDS-PAGE profiles and the corresponding immunoblot analysis of cod, cusk, herring, pilchard, and trout using individual serum from 7 fish-allergic subjects.

Figure 2. Colloidal-stained 2-DE profiles of cod, cusk, herring, pilchard, and trout and the corresponding immunoblot analysis of cod, cusk, herring, pilchard, and trout using pooled sera from 7 fish-allergic subjects

\section{CHAPTER 6}

Figure 1.

Inhibitors concentrations at $50 \%$ inhibition $\left(\mathrm{IC}_{50}\right)$ of antifrog $\mathrm{PV}$ MoAb, anticarp PV MoAb, and anticod PV PoAb binding to PBSextracted raw muscle proteins coated on plate, as determined by competitive-inhibition IgG-ELISA

Figure 2. Inhibitors concentrations at 50\% inhibition $\left(\mathrm{IC}_{50}\right)$ of anticarp PV MoAb, and anticod PV PoAb binding to native cod PV coated on plate, as determined by competitive-inhibition IgG-ELISA......... 222

Figure 3. Inhibitors concentrations at $50 \%$ inhibition $\left(\mathrm{IC}_{50}\right)$ of $\mathrm{IgE}$ binding to native cod PV coated on plate, as determined by competitiveinhibition IgE-ELISA.................................... 223

\section{CHAPTER 7}

Figure 1. Multiple alignment of the parvalbumin sequences from fish and non-fish species using Clustal W program..................... 242

Figure 2. $\quad$ Sequence of $\beta$-parvalbumin from Baltic $\operatorname{cod}(\mathrm{Gad} \mathrm{c} 1) \ldots \ldots \ldots \ldots \ldots$

Figure 3. Pairwise comparisons of the parvalbumin sequences between fish and non-fish species.........................................

Figure 4. Phylogenetic relationship of the parvalbumins from fish and nonfish ${ }^{2}$ ecies.......................................... 256 


\section{LIST OF APPENDICES}

PAGE

Appendix A. Characteristics of fish-allergic subjects and in vitro diagnosis....... 257

Appendix B. Immunoblot analysis of IgE binding from non-atopic, atopic, and 47 fish-allergic subjects (serum \#1 - \#47) to purified cod and carp parvalbumins, and crude extracts of fish and frog muscles......... 260

Appendix C. Frequency and mean IgE-binding intensity of sera from 39 fishallergic subjects to fish and frog proteins of different molecular weights ranges on immunoblots............................... 


\section{CHAPTER 1: LITERATURE REVIEW}

\section{INTRODUCTION}

Food is vital for life; however, food can provoke adverse allergic reactions, ranging from mild to life threatening in some sensitive individuals. Living with food sensitivity can be challenging for those affected and their families. To prevent the ingestion of the offending allergens, the susceptible individuals rely exclusively on a strict avoidance diet, diligent label reading, and careful selection of foods. Food allergies are on the rise, especially in developed countries. Although it affects only a small percentage of the population, extensive research and investigations have been devoted to this area in recent years due to the severity of some allergic reactions. This review will provide an overview of the various types of adverse reactions to foods, in particular food allergy, its mechanisms, prevalence, diagnosis, and treatments. Furthermore, general facts about fish, fish allergy and allergens, and detection methods for fish will be discussed.

\section{FOOD SENSITIVITIES}

Food sensitivity is used to describe individualistic adverse reaction to foods, which cover a broad range of food-related illnesses that primarily affect only a small proportion of the population (Taylor, 1987). In general, food sensitivities are classified as either primary food sensitivities or secondary food sensitivities as depicted in Figure 1. The primary food sensitivities are differentiated between responses that involve either the immunological system (food hypersensitivity/allergy) or the non-immunological mechanisms (food intolerance). Further classifications of non-immunological food 
sensitivities include anaphylactoid reaction, metabolic food disorder, and idiosyncratic reaction (Taylor and Hefle, 2002). Food intolerance can often be managed by restricting the amount of offending food or food ingredient intake. In contrast, allergy sufferers are obliged to follow a stricter avoidance diet (Taylor and Hefle, 2002). Compared to primary food sensitivities, secondary food sensitivities are less common and are those adverse food reactions that require a predisposed condition such as drug therapy or a preexisting illness (Taylor, 1987).

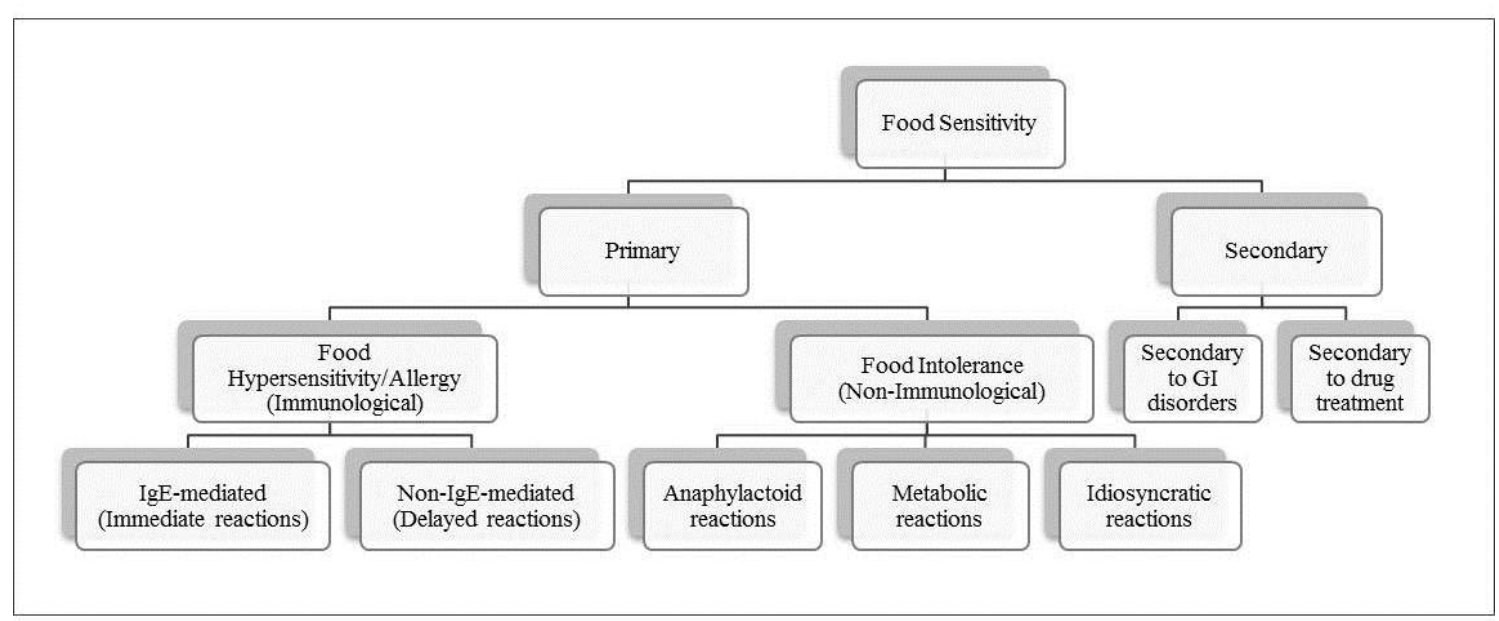

Figure 1. Classifications of various types of food sensitivities. (Modified from Taylor and Hefle, 2001).

\section{Food hypersensitivity}

The immune system is composed of a dynamic network of cells, tissues, and organs that defend and protect the host against infectious organisms, such as viruses, bacteria, parasites, and other foreign invaders. It is capable of distinguishing between foreign molecules and self antigens. When the immune system encounters foreign invaders, an appropriate immune response, called an effector response, is mounted that 
specifically eliminates or neutralizes the targeted invaders. A subsequent exposure of the host with the same invader induces a more rapid and heightened memory response, thereby providing life-long immunity to the foreign antigens (Goldsby et. al, 2003).

On occasion, the immune system can malfunction, resulting in inappropriate inflammatory response that can have damaging effects, such as tissue damage or even death in certain individuals. This altered biological state is referred to as hypersensitivity or allergy (Goldsby et. al., 2003). According to the Gell and Coombs classification (1975), these hypersensitivity reactions can be divided into four types based on the reaction mechanisms manifested. A Type I (IgE-mediated) hypersensitivity reaction is initiated by allergen or antigen crosslinking IgE antibodies bound on the surfaces of basophils and mast cells, leading to the release of pharmacologically active mediators. A Type II (antibody-mediated cytotoxic) hypersensitivity reaction occurs when an antibody reacts with antigenic components of a tissue cell, resulting in the destruction of cells by complement and antibody-dependent cell-mediated cytotoxicity. A Type III (immune complex-mediated) reaction involves the deposition of antigen-antibody complexes in various tissues, causing massive complement activation or local inflammation. A Type IV (delayed-type or cell-mediated) hypersensitivity reaction is induced by intracellular pathogens and contact antigens that activate sensitized $\mathrm{T}$ helper cells to release cytokines. This reaction has a delayed onset response due to the time required for the cytokines to recruit and attract macrophages and other non-specific inflammatory cells to the site of inflammation and mediate cellular damage (Coombs and Gell, 1975; Goldsby et al., 2003). Type I, III, and IV reactions may occur with foods (Lemke and Taylor, 1997; Taylor, 1987). 
Food hypersensitivities, also referred to as true food allergies, are defined as abnormal and heightened responses of the body's immune system to specific food components that are normally harmless. The allergens are typically naturally occurring proteins present in certain foods (Taylor and Hefle, 1999). Food hypersensitivity can be subdivided into two categories: immediate hypersensitivity mediated by allergen-specific IgE antibodies with a rapid onset, and delayed hypersensitivity (cell-mediated) induced by sensitized lymphocytes, with symptoms that become apparent at 6 to 24 hours after consumption of the offending foods (Lemke and Taylor, 1997; Taylor et. al, 2000).

\section{IgE-mediated}

Type I, IgE-mediated food allergic reactions are the most extensively studied and defined among the food hypersensitivity disorders. This reaction differs from other normal humoral responses in terms of IgE secretion. Most individuals mount IgE response primarily as a defense against parasitic infections. However, atopic individuals, who suffer from hereditary predisposition to the development of immediate hypersensitivity to environmental antigens, will generate type I allergic reactions to nonparasitic antigens by producing inappropriate IgE responses (Goldsby et al., 2003; Taylor and Hefle, 2001). Antigens that elicit immediate hypersensitivity reactions are called allergens (Mekori, 1996). Allergens eliciting IgE formation can be derived from environmental substances, such as pollens, mold spores, bee venoms, dust mites, and animal danders, besides foods (Taylor and Hefle, 2001).

The mechanism involved in IgE-mediated food-allergic reactions is illustrated in

Figure 2. When the susceptible individuals are exposed to allergens initially, B cells will 
synthesize allergen-specific IgM antibodies to capture, internalize and process the allergens. Subsequently, the processed peptide fragment is presented to allergen-specific $\mathrm{CD}^{+} \mathrm{T}_{\mathrm{H}} 2$ cells via major histocompatibility (MHC) class II molecules, leading to the activation of T cells to secrete IL-4 and express the CD40 ligand (Samaratín, 2001). The interaction between activated $\mathrm{T}$ cells and $\mathrm{B}$ cells facilitate immunoglobulin class switching from IgM to IgE antibodies production. In addition, the B cells are stimulated to differentiate into memory cells and IgE-secreting plasma cells (Austyn, 1997). Once the food-specific IgE antibodies are secreted by plasma cells, they bind to high affinity FceRI receptors on mast cells and basophils, resulting in the generation of sensitized cells (Sampson, 1997). Mast cells mainly reside throughout the connective tissues of the gastrointestinal system, respiratory tract, and skin. On the other hand, basophils are found circulating in the blood, constituting $0.5 \%$ of peripheral blood leukocytes (Costa et. al, 1997; Prussin and Metcalfe, 2006). Upon subsequent exposure to the same allergens, these allergens crosslink bound $\operatorname{IgE}$ antibodies on the surfaces of mast cells and basophils, triggering degranulation of the cells and the release of preformed pharmacologically active mediators into the blood stream and tissues (Taylor and Hefle, 2006a; Lemke and Taylor, 1994). These mediators include histamine, prostaglandins, and leukotrienes that cause smooth-muscle contraction, vasodilation, mucus secretion and other symptoms of immediate hypersensitivity reactions (Sampson, 1991; Winbery and Lieberman, 1995). 


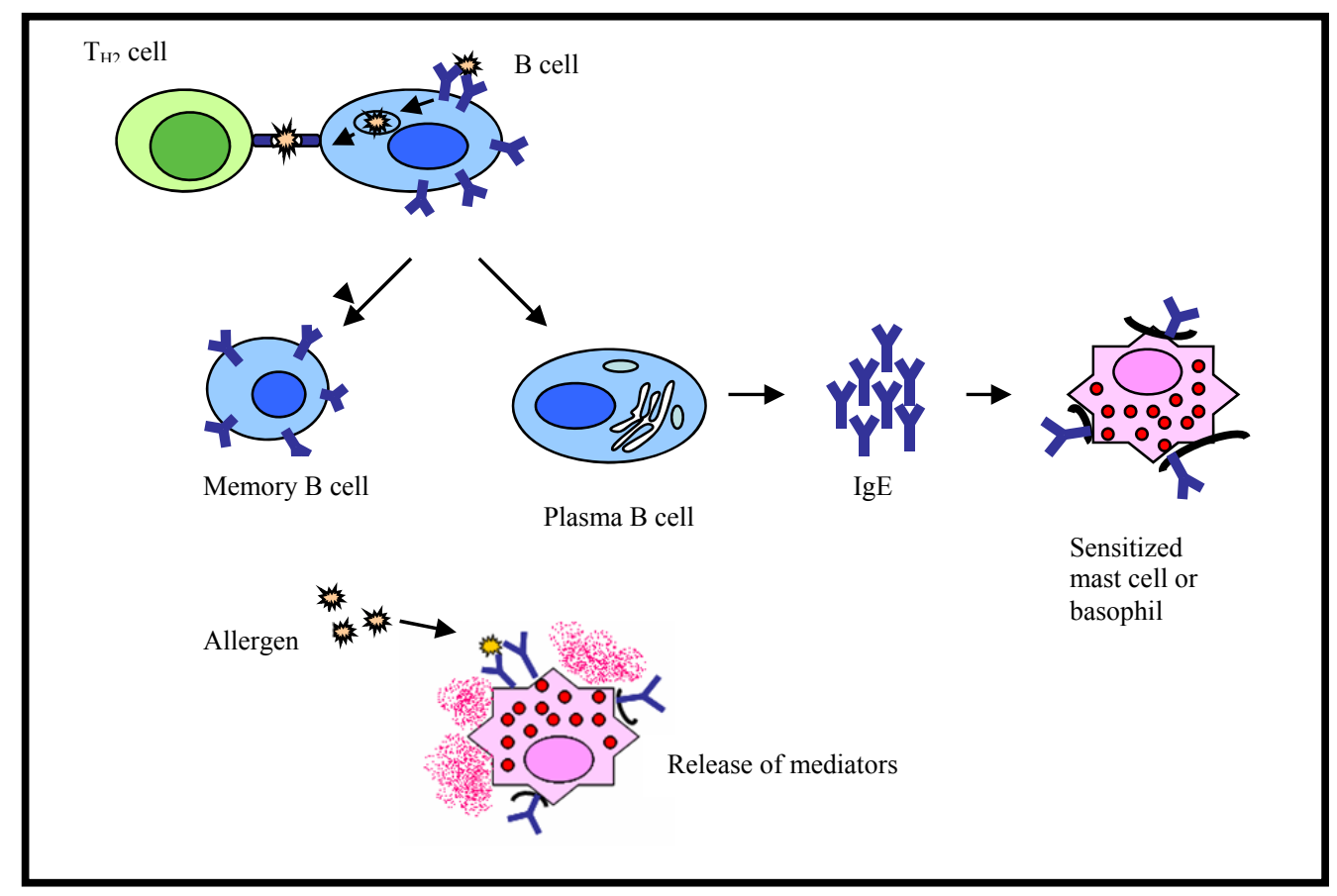

Figure 2. Mechanism involved in IgE-mediated reaction

The development of IgE-mediated food allergy is postulated to result from the breach in oral tolerance to dietary proteins (Chehade and Mayer, 2005). Oral tolerance is a process of tolerating a myriad of proteins through the suppression of cellular and humoral immune responses by means of prior exposure of the proteins orally (Burks et al., 2008). Oral tolerance can be induced by 2 types of mechanisms based on the dose of antigen administered. Low doses of antigen favor tolerance mediated by the regulatory $\mathrm{T}$ cells, whereas high doses of antigen induce lymphocyte anergy or deletion (Burks et al., 2008; Chehade and Mayer, 2005). Regulatory $\mathrm{T}$ cells, including $\mathrm{T}_{\mathrm{H}} 3, \mathrm{~T}_{\mathrm{R}} 1$, and $\mathrm{CD} 4^{+} \mathrm{CD} 25^{+}$cells are responsible for suppressing the immune responses through soluble or surface-bound downregulatory cytokines, such as IL-10 and TGF- $\beta$. CD $4{ }^{+} \mathrm{CD} 25^{+}$cells also express the transcription factor forkhead box P3 (FOXP3) that thought to block the 
$\mathrm{T}_{\mathrm{H}} 1$ and $\mathrm{T}_{\mathrm{H}} 2$ responses (Chehade and Mayer, 2005). Lymophocyte anergy occurs when $\mathrm{T}$ cell recognizes the antigen through T-cell receptor ligation, but in the absence of signals from co-stimulatory molecules, including IL-2. IL-2 is a soluble cytokine required for the proliferation and differention of $\mathrm{T}$ cells into effector cells when they encounter antigen. Another co-stimulatory effect involves the interaction between the receptors on $\mathrm{T}$ cell (CD28) and counterreceptors on antigen presenting cells (CD80 and CD86) (Brandtzaeg, 2002). High-dose tolerance is also mediated by the clonal deletion that occurs through FAS-mediated apoptosis (Burks et al., 2008). Factors affecting the induction of oral tolerance include dose and nature of the antigen, route and timing of exposure, and age, genetics, and normal flora of the host (Chehade and Mayer, 2005).

The symptoms of IgE-mediated food allergies usually appear within minutes or hours after the ingestion of the offending foods. The type and severity of symptoms vary with individuals, depending on the amount of offending food ingested, the tissue receptors that are affected and the degree of mast cell degranulation (Lemke and Taylor, 1994; Sampson and Metcalfe, 1992). Susceptible individuals usually experience only a few of the symptoms listed in Table 1 (Taylor and Hefle, 2001). The most severe response is the acute and potentially fatal anaphylactic shock. Anaphylactic shock, also referred to as systemic anaphylaxis, involves multiple organs and usually occurs within the first hour after ingestion of the offending food (Sampson et al., 1987). Generally, the reaction begins with variable expression of cutaneous, gastrointestinal, and respiratory symptoms, but further progresses to cardiovascular symptoms, including hypotension, vascular collapse, and cardiac dysrhythmias leading to death (Pumphrey, 2000). In the United States, food-induced anaphylaxis is estimated to account for 90,000 emergency 
room visits and 150 - 200 deaths each year (Clark et al., 2011; Sampson, 2003a). Peanut and tree nuts are responsible for the majority of the fatalities (greater than $90 \%$ ) in the United States (Bock et al., 2001, 2007).

Table 1. Symptoms of IgE-mediated food allergies (adapted from Taylor and Hefle, 2001)

\begin{tabular}{||c||l||}
\hline Cutaneous & Urticaria \\
& Eczema or atopic dermatitis \\
Angioedema \\
Pruritis
\end{tabular}

Almost any food with naturally occurring proteins can potentially induce allergic reactions in certain individuals. Despite the abundance of proteins found in foods, only a small percentage has been identified as allergens (Bush and Hefle, 1996; Hefle et al., 1996). In general, potent food allergens are water-soluble glycoproteins that exhibit stability under acidic conditions (Sicherer, 2002; Taylor et al., 1987; Taylor and Lehrer, 1996). The characterization of food allergens revealed that they are comparatively stable to heat, digestion, proteolysis, and processing (Astwood et al., 1996; Taylor and Lehrer, 1996). However, some exceptions do exist. For example, some allergens in fresh fruits and vegetables are relatively labile and sensitive to heat denaturation (Vieths et al., 1996). Among the wide variety of foods consumed, relatively few are frequent causes of 
allergies (Hefle et al., 1996). The eight most common allergenic foods or food groups, sometimes referred to as the Big Eight are peanuts, tree nuts (almond, cashew, pecans, walnut, etc.), wheat, soybeans, fish, crustacean shellfish (crab, lobster, shrimp, etc), cow's milk and egg $(\mathrm{FAO}, 1995)$. These foods account for more than $90 \%$ of all documented food-allergic reactions (Bousquet et al., 1998). Milk, egg, and peanut, are the most frequent causes of allergic reactions in children, whereas, peanuts, tree nuts, fish and shellfish are responsible for the majority of allergic reactions in adults (Sampson, 2004). Another 160 allergenic foods, which rarely cause allergic reactions, have also been reported (Hefle et al., 1996).

\section{Cell-mediated}

Cell-mediated food hypersensitivity disorders, also referred to as non-IgE mediated or delayed type hypersensitivity (Type IV), develop when sensitized T lymphocytes are activated by encountering a food antigen to secrete lymphokines and cytokines, resulting in a localized inflammatory response (Sampson, 1991; Taylor et al., 2000). The cell-mediated response normally becomes apparent at 6-24 hours following the ingestion of the offending foods (Taylor et al., 2000). The delayed onset of symptoms in Type IV reactions stems from the time required for the recruitment and infiltration of non-specific inflammatory cells, in particular, eosinophils and macrophages to sites of inflammation which leads to cell destruction (Goldsby et al., 2003). Several adverse reactions to foods have been defined as cell-mediated hypersensitivity, including contact dermatitis, dermatitis herpetiformis, food protein-induced enterocolitis, food proteininduced enteropathy syndromes, celiac disease, and Heiner syndrome (Sampson, 2003b). 
Substantial investigation in the area of celiac disease has been made in the past decade. Celiac disease, also termed celiac sprue, non-tropical sprue, and gluten-sensitive enteropathy is characterized by an inflammatory response in the small intestine, resulting in villous atrophy (villous flattening), crypt hyperplasia, and lymphocytic infiltration (Alaedini and Green, 2005; Taylor and Hefle, 2006b). The damage in the mucosal lining results in failure to absorb nutrients, thus retarding growth in children (Skerritt et al., 1990). Symptoms associated with this disorder are abdominal pain, diarrhea, an increased frequency of bowel movements, weight loss, bone disease, anemia, weakness, and malabsorption (Alaedini and Green, 2005; Strober, 1987). The causative agents of this disease have been identified as the alcohol-soluble prolamin fractions (gluten) found in certain cereal grains, including wheat, rye, barley, and triticale (Skerritt et al, 1990; Taylor et al., 2000). Consequently, a gluten-free diet is the treatment of choice, in which the patients avoid consuming food products containing wheat, rye, and barley and often substitute those grains with rice, corn, buckwheat, and sorghum. By eliminating gluten and related proteins from the diet, an improvement in both clinical and histological features is observed (Strober, 1987; Taylor et al., 2000). Celiac disease generally occurs in genetically susceptible individuals who express specific class II human leukocyte antigens (HLA) DQ-2 and DQ-8 (Alaedini and Green, 2005). The prevalence of celiac disease for the general population in Europe, USA, South America, and Australia was estimated at $0.5-1 \%$ and a higher prevalence of celiac disease is observed in first and second degree relatives of the celiac patients (Fasano et al., 2003; Heel and West, 2006). In addition to genetic predisposition, other risk factors for celiac disease include 
individuals with disorders such as type I diabetes mellitus, anemia, arthritis, osteoporosis, infertility, and Down syndrome (Fasano et al., 2003).

\section{Food Intolerance}

Unlike food hypersensitivity reactions, food intolerances are adverse reactions to foods that are not immunologically based (Taylor and Hefle, 2001). The mechanisms associated with food intolerances include, by some categorizations, the deficiency of a specific enzyme needed to metabolize certain foods, pharmacological effects exerted by naturally occurring food constituents, and the presence of toxic substances in foods that induce adverse symptoms, among others (Fraser et al., 2000). According to other classifications of food intolerances, toxic and pharmacological effects are not included as food intolerances because most individuals are susceptible. The scope of food intolerances is broad involving numerous mechanisms including primarily anaphylactoid reactions, metabolic disorders, idiosyncratic reactions, and pharmacological reactions.

\section{Anaphylactoid reactions}

Anaphylactoid reactions are manifested when substances in foods cause a spontaneous release of histamine and other mediators from the mast cells and basophils without the participation of IgE molecules (Taylor and Hefle, 2001). This reaction is clearly distinguished from true food allergies due to the lack of $\operatorname{IgE}$ involvement (Taylor, 1987). The substances that are responsible for destabilizing the mast cell membrane and the subsequent release of histamine and other mediators are yet to be isolated and identified (Taylor and Hefle, 2001). Although strawberries have been implicated as the 
best example of a food-induced anaphylactoid reaction, the evidence for the existence of this reaction mechanism remains tentative (Lemke and Taylor, 1994; Taylor 1987).

\section{Metabolic disorders}

Metabolic food disorders occur in individuals who inherit defects in the ability to metabolize certain components in foods or to maintain normal cellular function. A common example of metabolic food disorders is lactose intolerance (Lemke and Taylor, 1994).

Lactose intolerance arises from the deficiency of the enzyme lactase ( $\beta$ galactosidase) in the small intestine of susceptible individuals (Miller et al., 2007). As the enzyme lactase plays an important role in hydrolyzing lactose, which is a primary sugar present in milk, into its constituent monosaccharides, glucose and galactose, the lack of this enzyme results in an inability to metabolize and absorb lactose in the small intestine. Undigested lactose passes into the colon, where the naturally residing bacteria ferment the lactose into carbon dioxide, hydrogen, and water, causing symptoms associated with lactose intolerance, including abdominal pain, flatulence, and frothy diarrhea (Rusynyk and Still, 2001). The severity of the symptoms varies from person to person, depending on the degree of lactase deficiency and the amount of lactose ingested (Taylor et al., 2000). In general, approximately two-thirds of the world's adult population is affected by this disorder (Vesa et al., 2000). Lactose intolerance is more prevalent in certain ethnic groups, including Greeks, Arabs, Jews, Africans, Hispanics, and Asians. In contrast, European descendents rarely experience lactose intolerance (Suarez and Savaiano, 1997; Taylor and Hefle, 2001). Simple avoidance of the dairy products containing lactose is the 
usual treatment for lactose intolerance; however, this often results in inadequate calcium intake and an increased risk of osteoporosis (Vesa et al., 2000). Many individuals with lactose intolerance can tolerate some lactose in their diets (Miller et al., 2007; Suarez et al., 1995, 1997).

\section{Idiosyncratic reactions}

Idiosyncratic reactions are adverse reactions to foods that occur through unknown mechanisms in certain individuals. Due to the diversity of mechanisms that may possibly be involved, symptoms ranging from mild to life-threatening can occur (Taylor et al., 2000). The majority of the reports involving idiosyncratic reactions are anecdotal and are related to specific foods or food ingredients. The role of specific foods in causing this disorder remains to be elucidated in most cases, although the cause and effect relationship has been established for a few idiosyncratic reactions, such as sulfite-induced asthma and aspartame-induced urticaria (Taylor and Hefle, 2001). In addition to sulfites and aspartame, several other food additives have been implicated as the causative agents of idiosyncratic reactions, including tartrazine, salicyclates, benzoates and parabens, butylated hydroxyanisole (BHA), butylated hydroxytoluene (BHT), nitrate, nitrite, and monosodium glutamate, but the cause and effect relationship has not been proven by controlled clinical challenge trials (Taylor et al., 2000).

\section{Pharmacological reactions}

A pharmacological food reaction is defined as an adverse reaction to foods or food additives due to naturally-occurring or added chemicals that produce drug-like or 
pharmacologic effects. The dose of food necessary to elicit a clinical reaction typically varies among individuals and even within the same individual over time. Foods that have been implicated as causative agent in pharmacological reactions include biogenic amines, methylxanthines, and capsaicin, among others (Keeton et al., 2008).

Biogenic amines are low molecular weight, basic nitrogenous compounds, synthesized by the removal of the alpha-carboxyl group of free amino acids by specific microbial decarboxylase enzymes (Bulushi et al., 2009). The names of many biogenic amines are derived from their originating amino acids that undergo decarboxylation such as histamine from histidine, tyramine from tyrosine, beta-phenylethylamine from phenylalanine, and tryptamine from tryptophan. The formation of biogenic amines in foods depends on the availability of precursor free amino acids and the presence of microorganisms with existing decarboxylase activity (Bodmer et al., 1999). Endogenous levels of biogenic amines can be found in fruits and vegetables, but several kinds of food products are likely to contain elevated amounts of biogenic amines due to uncontrolled microbial activity, including fish products, meat products, dairy products, fermented vegetables and soy products, and alcoholic beverages like wine and beer (Bodmer et al., 1999). Under normal circumstances, the low intake of biogenic amines can be metabolized by amine oxidases to inactive metabolites in healthy individual. However, excessive intake of biogenic amines results in toxic effects on the vascular and nervous system due to the inability of the detoxification system to eliminate biogenic amines sufficiently (Önal, 2007).

The most common pharmacologic adverse food reaction is scombroid poisoning, which is caused by the ingestion of spoiled or bacterial-contaminated fish that contains 
high levels of histamine. During spoilage, free histidine in fish muscle is converted to histamine by bacterial histidine decarboxylase. Fish that are associated with scombroid poisoning are scombroid fish (e.g., tuna, mackerel, and saury) and non-scombroid species (e.g., mahi-mahi, sardines, pilchards, anchovies, marlin, and herring) that contain relatively high levels of histidine in muscles (Hungerford, 2010). Scombroid poisoning is often confused with food allergies due to the resemblance of symptoms that include a constellation of gastronintestinal (nausea, vomiting, and diarrhea), circulatory (hypotension), cutaneous (rash, urticarial, edema, and localized inflammation), and neurological (headache, palpitations, tingling, flushing, and itching) symptoms. These symptoms are exerted by the interaction between histamine and histamine receptors, namely $\mathrm{H}_{1}, \mathrm{H}_{2}$, and $\mathrm{H}_{3}$ receptors, which results in vasodilation, smooth muscle contraction, alteration of blood pressure, and stimulation of sensory and motor neurons (Keeton et al., 2008). The onset of symptoms ranges from minutes to hours following the consumption of spoiled fish and the symptoms subside after antihistamine treatment. All individuals, especially elderly and patients taking isoniazid that inhibits histaminase from metabolizing histamine in the body, are susceptible to scombroid poisoning (U.S. FDA). The toxic level of histamine in fish was reported as $500 \mathrm{ppm}(50 \mathrm{mg} / 100 \mathrm{~g})$, but FDA set the defect action level at $50 \mathrm{ppm}(5 \mathrm{mg} / 100 \mathrm{~g})$ to account for the non-uniform distribution of histamine in spoiled fish (Lehane and Olley, 2000).

\section{PREVALENCE OF FOOD ALLERGY}

The prevalence of IgE-mediated food allergies can be estimated at $6 \%$ of young children and 3-4\% of adults in westernized countries (Sicherer and Sampson, 2009). 
Based on a nationwide random telephone survey conducted in the U.S., the prevalence rate for peanut, tree nuts, sesame seeds, fish, and shellfish (crustacean) allergies was determined as $0.6 \%, 0.4 \%, 0.1 \%, 0.4 \%$, and $2.0 \%$, respectively (Sicherer et al., 2004, 2010). According to a meta-analysis of 51 studies, the prevalence rate of self-perceived allergy ranged from $1.2 \%$ to $17 \%$ for milk, $0.2 \%$ to $7 \%$ for egg, $0 \%$ to $2 \%$ for peanuts and fish, and $0 \%$ to $10 \%$ for shellfish, but the prevalence rate appeared to be lower when estimated based on any objective measures, including SPT, IgE assessement or food challenge (Rona et al., 2007). A subsequent study by the same group estimated the prevalence rate of allergy based on food challenge tests ranged from $0.1 \%$ to $4.3 \%$ each for fruits and tree nuts, $0.1 \%$ to $1.4 \%$ for vegetables, and $<1 \%$ each for wheat, soy, and sesame seed (Zuidmeer et al., 2008)

A comparison of 3 random-calling telephone surveys conducted in 1997, 2004, and 2008 in the U.S. indicated that the prevalence rates of self-reported peanut, tree nuts allergy, or both among adults remained relatively constant. However, the prevalence of peanut or tree nuts allergy among children $(<18$ years of age $)$ increased more than 3 -fold from 1997 to 2008. For instance, childhood tree nuts allergy increased from $0.2 \%$ in 1997 to $1.1 \%$ in 2008 , and peanut allergy increased from $0.4 \%$ in 1997 to $1.4 \%$ in 2008 (Sicherer et al., 1999, 2004, 2010). The hypothetical reasons for the increase in the prevalence of food allergy include the hygiene hypothesis, changes in dietary components, consumption of antacids, food processing applied to allergenic foods, and the delayed introduction of food allergens that could induce oral tolerance (Sicherer and Sampson, 2010). According to the hygiene hypothesis, the increase in allergy incidence in Western countries could partly be explained by a reduced microbial load (infection or 
exposure) early in infancy (Brandtzaeg et al. 2002). Microbial stimulation is necessary to protect individuals against aberrant immune responses to innocuous antigens by driving the production of IL-10 and TGF- $\beta$ cytokines that downregulate both $\mathrm{T}_{\mathrm{H}} 1$ and $\mathrm{T}_{\mathrm{H}} 2$ responses. It is suggested that changes in dietary composition, including dietary fat (increased consumption of $\omega-6$ fatty acid and reduced consumption of $\omega-3$ fatty acid), antioxidant (decreased consumption of fresh fruit and vegetables), and vitamin D levels (either a deficiency or an excess of vitamin D) could affect the IgE sensitization to foods (Lack 2008). Consumption of antacid and anti-ulcer medication has shown to elevate the gastric $\mathrm{pH}$ and impairs the digestion, leading to an increased risk for food sensitization (Untersmayr and Jensen-Jarolim, 2008). The stability and allergenicity of allergens may be altered through food processing. For instance, the roasting of peanuts modifies the stability of peanut allergens through the Maillard reaction and the modified peanut allergens have increased IgE binding capacity (Maleki et al., 2000). Early oral exposure to antigens is thought to be necessary in establishing oral tolerance to the respective antigen. A recent study demonstrated a strong inverse association between early consumption of peanuts in infancy and a lower prevalence of peanut allergy among Jewish children in Isreal than in the UK (Du Toit et al., 2008).

IgE-mediated food allergy appears to be more prevalent in infants and young children compared to adults, perhaps due to the immaturity of the intestinal mucosal barrier among infants and a comparative inability to develop tolerance against innocuous antigens, such as dietary proteins (Sampson, 1999a; 2003). The estimated prevalence of food allergy was $8 \%$ in children under age of 3 years and 2\% in adults (Sampson, 1999a). A few prospective studies indicated that many children outgrow their food allergies 
(Bock, 1987; Ford and Taylor, 1982; Sampson and Scanlon, 1989). Cow's milk and egg allergy are commonly outgrown, while peanut, tree nut, fish, and shellfish allergies often persist throughout life once sensitized, although studies performed by Skolnick et al. (2001) reported that $20 \%$ of young children develop tolerance to peanut (Wood, 2003).

\section{DIAGNOSIS OF FOOD ALLERGY}

The proper and accurate diagnosis of food allergy is crucial as misdiagnosis can bring serious consequences. For instance, people who have been erroneously diagnosed will restrict their dietary intake unnecessarily, hence placing them at risk of nutritional deficiencies, which may be fatal on occasion (Robertson et al., 1988; Woods et al., 2002). Self-diagnosis and parental diagnosis of food allergies are not recommended as they are often erroneous and result in identification of the wrong food (Bock et al., 1978).

Therefore, the diagnosis of an immediate IgE-mediated reaction to food should ideally be done by an allergist (Taylor and Hefle, 2001). Several diagnostic approaches to confirm suspected allergic reactions are available, including medical history, physical examination, elimination diets, in vivo (skin prick test, SPT) and in vitro (radioallergosorbent test, RAST) tests, and food challenges (Metcalfe, 1987).

The initial steps in diagnosis of food allergy usually involve medical historytaking and physical examination by physicians (Burks and Sampson, 1993). The historical information obtained from allergic patients is important and serves two major objectives: identify if the symptoms described share some characteristics of IgE-mediated reactions and provide guidance for a food challenge to be designed (Bock, 2000). The history of the adverse reaction must be thorough, attempting to establish whether a food- 
allergic reaction occurred and the possible inciting foods. Elimination diets, where many possible allergenic foods are removed from the diet simultaneously, can be helpful in confirming the role of food in the adverse reaction. Re-introduction of specific foods one at a time can help to identify the culprit food (Taylor and Hefle, 2001).

In the evaluation of IgE-mediated food allergy, several skin and serological tests are commonly used to detect food-specific IgE antibodies. One of the methods is SPT, which has been a key diagnostic tool for many years. The test measures the in vivo biological activity of specific IgE antibodies without providing information in regard to the absolute quantities of specific IgE (van Ree et al., 2006). SPTs are simple, inexpensive and rapid with results available within 15 minutes (Eigenmann and Sampson, 1994). It is performed by applying a drop of food extract on the skin, followed by puncturing through the drop into the epidermis using a sterile needle (Metcalfe, 1995; Sicherer, 2002). A wheal and flare reaction will develop at the pricked site if the foodspecific IgE is present on the surface of skin mast cells. The wheal and flare reaction is caused primarily by the release of histamine from the mast cells due to the interaction between IgE on the mast cells and the allergen in the extract. The SPT is interpreted as positive if the wheal mean diameter is $3 \mathrm{~mm}$ or greater, after the subtraction of the saline control (Sampson and Metcalfe, 1992; Sicherer, 2002).

Another method used alternatively to SPT is the in vitro RAST or other form of serum IgE measurement. The principal feature of RAST is the attempt to quantitatively measure antigen-specific IgE in blood serum to water-soluble food allergen extracts (Metcalfe, 1995; Sampson, 2003b). In the RAST technique, the extract of the allergen in question is coated onto the solid phase (e.g., paper disk, aluminium hydroxide gel, 
polystyrene tubes, cellulose polymers, and magnetic microparticles), followed by incubation with the patient's serum for a period of time (Poulsen, 2001). The level of bound IgE antibody is then quantified using a radiolabeled anti-human antibody (Sicherer, 2002). The ImmunoCAP ${ }^{\circledR}$ specific IgE blood test (Thermo Fisher Scientific) is the improved non-radioactive version of RAST, sharing similar features as RAST but using enzyme-labeled anti-human $\operatorname{IgE}$ antibody for measuring the bound $\operatorname{IgE}$ antibody. RAST is as effective as SPT, but it is more time consuming and costly than SPT. Therefore, SPT is the preferred method for identifying food-specific IgE, albeit RAST is useful for patients who have severe food reactions because SPT is risky for them (Bock et al., 1988; Taylor and Hefle, 2006a). Both SPT and RAST demonstrate sensitization to foods, which is the presence of food-specific IgE antibody, without verifying the existence of clinical reactions (Sicherer, 2002). The presence of a larger wheal size in SPT and a higher concentration of food-specific IgE level in serum increase the chance of an actual clinical food allergy, but do not normally correlate with the severity of the allergic reactions (Sicherer and Sampson, 2010).

Oral food challenges can be performed if the correlation between specific foods and symptoms remains unclear after obtaining the patient's history and IgE testing (Sicherer, 1999; Thompson and Chandra, 2002). Three types of oral food challenges are available: open, single-blind, and double-blind, placebo-controlled food challenges (Metcalfe, 1987; Sampson, 1999b). Open food challenge is conducted under conditions where the suspected foods are given openly (Sicherer, 1999). Open food challenges are useful to refute a history of an adverse food reaction that is vague and unlikely to be accurate (Bock, 2000). Open food challenges are also sometimes used with very young 
infants. Single-blind food challenge (SBFC) involves masking the suspected food and giving it to patient without revealing to the patient which sample contains the suspect (Sicherer, 1999). SBFCs are more useful than open food challenges, due to the elimination of any subjective bias of the patients. SBFC is practical for narrowing the possibilities of foods that are actually causing the problems (Bock, 2000). SBFCs are also often used in the diagnosis of food allergies in young infants (Moneret-Vautrin et al., 2001; Pucar et al., 2001).

The gold standard for diagnosing food allergy is the double-blind, placebocontrolled oral food challenge (DBPCFC). DBPCFC is performed in a manner that neither the patient nor the physician is aware of when the suspected offending food or placebo is going to be administered. The DBPCFC is designed to reproduce the information obtained from the patient's history, especially the timing of onset of any symptoms and the dosage of the causative agents with a substantial degree of certainty (Bock, 2000). The conventional starting dose in DBPCFC is approximately one half of the minimum amount likely to produce an immediate onset of symptoms based upon the patient's history. The dose administered may then be doubled at intervals specified by the history until the amount of food ingestion exceeds that taken by history (Bock, 2000; Metcalfe, 1995). The suspected food is hidden either in another food or in opaque capsules (Bock et al., 1999). If the patient has tolerated 10 grams of lyophilized food blinded in capsule or liquid form, clinical reactivity is ruled out (Sampson, 1999b). A negative DBPCFC should always be followed by an open food challenge using typical dietary quantities under observation to avoid rare false negative results (Burks and Sampson, 1993; Sampson and Metcalfe, 1992). Challenges for food anaphylaxis require 
the utmost precautions and must be administered in an intensive care unit. Patients with histories of life-threatening anaphylactic reactions should not be challenged in this manner (Sampson, 1999b).

\section{TREATMENT OF FOOD ALLERGY}

Strict avoidance of the incriminating foods is the only treatment currently available once the diagnosis of IgE-mediated food allergies is established (Sampson, 2004). As avoidance diets may result in malnutrition and eating disorders, the patient can benefit from the assistance of a dietitian to ensure adequate nutritional intake while adhering to a restricted diet (Ring et al., 2001). Diligent reading of food labels is necessary to prevent the ingestion of the offending foods. However, accidental ingestion is relatively common despite careful dietary avoidance due to several factors. For example, unsuspected food allergens hidden in other foods, misleading labels, and contamination of safe foods with trace amounts of offending foods that might occur through various processing or preparation errors can contribute to the incidence of allergic reactions (Burks et al., 2004; Taylor and Hefle, 2006a). Hence, an emergency plan must be in place to treat severe anaphylatic reactions. Several medications, such as epinephrine, antihistamines, corticosteroids, and bronchodilators have been utilized in an attempt to relieve the symptoms of acute, allergic reactions (Sicherer, 200).

The current advancement in the understanding of immunological mechanisms and the characterization of food allergens has lead to novel therapeutic strategies. A variety of immunotherapeutic approaches for IgE-mediated food-allergic reactions are currently under investigation (Burks et al., 2004). Injection immunotherapy used traditionally to 
treat inhalant allergies has been employed in the treatment of food allergy. A DBPCFC trial of rush immunotherapy for the treatment of peanut sensitivity has been conducted. Patients in these treatment groups were able to tolerate increased amounts of peanuts in food challenges after treatment. Although it is probably effective, it is impractical to treat food allergies due to the high risk of adverse systemic reactions associated with rush immunotherapy (Nelson et al., 1997; Oppenheimer et al., 1992).

Other approaches to immunotherapy include oral or sublingual ingestion of antigen or injection with genetically engineered proteins, in particular major allergens in peanuts. The ability of sublingual immunotherapy (SLIT) and oral immunotherapy (OIT) to induce desensitization in patients with food allergy has been evaluated. In SLIT, a liquid concentrate is used for administration under the tongue, whereas powdered food protein is administered orally in OIT (Scurlock et al., 2010). Both methods involve administering small, but gradually increasing doses of antigens under medical supervision during the initial dose escalation phase, followed by home dosing until a maximum tolerated maintenance dose of antigen is achieved during the build-up phase. The maximum tolerated dose is maintained until an open or blinded food challenge is conducted to determine desensitization and/or tolerance (Scurlock et al., 2010). Desensitization refers to the ability to tolerate higher amounts of an allergenic substance after the treatment, but it requires ongoing exposure of the antigen to maintain the desensitization state (Skripak et al., 2008). Desensitization is facilitated by an increase in IgG levels, and a reduction in both $\operatorname{IgE}$ and inflammatory mediators released by mast cells and basophils. In contrast, tolerance refers to the permanent loss of reactivity to previously inciting allergens, mediated through the development of regulatory $\mathrm{T}$ cells and 
skewing of the immunologic response away from the $\mathrm{T}_{\mathrm{H}} 2$ response, followed by anergy at later stages (Nowak-Wegrzyn and Sampson, 2011; Scurlock et al., 2010; Skripak et al., 2008). Although SLIT and OIT may represent promising regimens for food allergy, additional research is needed to determine whether SLIT and OIT strategies can induce long-term tolerance instead of short-term desensitization, and to address the safety, efficacy, and durations of the effects of SLIT and OIT.

The primary amino acid sequences of the IgE-binding epitopes of peanut allergens can be altered by genetic engineering techniques. Theoretically, the appropriately modified peanut allergens lose their ability to bind IgE, but retain their ability to stimulate $\mathrm{T}$ cell responses, leading to a $\mathrm{T}_{\mathrm{H}} 1$ response or tolerance in the peanutallergic patient. Although modified allergen is safe for the treatment of food allergy, an obstacle of this approach remains due to the presence of numerous allergens in each food (Erique and Cistero-Bahima, 2006; Li and Sampson, 2002). Alternatively, allergic individuals can be treated with the anti-IgE therapy, which utilizes a humanized IgG monoclonal antibody directed against the constant region $\left(\mathrm{F}_{\mathrm{c}}\right)$ of the $\operatorname{IgE}$ molecules, thus preventing the binding of $\operatorname{IgE}$ molecules to the high affinity $\mathrm{F}_{\mathrm{c}}$ receptors $(\mathrm{Fc} \varepsilon \mathrm{RI})$ on basophils and mast cells (Leung et al., 2003). In a clinical study conducted by Leung et al. (2003), patients with peanut hypersensitivity required significantly greater amounts of peanut to elicit an allergic reaction following the anti-IgE therapy when assessed by DBPCFC. Anti-IgE therapy may prove to be safe and effective in treating IgE-mediated food allergy, but repeated administration is required for continued protection ( $\mathrm{Li}$ and Sampson, 2002). 
Chinese herbal medicine is another therapeutic approach to food allergy that has recently been investigated. A food allergy herbal formula 2 (FAHF-2), consisting of a mixture of 9 herbs, has been demonstrated to confer protection against peanut-induced anaphylaxis in peanut-allergic mice for at least 6 months after the discontinuation of the treatment. The protection effect is associated with suppression in $\operatorname{IgE}$ and $\mathrm{T}_{\mathrm{H}} 2$ responses and an increase in IgG2a levels in mice treated with FAHF-2 (Srivastava et al., 2005). Moreover, human peripheral blood mononuclear cells treated with FAHF-2 in vitro significantly decreased IL-5 and increased IFN- $\gamma$ and IL-10 production. The phase I human trial indicated that FAHF-2 was safe for 19 subjects with food allergy. The efficacy of FAHF-2 will be further evaluated in the phase II study (Wang et al., 2010).

\section{FISH}

Fish provide an important source of dietary proteins, especially in coastal regions. On average, fish provide about 20-30 kilocalories per person per day (FAO, 2008). However, the consumption of fish can reach up to 180 kilocalories per person per day in a few countries where there is a lack of alternative foods and fish remain an important component of the diet, such as in Iceland and Japan (FAO, 2008). The per capita fish consumption has increased steadily in the past decade from $12.8 \mathrm{~kg} / \mathrm{capita} / \mathrm{year}$ in 1985 to $15.7 \mathrm{~kg} / \mathrm{capita} /$ year in 1997 (Delgado et al., 2003a). The intensive industrial aquaculture, accompanied with urbanization and the consumer shift towards healthier eating resulted in an increase in fish consumption (Delgado et al., 2003b). The health benefits of fish can be attributed to the fact that they are a rich source of high-quality protein, omega- 3 fatty acids, and minerals, and are low in saturated fat (Regenstein, 1991). 


\section{Fish classification, composition and uses}

Fish are defined as poikilothermic, aquatic chordate with appendages developed as fins, possessing gills as the main respiratory organs and having scales that cover the body. Alternatively, a fish is simply an aquatic vertebrate with gills and limbs in the shape of fins. To date, there are 27,977 living fish species, encompassing 515 families and 62 orders that have valid scientific descriptions (Helfman et al., 2009). Of these species, bony fishes accounts for more than 26,000 species, while the remaining are jawless fishes, sharks, skates and rays, and chimaeras (Helfman et al., 2009).

Three general approaches have been used to classify and infer the phylogenetic relationships among organisms, namely clasdistics, phenetics, and evolutionary systematics. Cladistic or phylogenetic systematics separate characters (observable parts or attributes of an organism) into apomorphies (more recently evolved, derived, or advanced characters) and plesiomorphies (more ancestral, primitive, or generalized characters). The species of organisms were then classified into monophyletic groups, or clades (groups containing an ancestor and all its descendant taxa) based on synapomorphies (shared derived characters) (Helfman et al., 2009). The second approach is the phenetics systemics that clusters species based on overall similarity, regardless of their evolutionary relationship. Evolutionary systematics classify organisms by taking into account both the phylogenetic relationship and overall similarities. Of the 3 systematics, the cladistics method offers the best solution for fish classification according to ichthyologists (Gill and Mooi, 2004; Helfman et al., 2009). Systematics categorizes fishes by the international nomenclature codes (kingdom, phylum, class, order, family, 
genus, and species) to show relationships at different taxanomic hierarchies. The ending for the order (-iformes), suborder (-oidei), family (-idae), subfamily (-inae), and tribe (ini) are uniform for all fishes (Helfman et al., 2009).

Fish is part of the kingdom Animalia, phylum Chordata, and subphylum Vertebrata. There are three classes of fish within the subphylum, including Agnatha (lamprey and hagfishes), Chondrichthyes (cartilaginous fish such as sharks and rays) and Osteichthyes (higher bony-fish). The latter group includes the subclass Sarcopterygii (fleshy-finned fish) and subclass Actinopterygii (ray-finned fish) (O’Neil et al., 1993; Regenstein, 1991). Agnatha is the most primitive fishes and represents a group of jawless fish (Helfman et al., 2009). Unlike Agnatha, both Chondrichthyes and Osteichthyes possess jaws for chewing foods and defense against predators. Sarcopterygii diversified into coelacanths, lungfishes, and tetrapodomorphs. The latter group represented the ancestors of amphibians, reptiles, birds, and mammals that colonize the terrestrial habitats (Helfman et al., 2009). Fish that are consumed and commercially important are mostly classified under the Actinopterygii, which consists of approximately 20,000 species. Despite the diverse fish species, only a few orders of fish are commonly consumed, namely Salmoniformes (salmon, trout, whitefish), Perciformes (perch, snapper, tuna, mackerel, tilapia), Gadiformes (cod, pollock, hake), Pleuronectiformes (sole, whiff), Clupeiformes (herring, sardine, anchovy), and Cypriniformes (carp) (O’Neil et al., 1993).

The major constituents in edible parts of both freshwater and marine fish include water, protein, lipids, and minerals (ash), estimated at $60-80 \%, 18-20 \%, 0.5-19 \%$, and 1\% respectively (Sen, 2005). Fish contains minute amounts of carbohydrate that is stored in the form of glycogen in liver or muscle tissues of fish. The chemical composition of fish 
depends on the genus and species (Table 2). Age and size, sex and sexual maturity, habitual environment and fishing season could affect the composition of fish within the same species (Sen, 2005).

Table 2. Proximate composition of edible parts of raw cod, tuna, and salmon (USDA, 2011)

\begin{tabular}{lccc}
\hline & $\begin{array}{c}\text { Atlantic cod } \\
\text { (Gadus morhua) }\end{array}$ & $\begin{array}{c}\text { Bluefin tuna } \\
\text { (Thunnus thynnus) }\end{array}$ & $\begin{array}{c}\text { Chinook salmon } \\
\text { (Oncorhynchus tshawytscha) }\end{array}$ \\
\hline Moisture (\%) & 81.2 & 68.1 & 71.6 \\
Protein (\%) & 17.8 & 23.3 & 19.9 \\
Total lipids (\%) & 0.7 & 4.9 & 10.4 \\
Ash (\%) & 1.2 & 1.2 & 1.3 \\
\hline
\end{tabular}

Proteins in muscle tissues are the second most abundant constituent in fish after water. Proteins consist of $75-80 \%$ of structural or myofibrillar proteins (actin, myosin, tropomyosin), $10-20 \%$ of sarcoplasmic proteins (albumin, globulin, myoglobulin, enzymes), and 3\% connective tissue proteins (collagen) (FAO, 2011; Sen, 2008). The solubility of the muscle proteins in salt solutions differs between protein groups. Collagen is insoluble in salt solutions, while structural proteins and sarcoplasmic proteins are soluble in high ionic strength $(0.3-0.6 \mathrm{M})$ and low ionic strength $(0.05 \mathrm{M})$ salt solution, respectively. Fish proteins provide a balanced source of essential amino acids. The fish proteins are particularly rich in lysine, thus serving as an excellent supplementary food to cereal proteins that are deficient in lysine (FAO, 2011; Jacobsen et al., 2010).

The lipid content could vary widely among fishes. Based on the lipid content, fish are categorized as lean, semi-fat, and high-fat species. Demersal (bottom dwelling) fish such as cod, saithe, and hake are examples of lean species, whereas the pelagic (dwelling in near-surface water) fish such as herring, mackerel, and salmon that are more active are 
high-fat species (FAO, 2011; Jacobsen et al., 2010). Epidemiological studies

demonstrated an inverse association between dietary fish intake and the risk of coronary heart diseases due to the rich source of omega-3 fatty acids in fish (Kris-Etherton et al., 2003).

The chemical composition of fish differs from the land animals with regard to the presence of a high content of non-protein nitrogen, such as trimethylamine-N-oxide (TMAO), ammonia, taurine, and urea. In addition, the lipid of fish contains high amounts of omega-3 fatty acids causing rapid rancidity. Finally, the low glycogen results in low postmortem pH drops in flesh to only $6.0-6.7$ (Jacobsen et al., 2010).

Fish is a versatile food commodity that can be consumed and used in various forms. In 2008, an estimate of nearly $81 \%$ (115 million tonnes) of the globe's fish production was consumed by humans, while the remainder (27 million tonnes) was used for non-food purposes, including fishmeal and fish oil production and pharmaceutical uses (FAO, 2008). Fish is a highly perishable food that requires proper handling, preservation and processing. Generally, it is distributed in the form of live, fresh, chilled, frozen, heat-treated, fermented, dried, smoked, salted, pickled, boiled, fried, freeze-dried, minced, powdered or canned. Of the fish used for direct human consumption, live or fresh fish is the most important product marketed (49.1\%), followed by frozen fish (25.4\%), prepared or preserved fish through canning (15.0\%) and cured fish through salting, drying, or smoking (10.6\%) (FAO, 2008). In the U.S., fillets and steaks represented the most important fresh or frozen fish products, in terms of value and volume produced. Cod and Alaskan pollock are the common species used to make fresh or frozen fillets. Frozen fillets of demersal fish, such as cod, haddock, and pollock, 
among others are manufactured into frozen blocks, from which they are cut into different shapes to produce breaded fish products. Larger fish, including halibut, swordfish, salmon, and tuna are typically processed into fish steaks (Corey, 2001).

The fish quality deteriorates rapidly after catch due to spoilage caused by enzymatic, bacterial and chemical actions. To extend the storage life and develop desirable sensory properties, the fish are preserved and cured by canning, salting, drying, and smoking. Canning utilizes heat to inactivate all microbial contaminants, followed by packing the product in hermetically sealed containers to prevent recontamination (Warne, 1988). Common fish for canning include anchovies, sardines, tuna, and salmon. In contrast to sardines, tuna, and salmon that are subjected to high temperature retort treatment, whole anchovies are packaged in salt and allowed to ripen before packing in oil and sealed. As no heating is involved, the anchovies have a shorter shelf life than other retorted fish products (Hall, 2011a). Curing increases the shelf-life of fish by removing the water (drying and smoking) or diffusing soluble substances into the product (salting), leading to an increase in the soluble solids content to a level that prevents the propagation of spoilage organisms in the fish product (Hall, 2011a). Fish drying involves either air-drying or freeze-drying to remove moisture (Sikorski and Ruiter, 1994). Smoked fish products can be produced by either cold smoking that takes place below $30^{\circ} \mathrm{C}$ or hot smoking that occurs mainly at $70-100^{\circ} \mathrm{C}$. Examples of cold-smoked fish are herring, smoked salmon, and Finnan haddock, which are often cooked prior to eating (Hall, 2011b). Fish salting can take the form of dry salting by mixing fish with dry salt or wet salting by immersion in brine (Sikorski and Ruiter, 1994). 
Improved processing technologies increase the utilization of fish as an ingredient in several applications. Fish gelatin is derived from the collagen obtained from fish skins and bones of various fish species, including cod, pollock, haddock, hake, tilapia, tuna, perch, cusk, flatfish, and redfish (Taylor et al., 2004; Weber et al., 2010). The production of fish gelatin involves heating the collagen in the presence of acid or alkali, which cleaves the intra- and intermolecular covalent crosslinks in collagen and converts it to soluble gelatin. Fish gelatin is used as thickener or stabilizer, for the microencapsulation of vitamins and other pharmaceutical additives, as a carrier for flavors and dye-stuffs, and as a processing aid in the production of beverages (Karim and Bhat, 2009). Isinglass is a pure form of collagen derived from dried swim bladders of tropical and subtropical fish, such as sturgeon, catfish, croaker, and threadfin (Weber et al., 2010). The swim bladder is a compressible air sac, located in the abdominal cavity below the backbone and its function is to regulate the specific gravity of fish, enabling the fish to maintain its position at any level in the water (Flick and Martin, 2000). Isinglass is produced through granulation of the dried swim bladder, followed by washing, sterilization with dilute hydrogen peroxide and rinsing. The temperature is maintained at $<15^{\circ} \mathrm{C}$ throughout the wet steps to prevent the denaturation of the collagen triple helix into the random coils of gelatin, which renders the collagen ineffective as a clarifying agent. Isinglass is available in the form of powder, paste, or highly viscous liquid (FSANZ, 2009). The main application of isinglass is their use as a clarifying agent in the alcohol beverage industry by entrapping and aggregating yeast cells, proteins and polyphenolic compounds (FSANZ, 2009). Isinglass also contributes to the organoleptic properties of wine, prevents proteinogenic haze and improves the filtration performance (Weber et al., 2009). 
The beer or wine typically contains low residual levels of isinglass as isinglass is removed from the final product by sedimentation, filtration or centrifugation (FSANZ, 2009).

\section{Fish allergy}

Despite the growing popularity of fish, the consumption of fish is a concern for fish-allergic individuals. Fish are considered to be among the most commonly allergenic foods on a worldwide basis (Codex Alimentarius Commission, 1999; Bousquet et al.1998). Fish are capable of inducing the IgE-mediated hypersensitivity reactions through ingestion, direct contact, and inhalation of fish odors and fumes generated during cooking (Göransson, 1981; Halkier-Sørensen and Thestrup-Pedersen, 1988, 1989; Crespo et al., 1995b; Domínguez et al., 1996; Rodríguez et al., 1997). The ingestion of the offending fish allergens can trigger a rapid onset of symptoms in patients with fish allergy. Untersmayr et al. (2007) revealed that codfish protein was readily absorbed pregastrically and distributed in the circulation of non-fish allergic individuals within 10 minutes following the oral ingestion of cooked codfish. The codfish proteins increased to the highest levels in the sera after 1 or 2 hours, indicating that the codfish allergen has the potential to trigger allergic reaction even after gastric passage. The symptoms usually are comprised of skin, respiratory, and gastrointestinal symptoms (Helbling et al., 1996; Taylor et al., 2004). In some cases, life-threatening and fatal anaphylaxis due to the ingestion of fish can also occur. Yunginger et al. (1988) reported an adult who died of an anaphylactic reaction to fish due to the ingestion of French fries prepared in oil contaminated with fish. Of 32 food allergy-related casualties documented between 1994 
and 1999, one case of a fatal anaphylactic reaction to fish was described (Bock et al., 2001). Pumphrey and Gowland (2007) reported one of 48 fatal allergic reactions was due to fish in the U. K. between 1999 and 2006. Unlike cow's milk and egg allergy that are commonly outgrown, fish allergies often persist throughout life once sensitized (Dannaeus and Inganäs, 1981; Bock, 1982; Priftis et al., 2008), although studies performed by Kajosaari (1982) and Solensky (2003) reported that children and adults can sometimes develop tolerance to fish.

\section{Prevalence}

Several studies have attempted to determine the prevalence of fish allergy. A telephone survey conducted in the United States showed that $0.4 \%$ of the general population had fish allergy with the prevalence rate being higher in adults compared to children (Sicherer et al., 2004). The frequency of fish allergy was estimated to be $0.1 \%$ in Norwegian populations (Aas, 1987). Björnsson et al. (1996) reported that 4 (0.3\%) out of 1397 adult Swedes had specific IgE to fish. In a cross-sectional study of 18-month-old children, the prevalence of fish allergy confirmed by SPT or DBPCFC was $2(0.6 \%)$ out of 324 in Iceland and $1(0.3 \%)$ out of 328 in Sweden (Kristjansson et al., 1999).

Studies on the prevalence of fish allergy have been conducted in France. André et al. (1994) reported that $24 \%$ of the IgE sensitization and $13 \%$ of the anaphylactic reactions were attributed to fish in a group of 580 patients with adverse reactions to foods. In a French study of schoolchildren aged 9-11 years, the prevalence of selfreported fish allergy confirmed by SPT was estimated at $0.7 \%$ among 6672 survey respondents (Pénard-Morand et al., 2005). Rancé et al. (2005) estimated that 7.8\% 
$(19 / 244)$ of foods cited for causing food allergies were attributed to fish in 183 children with self-reported food allergies in France. In Spain, fish has been identified as the second most commonly implicated food causing hypersensitivity reactions in children after eggs, with a prevalence rate of $17.8 \%$ (Crespo et al., 1995a). A survey that involved 15 countries and 17280 adults showed that $2.2 \%$ of individuals had fish allergy or fish intolerance (Woods et al., 2001).

Iikura (1998) indicated that the frequency of fish as a causative allergen was somewhat higher in Japan when compared to the western countries. The incidence of fish allergy documented in a nationwide survey in Japan showed that $110(4.5 \%)$ of 2434 patients were allergic to fish (Iikura and Imai, 2001; Aihara et al., 2003). A recent nationwide questionnaire survey conducted in Japan reported that red sea bream and tuna was responsible for causing anaphylaxis in $6(1.9 \%)$ and $5(1.6 \%)$ out of 319 patients with self-reported anaphylaxis (Imamura et al., 2008).

Allergy to fish is common among the fish-eating and fish-processing communities (Aas, 1987). It was suggested that the prevalence of fish allergy was associated with the amount of fish intake. For instance, Crespo et al. (1995a) reported allergy to fish is more frequent in the Scandinavian countries where the fish consumption is high. However, a comparative study showed that despite a consumption of fish that was three-fold higher in Reykjavík (Iceland) compared to Uppsala (Sweden), the prevalence of IgE sensitization to fish $(0.2 \%)$ was not significantly different between these two ethnically similar populations (Gislason et al., 1999).

\section{Diagnosis}


The diagnosis of fish allergy involves patient clinical history, SPT and/or fishspecific serum IgE tests, and oral food challenges. SPT is a rapid and relatively safe method to screen patients with clinical histories suggestive of an IgE-mediated reaction. The skin test results have to be interpreted with caution due to high false positive response from cross-reactive allergens (Wild and Lehrer, 2005). Alternatively, the measurements of fish-specific serum IgE tests by either RAST or improved methods, such as the Pharmacia CAP-RAST FEIA are commonly used for diagnosis (Wild and Lehrer, 2005). Both SPT and RAST have excellent sensitivity and negative predictive accuracy but poor specificity and positive predictive accuracy. The absence of fish allergy can basically be confirmed by negative SPT and RAST responses due to high negative predictive accuracy, whereas a positive response does not necessarily prove clinical fish allergy. Nevertheless, the presence of clinical allergy can be confirmed by a combination of positive SPT responses and a recent clear history of food-induced allergic reaction (Sicherer and Sampson, 2010). Sampson and Deborah (1997) evaluated the utility of quantitative allergen-specific IgE values in diagnosing IgE-mediated food allergy. According to the retrospective study, a serum $\operatorname{IgE}$ antibody level of $20 \mathrm{kU}_{\mathrm{A}} / \mathrm{L}$ or greater to fish was predictive of fish-induced clinical symptoms with greater than $95 \%$ certainty. A subsequent prospective study confirmed the effectiveness of the fish-specific IgE concentrations in predicting clinical reactivity (Sampson, 2001).

A food challenge test is required if the SPT or serological tests do not provide a clear indication of tolerance to specific fish species or the possible cross-reactivity among fish species is not well characterized. According to a case study reported by Pascual et al. (2008), a 2 year-old boy who was diagnosed with IgE-mediated fish allergy had 
swordfish-specific IgE of $\leq 0.35 \mathrm{kU} / 1$ and specific $\operatorname{IgE} \geq 0.9 \mathrm{kU} / 1$ to other fish species. Due to the presence of specific IgE against all fish species tested other than swordfish, tolerance to swordfish is not known. Subsequently, an oral challenge test was performed and showed positive reactivity to swordfish. Hence, a diet free of all fish species was recommended. Compared to other fish species studied, fish from the Tunidae (e.g. tuna) and Xiphiidae (e.g. swordfish) families appeared to be the least allergenic. Patients who react to these species in the food challenge test are very unlikely to tolerate any other fish species, and thus a complete fish-exclusion diet is necessary (Pascual et al., 2008).

The diagnosis of fish allergy can be challenging due to the inter-individual variation with regard to the specificity of fish allergy, including fish allergy to all species, fish allergy with partial tolerance to specific species, and monospecific fish allergy (Pascual et al., 2008). Individuals reacting to parvalbumin likely need to avoid all fish species, whereas individuals reacting to allergens that are species-specific appear to be tolerant to some species of fish (Taylor et al., 2004). The clinical cross-reactivity rates between one fish and the others are approximately $50 \%$, but individual differences do exist (Sicherer and Sampson, 2010). Generally, fish-allergic individuals are advised to exclude all fish species from their diet, unless otherwise diagnosed to be clinically tolerant to specific fish species by oral food challenge studies (Helbling et al., 1999). Dignostic procedures should be conducted with caution to avoid confusion with other adverse reactions to fish, such as IgE-mediated reaction to Anisakis simplex and scromboid fish poisoning.

\section{Threshold}


Fish are known to induce severe IgE-mediated allergic reactions at low doses of exposure. The lowest provoking doses for fish evaluated in a DBPCFC test of 14 fishallergic patients was estimated at $5 \mathrm{mg}$ of either cod or herring (Taylor et al., 2002). However, the threshold dose for fish remains to be elucidated as low-dose challenges have only been conducted on a small number of patients and with only a few species of fish (Taylor et al., 2002). Studies have revealed that the impaired gastric digestion could affect the threshold levels of codfish allergen in sensitized individuals (Untersmayr et al., 2005, 2007). According to the DBPCFC, codfish proteins that were digested under hypoacidic conditions at $\mathrm{pH} 3.0$ appeared to reduce the tolerable threshold dose of codfish proteins by 10 - to 30 -fold compared to digestion at $\mathrm{pH} 2$ (Untersmayr et al., 2007).

\section{Cross-reactivity among fish species}

Serological cross-reactivity between various fish species has been reported. DeMartino et al. (1990) found in a group of 20 cod-allergic children that all showed positive skin tests to 1 or more of 17 fish species. Nevertheless, these children were not uniformly sensitive to all the fish species tested. In fact, a higher frequency of positive skin tests to eel, bass, dentex, sole, and tuna was determined. In a study conducted by Hansen et al. (1997), all 8 clinically codfish-allergic adults demonstrated significant cross-reactivity to cod, mackerel, plaice, and herring as assessed by several tests, including SPT, histamine release test, RAST, and sodium dodecyl sulfate polyacrylamide gel electrophoresis (SDS-PAGE) with immunoblotting. Sten et al. (2004) examined whether codfish-allergic patients exhibited cross-reactivity to ocean pout, eelpout, and eel 
that were rarely consumed in the Scandinavian diet. All 18 patients had specific IgE to all four species of fish and 17/18 patients reacted to all fish species in the SPT. A recent cross-reactivity study in Norway demonstrated that $9 / 10$ of the fish-allergic patients had positive SPT to the native parvalbumins from cod, salmon, and pollock. Of the 7 patients who were skin tested with herring, wolfish, tuna, and mackerel, all patients reacted strongly to the herring and wolfish, whereas $6 / 7$ patients reacted weakly or were unresponsive to tuna and mackerel. The SPT results were supported by the in vitro tests of fish-specific IgE antibodies (Van Do et al., 2005a).

Despite the extensive serological cross-reactivity among fish species, several studies demonstrated that the fish-allergic patients are able to consume one or more fish species without experiencing any adverse reactions. An early study by Aas (1966) demonstrated that among 61 cod-allergic children, 34 of them reacted to all fish, but 27 children tolerated one or more fish species. Besides, salmon extracts elicited positive skin tests in children who could safely consume salmon. A prospective study by BernhiselBroadbent et al. (1992a) revealed that 26 patients with positive SPT to specific fish species could tolerate ingestion of these fish as judged by oral fish challenges. Through the use of immunoblotting and ELISA inhibition assays, serum specific-IgE showed reactivity to fish that the patients were able to clinically tolerate, as confirmed by oral challenges. These studies concluded that the serological and in vitro diagnostic tests of the cross-reactivity among fish species do not necessarily correlate to the clinical reactivity. However, Helbling et al. (1999) reported a high correlation between SPT and oral challenge responses. In this study, cross-reactivity among various fish species of taxonomically distinct orders was shown to be clinically relevant. 


\section{Fish allergens}

\section{Parvalbumin}

Parvalbumin (Gad c 1) was the first major cod (Gadus callarias) allergen identified and purified (Elsayed and Aas, 1971a). Subsequent studies have isolated the homologous allergens from Atlantic salmon (Salmo salar), horse mackerel (Trachurus japonicus), Japanese eel (Anguilla japonica), bigeye tuna (Thunnus obesus), carp (Cyprinus carpio), cod (Gadus morhua), mackerel (Scomber japonicus, S. australasicus, S. scombrus), and Alaska pollack (Theragra chalcogramma) (Lindstrøm et al., 1996; Shiomi et al., 1998, 1999; Van Do et al., 1999, 2003, 2005b; Swoboda et al., 2002; Hamada et al., 2003a, 2004). These allergens were either purified by combinations of gel filtration, anion exchange, and high performance liquid chromatography techniques or isolated by the cDNA cloning method. In these studies, the isolated parvalbumins were confirmed to represent the major allergens in fish due to their ability to bind serum specific-IgE from fish-allergic subjects.

Parvalbumin has been identified as a pan-allergen present in most species of fish and frog and that is responsible for the observed cross-reactivity (James et al., 1997; Bernhisel-Broadbent et al., 1992b; Hilger et al., 2004). This allergen was capable of sensitizing fish-allergic patients to multiple fish species, and in some cases, resulting in positive skin tests to certain fish species that the patients have never consumed (Tuft and Blumstein, 1946; Hansen et al., 1997; Sten et al., 2004; Van Do et al., 2005a). Parvalbumins are small, acidic, and water-soluble sarcoplasmic proteins (10-13 kDa), but the ability of cod parvalbumin to form dimers $(24 \mathrm{kDa})$ that still possessed IgE-binding 
capacity has been reported (Das Dores et al., 2002a). Parvalbumins are classified under the EF-hand superfamily, a group of proteins with a highly conserved helix-loop-helix structural motif that binds to divalent cations (e.g. calcium and magnesium) with varying affinities (Nakayama and Kretsinger, 1994). According to the crystal structure of carp parvalbumin that was solved by X-ray crystallography, the parvalbumin was comprised of three domains, namely AB, CD, and EF (Kretsinger and Nockolds, 1973). Each domain consists of a central loop flanked by two amphipatic (possessing both hydrophilic and hydrophobic regions) alpha-helices of 12 contiguous residues from which the oxygen ligands for calcium are derived (Strynadka and James, 1989; Permyakov et al., 2008). Both the $\mathrm{CD}$ and $\mathrm{EF}$ domains possess the calcium-binding properties; the $\mathrm{AB}$ domain lacks the ability to bind calcium although it has structure similar to the $\mathrm{CD}$ and $\mathrm{EF}$ regions (Kretsinger and Nockolds, 1973). The exact functions of parvalbumins remain unclear; nevertheless the consensus view of their functions in muscle include acting as calcium buffers in cytosol and promoting relaxation following muscle contraction by sequestering the intracellular calcium (Erickson and Moerland, 2006).

Parvalbumins are divided into two distinct phylogenetic lineages, $\alpha$ and $\beta$. The $\alpha-$ parvalbumin has a $\mathrm{pI}$ greater than 5 and contains an additional amino acid residue in the C-terminal helix, whereas $\beta$-parvalbumin has a pI lower than 4.5 (Goodman and Pechére, 1977). Moreover, both $\alpha$ and $\beta$ forms of parvalbumins differ in at least 11 residues; Cysteine at position 18 and aspartic acid at position 61 are typically found in $\beta$ parvalbumins (Permyakov, 2006). All vertebrates, including human, express parvalbumin in varying levels in the skeletal muscles. Lower vertebrates, such as fish contain higher quantities of parvalbumin in their muscles than higher vertebrates (Permyakov, 2006). 
The concentration of parvalbumins in the fish skeletal muscles also varies with the muscle types. Two types of muscle fibers, including white and red (dark) muscles are responsible for different locomotory systems in fish. White muscle is primarily used for short-duration burst swimming, such as movements associated with capturing prey or escaping from predators, whereas red muscle is mainly involved in slow and sustained swimming (Willmer et al., 2009). White muscle fatigues more quickly than red muscle as red muscle is highly vascularized and contains a rich oxygen supply. In contrast to white muscle that relies on anaerobic glycolysis for energy due to the lack of myoglobin and few mitochondria, the myoglobin and mitochondria are abundant in red muscle and the energy in red muscle is provided by the aerobic oxidation of fats (Helfman et al., 2009). Demersal gadoid fish tend to have lower amounts of dark muscle compared to the pelagic fish that swim continuously (Sen, 2005). White muscle typically contains more sarcoplasmic recticulum and parvalbumin than the dark muscle. Lim et al. (2005) reported that parvalbumin was found in the white muscle of tuna (Thunnus tonggol), but was absent in the red muscle. The allergenicity of the white and dark fish muscles is largely associated with the parvalbumin content. Kobayashi et al. (2006) showed that dark muscle was less allergenic than white muscle due to the lower content of parvalbumin in dark muscle.

Some fish species have been shown to express from two to five parvalbumin isotypes that possess different affinities for calcium and magnesium (Huriaux et al., 2002; Wilmert et al., 2006). Two distinct parvalbumin isotypes were identified by analysis of cDNA clones from Atlantic salmon, carp, Atlantic codfish, and Alaska pollock (Lindstrøm et al., 1996; Swoboda et al., 2002; Van Do et al., 2003, 2005b). A literature 
search failed to identify studies comparing the cross-reactivity or allergenicity of these parvalbumin isotypes for fish-allergic individuals. Gad c 1 is a very stable allergen. Studies have shown that the allergenicity of Gad c 1 was not significantly affected by extreme $\mathrm{pH}$, heat denaturation, and chemical modifications, suggesting that the allergenic activity of Gad c 1 is primarily dependent on the primary structure rather than on the molecular conformation (Elsayed and Aas, 1971b). However, the contribution of steric conformation on the allergenicity of fish parvalbumin is not negligible. Several studies have demonstrated that the depletion of calcium from carp and frog parvalbumins significantly reduced the IgE-binding to these parvalbumins (Bugajska-Schretter et al., 2000; Swoboda et al., 2002; Hilger et al., 2004). According to the circular dichroism analysis, the loss of IgE reactivity was associated with the change in conformation of the calcium-depleted parvalbumins (Bugajska-Schretter et al., 2000). These findings were further supported by the production of hypoallergenic mutants of the carp and Pacific mackerel parvalbumin using site-directed mutagenesis to replace the two aspartic acid residues in each of the calcium-binding domains with alanine residues. As a result, both mutants no longer had the ability to bind calcium and showed a significant reduction in the IgE reactivity compared to their wild-type counterpart (Swoboda et al., 2007; Tomura et al., 2008).

The elucidation of IgE-binding epitopes is essential for better understanding of the interaction between allergens and the $\operatorname{IgE}$ antibody components of the immune system. Early studies by Elaysed and Apold (1983) identified several IgE-binding epitopes based on the immunological reactivity of the limited trypsin-hydrolyzed peptide fragments and the synthetic peptides of Gad c 1 with the serum IgE from fish-allergic 
patients. Five different fragments corresponding to the residues 13-32 (AB domain), 3344 (axis joining $\mathrm{AB}$ and $\mathrm{CD}$ domains), 49-64 (calcium-binding loop of $\mathrm{CD}$ domain), 6574 (axis joining $\mathrm{CD}$ and $\mathrm{EF}$ domains), and 88-96 (calcium-binding loop of EF domain) of Gad c 1 were assumed to contain IgE-binding epitopes (Elsayed and Apold, 1983). Using the computational matching of mimitopes onto the molecular surface of the natural carp parvalbumin, three epitope regions were identified. Two of the epitopes were found in regions connecting the $\mathrm{AB}$ and $\mathrm{CD}$ domain and the $\mathrm{CD}$ and $\mathrm{EF}$ domain, respectively, while the third epitope were located in the calcium-binding region of the EF-domain (Untersmayr et al., 2006). A recent study by Yoshida et al. (2008) identified the region 21-40 in Pacific mackerel parvalbumin as the major IgE-binding epitope by the epitope mapping of 10 overlapping 20-mer peptides; the region 21-40 appeared to be rather specific to mackerel parvalbumin.

\section{Minor allergens}

In addition to the major fish parvalbumin allergens, a higher molecular weight allergen was found in the myostromal protein fraction of the bigeye tuna muscle by Hamada et al. (2001). The allergen has been identified as collagen based on the results of SDS-PAGE, immunoblotting, and amino acid analysis. In this study, the serum IgE from fish-allergic patients recognized two protein bands of $120 \mathrm{kDa}$ and a band of $240 \mathrm{kDa}$, which corresponded to the $\alpha$-chain and $\beta$-chain (dimer of $\alpha$-chain) of collagen, respectively (Hamada et al., 2001). Although cross-reactivity among collagens from various fish species is common, there is a lack of cross-reactivity between collagens from fish and other animals (Hamada et al., 2003b). Fish gelatin is comprised of collagen that 
is derived from the fish skins and bones and is commonly used as a stabilizer in pharmaceutical and food products (Taylor et al., 2004). Several studies have investigated the potential allergenicity of fish gelatin. Sakaguchi et al. (2000) showed that patients with fish allergy and bovine gelatin allergy had specific IgE antibodies reacting to fish gelatin, specifically to the $\alpha 1$ and $\alpha 2$ chains of the tuna fish type I collagen. In addition, cross-reactivity among gelatins from various fish species, including tuna, saurel, salmon, mackerel, and cod, was evident (Sakaguchi et al., 2000). André et al. (2003) reported that 3 of the 100 sera from fish-sensitive individuals showed reactivity to tuna flesh, tuna skin, and gelatin prepared from tuna skin in the immunoblotting, but no cross-reactivity was detected between bovine/porcine and fish gelatin. Nevertheless, further investigation showed that the 3 subjects did not have any clinical reactivity to the tuna skin gelatin; neither did they react to the tuna skin gelatin in the SPT nor to $5 \mathrm{~g}$ of tuna gelatin in a food challenge test (André et al., 2003). However, a later DBPCFC trial revealed that 1 of 30 clinically codfish-allergic individuals experienced a mild subjective reaction after ingesting a cumulative dose of $7.61 \mathrm{~g}$ of fish gelatin derived from codfish skins (Hansen et al., 2004). Hansen et al. (2004) concluded that $90 \%$ of fish-allergic consumers would not react to the ingestion of $3.61 \mathrm{~g}$ cumulative dose of fish gelatin with a $95 \%$ certainty (Hansen et al., 2004). Based on these reports, the potential risk of fish gelatin in eliciting an adverse reaction among fish-allergic individuals remained speculative.

There is also evidence of other minor allergens besides collagen in fish. Dory et al. (1998) demonstrated the presence of 7 IgE-binding and possibly allergenic proteins of $12,22,30,45,60,67,104$, and $130 \mathrm{kDa}$ in the pre-rigor mortis cod extracts using the pooled sera from 12 cod-allergic individuals. Higher relative content of the IgE-reactive 
bands was observed when the codfish was stored for a longer period of time (Dory et al., 1998). Galland et al. (1998) purified a $41 \mathrm{kDa}$ protein from the crude extracts of raw cod. The purified protein was considered an allergen due to its ability to bind IgE antibodies from the pooled sera of cod-allergic individuals that also recognized 5 other allergenic proteins having a molecular mass of $13,22,28,49$, and $60 \mathrm{kDa}$ in the crude cod extracts (Galland et al., 1998). Subsequent study identified that the $41 \mathrm{kDa}$ protein was homologous to the aldehyde phosphate dehydrogenase (Das Dores et al., 2002b). Moreover, the $41 \mathrm{kDa}$ protein was also recognized by a monoclonal anti-parvalbumin antibody, which is probably attributed to the low similarity of the $41 \mathrm{kDa}$ protein with the acidic residues of the calcium-binding domains in parvalbumin (Das Dores et al., 2002b). Lim et al. (2008) reported that sera from 2 of the 10 individuals with allergies to tropical fish showed IgE-binding to proteins of 29 and $54 \mathrm{kDa}$, in addition to the $12 \mathrm{kDa}$ parvalbumin in cod, threadfin, pomfret, and tengirri. One of the codfish-allergic European subjects also reacted to the protein bands of 12 and $29 \mathrm{kDa}$ in cod, pomfret, and tengirri (Lim et al., 2008).

While the majority of studies demonstrated that the fish-allergic subjects primarily reacted with a fish protein identified as parvalbumin, this is not always the case. Kelso et al. (1996) and James et al. (1997) reported 2 subjects with monospecific allergy who showed IgE-reactivity to only a protein band at $25 \mathrm{kDa}$ in swordfish and $40 \mathrm{kDa}$ in tuna. A research group in India compared the allergen profiles of two Indian fish: hilsa and pomfret (Das et al., 2005). The IgE-immunoblotting revealed that the sera from 10 fish-allergic patients reacted to protein bands ranging from 29-94 $\mathrm{kDa}$ and $32-97 \mathrm{kDa}$ in the raw muscle extracts of hilsa and pomfret, respectively (Das et al., 2005). The patients' 
sera also bound to a common protein of $50 \mathrm{kDa}$ in both fish extracts, but none of the sera showed binding to the low molecular weight allergen, i.e. parvalbumin, suggesting that the epitopes in the proteins of these Indian fish are species-specific (Das et al., 2005). However, no further studies were completed to purify and characterize these potential allergens. A later study investigated the IgE-binding properties of 4 thermally-treated Indian fish revealed that frying and boiling of the fish muscle abolished the binding of $\mathrm{IgE}$ antibodies to the allergenic proteins in hilsa and pomfret, whereas the allergenic proteins in bhetki and Indian mackerel were thermally stable (Chatterjee et al., 2006).

Recently, Liu et al. (2011a) identified two high molecular weight proteins from blunt snout bream as $47 \mathrm{kDa}$ enolase and $41 \mathrm{kDa}$ creatine kinase by 2-dimensional electrophoresis combined with IgE immunoblotting and matrix-assisted laser desorption/ionization time-of-flight mass spectrometry analysis. A subsequent study by the same group identified chromosome undetermined SCAF7145, fructose-biphosphate aldolase A and enolase 3 (beta muscle) as novel allergens in tilapia using the same proteomic approaches (Liu et al., 2011b). These studies did not demonstrate IgE binding to parvalbumin from blunt snout bream or tilapia.

\section{Detection methods for fish}

The detection of allergenic fish residues in foods is of particular interest for labeling purposes and the safe-guarding of fish-allergic consumers. Several fish authentication methods employing electrophoretic techniques, immunoassays, polymerase chain reaction (PCR) methodology, and matrix-assisted laser desorption ionization-time of flight mass spectrometry (MALDI-TOF MS) are currently available. 
Electrophoretic techniques, with isoelectric focusing being the most frequently used method, separate the sarcoplasmic proteins by their electrical charge differences and identifies the fish species based on the species-specific banding patterns of the whole proteins or parvalbumins (Esteve-Romero et al., 1996; Civera, 2003). Immunoassays like ELISA, on the other hand, uses either monoclonal or polyclonal antibodies against the soluble muscle proteins of specific fish species with no cross-reactivity to unrelated fish species to discriminate between the different species of fish (Huang et al., 1995; Carrera et al., 1996; Asensio et al., 2003, 2008). PCR-based methods involve amplification of the DNA regions of interest that are universal or species-specific, followed by the analysis of the PCR fragments for species recognition using various methods, including electrophoretic techniques, DNA sequencing, restriction fragment length polymorphism (RFLP), single-stranded conformational polymorphism (SSCP), and many others (Gil, 2007; Rasamussen and Morrissey, 2008; Sun et al., 2009). The MALDI-TOF MS method identifies fish species according to the parvalbumin isoform patterns displayed by the 2dimensional electrophoresis in conjunction with the unique MALDI-TOF mass fingerprints of the peptides generated by the trypsin-hydrolysis of the parvalbumin isoforms (Carrera et al., 2006). The fish authentication techniques are extremely specific for detecting single or multiple fish species. In addition, they are qualitative methods that are validated to identify the fish species among various seafood and meat samples instead of as components of formulated and processed foods. Hence, they have limited application in detecting and quantifying the allergenic protein residues derived from irrelevant fish species in foods. To utilize these authentication methods, the food manufacturers need to have advance knowledge about the particular fish species that may 
contaminate the processing plant facility or the finished food products, but this kind of situation seldom occurs in reality.

Research into the development of methods intended to detect allergenic residues from a wide range of fish species in foods has been published. Fǽste and Plassen (2008) developed a sandwich ELISA for the quantification of fish in foods using polyclonal anticod parvalbumin antibody as the capture and detector antibody. The ELISA has a limit of detection of $0.01 \mathrm{mg}$ parvalbumin $/ \mathrm{kg}$ food, which was equivalent to $5 \mathrm{mg}$ fish $/ \mathrm{kg}$ food. However, the detection of fish parvalbumin was inconsistent for different fish species. Among the 32 fish species tested, the ELISA showed the greatest recovery rates $(>50 \%)$ for fish that are most commonly consumed, such as cod, tilapia, salmon, carp, mackerel, and pollock. Nevertheless, several freshwater fish, including Nile perch, European eel, sturgeon, Northern pike, and a cartilaginous fish, the spiny dogfish, showed a recovery rate lower than $1 \%$. A similar observation was made by Chen et al. (2006) with respect to the variable immunoreactivity of the commercially available mouse monoclonal anti-frog parvalbumin antibody against the raw extracts from several fish species. Gajewski and Hsieh et al. (2009) have recently developed a monoclonal antibody against the crude extracts of the cooked catfish muscle proteins. The comparisons of their antibody with the commercially available mouse monoclonal anti-frog parvalbumin antibody showed further evidence of the variable specificity of both antibodies against the cooked extracts from different fish species. The quantitative variation of the ELISA when detecting various species of fish might be attributed to the variable amount of parvalbumin present in the fish extracts and differences in the binding affinity of the antibody to the antigen (Chen et al., 2006). Hence, the utilization of the anti-parvalbumin antibody that has equal 
specificity to parvalbumin from different species of fish is considered to be more advantageous for the quantification of fish residues in foods. Although monoclonal antibodies have also been produced against carp and bluefin tuna parvalbumin (Celio et al., 1988; Kawase et al., 2001), the cross-reactivity of these antibodies with various species of fish is largely unknown. An alternative to the anti-parvalbumin antibodies is to develop antibodies that recognize specific fish proteins or peptides that are highlyconserved across all fish species, but do not show cross-reactivity with other non-fish species.

In addition to the ELISA-based methods, surface plasmon resonance (SPR) biosensor and PCR-based techniques for the detection of fish parvalbumin have been described. Lu et al. (2008) first reported a rapid SPR biosensor for the detection and quantification of the fish allergen, parvalbumin. The detection limit for parvalbumin was determined at $3.55 \mu \mathrm{g} / \mathrm{L}$ based on the kinetic analysis of the interaction between the purified carp parvalbumin and the monoclonal antibody against the bluefin tuna parvalbumin (MAb EG8). Moreover, the SPR biosensor analysis of the sardine fish cake and dried skipjack tuna revealed that MAb EG8 bound to a common epitope on the fish parvalbumin from different food sources. Although this assay showed potential for use in fish parvalbumin detection and quantification, the applicability of this assay, including the detection of parvalbumin derived from additional fish species and the quantification of fish parvalbumin in complex food matrices has not been reported. In 2007, Choi and Hong (2007) published a PCR method using primers that specifically target the gene of mackerel parvalbumin. However, the use of this method is limited to the detection of allergenic residues derived from mackerel but not other fish species. Sun et al. (2009) 
later developed a real-time PCR method using a probe and primers that specifically detect the parvalbumin genes of 28 of 30 fish species, with the exceptions of golden threadfin bream and yellowfin tuna. The sensitivity of the assay was reported as $5 \mathrm{pg}$ of purified fish DNA. Their assay did not amplify DNA from 13 non-fish species. As reported by the authors, more research is required to verify the applicability of the method for additional fish species and to correlate the DNA copy numbers with the actual amount of allergenic fish residues present in foods. Hildebrandt (2010) recently developed a new MultiAnalyte Profiling $\left(\mathrm{xMAP}^{\mathrm{TM}}\right)$ technology-based method that detects parvalbumin genes from at least 8 allergenic fish species without amplifying DNA from beef, lamb, chicken, pork, turkey, shrimp, or vegetable soup. This method combined PCR amplication of the DNA encoding parvalbumin using a universal fish primer that targeted a highly conserved exon region in fish parvalbumin sequences, followed by application of $\mathrm{xMAP}^{\mathrm{TM}}$ technology to detect the presence of the fish parvalbumin gene using primers targeting the speciesspecific intron region on the gene. Detection of specifically spiked samples of Atlantic salmon muscle in uncooked vegetable soup demonstrated a detection limit of $0.02 \%$ (20 $\mathrm{mg}$ salmon fillet in $100 \mathrm{~g}$ of soup). This method could conceivably detect up to 100 fish species simultaneously in one sample, but more research is needed to validate the effects of processing and food matrices on the assay performance. As noted by the author, the method detects DNA and not allergenic protein. Despite the limitation, the use of DNA as markers for allergenic fish detection is more advantageous than protein-based method due to the differential distribution of parvalbumin proteins within the fish tissues.

All of the analytical methods published so far, regardless of protein-based or DNA-based methods for detecting allergenic fish residues, had a similar shortcoming, 
which is the inability of the existing methods in detecting the undeclared fish residues derived from all species of fish in foods. Therefore, the development of more broadly applicable methods for detecting fish allergens remains an area for more research and improvement.

\section{CONCLUSIONS}

Parvalbumin is a calcium-binding muscle protein that is present in all vertebrates, yet only fish and frog are capable of triggering IgE-mediated reactions in fish-allergic individuals. The IgE-binding patterns to parvalbumins tend to vary depending on the individuals and fish species. Despite the wide cross-reactivity among fish, individuals with fish hypersensitivity can sometimes tolerate several fish, although parvalbumin appears to be a pan-allergen present in all fish species. Previous studies also demonstrated that monoclonal and polyclonal antibodies raised against purified parvalbumin displayed varying specificity for different fish species. Consequently, no effective quantification method is currently available to detect allergenic residues from all fish species in foods.

The reasons for the variation in antibodies binding to parvalbumin of various fish species remain largely unknown, although studies have postulated that these observations might be attributed to the variable parvalbumin content in the fish extracts or to differences in the binding affinity due to dissimilarity in primary structure and structural conformation. Processing treatments and calcium concentrations may also affect the binding of antibodies to parvalbumin. Although research into fish allergy has increased 
over the years, there are gaps in the understanding of allergenic properties of parvalbumin with regard to its role in cross-reactivity among fish species.

The overall aim of this study is to investigate and compare the parvalbuminbinding characteristics of several antibodies, including monoclonal anti-frog parvalbumin IgG antibody, monoclonal anti-carp parvalbumin IgG antibody, rabbit polyclonal anticod parvalbumin IgG antibody, and serum IgE from individuals with fish allergy. Specific objectives are as follows:

1. To evaluate and compare the immunoreactivity of the 3 anti-parvalbumin $\operatorname{IgG}$ antibodies to crude muscle extracts of various fish species and frog using indirect ELISA and immunoblotting. This study allows for the determination of the utility and possible applications of these antibodies for detecting and quantifying parvalbumins from different fish species and frog (Chapter 2).

2. The conformation of fish muscle proteins can potentially be modified during frozen storage. Moreover, the expression of parvalbumin varies in different muscle locations within whole fish. To assess the extent to which frozen storage and muscle locations could influence the parvalbumin content in fish muscles, indirect ELISA, SDS-PAGE, and densitometry analysis is used. Our aim is to determine whether these factors contribute to the variable immunoreactivity of the anti-parvalbumin IgG antibodies to fish parvalbumins (Chapter 3).

3. To analyze the immunoreactivity of serum IgE to purified cod and carp parvalbumin, and crude muscle extracts of various fish species and frog using immunoblotting. This study allows for the comparisons of IgE-binding profiles on parvalbumin and non-parvalbumin proteins between fish and frog species. In 
addition, the diversity of $\operatorname{IgE}$ responses to parvalbumin and other fish proteins among the serum samples is evaluated (Chapter 4).

4. To identify the potential allergens in 5 fish species using two-dimensional gel electrophoresis and tandem mass spectrometry. This study may facilitate the identification of potential fish allergens and provide insights as to whether the parvalbumin and other fish allergens are cross-reactive or species-specific (Chapter 5).

5. To determine whether IgG and IgE binding to parvalbumin are affected by heating, calcium, and Maillard treatment using competitive inhibition ELISA. The goal is to examine the antigenicity and allergenicity of parvalbumin after food processing treatments. On the other hand, the results also aid in determining the usefulness of the IgG antibodies for detecting allergenic fish residues in processed foods (Chapter 6).

6. To perform multiple sequence alignment and explore the evolutionary relationships of the allergenic fish parvalbumins and the non-allergenic homologs from non-fish species using CLUSTAL W and PHYLIP programs. The aim is to determine how closely related the fish parvalbumins are to the non-allergenic homologs. The comparisons of the interspecies variation of the fish parvalbumin sequences, particularly in the regions corresponded to the identified IgE-binding epitopes may provide insights into the role of primary structure in the crossreactivity among fish species (Chapter 7). 


\section{REFERENCES}

Aas, K. 1966. Studies of hypersensitivity of fish - allergological and serological differentiation between various species of fish. Int. Arch. Allergy Appl. Immunol. 30: 257-267.

Aas, K. 1987. Fish allergy and the cod fish allergen model. In J. Brostoff, and S. J. Challacombe (eds.), Food allergy and intolerance. Baillière Tindall, London, UK, pp. 356-366.

Aihara, Y., R. Ito, and Y. Takahashi. 2003. Food allergy in school children in Japan. Food Allergy and Intolerance 4: 49-58.

Alaedini, A., and P. H. R. Green. 2005. Narrative review: celiac disease: understanding a complex autoimmune disorder. Ann. Intern. Med. 142: 289-298.

André, F., S. Cavagna, and C. André. 2003. Gelatin prepared from tuna skin: a risk factor for fish allergy or sensitization? Int. Arch. Allergy Immunol. 130: 17-24.

André, F., C. André, L. Colin, F. Cacaraci, and S. Cavagna. 1994. Role of new allergens and of allergens consumption in the increased incidence of food sensitizations in France. Toxicology 93:77-83.

Asensio, L., I. González, M. A. Rodríguez, P.E. Hernández, T. García, and R. Martín. 2003. Development of a monoclonal antibody for grouper (Epinephelus marginatus) and wreck fish (Polyprion americanus) authentication using an indirect ELISA. J. Food Sci. 68: 1900-1903.

Asensio, L., L. Samaniego, M. A. Pavón, I. González, T. García, and R. Martín. 2008. Detection of grouper mislabeling in the fish market by an immunostick colorimetric ELISA assay. Food Agric. Immunol. 19: 141-147.

Astwood, J. D., J. N. Leach, and R. L. Fuchs. 1996. Stability of food allergens to digestion in vitro. Nat. Biotechnol. 14: 1269-1273.

Austyn, J. M. 1997. Antigen processing and presentation. In A.B. Kay (eds.), Allergy and allergic diseases, vol. 1. Blackwell Science Ltd., Oxford, UK, pp. 113-130.

Bernhisel-Broadbent, J., S. M. Scanlon, and H. A. Sampson. 1992a. Fish hypersensitivity. I. In vitro and oral challenge results in fish-allergic patients. J. Allergy Clin. Immunol. 89: 730-737.

Bernhisel-Broadbent, J., S. M. Scanlon, and H. A. Sampson. 1992b. Fish hypersensitivity. II. Clinical relevance of altered fish allergenicity caused by various preparation methods. J. Allergy Clin. Immunol. 90: 622-629. 
Besler, M. 2001. Determination of allergens in foods. Trends Analyt. Chem. 20: 662-672.

Björnsson, E., C. Janson, P. Plaschke, E. Norrman, and O. Sjöberg. 1996. Prevalence of sensitization to food allergens in adulte Swedes. Ann. Allergy Asthma Immunol. 77: 327332.

Bock, S. A. 1982. The natural history of food hypersensitivity. J. Allergy Clin. Immunol. 69: 173-177.

Bock, S. A. 1987. Prospective appraisal of complaints of adverse reactions to foods in children during the first 3 years of life. Peadiatrics 79: 683-688.

Bock, S. A. 2000. Evaluation of IgE-mediated food hypersensitivities. J. Pediatr. Gastroenterol. Nutr. 30: S20-S27.

Bock, S. A., A. Muñoz-Furlong, and H. A. Sampson. 2001. Fatalities due to anaphylactic reactions to foods. J. Allergy Clin. Immunol. 107: 191-193.

Bock, S. A., A. Muñoz-Furlong, and H. A. Sampson. 2007. Further fatalities caused by anaphylactic reactions to food. J. Allergy Clin. Immunol. 119: 1016-1018.

Bock, S. A., W. Y. Lee., L. Remigio, and C. D. May. 1978. Studies of hypersensitivity reactions to foods in infants and children. J. Allergy Clin. Immunol. 62: 327-334.

Bock, S. A., H. A. Sampson, F. M. Atkins, R. S. Zeiger, S. Lehrer, M. Sachs, et al. 1988. Double-blind, placebo-controlled food challenge (DPBCFC) as an office procedure: A manual. J. Allergy Clin. Immunol. 82: 986-997.

Bodmer, S., C. Imark, and M. Kneubühl. 1999. Biogenic amines in foods: histamine and food processing. Inflamm. Res. 48: 296-300.

Bousquet J., B. Björkstén, C. A. F. M. Bruijnzeel-Koomen, A. Huggett, C. Ortolani, J. O. Warner, et al. 1998. Scientific criteria and the selection of allergenic foods for product labeling. Allergy 53: 3-21.

Brandtzaeg, P. E. 2002. Current understanding of gastrointestinal immunoregulation and its relation to food allergy. Ann. N. Y. Acad. Sci. 964:13-45.

Bugajska-Schretter, A., M. Grote, L. Vangelista, P. Valent, W. R. Sperr, H. Rumpold, et al. 2000. Purification, biochemical, and immunological characterization of a major food allergen: different immunoglobulin E recognition of the apo- and calcium-bound forms of carp parvalbumin. Gut 46: 661-669.

Bulushi, I. A., S. Poole, H. C. Deeth, and G. A. Dykes. 2009. Biogenic amines in fish: roles in intoxication, spoilage, and nitrosamine formation - a review. Crit. Rev. Food Sci. Nutr. 49: 369-377. 
Burks, A. W., and H. Sampson. 1993. Food allergies in children. Curr. Probl. Pediatr. 23: 230-252.

Burks, A. W., S. Laubach, and S. M. Jones. 2008. Oral tolerance, food allergy, and immunotherapy: implications for future treatment. J. Allergy Clin. Immunol. 121:44-50.

Burks, W., S. B. Lehrer, and G. A. Bannon. 2004. New approaches for treatment of peanut allergy. Clin. Rev. Allergy Immunol. 27: 192-196.

Bush, R. K., and S. L. Hefle. 1996. Food allergens. Crit. Rev. Food Sci. Nutr. 36 (Suppl.): S119-163.

Carrera, M., B. Cañas, C. Piñeiro, J. Vázquez, and J. M. Gallardo. 2006. Identification of commercial hake and grenadier species by proteomic analysis of parvalbumin fraction. Proteomics 6: 5278-5287.

Carrera, E., R. Martín, T. García, I. González, B. Sanz, and P.E. Hernández. 1996. Development of an enzyme-linked immunosorbent assay for the identification of smoked salmon (Salmo salar), trout (Oncorhynchus mykiss) and bream (Brama raii). J. Food Prot. 59: 521-524.

Celio, M. R., W. Baier, L. Schärer, P. A. De Viragh, and C. H. Gerday. 1988. Monoclonal antibodies directed against the calcium binding protein parvalbumin. Cell Calcium, 9: 81-86.

Chatterjee, U., G. Mondal, P. Chakraborti, H. K. Patra, and B. P. Chatterjee. 2006.

Changes in the allergenicity during different preparations of pomfret, hilsa, bhetki and mackerel fish as illustrated by enzyme-linked immunosorbent assay and immunoblotting. Int. Arch. Allergy Immunol. 141: 1-10.

Chehade, M, and L. Mayer. 2005. Oral tolerance and its relation to food hypersensitivities. J. Allergy Clin. Immunol. 115:3-12.

Chen, L., S. L. Hefle, S. L. Taylor, I. Swoboda, and R. E. Goodman. 2006. Detecting fish parvalbumin with commercial mouse monoclonal anti-frog parvalbumin IgG. J. Agric. Food Chem. 54: 5577-5582.

Choi, K. Y., and K. W. Hong. 2007. Genomic DNA sequence of mackerel parvalbumin and a PCR test for rapid detection of allergenic mackerel ingredients in food. Food Sci. Biotechnol. 16: 67-70.

Civera, T. 2003. Species identification and safety of fish products. Vet. Res. Commun. 27: 481-489. 
Clark, S., J. Espinola, S. A. Rudders, A. Banerji, and C. A. Camargo. 2011. Frequency of US emergency department visits for food-related acute allergic reactions. J. Allergy Clin. Immunol. 127: 682-683.

Codex Alimentarius Commission. 1999. Report of the Twenty-third Session of the Codex Alimentarius Commission. Alinorm 99/37. Rome, Italy: Food and Agriculture Organization of the United Nations/World Health Organization.

Coombs, R. R. A., and P. G. H. Gell. 1978. Classification of allergic reactions responsible for clinical hypersensitivity and disease. In P. G. H. Gell, R. R. A. Coombs, and P. J. Lachmann (eds.), Clinical aspects of immunology, 3rd ed. Blackwell Scientific, Oxford, UK, pp. 761-781.

Corey, R. 2001. Freh or frozen fish. Available at:

http://permanent.access.gpo.gov/websites/ftpusitcgov/ftp.usitc.gov/pub/reports/studies/pu b3463.pdf. Accessed November 29, 2011.

Costa, J. J., P. F. Weller, and S. J. Galli. 1997. The cells of the allergic response: mast cells, basophils, and eosinophils. J. Am. Med. Assoc. 278: 1815-1822.

Crespo, J. F., C. Pascual, A. W. Burks, R, M. Helm, and M. M. Esteban. 1995a. Frequency of food allergy in a pediatric population from Spain. Pediatr. Allergy Immunol. 6: 39-43.

Crespo, J. F., C. Pascual, C. Dominguez, I. Ojeda, F. M. Muñoz, and M. M. Esteban. 1995b. Allergic reactions associated with airborne fish particles in IgE-mediated fish hypersensitive patients. Allergy 50: 257-261.

Dannaeus, A., and M. Inganäs. 1981. A follow-up study of children with food allergy. Clinical course in relation to serum IgE- and IgG-antibody levels to milk, egg and fish. Clin. Allergy 11: 533-539.

Das, A., P. Chakraborti, U. Chatterjee, G. Mondal, and B. P. Chatterjee. 2005. Identification of allergens in Indian fishes: Hilsa and Pomfret exemplified by ELISA and immunoblotting. Indian J. Exp. Biol. 43: 1170-1175.

Das Dores, S., C. Chopin, C. Villaume, J, Fleurence, and J.-L. Guéant. 2002a. A new oligomeric parvalbumin allergen of Atlantic cod ( $\mathrm{Gad} \mathrm{m} \mathrm{I}$ ) encoded by a gene distinct from that of Gad c I. Allergy 57(Suppl. 72): 79-83.

Das Dores, S., C. Chopin, A. Romano, A.-V. Galland-Irmouli, D. Quaratino, C. Pascual, et al. 2002b. IgE-binding and cross-reactivity of a new $41 \mathrm{kDa}$ allergen of codfish. Allergy 57(Suppl 72):84-7. 
De Martino, M., E. Novembre, L. Galli, A. de Marco, P. Botarelli, E. Marano, and A. Vierucci. 1990. Allergy to different fish species in cod-allergic children: In vivo and in vitro studies. J. Allergy Clin. Immunol. 86: 909-914.

Delgado, C. L., N. Wada, M. W. Rosegrant, S. Meijer, and M. Ahmed. 2003a. Outlook for fish to 2020: meeting global demand. In A 2020 vision for food, agriculture, and the environment initiative. International Food Policy Research Institute, Washington, DC, pp. $1-10$.

Delgado, C. L., N. Wada, M. W. Rosegrant, S. Meijer, and M. Ahmed. 2003b. Fish to 2020: supply and demand in changing global markets. In WorldFish Center technical report no. 62. International Food Policy Research Institute, Washington, DC, pp. 29-44.

Domínguez, C., I. Ojeda, J. F. Crespo, C. Pascual, A. Ojeda, and M. Martín-Esteban. 1996. Allergic reactions following skin contact with fish. Allergy Asthma Proc. 17: 8387.

Dory, D., C. Chopin, L. Aimone-Gastin, J. L. Guéant, L. Geurin, J. Sainte-Laudy, et al. 1998. Recognition of an extensive range of IgE-reactive proteins in cod extract. Allergy 53: $42-50$.

Du Toit, G., Y. Katz, P. Sasieni, D. Mesher, S. J. Maleki, H. R. Fisher, et al. 2008. Early consumption of peanuts in infancy is associated with a low prevalence of peanut allergy. J. Allergy Clin. Immunol. 122: 984-991.

Eigenmann, P. A., and H. A. Sampson. 1994. An update on food hypersensitivity. Fund. Clin. Immunol. 2: 121-133.

Elsayed, S., and K. Aas. 1971a. Isolation of purified allergens (cod) by isoelectric focusing. Int. Arch. Allergy Appl. Immunol. 40: 428-438.

Elsayed, S., and K. Aas. 1971b. Characterization of a major allergen (cod). Observations on effect of denaturation on the allergenic activity. J. Allergy 47: 283-291.

Elsayed, S., and J. Apold. 1983. Immunochemical analysis of cod fish Allergen M: locations of the immunoglobulin binding sites as demonstrated by the native and synthetic peptides. Allergy 38: 449-459.

Enrique, E., and A. Cistero-Bahima. 2006. Specific immunotherapy for food allergy: basic principles and clinical aspects. Curr. Opin. Allergy Clin. Immunol. 6: 466-469.

Erickson, J. R., and T. S. Moerland. 2006. Functional characterization of parvalbumin from the Arctic cod (Boreogadus saida): similarity in calcium affinity among parvalbumins from polar teleosts. Comp. Biochem. Physiol., Part A Mol. Integr. Physiol. 143: $228-233$. 
Eriksson, N. E., C. Moller, S. Werner, J. Magnusson, U. Bengtsson, and M. Zolubus. 2004. Self-reported food hypersensitivity in Sweden, Denmark, Estonia, Lithuania, and Russia. J. Investig. Allergol. Clin. Immunol. 14: 70-79.

Esteve-Romero, J. S., I. M. Yman, A. Bossi, and P. G. Righetti. 1996. Fish species identification by isoelectric focusing of parvalbumins in immobilized $\mathrm{pH}$ gradients. Electrophoresis 17: 1380-1385.

Food and Agriculture Organization of the United Nations (FAO). 1995. Food Allergies. Report of the FAO Technical Organization of the United Nations, Rome, Italy, November 13-14.

FAO, Fisheries and Aquaculture Department. 2008. The state of world fisheries and aquaculture (SOFIA). Available at: http://www.fao.org/fishery/. Accessed November 29, 2011.

FAO, Fisheries and Aquaculture Department. 2011. Composition of fish. Available at: http://www.fao.org/fishery/topic/12318/en. Accessed November 29, 2011.

Fasano, A., I. Berti, T. Gerarduzzi, T. Not, R. B. Colletti, S. Drago, et al. 2003. Prevalence of celiac disease in at-risk and not-at-risk groups in the United States: a large multicenter study. Arch. Intern. Med. 163: 286-292.

Fǽste, C.K., and C. Plassen. 2008. Quantitative sandwich ELISA for the determination of fish in foods. J. Immunol. Methods. 329: 45-55.

Flick, G. J., and R. E. Martin. 2009. Industrial products: gelatin and isinglass production. In R. E. Martin, E. P. Carter, G. J. Flick, and L. M. Davis (eds.), Marine and freshwater products handbook. Technomic Publishing Company, Inc., Lancaster, PA, pp. 605-612.

Food Standards Australia New Zealand (FSANZ). 2009. Final assessment report, application A490: exemption of allergen declaration for isinglass. Available at: http://www.foodstandards.gov.au/foodstandards/applications/applicationa490exemp3017. cfm. Accessed November 29, 2011.

Ford, R. P., and B. Taylor. 1982. Natural history of egg hypersensitivity. Arch. Dis. Child. 57: 649-652.

Fraser, O., S. Sumar, and N. Sumar. 2000. Adverse reaction to foods. Nutr. Food Sci. 30: 236-242.

Galland, A. V., D. Dory, L. Pons, C. Chopin, H. Rabesona, J. L. Guéant, and J. Fleurence. 1998. Purification of a $41 \mathrm{kDa}$ cod-allergenic protein. J. Chromatogr. B Biomed. Sci. Appl. 706: 63-71. 
Gajewski, K. G., and Y-H. P. Hsieh. 2009. Monoclonal antibody specific to a major fish allergen: parvalbumin. J. Food Prot.72: 818-825.

Gil, L. A. 2007. PCR-based methods for fish and fishery products authentication. Trends in Food Science \& Technology 18: 558-566.

Gill, A. C., and R. D. Mooi. 2004. Phylogeny and systematics of fishes. In P. J. B. Hart, and J. D. Reynolds (eds.), Handbook of fish biology and fisheries, volume 1. Blackwell Science Ltd, Malden, MA, pp. 15-42.

Gislason, D., E. Björnsson, T. Gislason, C. Janson, O. Sjöberg, L. Elfman, and G. Boman. 1999. Sensitization to airborne and food allergens in Reykjavík (Iceland) and Uppsala (Sweden) - a comparative study. Allergy 54: 1160-1167.

Goldsby, R. A., T. J. Kindt, B. A. Osborne, and J. Kuby. 2003. Immunology, 5th ed. W. H. Freeman and Company, New York, NY, pp. 1-23, 57-75, 361-386.

Goodman, M., and J-F. Pechére. 1977. The evolution of muscular parvalbumins investigated by the maximum parsimony method. J. Mol. Evol. 29: 131-158.

Göransson, K. 1981. Contact urticaria to fish. Contact Derm. 7: 282-283.

Halkier-Sørensen, L., and K. Thestrup-Pedersen. 1988. Skin temperature and skin symptoms among workers in the fish processing industry. Contact Derm. 19: 206-209.

Halkier-Sørensen, L., and K. Thestrup-Pedersen. 1989. Skin irritancy from fish is related to its postmortem age. Contact Derm. 21: 172-178.

Hall, G. M. 2011a. Canning fish and fish products. In G. M. Hall (eds.), Fish processing: sustainability and new opportunities. John Wiley \& Sons Ltd, West Sussex, UK, pp. 5176.

Hall, G. M. 2011b. Preservation by curing (drying, salting, and smoking). In G. M. Hall (eds.), Fish processing: sustainability and new opportunities. John Wiley \& Sons Ltd, West Sussex, UK, pp. 30-50.

Hamada, Y., Y. Nagashima, and K. Shiomi. 2001. Identification of collagen as a new fish allergen. Biosci. Biotechnol. Biochem. 65: 285-291.

Hamada, Y., H. Tanaka, S. Ishizaki, M. Ishida, Y. Nagashima, and K. Shiomi. 2003a. Purification, reactivity with $\mathrm{IgE}$ and cDNA cloning of parvalbumin as the major allergen of mackerel. Food Chem. Toxicol. 41: 1149-1156.

Hamada, Y., Y. Nagashima, and K. Shiomi, N. Shimojo, Y. Kohno, R. Shibata, et al. 2003b. Reactivity of IgE in fish-allergic patients to fish muscle collagen. Allergol Int. 52: 139-147. 
Hamada, Y., H. Tanaka, A. Sato, S. Ishizaki, Y. Nagashima, and K. Shiomi. 2004. Expression and evalution of IgE-binding capacity of recombinant Pacific mackerel parvalbumin. Allergol. Int. 53: 271-278.

Hansen, T. K., C. Bindslev-Jensen, P. S. Skov, and L. K. Poulsen. 1997. Codfish allergy in adults: IgE cross-reactivity among fish species. Ann. Allergy Asthma Immunol. 78: 187-194.

Hansen, T. K., L. K. Poulsen, P. S. Skov, S. L. Hefle, J. J. Hlywka, S. L. Taylor, et al. 2004. A randomized, double-blinded, placebo-controlled oral challenge study to evaluate the allergenicity

Heel, D. A., and V. J. West. 2006. Recent advances in coeliac disease. Gut. 55: 1037 1046.

Hefle, S. L., J. A. Nordlee, and S. L. Taylor. 1996. Allergenic foods. Crit. Rev. Food Sci. Nutr. 36: S69-S89.

Helbling, A., M. L. McCants, J. J. Musmand, H. J. Schwartz, and S. B. Lehrer. 1996. Immunopathogenesis of fish allergy: identification of fish-allergic adults by skn test and radioallergosorbent test. Ann. Allergy Asthma Immunol. 77: 48-54.

Helbling, A., R. Haydel, M. L. McCants, J. J. Musmand, J. El-Dahr, and S. B. Lehrer. 1999. Fish allergy: is cross-reactivity among fish species relevant? Double-blind placebocontrolled food challenge studies of fish allergic adults. Ann. Allergy Asthma Immunol. 83: 517-523.

Helfman, G., B. B. Collette, D. E. Facey, and B. W. Bowen. 2009. The diversity of fishes: biology, evolution, and ecology, 2nd ed. Johm Wiley \& Sons Ltd, Hoboken, NJ, pp. 3-9, 11-19, 41-56, 169-204.

Hildebrandt, S. 2010. Multiplexed identification of different fish species by detection of parvalbumin, a common fish allergen gene: a DNA application of multi-analyte profiling (xMAPTM) technology. Anal. Bioanal. Chem. 397: 1787-1796.

Hilger, C., L. Thill, F. Grigioni, C. Lehners, P. Falagiani, A. Ferrara, et al. 2004. IgE antibodies of fish allergic patients cross-react with frog parvalbumin. Allergy 59: 653660.

Huang, T-S., M. R. Marshall, K-J. Kao, W. S. Otwell, and C-I. Wei. 1995. Development of monoclonal antibodies for red snapper (Lutjanus campechanus) identification using enzyme-linked immunosorbent assay. J. Agric. Food Chem. 43: 2301-2307.

Hungerford, J. M. 2010. Scromboid poisoning: a review. Toxicon. 56: 231-243. 
Huriaux, F., P. Vandewalle, and B. Focant. 2002. Immunological study of muscle parvalbumin isotypes in three African catfish during development. Comp. Biochem. Physiol. B, Biochem. Mol. Biol. 132: 579-584.

Iikura, Y. 1998. Survey of food allergy in Japan. The annual report of the study group of food allergy supported by the Ministry of Welfare of Japan, pp. 1-72.

Iikura, Y., T. Imai, 2001. The nationwide study of severe cases with food allergy in Japan. The annual report of the study group of food allergy supported by the Ministry of Welfare and Labor of Japan, pp. 16-18.

Imamura, T., Y. Kanagawa, and M. Ebisawa. 2008. A survey of patients with selfreported severe food allergies in Japan. Pediatr. Allergy Immunol. 19: 270-274.

Jacobsen, C., H. H. Nielsen, B. Jørgensen, and J. Nielsen. 2010. Chemical processes responsible for quality deterioration in fish. In L. H. Skibsted, J. Risbo, and M. L. Anderson (eds.), Chemical deterioration and physical instability of food and beverages. CRC Press LLC, Boca Raton, FL, pp. 439-465.

James, J. M., R. M. Helm, A. W. Burks, and S. B. Lehrer. 1997. Comparison of pediatric and adult IgE antibody binding to fish proteins. Ann. Allergy Asthma Immunol. 79: 131137.

Kajosaari, M. 1982. Food allergy in Finnish children aged 1 to 6 years. Acta. Paediatr. Scand. 71: 815-819.

Karim, A. A., and R. Bhat. 2009. Fish gelatin: properties, challenges, and prospects as an alternative to mammalian gelatins. Food Hydrocolloids 23: 563-576.

Kawase, S., H. Ushio, T. Ohshima, H. Yamanaka, and H. Fukuda. 2001. Preparation of monoclonal antibodies against tuna parvalbuin. Fish. Sci. 67: 559-561.

Keeton, R. W., J. L. Baldwin, and A. M. Singer. 2008. Pharmacologic food reactions. In D. D. Metcalfe, H. A. Sampson, and R. A. Simon (eds.), Adverse reactions to foods and food additives, 4th ed. Blackwell Publishing Ltd., Oxford, UK, pp. 431-442.

Kelso, J. M., R. T. Jones, and J. W. Yunginger. 1996. Monospecific allergy to swordfish. Ann. Allergy Asthma Immunol. 77: 227-228.

Kobayashi, A., H. Tanaka, Y. Hamada, S. Ishizaki, Y. Nagashima, and K. Shiomi. 2006. Comparison of allergenicity and allergens between fish white and dark muscles. Allergy 61: 357-363.

Kocian, J. 1988. Lactose intolerance. Int. J. Biochem. 20: 1-5. 
Kretsinger, R. H., and C. E. Nockolds. 1973. Carp muscle calcium-binding protein. II. Structure determination and general description. J. Biol. Chem. 248: 3313-3326.

Kris-Etherton, P. M., W. S. Harris, and L. J. Appel. 2003. Fish consumption, fish oil, omega-3 fatty acids, and cardiovascular disease. Arterioscler Thromb Vasc Biol. 23: e20e30.

Kristjansson, I., B. Ardal, J. S. Johnsson, J. A. Sigurdsson, M. Foldevi, and B. Björkstén. 1999. Adverse reactions to food and food allergy in young children in Iceland and Sweden. Scand. J. Prim. Health Care. 17: 29-34.

Lack, G. 2008. Epidemiologic risks for food allergy. J. Allergy Clin. Immunol. 121: 1331-1336.

Lehane, L., and J. Olley. 2000. Histamine fish poisoning revisited. Int. J. Food Microbiol. 58: $1-37$.

Lemke, P. J., and S. L. Taylor. 1994. Allergic reactions and food intolerances. In F.N. Kotsonis, M. Mackey, and J. Hjelle (eds.), Nutritional Toxicology. Raven Press, Ltd., New York, NY, pp. 117-137.

Leung, D. Y. M., H. A. Sampson, J. W. Yunginger, W. Burks, L. C. Schneider, C. H. Wortel, et al. 2003. Effect of anti-IgE therapy in patients with peanut allergy. N. Engl. J. Med. 348: 986-993.

Li, X-M, and H. A. Sampson. 2002. Novel approaches for the treatment of food allergy. Curr. Opin. Allergy Clin. Immunol. 2: 273-278.

Lim, D. L., K. H. Neo, D. L. Goh, L. P. Shek, and B. W. Lee. 2005. Missing parvalbumin: implications in diagnostic testing for tuna allergy. J. Allergy Clin. Immunol. 115: 874-875.

Lim, D. L-C., K. H. Neo, F. C. Yi, K. Y. Chua, D. L-M. Goh, L. P-C. Shek, et al. 2008. Parvalbumin - the major tropical fish allergen. Pediatr. Allergy Immunol. 19: 399-407.

Lindstrøm, C. D-V., T. Van Do, I. Hordvik, C. Endresen, and S. Elsayed. 1996. Cloning of two distinct cDNAs encoding parvalbumin, the major allergen of Atlantic salmon (Salmo salar). Scand. J. Immunol. 44: 335-344.

Liu, R., H. B. Krishnan, W. Xue, and C. Liu. 2011a. Characterization of allergens isolated from the freshwater fish blunt snout bream (Megalobrama amblycephala). J. Agric. Food Chem. 59: 458-463.

Liu, R., E. Yang, C. Liu, and W. Xue. 2011b. Tilapia (Oreochromis mossambicus) allergens characterized by ELISA, SDS-PAGE, 2D gels, Western blotting and MALDITOF mass spectrometry. Int. J. Food Sci. Nutr. (in press). 
Lopata, A. L., and S. B. Lehrer. 2009. New insights into seafood allergy. Curr. Opinion Allergy Clin. Immunol. 9: 270-277.

Lu, Y., T. Ohshima, and H. Ushio. 2008. Rapid detection of fish major allergen parvalbumin by surface plasmon resonance biosensor. J. Food Sci. 69: C652-C658.

Maleki, S. J., S-Y. Chung, E. T. Champagne, and J-P, Raufman. 2000. The effects of roasting on the allergenic properties of peanut proteins. J. Allergy Clin. Immunol. 106: 763-768.

Mekori, Y. A. 1996. Introduction to allergic diseases. Crit. Rev. Food Sci. and Nutr. 36: S1-S18.

Metcalfe, D. D. 1987. A current practical approach to diagnosis of suspected adverse reactions to foods. N. Engl. Reg. Allergy Proc. 8: 22-26.

Metcalfe, D. D. 1995. Allergic reactions to foods. In M. M. Frank, K. F. Austen, H. N. Claman, and E. R. Unanue (ed.), Samter's immunologic disease, 5th ed. Little Brown and Company, New York, NY. pp. 1357-1366.

Miller, G. D., J. K. Jarvis, and L. D. McBean. 2007. Lactose digestion. In Handbook of dairy foods and nutrition, 3th ed. CRC Press, Boca Raton, FL. pp. 299-338.

Moneret-Vautrin, D. A., G. Kanny, M. Morisset, J. Flabbee, L. Guénard, E. Beaudouin, et al. 2001. Food anaphylaxis in schools: evaluation of the management plan and the efficiency of the emergency kit. Allergy 56: 1071-1076.

Nakayama, S., and R. H. Kretsinger. 1994. Evolution of the EF-hand family of proteins. Annu. Rev. Biophys. Biomol. Struct. 23: 473-507.

Nelson, H. S., J. Lahr, R. Rule, A. Bock, and D. Leung. 1997. Treatment of anaphylactic sensitivity to peanuts by immunotherapy with injections of aqueous peanut extract. J. Allergy Clin. Immunol. 99: 744-751.

Nowak-Wegrzyn, A., and H. A. Sampson. 2011. Future therapies for food allergy. J. Allergy Clin. Immunol. 127: 558-573.

O’Neil, C., A. A. Helbling, and S. B. Lehrer. 1993. Allergic reactions to fish. Scand. J. Prim. Health Care. Clin. Rev. Allergy 11: 183-200.

Onal, A. 2007. A review: current analytical methods for the determination of biogenic amines in foods. Food Chem. 103: 1475-1486. 
Oppenheimer, J., H. S. Nelson, S. A. Bock, F. Christensen, and D. Y. M. Leung. 1992. Treatment of peanut allergy with rush immunotherapy. J. Allergy Clin. Immunol. 90: 256-262.

Pascual, C. Y., M. Reche, A. Fianodor, T. Valbuena, T. Cuevas, and M. M. Esteban. 2008. Fish allergy in childhood. Pediatr. Allergy Immunol. 19: 573-579.

Pénard-Morand, C., C. Raherison, C. Kopferschmitt, D. Caillaud, F. Lavaud, D. Chairpin, et al. 2005. Prevalence of food allergy and its relationship to asthma and allergic rhinitis in schoolchildren. Allergy 60: 1165-1171.

Permyakov, E. A. 2006. Parvalbumin. Nova Science Pulishers, NY, pp. 5-42.

Permyakov, S. E., A. G. Bakunts, A. I. Denesyuk, E. L. Knyazeva, V. N. Uversky, and E. A. Permyakov. 2008. Apo-parvalbumin as an intrinsically disordered protein. Proteins 15: 822-836.

Poulsen, L. K. 2001. In-vitro diagnosis: serum-based methods used for risk assessment of allergenic foods. Curr. Opin. Allergy Clin. Immunol. 1: 249-254.

Priftis, K. N., D. Mermeri, A. Papadopoulou, M. Papadopoulos, A. Fretzayas, and E. Lagona. 2008. Asthma symptoms and brochial reactivity in school children sensitized to food allergens in infancy. J. Asthma 45: 590-595.

Prussin, C., and D. D. Metcalfe. 2006. IgE, mast cells, basophils, and eosinophils. J. Allergy Clin. Immunol. 117: 450-456.

Pucar, F., R. Kagan, H. Lim, and A. E. Clarke. 2001. Peanut challenge: a retrospective study of 140 patients. Clin. Exp. Allergy 31: 40-46.

Pumphrey, R. S. H. 2004. Fatal anaphylaxis in the U.K., 1992-2001. Novartis Foundation Symposium 257: 116-128.

Pumphrey, R. S. H. 2000. Lessons for management of anaphylaxis from a study of fatal reactions. Clin. Exp. Allergy 30: 1144-1150.

Pumphrey, R. S. H., and M. H. Gowland. 2007. Further fatal allergic reactions to food in the United Kingdom, 1999-2006. J. Allergy Clin. Immunol. 119: 1018-1019.

Rancé, F., X. Grandmottet, and H. Grandjean. 2005. Prevalence and main characteristics of schoolchildren diagnosed with food allergies in France. Clin. Exp. Allergy 35: 167172.

Rasmussen, R. S., and M. T. Morrissey. 2008. DNA-based methods for the identification of commercial fish and seafood species. Compr. Rev. Food Sci. Food Saf. 7: 280-295. 
Regenstein, J. M., and C. E. Regenstein. 1991. Introduction to fish technology. Van Nostrand Reinhold, New York, NY, pp. 200-207.

Ring, J., K. Brockow, H. Behrendt. 2001. Adverse reactions to foods. J. Chromatogr. B. 756: 3-10.

Robertson, D. A., R. C. Ayres, C. L. Smith, and R. Wright. 1988. Adverse consequences arising from misdiagnosis of food allergy. Br. Med. J. 297: 719-720.

Rodríguez, J., M. Reaño, R. Vives, G. Canto, P. Daroca, J. F. Crespo, et al. 1997. Occupational asthma caused by fish inhalation. Allergy 52: 866-869.

Rona, R. J., T. Keil, C. Summers, D. Gislason, L. Zuidmeer, E. Sodergren, et al. 2007. The prevalence of food allergy: a meta-analysis. J. Allergy Clin. Immunol. 120: 638-646.

Rusynyk, R. A., and C. D. Still. 2001. Lactose intolerance. J. Am. Ostepath. Assoc. 101: S10-S12.

Sakaguchi, M., M. Toda, T. Ebihara, S. Irie, H. Hori, A. Imai, et al. 2000. IgE antibody to fish gelatin (type I collagen) in patients with fish allergy. J. Allergy Clin. Immunol. 106: 579-584.

Samaratín, S., A. Marcos, and R. K. Chandra. 2001. Food hypersensitivity. Nutr. Res. 21: 473-497.

Sampson, H. A. 1991. Immunologic mechanisms in adverse reactions to foods. Immunol. Allergy Clin. North Am. 11: 701-716.

Sampson, H. A. 1997. Food allergy. J. Am. Med. Assoc. 278: 1888-1894.

Sampson, H. A. 1999a. Food allergy. Part 1: Immunopathogenesis and clinical disorder. J. Allergy Clin. Immunol. 103: 717-728.

Sampson, H. A. 1999b. Food allergy. Part 2: Diagnosis and management. J. Allergy Clin. Immunol. 103: 981-989.

Sampson, H. A. 2003a. Anaphylaxis and emergency treatment. Pediatrics 111: 16011608.

Sampson, H. A. 2003b. Food allergy. J. Allergy Clin. Immunol. 111: S540-547.

Sampson, H. A. 2004. Update on food allergy. J. Allergy Clin. Immunol. 113: 805-819.

Sampson, H. A., and G. H. Deborah. 1997. Relationship between food-specific IgE concentrations and the risk of positive food challenges in children and adolescents. J. Allergy Clin. Immunol. 100: 444-451. 
Sampson, H. A., and D. D. Metcalfe. 1992. Food allergies. J. Am. Med. Assoc. 268: 2840-2844.

Sampson, H. A., and S. M. Scanlon. 1989. Natural history of food hypersensitivity in children with atopic dermatitis. J. Peadiatr. 115: 23-27.

Sampson, H. A., R. H. Buckley, and D. D. Metcalfe. 1987. Food allergy. J. Am. Med. Assoc. 258: 2886-2890.

Scurlock A. M., B. P. Vickery, J. O. Hourihane, and A. W. Burks. 2010. Pediatric food allergy and mucosal tolerance. Mucosal Immunol. 3: 345-354.

Sen, D. P. 2005. Advances in fish processing technology. Allied Publishers Private Ltd, New Delhi, India, pp. 43-119.

Shiomi, K., S. Hayashi, M. Ishikawa, K. Shimakura, and Y. Nagashima. 1998. Identification of parvalbumin as an allergen in horse mackerel. Fish. Sci. 64: 300-304.

Shiomi, K., Y. Hamada, K. Sekiguchi, K. Shimakura, and Y. Nagashima. 1999. Two classes of allergens, parvalbumins and higher molecular weight substances, in Japanese eel and bigeye tuna. Fish. Sci. 65: 943-948.

Skolnick H. S., M. K. Conover-Walker, C. B. Koemer, H. A. Sampson, W. Burks, and R. A. Wood. 2001. The natural history of peanut allergy. J. Allergy Clin. Immunol. 107: 367-374.

Skripak, J. M., S. D. Nash, H. Rowley, N. H. Brereton, S. Oh, R. G. Hamilton, et al. 2008. A randomized, double-blind, placebo-controlled study of milk oral immunotherapy for cow’s milk allergy. J. Allergy Clin. Immunol. 122: 1154-1160.

Sicherer S. H. 1999. Food allergy: when and how to perform oral food challenges. Pediatr. Allergy Immunol. 10: 226-234.

Sicherer, S. H. 2002. Food Allergy. Lancet 360: 701-710.

Sicherer, S. H., and H. A. Sampson. 2009. Food allergy: recent advances in pathophysiology and treatment. Annu. Rev. Med. 60: 261-277.

Sicherer, S. H., and H. A. Sampson. 2010. Food allergy. J. Allergy Clin. Immunol. 125: S116-S125.

Sicherer, S. H., A. Muñoz-Furlong, and H. A. Sampson. 1999. Prevalence of peanut and tree nut allergy in the U.S. determined by a random digit dial telephone survey. J. Allergy Clin. Immunol. 103: 559-562. 
Sicherer, S. H., A. Muñoz-Furlong, and H. A. Sampson. 2004. Prevalence of seafood allergy in the United States determined by a random telephone survey. J. Allergy Clin. Immunol. 114: 159-165.

Sicherer, S. H., A. Muñoz-Furlong, J. H. Godbold, H. A. Sampson. 2010. US prevalence of self-reported peanut, tree nut, and sesame seed allergy: 11 year follow up. J. Allergy Clin. Immunol. 125: 1322-1326.

Sikorski, Z. E., and A. Ruiter. 1994. Changes in proteins and nonprotein nitrogen compounds in cured, fermented, and dried seafoods. In Z. E. Sikorski, B. S. Pan, and F. Shahidi (eds.), Seafood proteins. Chapman and Hall, New York, NY, pp. 113-126.

Skerritt, J. H., J. M. Devery, and A. S. Hill. 1990. Gluten intolerance: chemistry, celiactoxicity, and detection of prolamins in foods. Cereal Foods World. 35: 638-644.

Solensky, R. 2003. Resolution of fish allergy: a case report. Ann. Allergy Asthma Immunol. 91: 411-412.

Srivastava, K. D., J. D. Kattan, Z. M. Zou, J. H. Li, L. Zhang, S. Wallenstein, et al. 2005. The Chinese herbal medicine formula FAHF-2 completely blocks anaphylactic reactions in a murine model of peanut allergy. J. Allergy Clin. Immunol. 115: 171-178.

Sten, E., T. K. Hansen, P. S. Skov, S. B. Andersen, A. M. Torp, U. Bindslev-Jensen, et al. 2004. Cross-reactivity to eel, eelpout and ocean pout in codfish-allergic patients. Allergy 59: 1173-1180.

Strober, W. 1986. Gluten sensitive enteropathy: a nonallergic immune hypersensitivity of the gastrointestinal tract. J. Allergy Clin. Immunol. 78: 202-211.

Strynadka, N. C. J., and M. N. G. James. 1989. Crystal structures of the helix-loop-helix calcium-binding proteins. Annu. Rev. Biochem. 58: 951-998.

Suarez, F. L., and D. A. Savaiano. 1997. Diet, genetics, and lactose intolerance. Food Technol. 51: 74-76.

Suarez, F. L., M. D. Dennis, A. Savaiano, and M. D. Levitt. 1995. A comparison of symptoms after the consumption of milk or lactose-hydrolyzed milk by people with selfreported severe lactose intolerance. N. Engl. J. Med. 333: 1-4.

Suarez, F. L., D. Savaiano, P. Arbisi, and M. D. Levitt. 1997. Tolerance to the daily ingestion of two cups of milk by individuals claiming lactose intolerance. Am. J. Clin. Nutr. 65: 1502-1506.

Sun, M., C. Liang, H. Gao, C. Lin, and M. Deng. 2009. Detection of parvalbumin, a common fish allergen gene in food, by real-time polymerase chain reaction. J. AOAC Int. 92: 234-240. 
Swoboda, I., A. Bugajska-Schretter, B. Linhart, P. Verdino, W. Keller, U. Schulmeister, et al. 2007. A recombinant hypoallergenic parvalbumin mutant for immunotherapy of IgE-mediated fish allergy. J. Immunol. 178: 6290-6296.

Swoboda, I., A. Bugajska-Schretter, P. Verdino, W. Keller, W. R. Sperr, P. Valent, et al. 2002. Recombinant carp parvalbumin, the major cross-reactivity fish allergen: a tool for diagnosis and therapy of fish allergy. J. Immunol. 168: 4576-4584.

Taylor, S. L. 1987. Allergic and sensitivity reactions to food components. In J. N. Hathcocok (eds.), Nutritional toxicology, vol. 2. Academic Press, Inc., Orlando, FL, pp. 173-198.

Taylor, S. L., and S. L. Hefle. 1999. Food allergy, intolerance and behavioral reactions. In I. Knight (eds.), Chocolate and cocoa: health and nutrition. Blackwell Science, Oxford, UK, pp. 218-228.

Taylor, S. L., and S. L. Hefle. 2001. Food allergies and other food sensitivities. Food Tech. 55: 68-83.

Taylor, S. L., and S. L. Hefle. 2002. Allergic reactions and food intolerance. In F.N. Kotsonis, M. A. Mackey (eds.), Nutritional toxicology, 2nd ed. Taylor and Francis, New York, NY, pp. 93-121.

Taylor, S. L., and S. L. Hefle. 2005. Food Allergy. In B. A. Bowman, and R. M. Russell (eds.), Present knowledge in nutrition, 9th ed. International Life Science Institute Press, Washington, DC, pp. 625-634.

Taylor, S. L., and S. L. Hefle. 2006a. Introduction to food allergy. In Y. Mine, and F. Shahidi (eds.), Nutraceutical proteins and peptides in health and disease. Taylor \& Francis, Boca Raton, FL, pp. 393-410.

Taylor, S. L., and S. L. Hefle. 2006b. Food allergies and intolerances. In M. Shils, M. Shike, A. C. Ross, B. Caballero, and R. J. Cousins (eds.), Modern nutrition in health and disease, 10th ed. Lippincott Williams and Wilkins, Baltimore, MD, pp. 1512-1527.

Taylor, S. L., and S. B. Lehrer. 1996. Principles and characteristics of food allergens. Crit. Rev. Food Sci. Nutr. 36: S91-S118.

Taylor, S. L., S. L. Hefle, and B. J. Gauger. 2000. Food allergies and sensitivities. In W. Helferich, and C. K. Winter (eds.), Food toxicology. CRC Press, Boca Raton, FL, pp. 136.

Taylor, S. L., J. L. Kabourek, and S. L. Hefle. 2004. Fish allergy: fish and products thereof. J. Food Sci. 69: 175-180. 
Taylor, S. L., R. F. Lemanske, R. K. Bush, and W. W. Busse. 1987. Food allergens: structure and immunological properties. Ann. Allergy 59: 93-99.

Taylor, S. L., S. L. Hefle, C. Bindslev-Jensen, S. A. Bock, A. W. Burks, L. Christie, et al. 2002. Factors affecting the determination of threshold doses for allergenic foods: how much is too much? J. Allergy Clin. Immunol. 109: 24-30.

Thompson, K., and R. K. Chandra. 2002. The management and prevention of food anaphylaxis. Nutr. Res. 22: 89-110.

Tomura, S., S. Ishizaki, Y. Nagashima, and K. Shiomi. 2008. Reduction in the IgE reactivity of Pacific mackerel parvalbumin by mutations at $\mathrm{Ca}^{2+}$-binding sites. Fish. Sci. 74: 411-417.

Tuft, L., and G. I. Blumstein. 1946. Studies in food allergy. V. Antigenic relationship among members of fish family. J. Allergy. 17: 329-339.

Untersmayr, E., and E. Jensen-Jarolim. 2008. The role of protein digestibility and antacids on food allergy outcomes. J. Allergy Clin. Immunol. 121: 1301-1308.

Untersmayr, E., L. K. Poulsen, M. H. Platzer, M. H. Pedersen, G. Boltz-Nitulescu, P. S. Skov, et al. 2005. The effects of gastric digestion on codfish allergenicity. J. Allergy Clin. Immunol. 115: 377-382.

Untersmayr, E., K. Szalai, A. B. Riemer, W. Hemmer, I. Swoboda, B. Hantusch, et al. 2006. Mimitopes identify conformational epitopes on parvalbumin, the major fish allergen. Mol. Immunol. 43: 1454-1461.

Untersmayr, E., H. Vestergaard, H-J, Malling, L. B. Jensen, M. H. Platzer, G. BoltzNitulescu, et al. 2007. Incomplete digestion of codfish represents a risk factor for anaphylaxis in patients with allergy. J. Allergy Clin. Immunol. 119: 711-717.

United States Department of Agriculture (USDA), Agricultural Research Service. 2011. USDA national nutrient database for standard reference, release 24. Available at: http://www.ars.usda.gov/Services/docs.htm?docid=8964. Accessed November 29, 2011.

U.S. Food and Drug Administration (U.S. FDA). 2011. Bad bug book: foodborne pathogenic microorganisms and natural toxins handbook scombrotoxin. Available at: http://www.fda.gov/Food/FoodSafety/FoodborneIllness/FoodborneIllnessFoodbornePath ogensNaturalToxins/BadBugBook/ucm070823.htm. Accessed November 29, 2011.

Van Do, T., I. Hordvik, C. Endresen, and S. Elsayed. 1999. Expression and analysis of recombinant salmon parvalbumin, the major allergen in Atlantic salmon (Salmo salar). Scand. J. Immunol. 50: 619-625. 
Van Do, T., I. Hordvik, C. Endresen, and S. Elsayed. 2003. The major allergen (parvalbumin) of codfish is encoded by at least two isotypic genes: cDNA cloning, expression and antibody binding of the recombinant allergens. Mol. Immunol. 39: 595602.

Van Do, T, S. Elsayed, E. Florvaag, I. Hordvik, and C. Endresen. 2005a. Allergy to fish parvalbumins: studies on the cross-reactivity of allergens from 9 commonly consumed fish. J. Allergy Clin. Immunol. 116: 1314-1320.

Van Do, T., I. Hordvik, C. Endresen, and S. Elsayed. 2005b. Characterization of parvalbumin, the major allergen in Alaska Pollack and comparison with codfish Allergen M. Mol. Immunol. 42: 345-353.

Van Ree, R., S. Veiths, and L. K. Poulsen. 2006. Allergen-specific IgE testing in the diagnosis of food allergy and the event of a positive match in the bioinformatics search. Mol. Nutr. Food Res. 50: 645-654.

Vesa, T. H., P. Marteau, and R. Korpela. 2000. Lactose intolerance. J. Am. Coll. Nutr. 19: $165 \mathrm{~S}-175 \mathrm{~S}$.

Vieth, S., H. Aulepp, W. M. Becker, and L. Buschmaan. 1996. Characterization of labile and stable allergens in foods of plant origin. In G. Eisenbrand, A. D. Dayan, J. Ring, H. Aulepp, P. S. Elias, and W. Grunow (eds.), Food allergies and intolerances: symposium. VCH Publishers, Inc., Weinhiem, NY, pp. 130-149.

Wang, J., S. P. Patil, N. Yang, J. Ko, J. Lee, S. Noone, et al. 2010. Safety, tolerability, and immunologic effects of a food allergy herbal formula in food allergic individuals: a randomized, double-blinded, placebo-controlled, dose escalation, phase 1 study. Ann. Allergy Asthma Immunol. 105: 75-84.

Warne, D. 1988. Manual on fish canning. FAO Fisheries technical paper 285. Available at: http://www.fao.org/DOCREP/003/T0007E/T0007E00.htm\#Contents. Accessed November 29, 2011.

Weber, P., H. Steinhart, and A. Paschke. 2009. Competitive indirect ELISA for the determination of parvalbumins from various fish species in food grade fish gelatins and isinglass with PARV-19 anti-parvalbumin antibodies. J. Agric. Food Chem. 57: 1132811334.

Weber, P., H. Steinhart, and A. Paschke. 2010. Characterization, antigenicity and detection of fish gelatin and isinglass used as processing aids in wines. Food Addit. Contam. 27: 273-282.

Wild, L. G., and S. B. Lehrer. 2005. Fish and shellfish allergy. Curr. Allergy Asthma Rep. 5: 74-79. 
Willmer, P., G. Stone, and I. Johnston. 2005. Environmental physiology of animals, 2nd ed. Blackwell Science Ltd, Malden, MA, pp. 223-341.

Wilmert, J. L., N. M. Madhoun, and D. J. Coughlin. 2006. Parvalbumin correlates with relaxation rate in the swimming muscle of sheepshead and kingfish. J. Exp. Biol. 209: 227-237.

Wood, R. A. 2003. The natural history of food allergy. Pediatrics 111: 1631-1637.

Woods, R. K., R. M. Stoney, J. Raven, E. H. Walters, M. Abramson, and F. C. K. Thien. 2002. Reported adverse food reactions overestimate true food allergy in the community.

Eur. J. Clin. Nutr. 56: 31-36.

Woods, R. K., M. Abramson, M. Bailey, and E. H. Walters. 2001. International prevalences of reported food allergies and intolerances. Comparisons arising from the European Community Respiratory Health Survey (ECRHS) 1991-1994. Eur. J. Clin. Nutr. 55:298-304.

Winbery, S. L., and P. L. Lieberman. 1995. Anaphylaxis. Immunol. Allergy Clin. North Am. 15(3): 447-475.

Yoshida, S., A. Ichimura, and K. Shiomi. 2008. Elucidation of a major IgE epitopes of Pacific mackerel parvalbumin. Food Chem. 111: 857-861.

Yunginger, J. W., K. G. Sweeney, W. Q. Sturner, L. A. Giannandrea, J. D. Teigland, M. Bray, et al. 1988. Fatal food-induced anaphylaxis. JAMA 260: 1450-1452.

Zuidmeer, L., K. Goldhahn, R. J. Rona, D. Gislason, C. Madsen, C. Summers, et al. 2008. The prevalence of plant food allergies: a systematic review. J. Allergy Clin. Immunol. 121: 1210-1218. 


\section{CHAPTER 2: EVALUATION AND COMPARISON OF THE SPECIES- SPECIFICITY OF 3 ANTI-PARVALBUMIN IgG ANTIBODIES ${ }^{\S}$}

Poi-Wah Lee ${ }^{1}$, Julie A. Nordlee ${ }^{1}$, Stef J. Koppelman ${ }^{1}$, Joseph L. Baumert ${ }^{1}$, and Steve L. Taylor $^{1^{*}}$

${ }^{1}$ Food Allergy Research and Resource Program, University of Nebraska, Lincoln, NE, United States

*Corresponding author. Tel: +1-402-472-2833; Fax: +1-402-472-5307.

E-mail address: staylor2@unl.edu

Short title: Species-specificity of anti-parvalbumin IgG antibodies

§ Adapted from J. Agric. Food Chem 2011, 59, $12309-12316$.

Copyright (2011) American Chemical Society. 


\begin{abstract}
Parvalbumin is a pan-allergen in fish and frog that triggers IgE-mediated reactions in fish-allergic individuals. Previous studies demonstrated that antibodies raised against fish and frog parvalbumins displayed varying specificity for different fish species, and thus the applicability of these antibodies for potential use in immunoassays to detect fish residues were limited. We aimed to determine the specificity of $3 \mathrm{IgG}$ antibodies for various fish species. Indirect enzyme-linked immunosorbent assay (ELISA) and IgGimmunoblotting were used to compare the reactivity of the polyclonal anti-cod parvalbumin antibody, and the commercially-available, monoclonal anti-frog and monoclonal anti-carp parvalbumin antibodies against raw muscle extracts of 29 fish species. All antibodies demonstrated varying specificity for different fish species. Of the 3 antibodies, the polyclonal anti-cod parvalbumin antibody is the most suitable for the detection of fish parvalbumins as it showed reactivity to the widest range of species, including herring, pilchard, carp, pike, cod, pollock, haddock, cusk, hake, bluegill, tilapia, bass, grouper, trout, catfish, and perch, although detection was still limited for several key fish species.
\end{abstract}

Keywords: Fish allergy; IgG binding; fish parvalbumin; cross-reactivity; fish species 


\section{INTRODUCTION}

Fish is a general term that refers to a collection of taxonomic groups, including hagfish, lampreys, sharks, rays, and bony fish. At least 27,000 species of fish have been scientifically described (1). Despite the enormous diversity of fish species, only a few orders of fish within the class Actinopterygii (ray-finned fish) are commonly consumed, namely Salmoniformes, Perciformes, Gadiformes, Pleuronectiformes, Clupeiformes, and Cypriniformes (2). Fish allergy limits the consumption of fish for some individuals. Fish is considered as a commonly allergenic food in the U.S., Europe, Canada, Australia, New Zealand and elsewhere. The prevalence of fish allergy is not precisely known but was estimated at $0.4 \%$ of the general populations in the United States on the basis of a random digit-dial telephone survey (3). A meta-analysis showed the prevalence of fish allergy varied from $0 \%$ to $2 \%$, depending on type of diagnosis for fish allergy, including selfreport, specific IgE measurement, skin prick test, symptoms combined with sensitization, and food challenge studies (4). IgE-mediated hypersensitivity to fish can be induced through ingestion, direct contact, and inhalation of fish odors and fumes generated during cooking $(5-7)$. Typical symptoms of fish allergy range from skin, respiratory, and gastrointestinal symptoms to fatal anaphylaxis $(8,9)$. In contrast to milk and egg allergy that are commonly outgrown, fish allergy often persists throughout life once sensitized $(10,11)$.

Parvalbumin ( $\mathrm{Gad} \mathrm{c} \mathrm{1)} \mathrm{isolated} \mathrm{from} \mathrm{cod} \mathrm{was} \mathrm{the} \mathrm{first} \mathrm{major} \mathrm{fish} \mathrm{allergen}$ described (12). Later, homologous allergens from Atlantic salmon, carp, cod, Alaska pollock, horse mackerel, Japanese eel, bigeye tuna, mackerel, whiff, and swordfish, were isolated and characterized (13-22). These allergens displayed the ability to bind serum- 
specific IgE from fish-allergic individuals. Parvalbumin is a small, water-soluble, calcium-binding muscle protein involved in the muscle relaxation process (23). Gad c 1 retains its allergenicity after heat treatment or exposure to extreme $\mathrm{pH}$ and denaturing chemicals (24-25). Two separate lineages of parvalbumin, namely $\alpha$ - and $\beta$-parvalbumin were identified (26). The $\beta$-parvalbumin is responsible for the allergenicity of various fish species, but the allergenicity of frog $\alpha$-parvalbumin has also been reported $(27,28)$.

The current treatment for fish allergy is to strictly avoid all species of fish due to the cross-reactivity reported between various fish species (29). Hence, the detection of allergenic fish residues in foods is necessary to protect the fish-allergic consumers and to ensure accurate labeling of food products. Compared to the methods available for detecting the allergenic proteins derived from the other commonly allergenic foods, there were fewer studies describing the detection of allergenic proteins in fish. Fǽste and Plassen (30) developed a sandwich enzyme-linked immunosorbent assay (ELISA) for the quantification of fish in foods using polyclonal anti-cod parvalbumin antibody as the capture and detector antibody. The ELISA had a low detection limit for parvalbumin in foods, but the quantification capability of this method varied with different fish species due to the inconsistent binding of the anti-cod parvalbumin antibody. Similar observations on the variable binding of the anti-parvalbumin IgG antibody to parvalbumin and crude extracts derived from different fish species has also been reported by others. Chen et al. (31) demonstrated variable immunoreactivity of the commerciallyavailable mouse monoclonal anti-frog parvalbumin antibody (PARV-19) to the extracts from several fish species. A monoclonal antibody against the crude extracts of the cooked catfish muscle proteins was developed by Gajewski and Hsieh (32). The comparisons of 
their antibody with the PARV-19 showed further evidence of the variable specificity of both antibodies to the cooked extracts from different fish species. Recently, Weber et al. (33) developed a competitive ELISA using PARV-19 to detect fish parvalbumins in food grade fish gelatins and isinglass samples. Variable cross-reactivity of PARV-19 to cod, hake, tilapia, pollock, sturgeon, and haddock was also observed in that ELISA.

The aim of this study was to compare the polyclonal anti-cod parvalbumin antibody developed by our group to both commercially-available, monoclonal anti-carp and anti-frog parvalbumin antibodies with regard to their immunoreactivity to different fish species. This approach allowed us to determine the utility and possible applications of these antibodies for detecting parvalbumins derived from commercially important fish species.

\section{MATERIALS AND METHODS}

\section{Materials}

Mouse monoclonal anti-frog parvalbumin antibody (anti-frog MoAb; clone PARV-19) was purchased from Sigma-Aldrich (St. Louis, MO), mouse monoclonal anticarp parvalbumin antibody (anti-carp MoAb; clone PV 235) was from Swant, Inc. (Switzerland) and rabbit polyclonal anti-cod parvalbumin antibody (anti-cod PoAb) was developed using purified cod parvalbumin as the antigen with an immunization protocol that has been previously described (34). Briefly, rabbit was injected with $200 \mu \mathrm{g}$ of purified parvalbumin protein emulsified with TiterMax Classic adjuvant (Sigma-Aldrich, St. Louis, MO) for the initial immunization. The subsequent booster injections were administered with $100 \mu \mathrm{g}$ of parvalbumin protein at 28-day intervals after the initial 
immunization. Cod and carp parvalbumin were purified from the fish fillets by a combination of diafiltration and chromatography steps as described previously $(35,36)$.

Twenty nine commonly consumed fish species and frog legs were obtained from different fish and seafood distributors in the U.S. and The Netherlands. Upon receipt, the raw fish fillets or whole fish were skinned, gutted and rinsed briefly with distilled water. After the fish samples were patted dry with absorbent liner, several pieces of the fillets from each individual species were ground to a uniform consistency using a commercial food processor. The ground fish samples were then stored frozen at $-20^{\circ} \mathrm{C}$ until used. The species of the fish samples were identified by Eurofins GeneScan, Inc. (Metairie, LA) using either the Food and Drug Administration (FDA)-validated DNA barcode analysis (37) or nucleotide sequence analysis of the cytochrome $b$ and $16 \mathrm{~S}$ genes.

\section{Extraction of fish proteins}

Soluble proteins from the ground fish samples were extracted 1:10 (w/v) in 0.01 M phosphate buffered saline (PBS; $0.002 \mathrm{M} \mathrm{NaH}_{2} \mathrm{PO}_{4}, 0.008 \mathrm{M} \mathrm{Na}_{2} \mathrm{HPO}_{4}, 0.85 \% \mathrm{NaCl}$, $\mathrm{pH}$ 7.4) overnight with gentle rocking at $4^{\circ} \mathrm{C}$. Extracts were then centrifuged at $3612 \times \mathrm{g}$ in a tabletop centrifuge at $4^{\circ} \mathrm{C}$ for 30 minutes. The clarified solutions were divided into aliquots and stored at $-20^{\circ} \mathrm{C}$ until use. The protein content of the solutions was determined by the Lowry method (38).

\section{Indirect ELISA}

Polystyrene microtiter plates (Nagle Nunc International, Rochester, NY) were coated with $100 \mu \mathrm{l} /$ well of the crude fish extracts and purified parvalbumins at $10 \mu \mathrm{g} / \mathrm{ml}$ 
in coating buffer $\left(0.015 \mathrm{M} \mathrm{Na}_{2} \mathrm{CO}_{3}, 0.035 \mathrm{M} \mathrm{NaHCO}_{3}\right.$, and $\left.0.02 \% \mathrm{NaN}_{3}, \mathrm{pH} 9.6\right)$ and incubated overnight at $4^{\circ} \mathrm{C}$. Thereafter, all incubation steps were performed for 1 hour at $37^{\circ} \mathrm{C}$, except for the incubation after the addition of substrate. Following the overnight incubation, the plates were washed with wash buffer (0.01 M PBS containing $0.05 \%$ Tween 20 , and $0.02 \% \mathrm{NaN}_{3}, \mathrm{pH} 7.4$ ), then incubated with $350 \mu \mathrm{l} /$ well of blocking buffer consisting of $0.1 \%$ porcine skin gelatin (Sigma-Aldrich, St. Louis, MO) in $0.01 \mathrm{M}$ PBS, $\mathrm{pH}$ 7.4. After the plates were washed, $100 \mu \mathrm{l} /$ well of the 3 anti-parvalbumin antibodies diluted 1:15,000 in conjugate buffer [0.01 M PBS containing $0.1 \%$ bovine serum albumin (BSA; Affymetrix-USB, Cleveland, $\mathrm{OH}$ ), $\mathrm{pH}$ 7.4] was added to the plates and incubated. Next, the plates were washed and incubated with $100 \mu 1 /$ well of rabbit antimouse IgG (diluted 1:5,000 and 1:1,000 in conjugate buffer for anti-frog and anti-carp MoAb, respectively) and goat anti-rabbit IgG (diluted 1:4,500 in conjugate buffer for anti-cod PoAb) labeled with alkaline phosphatase enzyme (Pierce Biotechnology, Inc., Rockford, IL). Binding was visualized with p-nitrophenyl phosphate substrate (Sigma Fast $^{\mathrm{TM}}$, Sigma-Aldrich, St. Louis, MO) and the color formed was measured at $405 \mathrm{~nm}$. The dilutions of the 3 anti-parvalbumin antibodies in the indirect ELISA were selected based on the statistically similar absorbance values (Dunnet's test, SAS programs, SAS Institute Inc., Cary, NY) for the northern pike. Each of the fish samples was extracted in triplicate and each extract was analyzed in triplicate in 2 independent ELISA trials.

\section{Sodium dodecyl sulfate-polyacrylamide gel electrophoresis (SDS-PAGE)}

The protein separation by SDS-PAGE was carried out with a Bio-Rad Mini

Protean ${ }^{\circledR}$ II electrophoresis cell (Bio-Rad Laboratories, Hercules, CA). Five micrograms 
of crude cod extract and $1 \mu \mathrm{g}$ of the purified cod and carp parvalbumin were boiled in Laemmli sample buffer containing 5.4\% dithiothreitol (w/v) and separated on a $15 \%$ Tris-HCl precast gel (Bio-Rad Laboratories, Hercules, CA) at 200V (constant voltage) for 35 minutes. After the electrophoretic transfer, the gel was fixed and stained with Brilliant Blue G-Colloidal Stain (Sigma-Aldrich, St. Louis, MO). The gel image was captured using a Kodak Gel Logic 440 Imaging System (Eastman Kodak, Rochester, NY) equipped with Kodak 1D v. 3.6.5 software (Kodak Scientific Imaging Systems, New Haven, CT).

\section{IgG-immunoblotting of anti-parvalbumin antibodies}

One microgram of soluble fish proteins and $0.1 \mu \mathrm{g}$ of purified cod and carp parvalbumin were separated by SDS-PAGE using the conditions as described above. After electrophoresis, the proteins were transferred onto polyvinyl difluoride (PVDF) membrane (Millipore Corporation, Billerica, MA) at $65 \mathrm{~V}$ (constant voltage) for 80 minutes. The membrane was then blocked by incubation with $0.01 \mathrm{M}$ PBS, pH 7.4 containing $0.05 \%$ Tween 20 (PBS-T) and 0.2\% BSA (Affymetrix-USB, Cleveland, OH) for 2 hours at room temperature. The anti-frog, anti-carp, and anti-cod parvalbumin antibodies were diluted 1:20,000, 1:12,500, and 1:75,000, respectively, in PBS-T containing $0.2 \%$ BSA. After washing the membrane with PBS-T, the diluted antiparvalbumin antibodies were added and incubated for 1 hour at room temperature, followed by washing and incubation with rabbit anti-mouse IgG (diluted 1:80,000 and 1:100,000 in PBS-T containing 0.2\% BSA for anti-frog and anti-carp MoAb, respectively) and goat anti-rabbit IgG (diluted 1:80,000 in PBS-T containing 0.2\% BSA 
for anti-cod PoAb) labeled with alkaline phosphatase (Pierce Biotechnology, Inc., Rockford, IL) for 1 hour. The bound antibodies was visualized with 1 -Step ${ }^{\mathrm{TM}} \mathrm{NBT} / \mathrm{BCIP}$ substrate solution (Pierce Biotechnology, Inc., Rockford, IL) diluted 1:1 with distilled water. The membrane was photographed using the Kodak Gel Logic 440 Imaging System (Eastman Kodak, Rochester, NY) equipped with Kodak 1D v. 3.6.5 software (Kodak Scientific Imaging Systems, New Haven, CT).

\section{RESULTS AND DISCUSSION}

\section{Identification of fish species}

Since mis-identification of fish is a frequently encountered problem $(39,40)$, it was essential to identify all fish samples used in this study obtained from different seafood distributors. Fish species identification based on morphological characteristics was impossible because several fish samples were received in the forms of fillets and steaks. Hence, DNA-based methods were used to authenticate the fish samples to the species levels. The methods confirmed that the fish samples were accurately labeled by the suppliers and the scientific names of the fish used in the study are indicated in Table 1.

\section{SDS-PAGE analysis of protein profiles in fish extracts}

The SDS-PAGE profiles of the crude muscle extracts of 29 fish species are shown in Figure 1. The fish species whether within the same orders or from different orders displayed heterogeneity in the protein banding patterns. Our analysis focused primarily on the protein bands with a molecular weight range of $10-13 \mathrm{kDa}$ where parvalbumin is 
known to migrate. The bands for purified cod and carp parvalbumin did migrate at 10-13 $\mathrm{kDa}$ as expected. All frog and fish species contained either one or two protein bands between 10 to $13 \mathrm{kDa}$ at different intensities, with the exception of mahi-mahi, albacore tuna, and swordfish. Gajeswski et al. (32) indicated that the multiple parvalbumin bands may represent the presence of isoforms as some fish species have been shown to express from two to five parvalbumin isotypes (15). The absence of parvalbumin bands in tuna was in agreement with the observation made by Chen et al. (31) and Van Do et al. (41) even though a different species of tuna (albacore) was analyzed here. Kuehn et al. (42) recently reported that the raw muscles of tuna contained between $1 / 40$ to $1 / 110$ of the parvalbumin content of raw muscles of herring, carp, redfish, trout, salmon, and cod, according to quantitative determination by ELISA. This is in line with the clinical observation of Sampson that tuna rarely causes allergic reactions compared to other fish (43). Lim et al. (44) stated that the muscles from different parts of tuna have markedly different concentrations of parvalbumin content. Shiomi et al. (18) were able to purify parvalbumin from bigeye tuna while some have reported no detectable parvalbumin in tuna muscle. Similar to tuna, no $10-13 \mathrm{kDa}$ band was observed with swordfish in our study (Figure 1). Griesmeier et al. (22) also stated that the swordfish expressed low levels of parvalbumin compared to cod and whiff. Although SDS-PAGE suggested that mahi-mahi, swordfish, and tuna contained no or low amounts of parvalbumins, additional research is necessary to confirm this finding because the SDS-PAGE only allows for an approximate estimation of the parvalbumin content, as dye-binding differs among proteins.

\section{Species-specific immunoreactivity by indirect ELISA}


The bindings of anti-frog MoAb, anti-carp MoAb, and anti-cod PoAb to the parvalbumins in raw fish muscle extracts were compared using indirect ELISA (Figure 2a and $\mathbf{2 b}$ ). The mean absorbance value plus three standard deviations of wells containing all reagents except anti-parvalbumin antibodies was used as an arbitrary cutoff point for the positive measurement $(\sim 0.15)$. The anti-frog MoAb was produced by using the parvalbumin purified from frog muscle as an immunogen, according to SigmaAldrich. The anti-frog MoAb bound to extracts of frog, pilchard, sardine, carp, pike, bluegill, tilapia, snapper, catfish, and ocean perch. No binding was observed to herring, mahi-mahi, albacore tuna, swordfish, and all fish species in the order of Gadiformes. The anti-frog MoAb showed consistently low and variable binding to all fish species in the orders of Pleuronectiformes and Salmoniformes. It bound to sardine extract, but failed to bind to extract of herring in the order of Clupeiformes. It also bound strongly or moderately to bluegill, tilapia, and snapper, but only weakly or not at to all the remaining 6 species in the order of Perciformes.

Our results were similar to those found by Gajewski and Hsieh (32) regarding immunoreactivity of the anti-frog MoAb with the majority of species, with the exception mahi-mahi and striped bass. The dissimilarities in the reactivity may be due to the use of different species of mahi-mahi and striped bass, or the use of different forms of antigens (the use of raw fish extracts in this study versus cooked fish extracts in their study) for reacting with the anti-frog $\mathrm{MoAb}$ in the indirect ELISA. While the present study confirms the finding by Gajewski and Hsieh (32) that the anti-frog MoAb did not react with cod, hake, pollock, and haddock, a recent study by Weber et al. (33) reported the anti-frog MoAb did bind to those four species based on a competitive ELISA. Weber et al. (33) 
attributed the differences to the use of fish extracts by Gajewski and Hsieh (32) rather than purified parvalbumins as fish extracts would not contain standardized amounts of parvalbumins. Additionally, Weber et al. (33) discussed that the presence of other soluble, non-parvalbumin fish proteins in the extracts may affect the ability of parvalbumins to be coated effectively on the wells, and thus the detectability of parvalbumins by the anti-frog MoAb in the indirect ELISA. Nevertheless, this study showed that the anti-frog MoAb did not bind to the purified cod parvalbumin in the indirect ELISA, suggesting that cod parvalbumin in its native form does not contain cross-reactive epitopes recognized by the anti-frog MoAb.

The commercially-available anti-carp MoAb was produced by immunizing mice with parvalbumin purified from carp muscle (45). To date, no published study has extensively evaluated the specificity of this antibody to various fish species. This study revealed that the anti-carp MoAb bound equally well with the purified carp parvalbumin and the parvalbumin in raw carp extracts. Interestingly, the anti-carp MoAb bound strongly to all fish species in the order of Gadiformes, except for the haddock from both suppliers (Norland Products Inc. and Gorton's Inc.). Moreover, the anti-carp MoAb bound to the remaining fish species, with the exception of frog, mahi-mahi, swordfish, ocean perch and fish species in the order of Pleuronectiformes.

Of the 3 antibodies, the anti-cod PoAb showed binding to the widest range of fish species, but did not bind to mahi-mahi and swordfish. The anti-cod PoAb bound strongly or moderately to the majority of the fish species, but weakly with frog, albacore tuna, and chub mackerel. Similar to the observation made with the anti-frog MoAb, both the anticarp MoAb and the anti-cod PoAb showed variable binding to fish species that belong to 
the same orders. The inconsistent binding may possibly be due to the differences in the plate-coating efficiency, quantity and the primary or conformational structure of the parvalbumins among the fish species within the same orders. Faste et al. (30) published results of a sandwich ELISA for the quantification of fish in foods using a rabbit polyclonal anti-cod parvalbumin antibody that cross-reacted with other fish species to a different extent. Fish species that were optimally detected included cod, tilapia, herring, pollock, salmon, and carp, but the antibody reactivity to rainbow trout, tuna, swordfish, and northern pike, among others were quite low. This observation was in accordance with our finding, with the exception of trout and pike which showed higher binding in our study.

Overall, the 3 anti-parvalbumin antibodies showed rather similar binding to pilchard, northern pike, tilapia, snapper, and catfish, but much more diverse binding to other fish species. Additionally, no binding to the mahi-mahi and swordfish was noted for all 3 antibodies, probably owing to either the lack of detectable amounts of parvalbumins in the fish muscles or the lack of Ab-binding epitopes in the parvalbumins of these species. All fish samples were tested in the raw and unprocessed form, with the exception of salted herring, which is widely consumed in Europe. Salting of herring is a typical non-thermal process to preserve fish and the immunoreactivity of both the anti-carp MoAb and anti-cod PoAb to the salted herring was shown to be unaffected as a result of the salting process.

\section{Species-specific immunoreactivity by IgG-immunoblotting}


The IgG immunoblotting was performed to further investigate the binding of the antibodies to parvalbumins in the frog and fish species (Figures 3-5). In general, all 3 anti-parvalbumin antibodies showed a lack of binding to proteins in the mahi-mahi and swordfish extracts in both the immunoblotting and the indirect ELISA even though the detection was conducted under both reducing (immunoblotting) and non-reducing conditions (indirect ELISA). The reasons for this lack of binding are not yet clear.

The results obtained from immunoblotting agreed with the ELISA analysis for the majority of the fish species. Based on the immunoblotting results, the anti-frog MoAb did not bind to parvalbumins from species with an absorbance value $\leq 0.15$ OD in the ELISA, including the unsalted and salted herring, all species in the order of Gadiformes, mahi-mahi, albacore tuna, swordfish, and salmon. Besides, the anti-frog MoAb also did not bind to all species in the order of Pleuronectiformes in the immunoblot despite the occurrence of absorbance values $>0.15$ OD in the ELISA, but these species reacted weakly with the anti-frog MoAb in the ELISA (absorbance values of $>0.15$ but $<0.3$ OD). Based on the immunoblotting results, the anti-carp MoAb did not bind to species with an absorbance value $\leq 0.15$ OD in the ELISA, including frog, mahi-mahi, swordfish, Pacific halibut, yellowtail flounder, and ocean perch. In addition, the anti-carp MoAb did not bind to unsalted and salted herring, haddock, and salmon in the immunoblot despite the occurrence of absorbance values $>0.15$ OD in the ELISA, but the reactivity of the anti-carp MoAb to these species were also relatively low in the ELISA (absorbance values $>0.15$ but $<0.6$ OD). The anti-cod PoAb bound to parvalbumins in all species but albacore tuna, mahi-mahi, and swordfish. 
In conclusion, both the indirect ELISA and IgG immunoblotting consistently showed that the 3 anti-parvalbumin antibodies had varying specificity for proteins in extracts of different fish species, which can probably be attributed to differences in the parvalbumin content or immunoreactivity among fish species. The polyclonal anti-cod parvalbumin antibody showed binding to the widest range of fish species probably due to recognition of multiple epitopes based upon the polyclonal nature of the antisera. In comparison, the monoclonal anti-frog parvalbumin antibody showed the least crossreactivity due to the recognition of single epitope and the frog parvalbumin being less homologous to fish than cod parvalbumin. The anti-cod parvalbumin antibody appeared to be more suitable for the detection of parvalbumin derived from different fish species, however, limitations still exist regarding to the inconsistent binding to different fish species. These 3 anti-parvalbumin antibodies can potentially be applied to the standardization of the parvalbumin content in the fish extracts used for the skin prick test and radioallergosorbent test. In addition, the antibodies would be useful for monitoring the purification and localization of fish parvalbumins in research studies. Our study may serve as a guide when selecting the appropriate antibodies for detecting the fish parvalbumins. However, the disadvantages associated with the use of any of the 3 antiparvalbumin antibody in detecting allergenic fish residues in foods is that the antiparvalbumin antibody may fail to detect certain fish species that are possibly deficient in parvalbumin. Examples include tuna, mahi-mahi, and swordfish, as demonstrated in the SDS-PAGE, IgG immunoblotting, and indirect ELISA. Some may argue that the absence of parvalbumin allergens in food samples may result in a lower risk of eliciting an allergic reaction, but some fish-allergic subjects may be allergic to proteins that are not 
parvalbumins. Kelso et al. (46) and James et al. (47) reported 2 subjects with monospecific allergy who showed IgE-reactivity to only a protein band at $25 \mathrm{kDa}$ in swordfish and $40 \mathrm{kDa}$ in tuna. Therefore, even if parvalbumins are undetectable in foods, that does not necessarily indicate that the foods are safe for individuals with fish allergy. Efforts can be made in the future research to produce antibodies that are targeted specifically to fish proteins that have equal abundance in all fish species for the development of an ELISA to detect allergenic fish residues in foods.

\section{ACKNOWLEDGEMENTS}

Financial support was provided by the Food Allergy Research and Resource Program at the University of Nebraska. The authors thank Martha R. Wiberg (Gorton's Inc.), Richard Norland (Norland Products Inc.), Dr. Yi-Cheng Su (Oregon State University), and Tony Korth (Nebraska Game and Parks Commission) for providing the fish samples. We also thank E. Pearce Smith (Eurofins GeneScan, Inc.) for technical assistance.

\section{REFERENCES}

(1) Nelson, J. S. Fishes of the world, 4th ed.; Wiley \& Sons: Hoboken, 2006.

(2) O’Neil, C.; Helbling, A. A; Lehrer, S. B. Allergic reactions to fish. Clin. Rev. Allergy 1993, 11, 183-200.

(3) Sicherer, S. H.; Muñoz-Furlong, A.; Sampson. H. A. Prevalence of seafood allergy in the United States determined by a random telephone survey. J. Allergy Clin. Immunol. 2004, 114, 159-165. 
(4) Rona, R. J.; Keil, T.; Summers, C.; Gislason, D.; Zuidmeer, L.; Sodergren, E.; Sigurdardottir, S. T.; Lindner, T.; Goldhahn, K.; Dahlstrom, J.; McBride, D.; Madsen, C. The prevalence of food allergy: a meta-analysis. J. Allergy Clin. Immunol. 2007, 120, 638-646.

(5) Crespo, J. F.; Pascual, C.; Dominguez, C.; Ojeda, I.; Muñoz, F. M.; Esteban, M. M. Allergic reactions associated with airborne fish particles in IgE-mediated fish hypersensitive patients. Allergy 1995, 50, 257-261.

(6) Domínguez, C.; Ojeda, I.; Crespo, J. F.; Pascual, C.; Ojeda, A.; Martín-Esteban, M. Allergic reactions following skin contact with fish. Allergy Asthma Proc. 1996, $17,83-87$.

(7) Rodríguez, J.; Reaño, M.; Vives, R.; Canto, G.; Daroca, P.; Crespo, J. F.; Vila, C.; Villarreal, O.; Bensabat, Z. Occupational asthma caused by fish inhalation. Allergy 1997, 52, 866-869.

(8) Taylor, S. L.; Kabourek, J. L.; Hefle. S. L. Fish allergy: fish and products thereof. J. Food Sci. 2004, 69, 175-180.

(9) Yunginger, J. W.; Sweeney, K. G.; Sturner, W. Q.; Giannandrea, L. A.; Teigland, J. D.; Bray, M.; Benson, P. A.; York, J. A.; Biedrzycki, L.; Squillace, D. L.; Helm. R. M. Fatal food-induced anaphylaxis. J. Am. Med. Assoc. 1988, 260, 1450-1452.

(10) Dannaeus, A.; Inganäs, M. A follow-up study of children with food allergy. Clinical course in relation to serum IgE- and IgG-antibody levels to milk, egg and fish. Clin. Allergy 1981, 11, 533-539. 
(11) Bock, S. A. The natural history of food hypersensitivity. J. Allergy Clin. Immunol. 1982, 69, 173-177.

(12) Elsayed, S.; Aas, K. Isolation of purified allergen (cod) by isoelectric-focusing. Int. Arch. Allergy Appl. Immunol. 1971, 40, 428-438.

(13) Lindstrøm, C. D-V.; Van Do, T.; Hordvik, I.; Endresen, C.; Elsayed, S. Cloning of two distinct cDNAs encoding parvalbumin, the major allergen of Atlantic salmon (Salmo salar). Scand. J. Immunol. 1996, 44, 335-344.

(14) Swoboda, I.; Bugajska-Schretter, A.; Verdino, P.; Keller, W.; Sperr, W. R.; Valent, P.; Valenta, R.; Spitzauer, S. Recombinant carp parvalbumin, the major cross-reactivity fish allergen: a tool for diagnosis and therapy of fish allergy. $J$. Immunol. 2002, 168, 4576-4584.

(15) Van Do, T.; Hordvik, I.; Endresen, C.; Elsayed, S. The major allergen (parvalbumin) of codfish is encoded by at least two isotypic genes: cDNA cloning, expression and antibody binding of the recombinant allergens. Mol. Immunol. 2003, 39, 595-602.

(16) Van Do, T.; Hordvik, I.; Endresen, C.; Elsayed, S. Characterization of parvalbumin, the major allergen in Alaska Pollack and comparison with codfish Allergen M. Mol. Immunol. 2005, 42, 345-353.

(17) Shiomi, K.; Hayashi, S.; Ishikawa, M.; Shimakura, K.; Nagashima, Y. Identification of parvalbumin as an allergen in horse mackerel. Fish. Sci. 1998, 64, 300-304. 
(18) Shiomi, K.; Hamada, Y.; Sekiguchi, K.; Shimakura, K.; Nagashima, Y. Two classes of allergens, parvalbumins and higher molecular weight substances, in Japanese eel and bigeye tuna. Fish. Sci. 1999, 65, 943-948.

(19) Van Do, T.; Hordvik, I.; Endresen, C.; Elsayed, S. Expression and analysis of recombinant salmon parvalbumin, the major allergen in Atlantic salmon (Salmo salar). Scand. J. Immunol. 1999, 50, 619-625.

(20) Hamada, Y.; Tanaka, H.; Ishizaki, S.; Ishida, M.; Nagashima, Y.; Shiomi, K. Purification, reactivity with IgE and cDNA cloning of parvalbumin as the major allergen of mackerel. Food Chem. Toxicol. 2003, 41, 1149-1156.

(21) Hamada, Y.; Tanaka, H.; Sato, A.; Ishizaki, S.; Nagashima, Y.; Shiomi, K. Expression and evalution of IgE-binding capacity of recombinant Pacific mackerel parvalbumin. Allergol. Int. 2004, 53, 271-278.

(22) Griesmeier, U.; Vázquez-Cortés, S.; Bublin, M.; Radauer, C.; Ma, Y.; Briza, P.; Fernández-Rivas, M.; Breiteneder, H. Expression levels of parvalbumins determine allergenicity of fish species. Allergy 2010, 65, 191-198.

(23) Permyakov, S. E.; Bakunts, A. G.; Denesyuk, A. I.; Knyazeva, E. L.; Uversky, V. N.; Permyakov, E. A. Apo-parvalbumin as an intrinsically disordered protein. Proteins 2008, 15, 822-836.

(24) Elsayed, S.; Aas, K. Characterization of a major allergen (cod). Observations on effect of denaturation on the allergenic activity. J. Allergy 1971, 47, 283-291.

(25) Bugajska-Schretter, A.; Grote, M.; Vangelista, L.; Valent, P.; Sperr, W. R.; Rumpold, H.; Pastore, A.; Reichelt, R.; Valenta, R.; Spitzauer, S. Purification, biochemical, and immunological characterisation of a major food allergen: 
different immunoglobulin E recognition of the apo- and calcium-bound forms of carp parvalbumin. Gut 2000, 46, 661-669.

(26) Goodman, M.; Pechére, J-F. The evolution of muscular parvalbumins investigated by the maximum parsimony method. J. Mol. Evol. 1977, 29, 131-158.

(27) Jenkins, J. A.; Breiteneder, H.; Claire Mills, E. N. Evolutionary distance from human homologs reflects allergenicity of animal food proteins. J. Allergy Clin. Immunol. 2007, 120, 1399-1405.

(28) Hilger, C.; Thill, L.; Grigioni, F.; Lehners, C.; Falagiani, P.; Ferrara, A.; Romano, C.; Stevens, W.; Hentges, F. IgE antibodies of fish allergic patients cross-react with frog parvalbumin. Allergy 2004, 59, 653-660.

(29) Helbling, A.; Haydel, R.; McCants, M. L.; Musmand, J. J.; El-Dahr, J.; Lehrer, S. B. Fish allergy: is cross-reactivity among fish species relevant? Double-blind placebo-controlled food challenge studies of fish allergic adults. Ann. Allergy Asthma Immunol. 1999, 83, 517-523.

(30) Fǽste, C. K.; Plassen, C. Quantitative sandwich ELISA for the determination of fish in foods. J. Immunol. Methods 2008, 329, 45-55.

(31) Chen, L.; Hefle, S. L.; Taylor, S. L.; Swoboda, I.; Goodman, R. E. Detecting fish parvalbumin with commercial mouse monoclonal anti-frog parvalbumin IgG. $J$. Agric. Food Chem. 2006, 54, 5577-5582.

(32) Gajewski, K. G.; Hsieh, Y. H. Monoclonal antibody specific to a major fish allergen: parvalbumin. J. Food Prot. 2009, 72, 818-825.

(33) Weber, P.; Steinhart, H.; Paschke, A. Competitive indirect ELISA for the determination of parvalbumins from various fish species in food grade fish 
gelatins and isinglass with PARV-19 anti-parvalbumin antibodies. J. Agric. Food Chem. 2009, 57, 11328-11334.

(34) Koppelman, S. J.; Nordlee, J. A.; Lee, P.-W.; Happe, R. P.; Hessing, M.; Norland, R.; Manning, T.; de Jong, G. A. H.; Taylor, S. L. Parvalbumin in fish skin-derived gelatin, Food Additives Contaminants, submitted for publication.

(35) Koppelman, S. J.; Romijn, R. A.; de Jongh, H. H.; Nordlee, J. A.; Piersma, S.; Hessing, M.; Taylor, S. L. Purification of parvalbumin from carp: a protocol that avoids heat-treatment. J. Food Sci. 2010, 75, T49-56.

(36) de Jongh, H. H.; Taylor, S. L.; Koppelman, S. J. Controlling the aggregation propensity and thereby digestibility of allergens by Maillardation as illustrated for cod fish parvalbumin. J. Biosci. Bioeng. 2010, 111, 204-211.

(37) Yancy, H. F.; Fry, F. S.; Randolph, S. C.; Deeds, J.; Ivanova, N. V.; Grainger, C. M.; Hanner, R.; Weigt, L. A.; Driskell, A.; Hunt, J.; Ormos, A.; Hebert, P. D. N. A protocol for validation of DNA-barcoding for the species identification of fish for FDA regulatory compliance. Laboratory Information Bulletin 4420 [Online], 2008, 24. U. S. Food and Drug Administration. http://www.fda.gov/food/scienceresearch/laboratorymethods/ucm169034.htm (accessed May 20, 2011).

(38) Lowry, O. H.; Rosebrough, N. J.; Farr, A. L.; Randall, R. J. Protein measurement with the Folin phenol reagent. J. Biol. Chem. 1951, 193, 265-275.

(39) Rasmussen, R. S.; Morrissey, M. T. Application of DNA-based methods to identify fish and seafood substitution on the commercial market. Compr. Rev. Food Sci. Food Saf. 2008, 8, 118-154. 
(40) U. S. Food and Drug Administration. Seafood species substitution and economic fraud. http://www.fda.gov/Food/FoodSafety/ProductSpecificInformation/Seafood/RegulatoryFishEncyclopediaRFE/ucm071528.htm (accessed May 20, 2011).

(41) Van Do, T.; Elsayed, S.; Florvaag, E.; Hordvik, I.; Endresen, C. Allergy to fish parvalbumins: studies on the cross-reactivity of allergens from 9 commonly consumed fish. J. Allergy Clin. Immunol. 2005b, 116, 1314-1320.

(42) Kuehn, A.; Scheuermann, T.; Hilger, C.; Hentges, F. Important variations in parvalbumin content in common fish species: a factor possibly contributing to variable allergenicity. Int. Arch. Allergy Immunol. 2010, 153, 359-366.

(43) Sampson, H. A. Food anaphylaxis. Br. Med. Bull. 2000, 56: 925-935.

(44) Lim, D. L.; Neo, K. H.; Yi, F. C.; Chua, K. Y.; Goh, D. L.; Shek, L. P.; Giam, Y. C.; Van Bever, H. P.; Lee, B. W. Parvalbumin - the major tropical fish allergen. Pediatr. Allergy Immunol. 2008, 19, 399-407.

(45) Celio, M. R.; Baier, W.; Scharer, L.; de Viragh, P. A.; Gerday, C. Monoclonal antibodies directed against the calcium binding protein parvalbumin. Cell Calcium 1988, 9, 81-86.

(46) Kelso, J. M.; Jones, R. T.; Yunginger, J. W. Monospecific allergy to swordfish. Ann. Allergy Asthma Immunol. 1996, 77, 227-228.

(47) James, J. M.; Helm, R. M.; Burks, A. W.; Lehrer, S. B. Comparison of pediatric and adult IgE antibody binding to fish proteins. Ann. Allergy Asthma Immunol. 1997, 79, 131-137. 


\section{FIGURE CAPTIONS}

Figure 1. SDS-PAGE profiles of the raw muscle protein extracts of frog and fish species. Five micrograms of crude fish extract and $1 \mu \mathrm{g}$ of the purified cod and carp parvalbumin were separated under reducing condition. The family and order of the species were represented by bold and italic characters, respectively.

Figure 2. Reactivity of anti-frog, anti-carp, and anti-cod parvalbumin antibodies with the raw muscle extracts of frog and fish species, as determined by the indirect ELISA. Each column and error bars represents the mean absorbance values and standard error of the mean of 18 readings, respectively.

Figure 3. IgG-immunoblot analysis of the anti-frog MoAb reactivity with the raw muscle protein extracts of frog and fish species.

Figure 4. IgG-immunoblot analysis of the anti-carp MoAb reactivity with the raw muscle protein extracts of frog and fish species.

Figure 5. IgG-immunoblot analysis of the anti-cod PoAb reactivity with the raw muscle protein extracts of frog and fish species. 
Table 1. Scientific names and sources of fish and frog samples

\begin{tabular}{|c|c|c|}
\hline Common name & Scientific name & Supplier \\
\hline American bullfrog & Rana catesbeiana & Little Saigon $\left(\mathrm{L}^{1}\right)$ \\
\hline Unsalted, Atlantic herring & Clupea harengus & Local fresh fish store, the Netherlands $\left(\mathrm{K}^{1}\right)$ \\
\hline Salted, Atlantic herring & Clupea harengus & Local fresh fish store, the Netherlands \\
\hline Pilchard or sardine & Sardina pilchardus & All Fresh Seafood Inc. $\left(\mathrm{A}^{1}\right)$ \\
\hline Pacific sardine & Sardinops sagax & Dr. Yi-Cheng Su, Oregon State $\left(\mathrm{O}^{1}\right)$ \\
\hline Carp & Cyprinus carpio & Joe Tess Live Fish Market $\left(\mathrm{J}^{1}\right)$ \\
\hline Northern pike & Esox lucius & Julie Nordlee, Wisconsin $\left(\mathrm{W}^{1}\right)$ \\
\hline Atlantic cod & Gadus morhua & Norland Products Inc. $\left(\mathrm{N}^{1}\right)$, All Fresh Seafood Inc. \\
\hline Pollock & Pollachius virens & Norland Products Inc. \\
\hline Alaska pollock & Theragra chalcogramma & Gorton's, Inc. $\left(\mathrm{G}^{1}\right)$ \\
\hline Haddock & Melanogrammus aeglefinus & Norland Products Inc., Gorton's, Inc. \\
\hline Cusk & Brosme brosme & Norland Products Inc. \\
\hline Hake & Urophycis tenuis & Norland Products Inc, All Fresh Seafood Inc. \\
\hline Bluegill & Lepomis macrochirus & Julie Nordlee and Tony Korth, Nebraska $\left(\mathrm{NE}^{1}\right)$ \\
\hline Tilapia & Oreochromis niloticus & Surf and Turf Food Co. $\left(\mathrm{S}^{1}\right)$ \\
\hline Mahi-mahi & Coryphaena hippurus & All Fresh Seafood Inc. \\
\hline Snapper & Lutjanus guttatus/synagris & All Fresh Seafood Inc. \\
\hline Hybrid striped bass & Morone chrysops $\mathrm{x}$ saxatilis & All Fresh Seafood Inc. \\
\hline (Red) Grouper & Epinephelus morio & All Fresh Seafood Inc. \\
\hline Albacore tuna & Thunnus alalunga & Surf and Turf Food Co. \\
\hline Chub mackerel & Scomber japonicas & Dr. Yi-Cheng Su, Oregon State \\
\hline Swordfish & Xiphias gladius & All Fresh Seafood Inc. \\
\hline Pacific halibut & Hippoglossus stenolepis & All Fresh Seafood Inc. \\
\hline American plaice or sole & Hippoglossoides platessoides & Norland Products Inc. \\
\hline Yellowtail flounder & Limanda ferruginea & Gorton's, Inc. \\
\hline Steelhead or Rainbow trout & Oncorhynchus mykiss & Surf and Turf Food Co. \\
\hline Atlantic salmon & Salmo salar & Midwest Seafood $\left(\mathrm{M}^{1}\right)$ \\
\hline Chinook salmon & Oncorhynchus tshawytscha & Dr. Yi-Cheng Su, Oregon State \\
\hline Catfish & Ictalurus punctatus & Joe Tess Live Fish Market \\
\hline Ocean perch & Sebastes fasciatus & Norland Products Inc., All Fresh Seafood Inc. \\
\hline
\end{tabular}

${ }^{1}$ Letters represented the different suppliers and was used in the subsequent figures. 


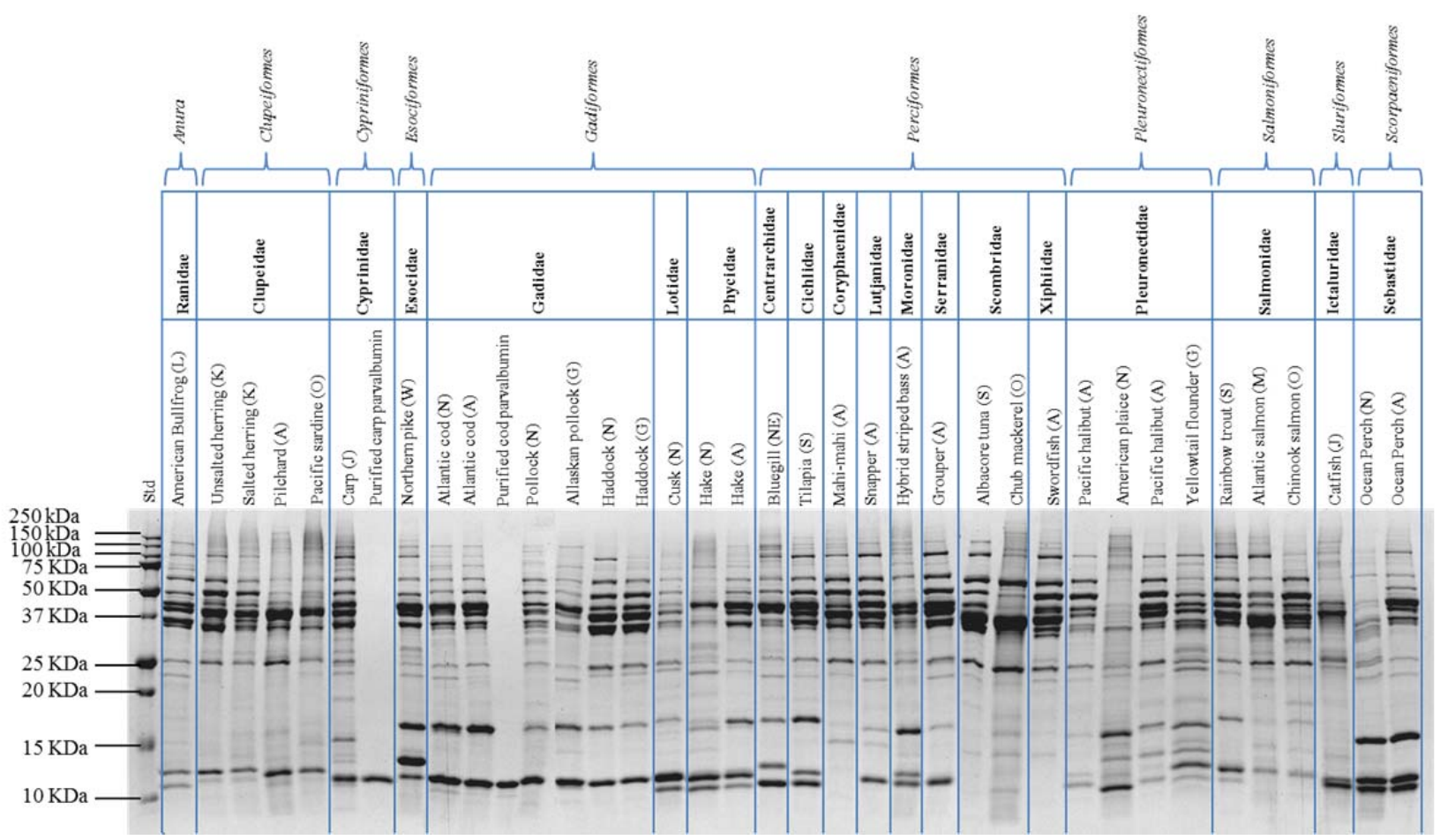

Figure 1. 
$2 a$.

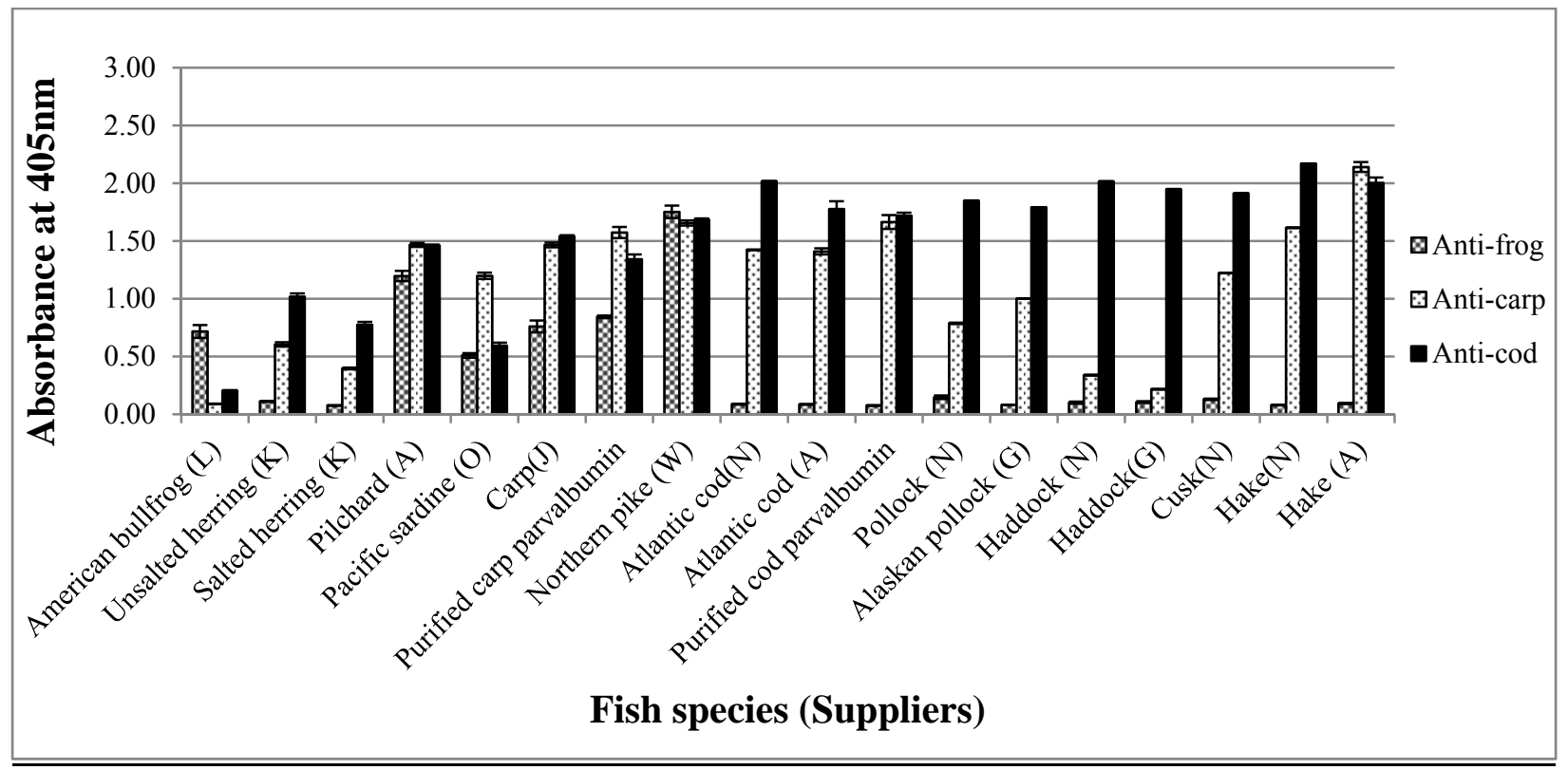

$2 b$.

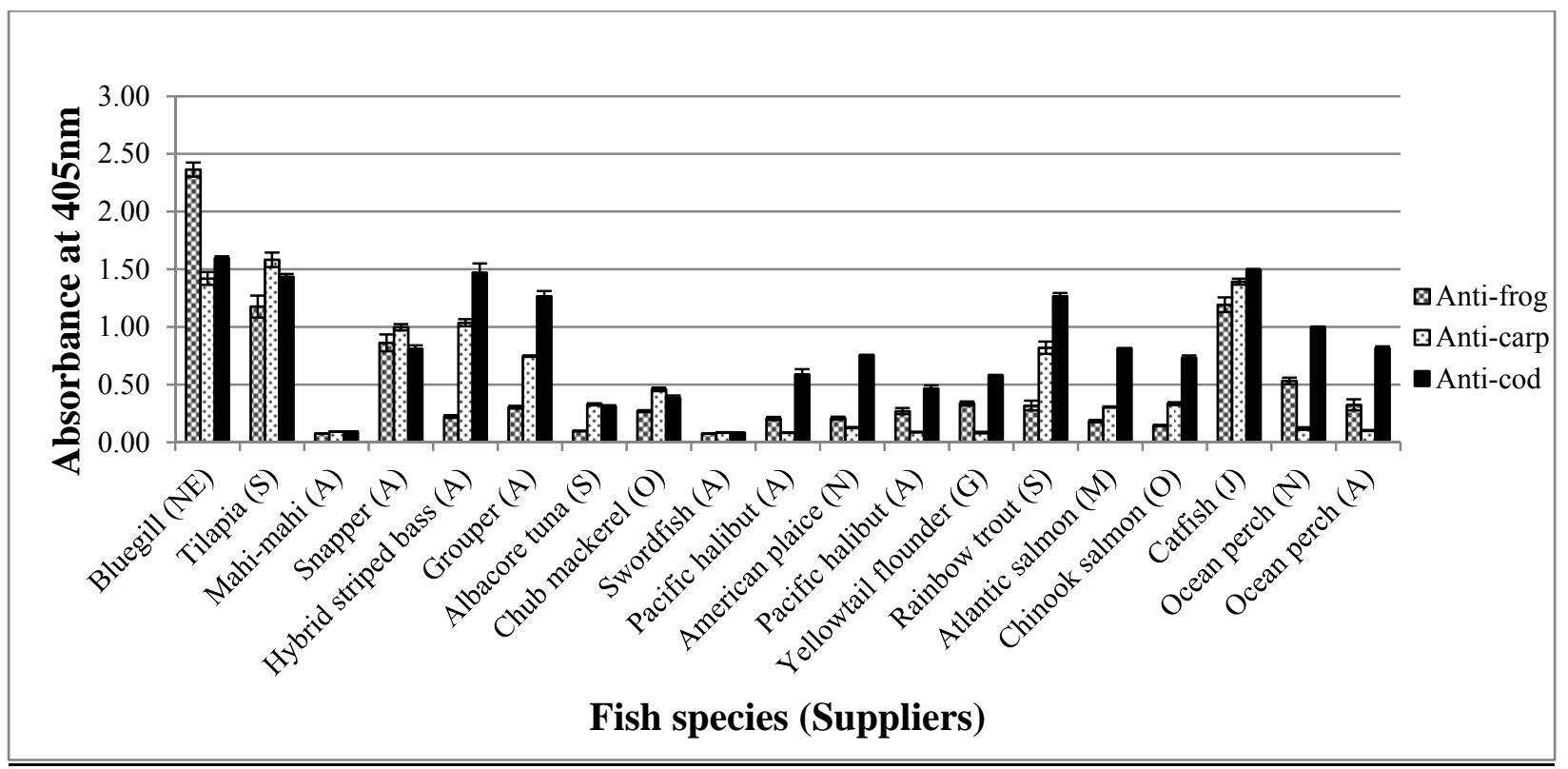

Figure 2. 


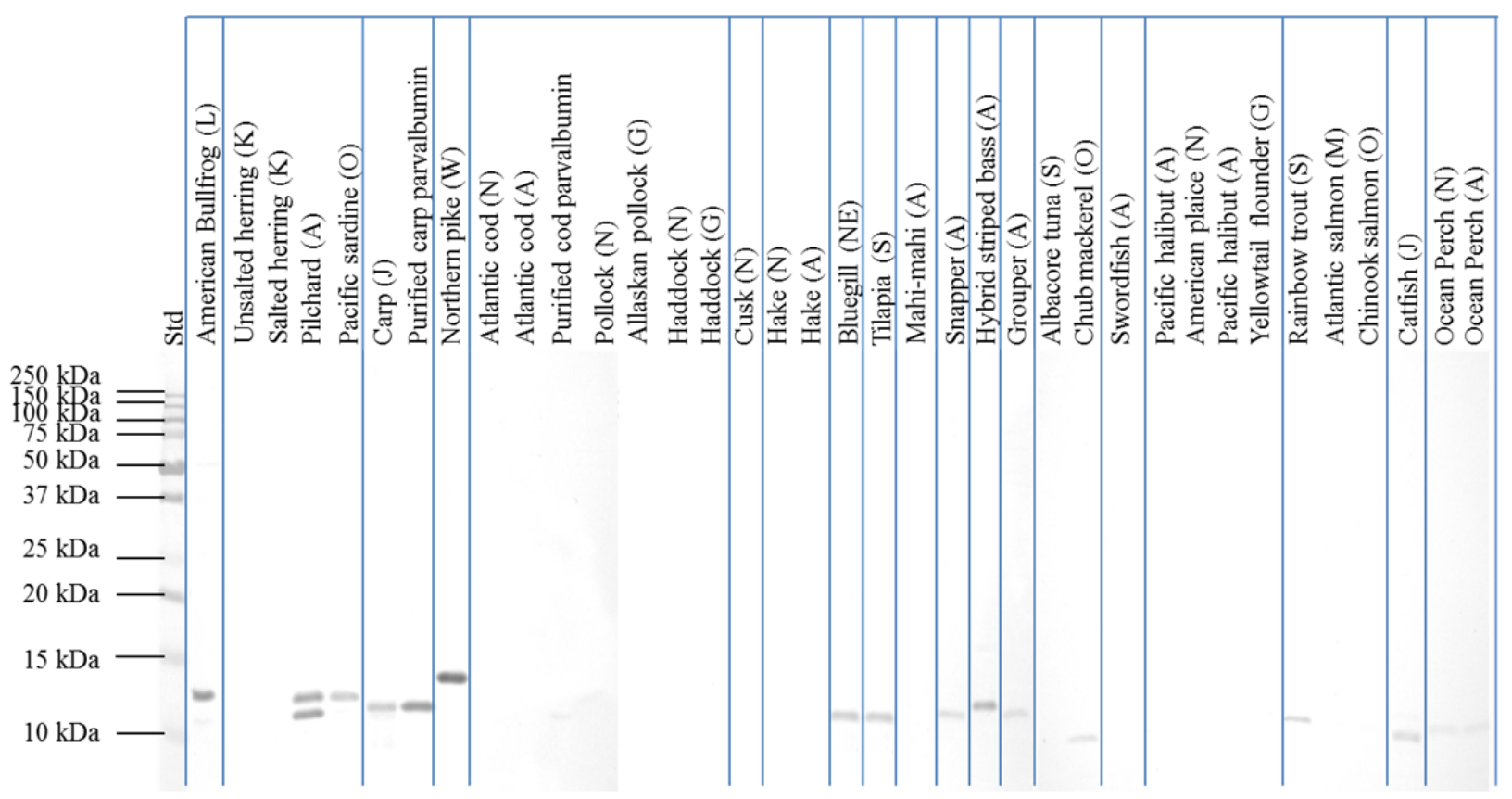

Figure 3. 


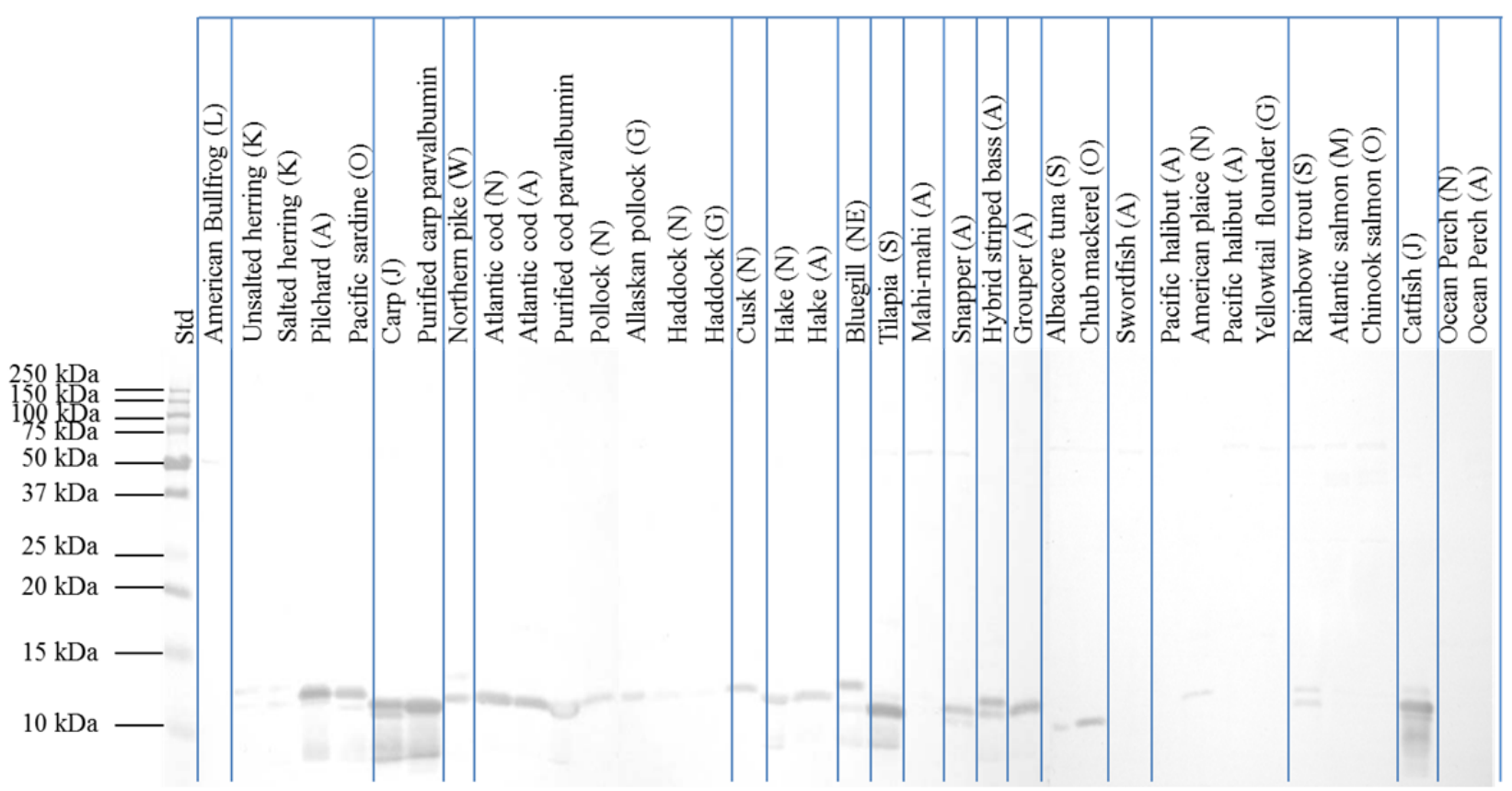

Figure 4. 


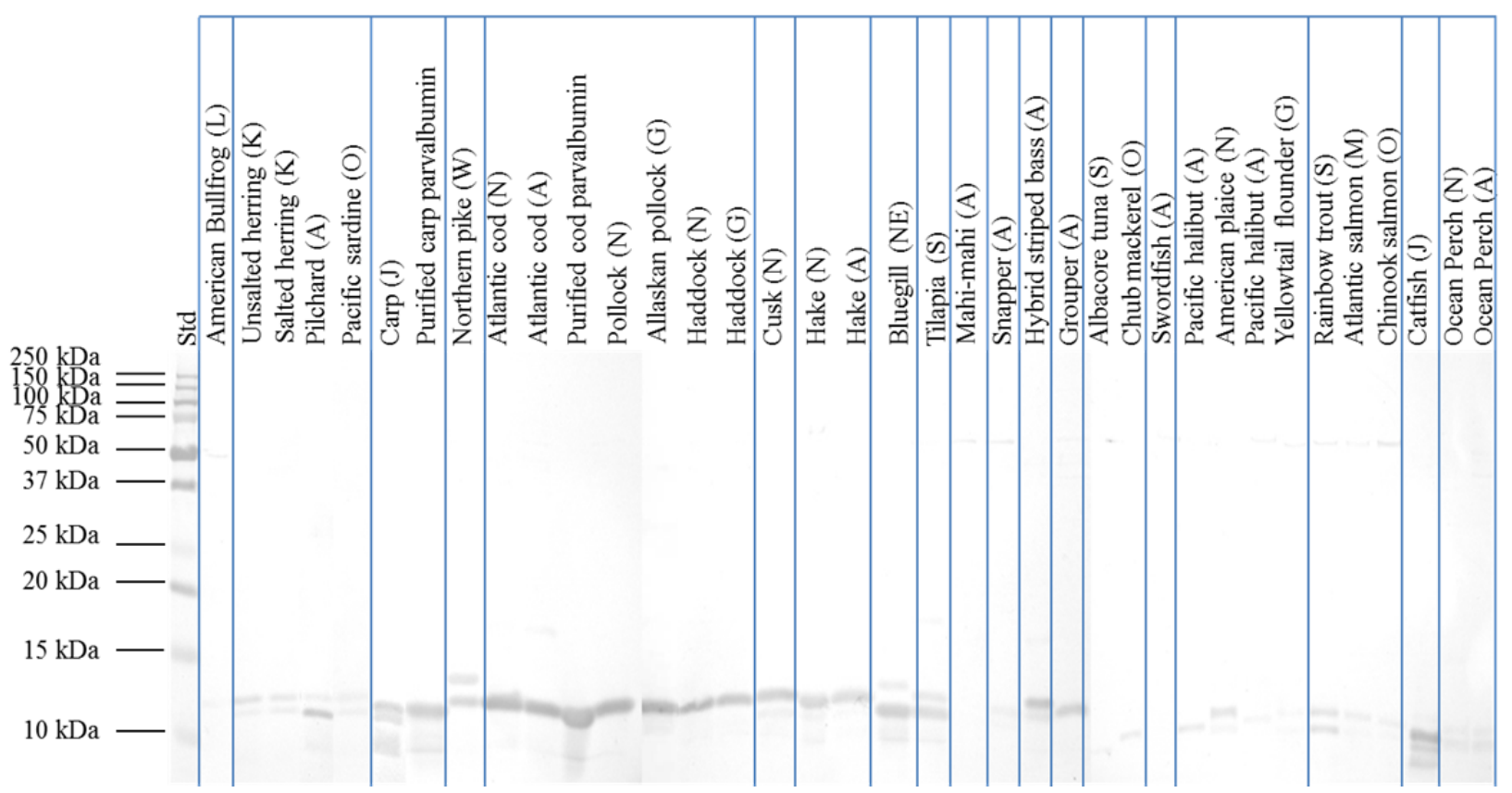

Figure 5. 


\section{CHAPTER 3: MEASURING PARVALBUMIN LEVELS IN FISH MUSCLE \\ TISSUE: RELEVANCE OF MUSCLE LOCATIONS AND STORAGE CONDITIONS}

Poi-Wah, Lee ${ }^{1}$, Julie A. Nordlee ${ }^{1}$, Stef J. Koppelman ${ }^{1}$, Joseph L. Baumert ${ }^{1}$, and Steve L. Taylor $^{1 *}$

${ }^{1}$ Food Allergy Research and Resource Program, University of Nebraska, Lincoln, NE, United States

* Corresponding author: 255 Food Industry Complex, Lincoln, NE 68583-0919, USA.

E-mail address: staylor2@unl.edu

Phone: +1-402-472-2833

Fax: +1-402-472-5307 


\begin{abstract}
Fish is an allergenic food capable of provoking severe anaphylactic reactions. Parvalbumin is the major allergen identified in fish and frog muscles. Antibodies against fish and frog parvalbumin have been used to quantify parvalbumin levels from fish. However, these antibodies react variably with parvalbumin from different fish species. Several factors might be responsible for this variation including instability of parvalbumin in fish muscle as a result of frozen storage and differential parvalbumin expression in muscles from various locations within the whole fish. We aimed to investigate whether these factors contribute to the previously observed variable immunoreactivity of the anti-parvalbumin antibodies. Results showed the detection of parvalbumin by these antibodies was unaffected by frozen storage of muscles for 112 days. However, the parvalbumin content decreased in fish muscles from anterior to posterior positions. This factor may partially explain for the inconsistent reactivity of anti-parvalbumin antibodies to different fish species.
\end{abstract}

Keywords: parvalbumin detection; anti-parvalbumin IgG antibodies; frozen storage; muscle localization; fish allergy 


\section{INTRODUCTION}

Fish is one of the eight most common allergenic foods, that also includes peanuts, tree nuts, wheat, soybeans, crustacean shellfish, cow milk and egg, that account for more than $90 \%$ of all documented food allergies (FAO, 1995). In the U.S., fish allergy affects approximately $0.4 \%$ of the population (Sicherer, Muñoz-Furlong, \& Sampson, 2004).

Fish can be a potent allergenic food that occasionally causes severe allergic reactions and even fatalities (Pumphrey \& Gowland, 2007; Yunginger et al., 1988). Some fish-allergic individuals can react to ingestion doses as low at $5 \mathrm{mg}$ of either cod or herring in doubleblind placebo-controlled food challenge tests although relatively few patients have been evaluated with such low-dose challenges (Taylor et al., 2002).

The major allergen in fish is parvalbumin. Parvalbumin is an intracellular calcium-binding muscle protein that promotes relaxation in the fast-twitch muscle fibers (Rall, 1996). Parvalbumin belongs to the EF-hand protein family that contains some other important allergens such as Bet v 4 (polcalin) from birch pollen (Ferreira, Engel, Briza, Richter, Ebner, \& Breitenbach, 1999) and the sacroplasmic calcium-binding protein from shrimp (Ayuso et al., 2009). In some studies, parvalbumin reacted with specific IgE from greater than $95 \%$ of the fish-allergic individuals (Bugajska-Schretter et al., 2000).

However, in other studies, the percentage of fish-allergic individuals with parvalbuminspecific IgE is somewhat smaller (Griesmeier et al., 2010). Still, parvalbumin is often considered as a pan-allergen responsible for the cross-reactivity between various fish species among fish-allergic individuals (Hansen, Bindslev-Jensen, Skov, \& Poulsen, 1997; Taylor, Kabourek, \& Hefle, 2004). Accordingly, fish-allergic individuals are advised to strictly avoid consumption of all species of fish (Helbling, Haydel, McCants, 
Musmand, El-Dahr, \& Lehrer, 1999). However, despite this advice, some fish-allergic patients are able to tolerate ingestion of some fish species in oral challenge studies (Bernhisel-Broadbent, Scanlon, \& Sampson, 1992; de Martino et al., 1990). The basis for this variable reactivity to fish observed in some fish-allergic patients has not been studied. One explanation could be that variable amounts of parvalbumin are expressed in different species of fish. A recent study by our group (Lee, Nordlee, Koppelman, Baumert, \& Taylor, 2011) revealed variable binding of 3 anti-parvalbumin IgG antibodies to crude extracts of different fish species, perhaps indicating a variation in parvalbumin content between the muscle tissues of different fish species.

It is well recognized that fish undergo deterioration after death, including the degradation of muscle proteins (Santos-Yap, 1996). The variation of parvalbumin content in fish muscles could perhaps be attributed to the denaturation of parvalbumin during frozen storage, but no studies have specifically evaluated the changes in parvalbumin content during frozen storage. On the other hand, studies have demonstrated that parvalbumin expression varied between muscles from different locations within whole fish (Coughlin, Solomon, \& Wilmert, 2007; Lim, Neo, Goh, Shek, \& Lee, 2005; Thys, Blank, Coughlin, \& Schachat, 2001). Additionally, the parvalbumin content also varied with the muscle types; dark muscle contained less parvalbumin than white muscle (Kobayashi, Tanaka, Hamada, Ishizaki, Nagashima, \& Shiomi, 2006). Hence, the muscles sampled from multiple parts of the fish body may differ in parvalbumin content, which could account for the differences in binding of the anti-parvalbumin antibodies to fish parvalbumin extracts. 
Considering the possible influence of frozen storage and muscles sampling on the parvalbumin levels, the present study was undertaken to investigate whether these factors contribute to the variable immunoreactivity of the anti-parvalbumin antibodies.

\section{MATERIALS AND METHODS}

\section{Sampling and extraction of fish muscles}

\section{Fish samples}

Fresh and non-frozen carp (Cyprinus carpio), catfish (Ictalurus punctatus), chub mackerel (Scomber japonicus), sardine (Sardinops sagax), Chinook salmon (Oncorhynchus tshawytscha), albacore tuna (Thunnus alalunga), and mahi-mahi (Coryphaena hippurus) were obtained from different fish and seafood distributors in the U.S. Upon receipt, the whole fish were skinned, gutted, rinsed briefly with distilled water, and patted dry with absorbent liner. The species of the fish samples were identified by Eurofins GeneScan, Inc. (Metairie, LA) using either the Food and Drug Administration (FDA)-validated DNA barcode analysis (Handy et al., 2011) or nucleotide sequence analysis of the cytochrome $\mathrm{b}$ and $16 \mathrm{~S}$ genes.

\section{Sampling after frozen storage}

Several pieces of the fish fillets from each individual species, including carp, catfish, mackerel, sardine, salmon, and tuna were ground to a uniform consistency using a commercial food processor. Three samples from a single batch of each ground sample were then extracted and the supernatant solution was kept at $-80^{\circ} \mathrm{C}$ until analyzed to minimize any changes in fish proteins. Sampling and extraction of the remaining ground 
fish samples that were kept frozen at $-20^{\circ} \mathrm{C}$ were repeated every 28 days for 4 consecutive months. After the sampling was completed, all supernatant solutions were analyzed together in the indirect ELISA.

\section{Sampling from various muscle locations within whole fish}

Six white muscle samples of $2 \mathrm{~cm}$ in width and $1 \mathrm{~cm}$ in length were obtained from different locations of 2 whole carp and catfish, and 1 whole tuna and mahi-mahi. The locations comprised of 3 longitudinal positions, including anterior [25\% of the total muscle length (TML), excluding head and tail], middle (50\% TML), and posterior (75\% TML). At each longitudinal position, muscle sample was obtained from the dorsal (located at $1 \mathrm{~cm}$ from the upper edge) and the ventral side (located at $1 \mathrm{~cm}$ from the lower edge). The muscle samples were then extracted and analyzed by indirect ELISA and SDS-PAGE.

\section{Extraction of fish proteins}

Soluble proteins from the ground fish samples were extracted 1:10 (w/v) in 0.01 M phosphate buffered saline (PBS; $0.002 \mathrm{M} \mathrm{NaH}_{2} \mathrm{PO}_{4}, 0.008 \mathrm{M} \mathrm{Na}_{2} \mathrm{HPO}_{4}, 0.85 \% \mathrm{NaCl}$, $\mathrm{pH}$ 7.4) overnight with gentle rocking at $4^{\circ} \mathrm{C}$. Extracts were then centrifuged at $3612 \times \mathrm{g}$ in a tabletop centrifuge at $4^{\circ} \mathrm{C}$ for 30 minutes. Insoluble material was discarded and the supernatant solution was used for protein determination by the Lowry method as described previously (Lee et al., 2011).

\section{Indirect ELISA}


Indirect ELISA was performed according to the methods as described elsewhere (Lee et al., 2011). Briefly, microtiter plates were coated by overnight incubation at $4^{\circ} \mathrm{C}$ with $1 \mu \mathrm{g}$ protein/well of the fish extracts in sodium carbonate-bicarbonate buffer. Thereafter, all incubation steps were performed for 1 hour at $37^{\circ} \mathrm{C}$, except for the incubation after the addition of substrate. The plates were washed with PBS-Tween 20 $(0.05 \%)$ between steps. Following blocking of the plates with PBS-gelatin $(0.1 \%)$, monoclonal anti-frog parvalbumin antibody (anti-frog MAb), monoclonal anti-carp parvalbumin antibody (anti-carp MAb), or polyclonal anti-cod parvalbumin antibody (anti-cod PAb) diluted 1:15,000 in PBS-bovine serum albumin (BSA; 0.1\%) were added to the plates and incubated. The bound antibodies were detected by rabbit anti-mouse IgG (diluted 1:5,000 and 1:1,000 in PBS-BSA for anti-frog and anti-carp MAb, respectively) and goat anti-rabbit IgG (diluted 1:4,500 in PBS-BSA for anti-cod PAb) labeled with alkaline phosphatase enzyme. Binding was visualized by incubation with p-nitrophenyl phosphate substrate for 30 minutes at room temperature in a dark environment. The enzymatic reaction was then stopped by the addition of $1.0 \mathrm{~N} \mathrm{NaOH}$ and the color formed was measured at $405 \mathrm{~nm}$. Each fish extract was analyzed in triplicate wells in 2 independent ELISA trials.

\section{Sodium dodecyl sulfate-polyacrylamide gel electrophoresis (SDS-PAGE)}

SDS-PAGE was performed according to the methods as described elsewhere (Lee et al., 2011). Briefly, $5 \mu \mathrm{g}$ of protein from the crude fish extract was heated to approximately $100^{\circ} \mathrm{C}$ in Laemmli sample buffer-dithiothreitol (5.4\%) for five minutes and separated on a $15 \%$ TRIS-HCl precast gel at $200 \mathrm{~V}$ for 35 minutes. After the 
electrophoretic separation, the gels were fixed and stained with Brilliant Blue G-Colloidal Stain (Sigma Chemical Co., St. Louis, MO) overnight at room temperature. Gels were then photographed using a Kodak Gel Logic 440 Imaging System (Eastman Kodak, Rochester, NY) equipped with Kodak 1D v. 3.6.5 software (Kodak Scientific Imaging Systems, New Haven, CT). The bands in each sample lane on the gel were selected by "auto-band finding" using the Kodak 1D v. 3.6.5 software, followed by the generation of an intensity profile for each lane by the software. The band intensity ratio of parvalbumin to total fish proteins was then calculated.

\section{Statistical analysis}

Differences between the mean absorbance values obtained during frozen storage were statistically evaluated by one-way analysis of variance (ANOVA) followed by Dunnett's test (SAS programs, SAS Institute Inc., Cary, NY).

\section{RESULTS AND DISCUSSION}

\section{Parvalbumin variation due to frozen storage}

Protein denaturation commonly occurs in fish muscle during frozen storage. It was postulated that the protein denaturation during frozen storage is caused by several factors, including dehydration and an increase in solute concentrations due to removal of water. Such changes disrupt the protein-water interaction and the native conformation of the proteins, leading to the exposure of the buried hydrophobic groups. Consequently, intermolecular cross-linkages form either within the same protein molecule or between two adjacent protein molecules through hydrophobic-hydrophobic or hydrophilic- 
hydrophilic interactions, causing aggregation and the formation of higher molecular weight polymers (Santos-Yap, 1996). Additionally, the interaction between proteins and lipids or formaldehyde in the frozen-stored fish was found to correlate with the decrease in protein solubility and extractability (Shenouda, 1980). The stability of fish proteins during frozen storage vary for different types of muscle proteins. Proteins in the myofibrillar groups are more susceptible to denaturation than the sarcoplasmic proteins (Sikorski, Olley, \& Kostuch, 1976). Most studies have examined the biochemical changes of myofibrillar proteins in frozen stored fish muscles (del Mazo, Torrejón, Careche, \& Tejada, 1999; Jiang, \& Lee, 1985; Tejada et al., 1996), but no research on the alteration of parvalbumin during frozen storage has been reported.

In this study, the detectability of parvalbumin from several fish species during frozen storage was evaluated by the 3 anti-parvalbumin antibodies by indirect ELISA. In general, statistically significant changes in the parvalbumin content of several fish species were observed, but these changes were minimal and the parvalbumin remained detectable throughout 112 days of frozen storage (Figure 1). Among the species tested, sardine had significantly lower reactivity with the 3 anti-parvalbumin antibodies after $28,56,84$, and 112 days of frozen storage, compared to that obtained in fresh sardine at day 0 . Similar to the sardine, the reactivity of anti-cod PAb to Chinook salmon was significantly lower throughout 112 days of frozen storage in comparison to the reactivity in fresh salmon. For carp, the detectable parvalbumin by both anti-frog and anti-carp MAb was significantly lower after 84 and 112 days of frozen storage, as compared to fresh carp. After 112 days of frozen storage, catfish had significantly lower parvalbumin when 
analyzed by the anti-frog MAb. Although the decline in immunoreactivity was statistically significant, the decrease was considered minimal.

The results suggested that the parvalbumin in fish muscles was relatively stable to frozen storage at $-20^{\circ} \mathrm{C}$. Furthermore, the extractability of parvalbumin and the subsequent binding of the antibodies to parvalbumin in the indirect ELISA was unaffected by freezing the fish muscles. Babbitt, Crawford, and Duncan (1972) demonstrated that there is only a slight decrease in the extractable sarcoplasmic proteins during frozen storage of intact or minced hake at $-20^{\circ} \mathrm{C}$, and thus our findings were in accordance with their observation as parvalbumin is a sarcoplasmic protein. Babbitt et al. (1972) also found that the denaturation of fish muscle proteins induced by frozen storage is predominantly due to the alteration of the myofibrillar proteins.

The stability of parvalbumin during frozen storage of fish muscles, as shown in this study, could not explain the previously observed variation in the binding of parvalbumin by the 3 anti-parvalbumin antibodies among fish species. It should be noted however, that fish protein denaturation induced by freezing appeared to be less pronounced in intact muscle than in the extracted protein in the form of solutions or suspensions (Sikorski \& Kotakowska, 1994). Therefore, the influence of freezing should be considered when developing an immunoassay method based on antibody reactivity for fish proteins and intended for detecting trace residues of fish that might contaminate other foods and pose a potential risk to fish-allergic consumers.

\section{Parvalbumin variation due to muscle locations}


To examine the expression of parvalbumin in various muscle locations of carp, catfish, albacore tuna, and mahi-mahi, the muscle proteins were separated by SDSPAGE, followed by densitometry analysis of the intensity of the parvalbumin bands with molecular weights ranging from 11 to $12 \mathrm{kDa}$ (Figure 2 and 3). Variations in the sample loading and/or pipetting errors that might occur during SDS-PAGE were normalized by computing the band intensity ratio of parvalbumin to total fish proteins. Compared to the muscles at the anterior and middle position, muscles at the posterior positions had a lower band intensity ratio regardless of fish species, indicating that muscles located near the tail contained lower amounts of parvalbumin than muscles near the head and the middle portions of the fish body. The effect of muscle locations on the expression of parvalbumin was more pronounced in tuna and mahi-mahi when compared to that observed in carp and catfish.

All species, with the exception of tuna, revealed no difference in the parvalbumin content between the dorsal and ventral side of the muscles. It was observed that tuna muscles located at both the anterior and middle positions demonstrated higher levels of parvalbumin at the ventral side, as compared to that obtained from the dorsal side. Furthermore, tuna muscles showed a gradual decrease in parvalbumin content from the anterior to the posterior positions. A study by Lim et al. (2005) investigated the parvalbumin content in the rostral (anterior), middle, and caudal (posterior) portions of tuna, Thunnus tonggol. For each of these portions, muscles were sampled from 3 different parts, including the dorsal and ventral white muscle, and the middle red muscle. According to the immunoblotting analysis of the muscle extracts using the anti-frog $\mathrm{MAb}$, the parvalbumin content decreased from the rostral and caudal regions. Moreover, 
the ventral white muscles contained higher amounts of parvalbumin than dorsal white muscles. Our observations with a different species of tuna confirm these earlier findings. A similar trend of parvalbumin expression was observed in rainbow trout parr and smolts, and largemouth bass, according to the relative intensity of the parvalbumin bands on the stained SDS-PAGE gels (Coughlin et al., 2007; Thys et al., 2001).

Parvalbumin has been proposed to act as an intracellular calcium buffer and facilitate relaxation in fast-contracting muscle. During muscle contraction, the calcium released from sarcoplasmic recticulum binds troponin $\mathrm{C}$, causing movements of the tropomyosin and subsequent interaction between myosin and actin. The contractile activity ceases when parvalbumin sequesters calcium from the troponin $\mathrm{C}$ into the sarcoplasmic recticulum via a calcium pump (Ca-ATPase), allowing muscle relaxation to occur (Arif, 2009; Rall, 1996). Studies have demonstrated that the higher concentration of parvalbumin in rostral muscle is correlated with a faster rate of relaxation, whereas caudal muscle relaxes at a slower rate due to the lower concentration of parvalbumin (Coughlin et al., 2007; Thys et al., 2001).

The parvalbumin expression in different muscle locations were further analyzed by determining the reactivity of the 3 anti-parvalbumin antibodies to the muscle extracts in the indirect ELISA (Figure 4). The reactivity, measured via absorbance values, was directly proportional to the parvalbumin content within individual species as these antibodies specifically recognized parvalbumin. Overall, the results obtained from the indirect ELISA supported the densitometry results. However, the variation in the antibodies reactivity to mahi-mahi appeared to be less prominent when detected by both the anti-frog and anti-carp MAb. This observation might be due to the exceptionally low 
reactivity of these antibodies with parvalbumin from mahi-mahi, which thus impairs the ability of these antibodies to detect the parvalbumin variations.

\section{CONCLUSIONS}

Our current findings revealed no substantial change in the ability of the 3 antiparvalbumin antibodies to detect parvalbumin from fish muscle that had been stored frozen at $-20^{\circ} \mathrm{C}$ for 112 days. Investigation of the expression of parvalbumin in different muscle locations within whole fish demonstrated that muscles at the posterior position had lower parvalbumin content than the muscles at the anterior and middle position of the fish body, especially in albacore tuna and mahi-mahi. Hence, the immunoreactivity of anti-parvalbumin antibodies will be affected by the spatial variation of parvalbumin in fish. When using parvalbumin as a marker for detecting undeclared fish residues in foods, it is important to realize that the parts of fish muscles used in the food preparation could influence the detectable amounts of parvalbumin and/or fish residues in foods. More work is necessary to further elucidate the factors and variables responsible for the differences in the immunoreactivity of the anti-parvalbumin antibodies to fish species. These factors include but are not limited to the differential expression of parvalbumin among fish species and the differences in the sequential and conformational IgG-binding epitopes on the parvalbumin of various fish species.

\section{ACKNOWLEDGEMENTS}

Financial support was provided by the Food Allergy Research and Resource Program at the University of Nebraska. The authors thank Dr. Yi-Cheng Su (Oregon 
State University) for providing some of the fish samples and E. Pearce Smith (Eurofins GeneScan, Inc.) for technical assistance.

\section{REFERENCES}

Arif, S. H. (2009). A $\mathrm{Ca}^{2+}$-binding protein with numerous roles and uses: parvalbumin in molecular biology and physiology. Bioessays, 31, 410-421.

Ayuso, R., Grishna, G., Ibanez, M. D., Blanco, C., Carrillo, T., Bencharitiwong, R., Sinchez, S., Nowak-Wegrzyn, A., \& Sampson H. A. (2009). Sarcoplasmic calciumbinding protein is an EF-hand-type protein identified as a new shrimp allergen. Journal of Allergy and Clinical Immunology, 124, 114-120.

Babbitt, J. K., Crawford, D. L., \& Duncan, K. L. (1972). Decomposition of trimethylamine oxide and changes in protein extractability during frozen storage of minced and intact hake (Merluccius productus) muscle. Journal of Agricultural and Food Chemistry, 20, 1052-1054.

Bernhisel-Broadbent, J., Scanlon, S. M., \& Sampson, H. A. (1992). Fish hypersensitivity. I. In vitro and oral challenge results in fish-allergic patients. Journal of Allergy and Clinical Immunology, 89, 730-737.

Bugajska-Schretter, A., Grote, M., Vangelista, L., Valent, P., Sperr, W. R., Rumpold, H., Pastore, A., Reichelt, R., Valenta, R., \& Spitzauer, S. (2000). Purification, biochemical, 
and immunological characterisation of a major food allergen: different immunoglobulin $\mathrm{E}$ recognition of the apo- and calcium-bound forms of carp parvalbumin. Gut, 46, 661-669.

Coughlin, D. K., Solomon, S., \& Wilwert, J. L. (2007). Parvalbumin expression in trout swimming muscle correlates with relaxation rate. Comparative Biochemistry and Physiology - Part A: Molecular \& Integrative Physiology, 147, 1074-1082.

de Martino, M., Novembre, E., Galli, L., de Marco, A., Botarelli, P., Marano, E., \& Vierucci, A. (1990). Allergy to different fish species in cod-allergic children: in vivo and in vitro studies. Journal of Allergy and Clinical Immunology, 86, 909-914.

del Mazo, M. L., Torrejón, P., Careche, M., \& Tejada, M. (1999). Characteristics of the salt-soluble fraction of hake (Merluccius merluccius) fillets stored at -20 and -30 degrees C. Journal of Agricultural and Food Chemistry, 47, 1372-1377.

FAO: Food and Agriculture Organization of the United Nations. (1995). Report of the FAO technical committee on food allergies. Rome, Italy, November 13-14.

Ferreira, F., Engel, E., Briza, P., Richter, K., Ebner, C., \& Breitenbach, M. (1999). Characterization of recombinant Bet $\mathrm{v}$ 4, a birch pollen allergen with two EF-hand calcium-binding domains. International Archives of Allergy and Immunology, 118, 304305. 
Griesmeier, U., Vázquez-Cortés, S., Bublin, M., Radauer, C., Ma, Y., Briza, P., Fernández-Rivas, M., \& Breiteneder, H. Expression levels of parvalbumins determine allergenicity of fish species. Allergy, 65, 191-198.

Handy, S. M., Deeds, J. R., Ivanova, N. V., Hebert, P. D. N., Hanner, R., Ormos, A., Weigt, L. A., Moore, M. M., Hellberg, R. S., \& Yancy, H. F. (2011). Single laboratory validated method for DNA-barcoding for the species identification of fish for FDA regulatory compliance. Retrieved from http://www.fda.gov/Food/ScienceResearch/LaboratoryMethods/ucm237391.htm.

Hansen, T. K., Bindslev-Jensen, C., Skov, P., \& Poulsen, L. K. (1997). Codfish allergy in adults: IgE cross-reactivity among fish species. Annals of Allergy, Asthma, and Immunology, 78, 187-194.

Helbling, A., Haydel, R., McCants, M. L., Musmand, J. J., El-Dahr, J., \& Lehrer, S. B. (1999). Fish allergy: is cross-reactivity among fish species relevant? Double-blind placebo-controlled food challenge studies of fish allergic adults. Annals of Allergy, Asthma and Immunology, 83, 517-523.

Jiang, S-T., \& Lee, T-C. (1985). Changes in free amino acids and protein denaturation of fish muscle during frozen storage. Journal of Agricultural and Food Chemistry, 33, 839844. 
Kobayashi, A., Tanaka, H., Hamada, Y., Ishizaki, S., Nagashima, Y., \& Shiomi, K. (2006). Comparison of allergenicity and allergens between fish white and dark muscles. Allergy, 61, 357-363.

Lee, P-W., Nordlee, J. A., Koppelman, S. J., Baumert, J. L., \& Taylor, S. L. (2011). Evaluation and comparison of the species-specificity of 3 anti-parvalbumin $\operatorname{IgG}$ antibodies. Journal of Agricultural and Food Chemistry, 59, 12309-12316.

Lim, D. L., Neo, K. H., Goh, D. L., Shek, L. P., \& Lee, B. W. (2005). Missing parvalbumin: implications in diagnostic testing for tuna allergy. The Journal of Allergy and Clinical Immunology, 115, 874-875.

Pumphrey, R. S. H., \& Gowland, H. (2007). Further fatal allergic reactions to food in the United Kingdom, 1999-2006. Journal of Allergy and Clinical Immunology, 119, 10181019.

Rall, J. A. (1996). Role of parvalbumin in skeletal muscle relaxation. News in Physiological Sciences, 11, 249-255.

Santos-Yap, E. E. M. (1996). Fish and seafood. In L. E. Jeremiah (Eds.), Freezing effects on food quality (pp. 109-133). New York: Marcel Dekker, Inc. 
Shenouda, S. Y. K. (1980). Theories of protein denaturation during frozen storage of fish flesh. Advances in Food Research, 26, 275-311.

Sicherer, S. H., Muñoz-Furlong, A., \& Sampson, H. A. (2004). Prevalence of seafood allergy in the United States determined by a random telephone survey. Journal of Allergy and Clinical Immunology, 114, 159-165.

Sikorski, Z. E., Olley, J., \& Kostuch, S. (1976). Protein changes in frozen fish. Critical Reviews in Food Science and Nutrition, 8, 97-129.

Sikorski, Z. E., \& Kotakowska, A. (1994). Changes in proteins in frozen stored fish. In Z. E. Sikorski, B. S. Pan, \& F. Shahidi (Eds.), Seafood proteins (pp. 99-112). New York: Chapman \& Hall, Inc.

Taylor, S. L., Hefle, S. L., Bindslev-Jensen, C., Bock, S. A., Burks, A. W., Christie, L., Hill, D. J., Host, A., Hourihane, J. O., Lack, G., Metcalfe, D. D., Moneret-Vautrin, D. A., Vadas, P. A., Rance, F., Skrypec, D. J., Trautman, T. A., Yman, I. M., \& Zeiger, R. S. (2002). Factors affecting the determination of threshold doses for allergenic foods: how much is too much. Journal of Allergy and Clinical Immunology, 109, 24-30.

Taylor, S. L., Kabourek, J. L., \& Hefle, S. L. (2004). Fish allergy: fish and products thereof. Journal of Food Science, 69, R175-R180. 
Tejada, M., Careche, M., Torrejón, P., del Mazo, M. L., Solas, M. T., García, M. L., \& Barba, C. (1996). Protein extracts and aggregates forming in minced cod (Gadus morhua) during frozen storage. Journal of Agricultural and Food Chemistry, 33, 839-844.

Thys, T. M., Blank, J. M., Coughlin, D. J., \& Schachat, F. (2001). Longitudinal variation in muscle protein expression and contraction kinetics of largemouth bass axial muscle. The Journal of Experimental Biology, 204, 4249-4257.

Yunginger, J. W., Sweeney, K. G., Sturner, W. Q., Giannandrea, L. A., Teigland, J. D., Bray, M., Benson, P. A., York, J. A., Biedrzycki, L., Squillace, D. L., \& Helm, R. M. (1988). Fatal food-induced anaphylaxis. The Journal of the American Medical Association, 260, 1450-1452. 


\section{FIGURE CAPTIONS}

Figure 1. Stability of parvalbumin during frozen storage of carp, catfish, chub mackerel, sardine, chinook salmon, and albacore tuna, as determined by the indirect ELISA using anti-frog MAb, anti-carp MAb, and anti-cod PAb. Each data point and error bar represents the mean absorbance value and standard error of the mean of 18 readings, respectively. Asterisk indicates statistical difference from the mean absorbance value at day $0(\mathrm{p}<0.05)$.

Figure 2. SDS-PAGE profiles of the raw muscles obtained from 6 different body positions of 2 carp (Carp A and B), 2 catfish (Catfish A and B), one albacore tuna, and one mahi-mahi. The body positions were represented by numbers: $1=25 \% \mathrm{TML}$, dorsal; $2=25 \% \mathrm{TML}$, ventral; $3=50 \% \mathrm{TML}$, dorsal; $4=50 \% \mathrm{TML}$, ventral; $5=75 \% \mathrm{TML}$, dorsal; $6=75 \% \mathrm{TML}$, ventral. The arrow represents the expected position of the parvalbumin band.

Figure 3. Band intensity ratio of parvalbumin to total proteins (expressed as a percentage) in 6 body positions of 2 carp (Carp A and B), 2 catfish (Catfish A and B), one albacore tuna, and one mahi-mahi, as determined by the densitometry analysis of stained SDS-PAGE gels.

Figure 4. Reactivity of anti-frog MAb, anti-carp MAb, and anti-cod PAb with the raw muscle extracts obtained from 6 different body positions of 2 carp (Carp A and B), 2 catfish (Catfish A and B), one albacore tuna, and one mahi-mahi, as determined by the 
indirect ELISA. Each column and error bars represents the mean absorbance values and standard error of the mean of 6 readings, respectively. 

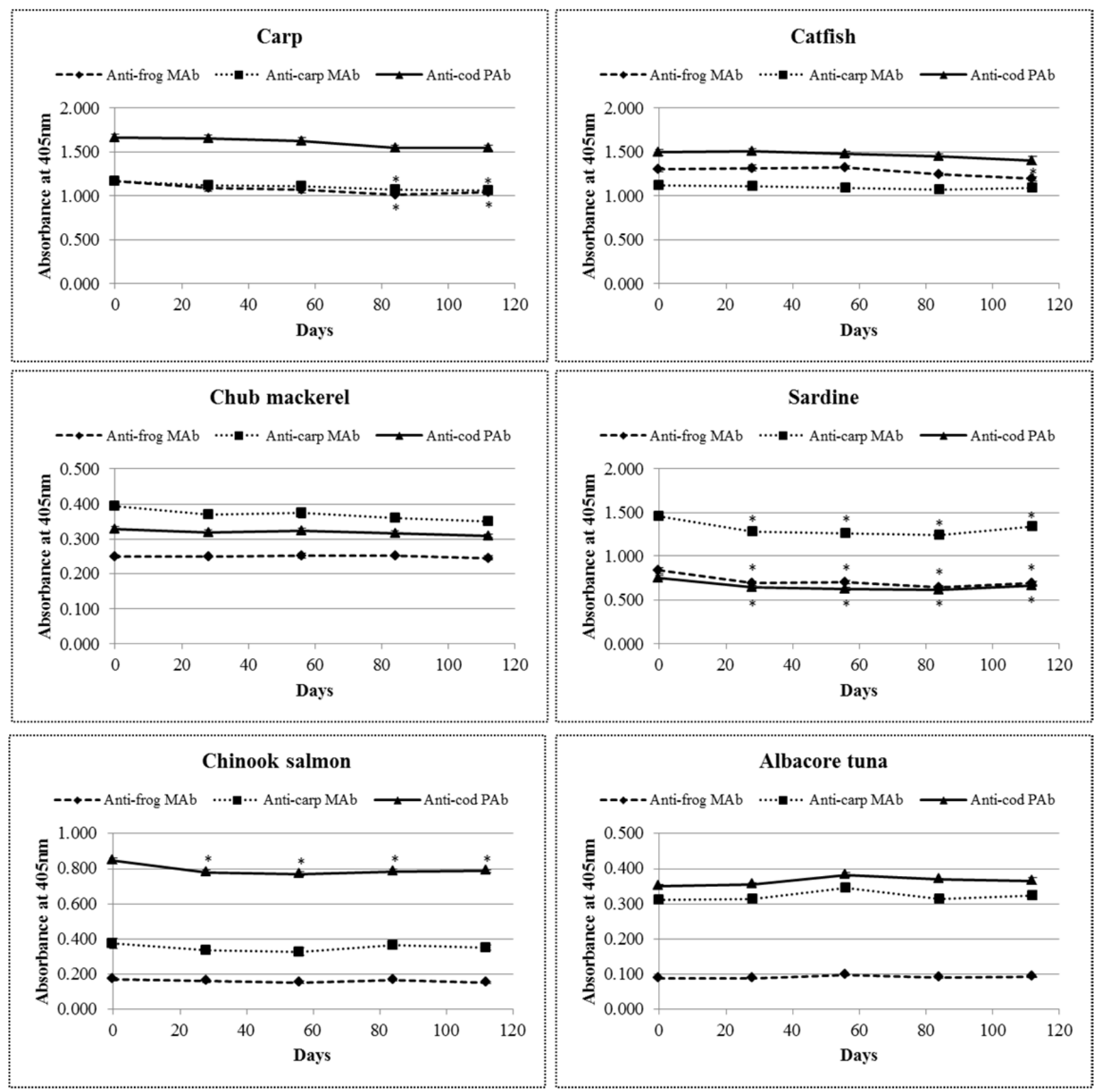

Figure 1. 


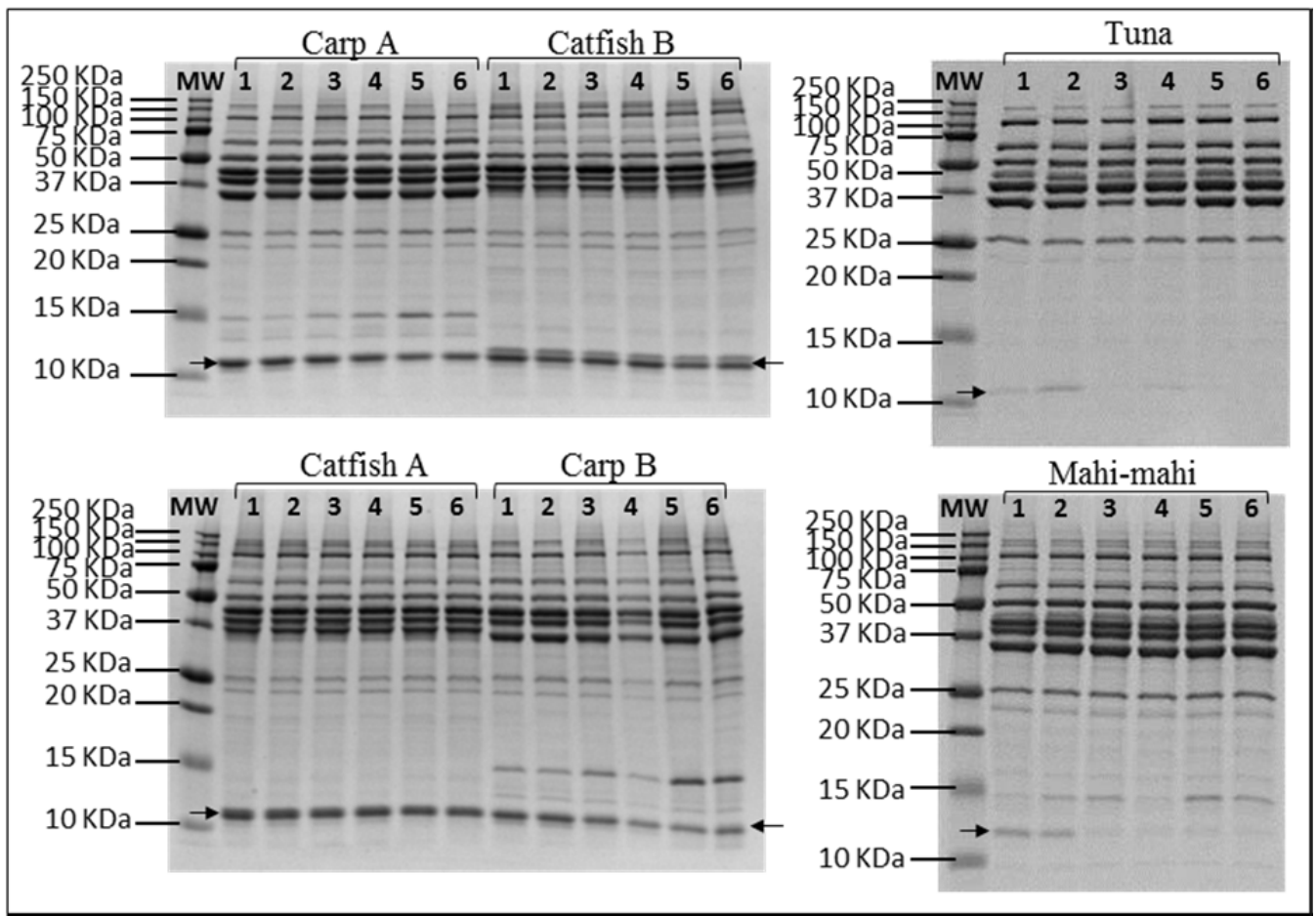

Figure 2. 


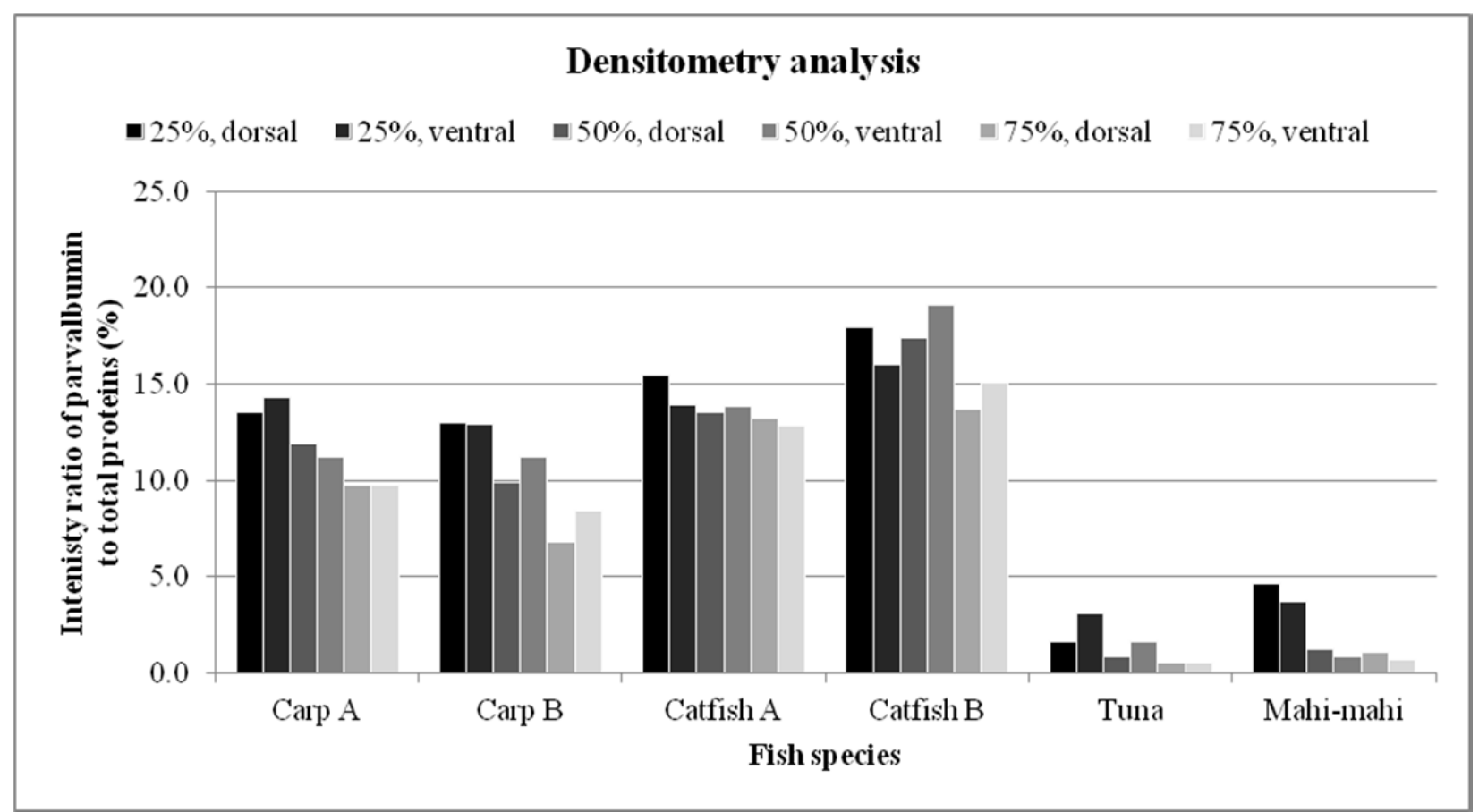

Figure 3. 


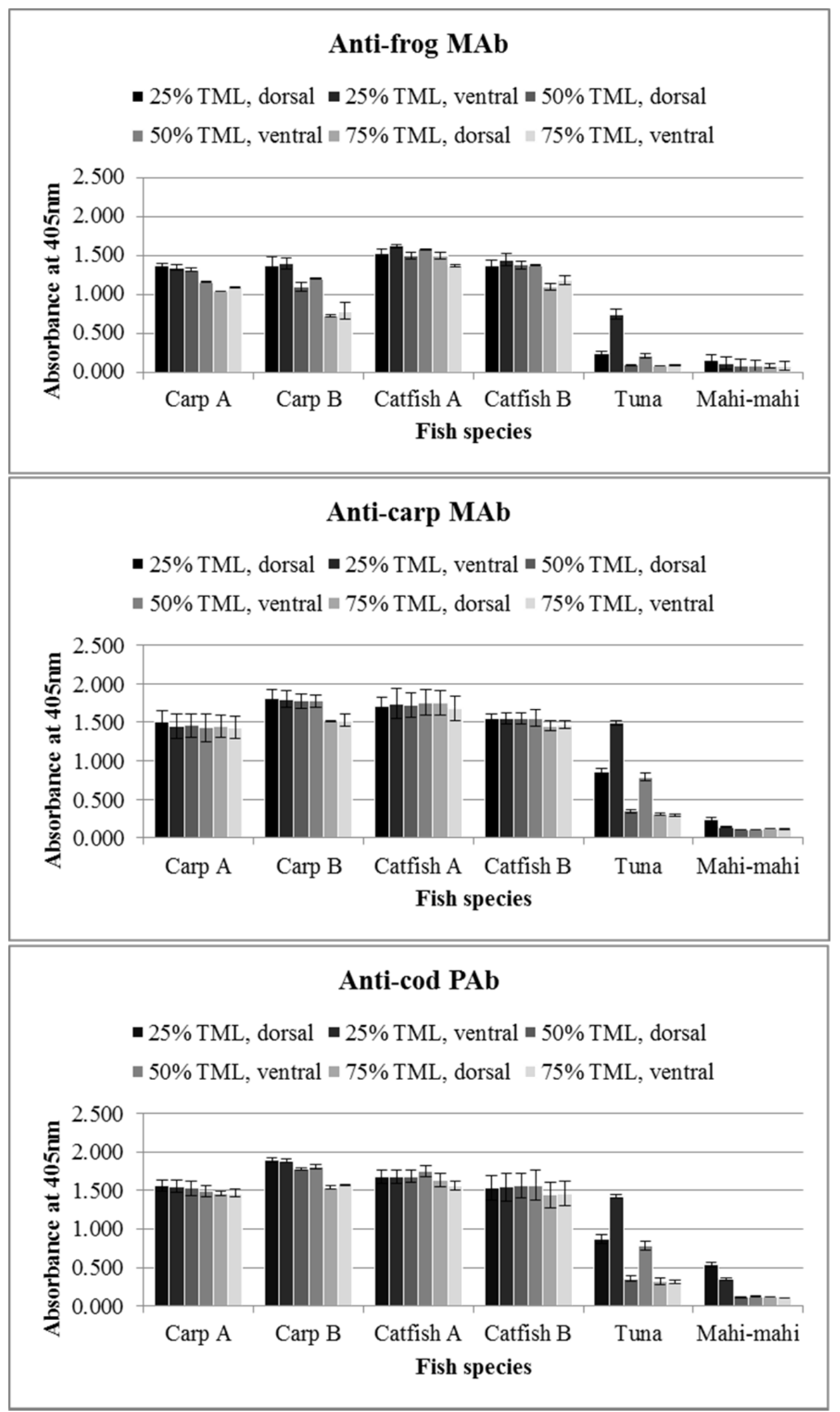

Figure 4. 


\section{CHAPTER 4: SEROLOGICAL SCREENING OF IgE BINDING TO PURIFIED PARVALBUMINS AND MUSCLE PROTEINS OF 26 FISH AND FROG SPECIES BY IMMUNOBLOTTING}

Poi-Wah Lee ${ }^{1}$, Julie A. Nordlee ${ }^{1}$, Stef J. Koppelman ${ }^{1}$, Joseph L. Baumert ${ }^{1}$, and Steve L. Taylor ${ }^{1}$

${ }^{1}$ Food Allergy Research and Resource Program, University of Nebraska, Lincoln, Nebraska, United States

Running title: IgE binding to fish parvalbumins

\section{Corresponding author}

Steve L. Taylor

Food Allergy Research and Resource Program

255 Food Industry Complex

University of Nebraska-Lincoln

Lincoln, NE 68593-0919

Telephone: +1-402-472-2833

Fax: $+1-402-472-5307$

E-mail: staylor2@unl.edu 


\section{ABSTRACT}

Background: Parvalbumin was identified as a major allergen causing cross-reactivity among fish and frog species. Objectives: This study aimed to evaluate and compare the differential IgE recognition of proteins from various fish and frog species obtained with serum samples of fish-allergic individuals. Methods: Individual serum samples from 39 subjects with a clinical history of fish allergy were analyzed for IgE-binding profiles to crude extracts of 26 raw muscle samples (25 fish, 1 frog), and purified cod and carp parvalbumin using IgE-immunoblotting. Results: Fish-allergic subjects demonstrated great diversity with respect to IgE-binding to parvalbumins and other proteins in fish and frog species. Of the 39 subjects, 27 (69\%) and 22 (56\%) reacted to cod and carp parvalbumins, respectively. Furthermore, $51-85 \%$ of the subjects presented sera IgE against proteins corresponding to parvalbumins in the extracts of 21 fish species, whereas $3-49 \%$ had IgE reactivity with proteins corresponding to parvalbumins from tuna, halibut, mahi-mahi, swordfish, and frog. The protein representing parvalbumin from catfish had the reactivity with the most sera samples, while swordfish showed the least reactivity. Conclusions \& Clinical Relevance: The variation in IgE-binding depended on the individuals and fish species analyzed by IgE-immunoblotting. The results suggest parvalbumin as the major cross-reactive allergen in the majority of fish species, except mahi-mahi, swordfish, and frog. Catfish parvalbumin should be considered as IgE binding protein and probable allergen for fish allergic subjects.

Keywords: Cross-reactivity, fish allergy, fish species, IgE-immunoblotting, parvalbumin 


\section{INTRODUCTION}

Fish is an important part of the human diet accounting for nearly $20 \%$ of the average per capita intake of animal protein in more than 1.5 billion people globally [1]. Although fish provides an excellent nutritional source of protein and polyunsaturated fatty acids, the consumption of fish can trigger IgE-mediated allergic reactions in fishsensitive individuals by oral, cutaneous or respiratory exposure [2-5]. Fish-allergic individuals display symptoms ranging in severity from mild oral or dermal reactions to life-threatening anaphylactic shock $[6,7]$. The prevalence of fish allergy is not precisely known, but figures ranging from $0.4 \%$ to $2 \%$ have been reported and is rarely outgrown $[8.9,10]$.

Cross-reactivity among fish species belonging to different taxonomic orders has been shown to be clinically relevant based on double-blind, placebo-controlled food challenges [11]. Therefore, individuals sensitized to fish are advised to avoid all fish species unless the individual species is proven safe to consume by oral challenges for that patient [11]. Nevertheless, early studies demonstrated that certain cod-allergic children were able to consume other fish species without experiencing any adverse reactions [12, 13]. A prospective study conducted by Bernhisel-Broadbent et al. [14] indicated that patients allergic to one or more fish species could safely consume other fish species without any allergic symptoms and the fish species tolerated differed among fish-allergic patients. In the past, several cases of monosensitivity to specific fish species have also been reported [15-18].

Parvalbumin, a calcium-binding muscle protein $(10-13 \mathrm{kDa})$, was first isolated from cod and described as a major fish allergen [19]. Later studies identified 
parvalbumins as pan-allergens in fish and frog species [14, 16, 20, 21]. However, many of these early studies $[14,16,21,22]$ were limited to the use of pooled sera and a rather small number of fish species. Thus, the importance of parvalbumin as an allergen in a wider variety of fish species merits further elucidation. The aim of this study was to analyze the immunoreactivity of individual serum IgE from fish-allergic subjects to purified cod and carp parvalbumin, and crude muscle extracts of 26 commonly consumed fish and frog species using immunoblotting. This study allows for the determination of intra- and inter-individual diversity in IgE responses of fish-allergic subjects to various fish species and one species of frog. The comparisons of IgE-binding proteins, particularly parvalbumins among fish and frog provided insights into role of parvalbumin as a fish allergen and as a pan-allergen among fish species.

\section{MATERIALS AND METHODS}

\section{Subjects' sera}

Sera were obtained from 39 fish allergic subjects (51\% females, age range 3.3 66 years, mean age 30.7 years) whose diagnostic characteristics are given in Table 1 and Appendix A. Inclusion criteria were a convincing history of fish allergy and positive skin prick test (SPT) to fish and/or specific-IgE test (Pharmacia CAP System FEIA) to an extract of at least one fish species, predominantly cod, with values $>0.35 \mathrm{kU} / \mathrm{L}$ to fish extracts. Sera from a non-atopic and an atopic subject tolerating fish were included as controls. The use of all serum samples in this study has been reviewed and approved by the Institutional Review Board of the University of Nebraska. 


\section{Preparation of parvalbumins and crude fish extracts}

Cod and carp parvalbumins were purified from fish fillets by a combination of diafiltration and chromatography steps as described previously [23, 24]. Twenty six raw muscle samples (25 fish, 1 frog) were obtained from different fish and seafood distributors in the U.S. and The Netherlands. The species of the samples were confirmed by Eurofins GeneScan, Inc. (Metairie, LA) using polymerase chain reaction (PCR), either the U.S. Food and Drug Administration (FDA)-validated DNA barcode analysis [25] or nucleotide sequence analysis of the cytochrome b and 16S genes (Table 2). The grinding, extraction, and protein determination of the fish and frog muscle extracts were performed according to methods described previously [26].

\section{Sodium dodecyl sulfate-polyacrylamide gel electrophoresis (SDS-PAGE) and IgE- immunoblotting}

Ten micrograms of soluble fish or frog proteins and $1 \mu \mathrm{g}$ of cod or carp parvalbumins were separated by SDS-PAGE (15\% Tris-HCl gel) under reducing conditions as described previously [26]. The proteins were either stained with Brilliant Blue G-Colloidal Stain (Sigma-Aldrich, St. Louis, MO) or transferred onto polyvinyl difluoride (PVDF) membranes (Millipore Corporation, Billerica, MA) at $65 \mathrm{~V}$ for 80 minutes using Mini Trans-Blot unit (Bio-Rad Laboratories, Hercules, CA) for immunoblotting. After blocking in $0.01 \mathrm{M}$ sodium phosphate buffered saline (PBS), $\mathrm{pH}$ 7.4 containing $0.05 \%$ Tween 20 (PBS-T) and 5\% non-fat dry milk (NFDM) for 2 hours, the membranes were incubated overnight at room temperature with serum samples from controls (1:10) or fish-allergic subjects $(1: 10,1: 20,1: 40$, or 1:50) diluted in PBS-T 
containing 2.5\% NFDM. Bound IgE was detected by incubation for 1 hour at room temperature with horseradish peroxidase-labeled mouse monoclonal anti-human IgE ( $\varepsilon$ chain specific, Southern Biotech, Birmingham, AL) diluted 1:1000 in PBS-T containing 2.5\% NFDM. The membranes were washed with PBS-T between incubation steps. The blot was developed in chemiluminescent substrate (Supersignal West Dura Extended Duration Substrate, Pierce/Thermo Scientific, Rockford, IL) and visualized using the Kodak Gel Logic 440 Imaging System (Eastman Kodak, Rochester, NY) equipped with Kodak 1D v. 3.6.5 software (Kodak Scientific Imaging Systems, New Haven, CT).

\section{Dot blotting and densitometry analysis}

Two microliters of serially-diluted human IgE proteins (Abcam, Inc., Cambridge, MA) were spotted onto a nitrocellulose membrane (Bio-Rad Laboratories, Hercules, CA) to achieve $100,10,1,0.1,0.01$, and $0.001 \mathrm{ng} / \mathrm{spot}$. After blocking and probing with antihuman IgE antibody, the membrane was developed by chemiluminescence according to the IgE-immunoblotting protocol described above. The images of the membranes from both dot blot and immunoblot assays were captured simultaneously for signal comparison. The intensity of IgE binding to fish proteins on immunoblots relative to the dot intensity of human IgE proteins was quantified densitometrically using Kodak 1D v. 3.6.5 software.

\section{RESULTS}

\section{SDS-PAGE analysis of protein profiles in fish and frog extracts}

Protein heterogeneity was evident as shown by SDS-PAGE banding patterns under reducing conditions for the various fish and frog muscle extracts (Figure 1), even 
for species within the same taxonomic order. With the exception of mahi-mahi, albacore tuna, and swordfish, all species displayed at least one band at $10-13 \mathrm{kDa}$. These bands probably correspond to parvalbumin based on the migration pattern of both purified cod and carp parvalbumins on the electrophoresis gel and the positive immunoreactivity to monoclonal and polyclonal IgG antibodies raised against carp, cod, and frog parvalbumins [26].

\section{IgE immunoreactivity of fish and frog proteins by immunoblotting}

Immunoblot analysis with individual serum IgE from 39 fish-allergic subjects demonstrated great variation in IgE binding to fish and frog proteins (Appendix B). No fish-specific IgE-binding was detected with serum from control subjects (Appendix B). Of the 39 subjects, sera from 33 subjects possessed IgE directed against proteins with molecular weight (MW) corresponding to parvalbumin $(10-13 \mathrm{kDa})$ in at least one fish species, while the remaining sera from subjects no. $12,13,17,27,32$, and 44 only recognized proteins of higher MW ( $>13 \mathrm{kDa})$. Representative blots of 2 subjects showing inter-individual differences in $\operatorname{IgE}$ response are displayed in Figure 2; in addition to $\operatorname{IgE}$ binding to proteins above $13 \mathrm{kDa}$, serum IgE from subject no. 24 also bound primarily to proteins at $10-13 \mathrm{kDa}$ in the majority of species, whereas serum IgE from subject no. 27 showed no binding to parvalbumins of any species, but reacted solely to proteins above $20 \mathrm{kDa}$. In terms of specificity and intensity within the same individual, marked heterogeneity was observed in apparent strength of IgE binding to purified cod and carp parvalbumin and soluble proteins of different fish and frog species. As an example, serum IgE from subject no. 24 bound to proteins in 23 of 26 fish and frog species (except 
mahi-mahi, swordfish, and frog). Moreover, serum IgE from subject no. 24 exclusively recognized bands corresponding to parvalbumin in pike, bluegill, tilapia, snapper, bass, mackerel, plaice, flounder, and perch, while IgE reactivity to both parvalbumins and higher MW proteins were detected in the remaining 14 species. The apparent intensity of IgE binding to bands analogous to parvalbumins also varied greatly among species, regardless of whether the species belong to the same order (Figure 2A). In the case of subject no. 27 (Figure 2B), IgE-reactive bands with different intensities occurred in somewhat fewer (18 of 26) species (except mahi-mahi, snapper, swordfish, halibut, flounder, trout, salmon, frog, and purified cod and carp parvalbumins).

The percentage of fish-allergic subjects who had specific IgE to blotted fish and frog proteins of specific MW ranges is shown in Table 3. The distribution of IgE-reactive bands varied among species. In general, a larger proportion of the sera exhibited IgE reactivity to $10-13 \mathrm{kDa}$ proteins compared to higher MW proteins in all species. Of 26 species, proteins above $13 \mathrm{kDa}$ in herring, pilchard, cod, cusk, hake, and trout were recognized by greater than $50 \%$ of the serum samples. Few subjects had IgE binding to proteins above $71 \mathrm{kDa}$ in all species. Compared to other fish species, a consistently low percentage of subjects showed IgE reactivity to any of the proteins from mahi-mahi, swordfish, and frog.

Figure 3 presents the frequency and intensity of IgE responses to purified cod and carp parvalbumins and proteins corresponding to parvalbumin in the MW range of $10-$ $13 \mathrm{kDa}$ in different fish and frog species (See Appendix C for the frequency and intensity of IgE responses to fish and frog proteins of all the MW ranges). Greater than $80 \%(31 / 39)$ of subject sera displayed IgE binding to proteins in the $10-13 \mathrm{kDa}$ range in 
catfish and bass. More than $50 \%$ of the 39 sera displayed IgE reactivity to proteins in this MW range indicating that parvalbumin is likely a major fish allergen in all species, except tuna, halibut, mahi-mahi, swordfish, and frog. The confirmation of parvalbumin as a major fish allergen is further supported by the observation that approximately $56 \%$ $(22 / 39)$ and $69 \%(27 / 39)$ of the serum samples contained specific IgE to the purified carp and cod parvalbumins, respectively. The numbers of serum samples recognizing protein corresponding to parvalbumin in tuna, halibut, frog, mahi-mahi, and swordfish were 19 $(49 \%), 18(46 \%), 4(10 \%), 5(13 \%)$, and $1(2.6 \%)$, respectively. The relative intensity of the IgE-reactive bands on immunoblot was determined by densitometry analysis compared to the dot intensity of known amounts of human IgE proteins. An intensity score, ranging from 0 to 4 was assigned to the IgE-reactive bands; intensity score 1, 2, 3, and 4 corresponded to dot-blot intensity of human $\operatorname{IgE}$ proteins at $<0.1,0.1-1,1-10$, and $>10 \mathrm{ng} / \mathrm{spot}$, respectively. The mean intensity was computed by adding all scores of the IgE-reactive bands at $10-13 \mathrm{kDa}$ and dividing by 39 serum samples. The mean intensity of IgE binding to parvalbumins varied from strong to medium in almost all species. In contrast, low IgE-binding intensity to proteins in this MW range was observed in only one species, swordfish.

\section{DISCUSSION}

The present study demonstrated that crude extracts of raw fish and frog muscles separated by SDS-PAGE contained multiple protein bands at $10-13 \mathrm{kDa}$ in all species but tuna, mahi-mahi, and swordfish. Some fish species were previously shown to express from two to five parvalbumin isotypes [21], and hence these protein bands may 
correspond to the parvalbumin isoforms. The undetectable parvalbumin bands in tuna, mahi-mahi, and swordfish could be explained by the much lower level of parvalbumin being expressed in dark muscle than in white muscle [27]. As previously reported, pelagic (dwelling in near-surface water) fish such as tuna, skipjack [27], mahi-mahi and swordfish tend to have higher amounts of dark muscle than demersal (bottom dwelling) fish such as cod and flounder [27].

The lack of definable parvalbumin bands in tuna observed in our study was similar to earlier published SDS-PAGE results [21, 28], although albacore tuna was analyzed here instead of yellowfin tuna. In fact, a recent study stated that the parvalbumin content in raw tuna muscle was considerably lower than herring, carp, redfish, trout, salmon, cod, and mackerel based on quantitative analysis by ELISA [29]. Moreover, parvalbumin could only be detected in the tuna white muscle rather than dark muscle [29]. Depending on the muscles that were sampled from tuna, the parvalbumin content could also vary due to the differential amounts of parvalbumin present in various locations within the whole tuna [30]. Despite the lack of detectable parvalbumin in tuna based on SDS-PAGE analysis, Shiomi et al. [31] were able to purify parvalbumin from bluefin tuna. Likewise, swordfish also demonstrated the absence of protein bands at $10-$ $13 \mathrm{kDa}$, probably owing to the low expression level of parvalbumin in swordfish muscle compared to cod and whiff, as described previously [32].

The comparison of IgE binding to fish and frog proteins by immunoblotting showed great intra- and inter-individual variation among fish-allergic subjects. For the majority of sera, both parvalbumin and other proteins at higher MW in different fish and frog species were bound by $\operatorname{IgE}$ from some subjects. For a very limited number of sera, 
e.g. subject no. 27 , the IgE antibodies did not bind parvalbumin in any fish species, but recognized exclusively non-parvalbumin proteins. These results indicate that proteins other than parvalbumins are responsible for causing sensitization in certain fish-allergic individuals. As previously reported, patients with monospecific allergy to a single fish species did not recognize parvalbumin, but had IgE directed to other proteins in swordfish, tuna, sole, pangasius, and tilapia [15-18].

Parvalbumin has been described as a major cross-reactive allergen across fish species [21], given the fact that the majority $(>50 \%)$ of fish-allergic individuals showed IgE binding to parvalbumin from different fish species [21, 33]. Our study confirmed that conclusion based on the IgE recognition of purified cod and carp parvalbumin by greater than $50 \%$ of fish-allergic subjects. Additionally, $50 \%$ or more of the subjects had serum specific IgE to proteins at $10-13 \mathrm{kDa}$ in 21 out of 26 fish and frog species studied; it was assumed that this protein range corresponds to parvalbumin. Of all fish species analyzed, catfish parvalbumin was shown to bind $\operatorname{IgE}$ from the sera of the highest percentage of fish-allergic subjects in this study. Thus, catfish parvalbumin may be the ideal protein to use diagnostically to identify parvalbumin-sensitized individuals. In the U.S. where catfish is commonly consumed, a previous clinical investigation demonstrated that a higher number of pediatric and adult fish-allergic patients had clinical histories of allergic reactions to catfish than cod and tuna [16]. Helbling et al. [34] also reported that catfish was the most frequently implicated offending species by subjects' histories, although the positive skin test responses to catfish were lower than anticipated in these fish-allergic subjects. 
The protein at $10-13 \mathrm{kDa}$ in tuna and halibut was not bound by sera $\mathrm{IgE}$ from more than $50 \%$ of the fish-allergic subjects in this study. Our results confirm the earlier findings of Van Do et al. [21], showing that halibut and tuna, besides flounder and mackerel, bound IgE from a lower percentage of sera than cod, salmon, pollock, herring, and wolfish based on IgE-imunoblotting, IgE ELISA inhibition and SPT. These findings correlated with the observations made by de Martino et al. [12], in which tuna induced positive SPT in 55\% of cod-allergic children. Furthermore, tuna extracts had lower inhibition capability than other fish extracts in the RAST inhibition assay [12]. Additionally, Pascual et al. [22] reported that tuna was the least allergenic among all species studied as it elicited the lowest IgE response. Tuna is less often implicated in causing allergic reactions compared to other fish, as observed clinically by Sampson [35]. In contrast, tuna was regarded as a highly allergenic species among Japanese fish-allergic children, probably attributed to the high tuna consumption in Japan [36]. Shiomi et al. [31] identified parvalbumin and/or higher molecular weight proteins as major allergens in bigeye tuna using 5 Japanese fish-sensitive subjects, but the IgE recognition pattern for these allergens varied among the subjects [31]. It remains to be determined if Japanese tuna-allergic patients are primarily reacting to parvalbumin using a larger group of subjects. Also, it remains to be determined if individuals sensitized to tuna parvalbumin would cross-react with the other species studied here such as cod.

Parvalbumins have previously been identified as cross-reactive allergens in frog and fish species including swordfish $[20,32]$. In the current study, only a small percentage of subjects had $\operatorname{IgE}$ antibodies directed against proteins at $10-13 \mathrm{kDa}$ in mahi-mahi, swordfish, and frog. The lack of IgE reactivity to these proteins may be 
explained by either the low abundance of parvalbumin in the muscles and/or the lack of cross-reactive IgE epitopes on the parvalbumins in these species. The SDS-PAGE profiles in the current study revealed the absence or low amounts of parvalbumins in the muscle extracts of mahi-mahi and swordfish. The weak IgE binding to swordfish is in agreement with a recent study, demonstrating that the low allergenicity of swordfish is attributed to the low parvalbumin content in swordfish [32]. Our results showed for the first time, that the protein possibly representing parvalbumin in mahi-mahi contained low IgE binding activity.

In conclusion, we demonstrated a high degree of intra- and inter-individual variation with regard to IgE binding to parvalbumin and non-parvalbumin proteins in different fish and frog species. Our results confirm that parvalbumin is a major allergen among numerous, but not all, fish species that are commonly consumed. Parvalbumin in catfish represented the most commonly and intensely bound proteins by the sera $\operatorname{IgE}$ of most fish-allergic individuals, suggesting that this parvalbumin may be used for in vitro diagnosis of fish allergy and may serve as an ideal candidate for the study of crossreactivity among fish species, especially in the elucidation of cross-reactive epitopes. However, further studies are warranted to investigate the clinical relevance of $\operatorname{IgE}$ antibodies directed to catfish parvalbumin and its frequency of sensitization. For some fish species, parvalbumin does not appear to be an important allergen based upon IgE binding. For example, sera from our group of fish-allergic subjects did recognize swordfish parvalbumin present in the muscle extracts that appeared to be the least allergenic compared to other fish species, probably owing to the low parvalbumin content in swordfish muscle. These results lead to a hypothesis that parvalbumin-sensitized, fish- 
allergic patients may be able to tolerate ingestion of swordfish; this hypothesis must be tested clinically. Additionally, IgE binding to higher MW proteins in different fish and frog species was also observed, albeit with a lower percentage of sera from fish-allergic individuals than was observed with parvalbumin. Further studies are needed to elucidate the identity of these higher MW IgE-reactive allergens.

\section{ACKNOWLEDGEMENTS}

Financial support was provided by the Food Allergy Research and Resource Program at the University of Nebraska. Sera were obtained from Allergy, Asthma and Immunology Associates (Lincoln and Omaha, NE), University Hospital (Zurich Switzerland), and University Medical Center (Utrecht, The Netherlands). Additionally, discarded and de-identified sera were obtained from the John Hopkins University Dermatology Allergy and Clinical Immunology Reference Laboratory (Baltimore, MD). We thank Martha R. Wiberg (Gorton's Inc.), Richard Norland (Norland Products Inc.), Dr. Yi-Cheng Su (Oregon State University), and Tony Korth (Nebraska Game and Parks Commission) for providing the fish samples. We also thank E. Pearce Smith (Eurofins GeneScan, Inc.) for technical assistance. All authors have no conflict of interests to declare.

\section{ABBREVIATIONS}

MW: Molecular weight; SPT: Skin prick test

\section{REFERENCES}


1 http://www.fao.org/fishery/sofia/en

2 Crespo JF, Pascual C, Dominguez C, Ojeda I, Muñoz FM, Esteban MM. Allergic reactions associated with airborne fish particles in IgE-mediated fish hypersensitive patients. Allergy 1995; 50: 257-61.

3 Domínguez C, Ojeda I, Crespo JF, Pascual C, Ojeda A, Martín-Esteban M. Allergic reactions following skin contact with fish. Allergy Asthma Proc 1996; 17: $83-7$.

4 Rodríguez J, Reaño M, Vives R, Canto G, Daroca P, Crespo JF, et al. Occupational asthma caused by fish inhalation. Allergy 1997; 52: 866-9.

5 Taylor SL, Kabourek JL, Hefle SL. Fish allergy: fish and products thereof. J Food Sci 2004; 69: R175-80.

6 Yunginger JW, Sweeney KG, Sturner WQ, Giannandrea LA, Teigland JD, Bray M, et al. Fatal food-induced anaphylaxis. JAMA 1988; 260: 1450-2.

7 Pumphrey RS, Gowland MH. Further fatal allergic reactions to food in the United Kingdom, 1999-2006. J. Allergy Clin Immunol 2007; 119: 1018-9.

8 Bock SA. The natural history of food sensitivity. J Allergy Clin Immunol 1982; 69: $173-7$.

9 Sicherer SH, Muñoz-Furlong A, Sampson HA. Prevalence of seafood allergy in the United States determined by a random telephone survey. J Allergy Clin Immunol 2004; 114: 159-65.

10 Rona RJ, Keil T, Summers C, Gislason D, Zuidmeer L, Sodergren E, et al. The prevalence of food allergy: a meta-analysis. J Allergy Clin Immunol 2007; 120: 638-46. 
11 Helbling A, Haydel R, McCants ML, Musmand JJ, El-Dahr J, Lehrer SB. Fish allergy: is cross-reactivity among fish species relevant? double-blind placebocontrolled food challenge studies of fish allergic adults. Ann Allergy Asthma Immunol 1999; 83: 517-23.

12 de Martino M, Novembre E, Galli L, de Marco A, Botarelli P, Marano E, et al. Allergy to different fish species in cod-allergic children: in vivo and in vitro studies. J Allergy Clin Immunol 1990; 86: 909-14.

13 Aas K. Studies of hypersensitivity of fish: allergological and serological differentiation between various species of fish. Int Arch Allergy Appl Immunol 1966; 30: 257-67.

14 Bernhisel-Broadbent J, Scanlon SM, Sampson HA. Fish hypersensitivity. I. in vitro and oral challenge results in fish-allergic patients. J Allergy Clin Immunol 1992; 89: 730-7.

15 Kelso JM, Jones RT, Yunginger JW. Monospecific allergy to swordfish. Ann Allergy Asthma Immunol 1996; 77: 227-8.

16 James JM, Helm RM, Burks WA, Lehrer SB. Comparison of pediatric and adult IgE antibody binding to fish proteins. Ann Allergy Asthma Immunol 1997; 79: $131-7$.

17 Asero R, Mistrello G, Roncarolo D, Casarini M, Falagiani P. True monosensitivity to a tropical sole. Allergy $1999 ; \mathbf{5 4 :}$ 1228-9.

18 Ebo DG, Kuehn A, Bridts CH, Hilger C, Hentges F, Stevens WJ. Monosensitivity to pangasius and tilapia caused by allergens other than parvalbumin. $J$ Investig Allergol Clin Immunol 2010; 20: 84-8. 
19 Elsayed S, Aas K. Isolation of purified allergen (cod) by isoelectric-focusing. Int Arch Allergy Appl Immunol 1971; 40: 428-38.

20 Hilger C, Thill L, Grigioni F, Lehners C, Falagiani P, Ferrara A, et al. IgE antibodies of fish allergic patients cross-react with frog parvalbumin. Allergy 2004; 59: 653-6 0 .

21 Van Do T, Elsayed S, Florvaag E, Hordvik I, Endresen C. Allergy to fish parvalbumins: studies on the cross-reactivity of allergens from 9 commonly consumed fish. J Allergy Clin Immunol 2005; 116: 1314-20.

22 Pascual C, Martín Esteban M, Crespo JF. Fish allergy: evaluation of the importance of cross-reactivity. J Pediatr 1992; 121: S29-34.

23 Koppelman SJ, Romijn RA, de Jongh HHJ, Nordlee JA, Piersma S, Hessing M, Taylor SL. Purification of parvalbumin from carp: a protocol that avoids heattreatment. J Food Sci 2010; 75: T49-56.

24 de Jongh HH, Taylor SL, Koppelman SJ. Controlling the aggregation propensity and thereby digestibility of allergens by Maillardation as illustrated for cod fish parvalbumin. J Biosci Bioeng 2011; 111: 204-11.

25 http://www.fda.gov/Food/ScienceResearch/LaboratoryMethods/ucm237391.htm

26 Lee PW, Nordlee JA, Koppelman SJ, Baumert JL, Taylor SL. Evaluation and comparison of the species-specificity of 3 antiparvalbumin IgG antibodies. $J$ Agric Food Chem 2011; 59: 12309-16.

27 Kobayashi A, Tanaka H, Hamada Y, Ishizaki S, Nagashima Y, Shiomi K. Comparison of allergenicity and allergens between fish white and dark muscles. Allergy 2006; 61: 357-63. 
28 Chen L, Hefle SL, Taylor SL, Swoboda I, Goodman RE. Detecting fish parvalbumin with commercial mouse monoclonal anti-frog parvalbumin IgG. $J$ Agric Food Chem 2006; 54: 5577-82.

29 Kuehn A, Scheuermann T, Hilger C, Hentges F. Important variations in parvalbumin content in common fish species: a factor possibly contributing to variable allergenicity. Int Arch Allergy Immunol 2010; 153: 359-66.

30 Lim DL, Neo KH, Yi FC, Chua KY, Goh DL, Shek LP. Parvalbumin: the major tropical fish allergen. Pediatr Allergy Immunol 2008; 19: 399-407.

31 Shiomi K, Hamada Y, Sekiguchi K, Shimakura K, Nagashima Y. Two classes of allergens, parvalbumins and higher molecular weight substances, in Japanese eel and bigeye tuna. Fish Sci 1999; 65: 943-8.

32 Griesmeier U, Vázquez-Cortés S, Bublin M, Radauer C, Ma Y, Briza P, et al. Expression levels of parvalbumins determine allergenicity of fish species. Allergy 2010; 65: 191-8.

33 Lehrer SB, Horner WE, Reese G. Why are some proteins allergenic? implications for biotechnology. Crit Rev Food Sci Nutr 1996; 36: 553-64.

34 Helbling A, McCants ML, Musmand JJ, Schwartz HJ, Lehrer SB. Immunopathogenesis of fish allergy: identification of fish-allergic adults by skin test and radioallergosorbent test. Ann Allergy Asthma Immunol 1996; 77: 48-54.

35 Sampson HA. Food anaphylaxis. Br Med Bull 2000; 56: 925-35.

36 Koyama H, Kakami M, Kawamura M, Tokuda R, Kondo Y, Tsuge I, et al. Grades of 43 fish species in Japan based on IgE-binding activity. Allergol Int 2006; 55: $311-6$. 
37 Koppelman SJ, Romijn RA, de Jongh HHJ, Nordlee JA, Piersma S, Hesssing M, et al. Purification of parvalbumin from carp: a protocol that avoids heat-treatment. J Food Sci 2010; 75: T49-56.

38 Gerday C. The primary structure of the parvalbumin II of pike (Esox Lucius). Eur J Biochem 1976; 70: 305-18.

39 Ma Y, Griesmeier U, Susani M, Radauer C, Briza P, Erler A, et al. Comparison of natural and recombinant forms of the major fish allergen parvalbumin from cod and carp. Mol Nutr Food Res 2008; 52: S196-207.

40 Van Do T, Hordvik I, Endresen C, Elsayed S. Characterization of parvalbumin, the major allergen in Alaska Pollack and comparison with codfish Allergen M. Mol Immunol 2005; 42: 345-53.

41 Hamada Y, Tanaka H, Ishizaki S, Ishida Y, Shiomi K. Purification, reactivity with IgE and cDNA cloning of parvalbumin as the major allergen of mackerels. Food Chem Toxicol 2003; 41: 1149-56. 


\section{FIGURE CAPTIONS}

Figure 1. SDS-PAGE profiles of purified cod and carp parvalbumin, and raw muscle protein extracts of frog and fish species. The taxanomic family and order of the species were represented by bold and italic characters, respectively.

Figure 2. Immunoblot analysis of purified cod and carp parvalbumins, and crude extracts of fish and frog muscles with sera IgE from fish-allergic Subject no. 24 (A) and 27 (B). Dot blotting of serially-diluted human IgE proteins $\left(10^{2}-10^{-3} \mathrm{ng} / \mathrm{spot}\right)$ are shown in square boxes.

Figure 3. Frequency and mean IgE-binding intensity of sera from 39 fish-allergic subjects to fish and frog proteins at $10-13 \mathrm{kDa}$ on immunoblots. The degree of IgEbinding intensity relative to amounts of human IgE proteins on dot blots ranged from extremely strong (>10 ng/spot), strong $(1-10 \mathrm{ng} / \mathrm{spot})$, medium $(0.1-1 \mathrm{ng} / \mathrm{spot})$, and low $(<0.1 \mathrm{ng} / \mathrm{spot})$ intensity. 
Table 1. Characteristics of fish-allergic subjects and in vitro diagnosis

\begin{tabular}{|c|c|c|c|c|c|}
\hline $\begin{array}{l}\text { Subjects } \\
\text { no. }\end{array}$ & Sex & $\begin{array}{l}\text { Age } \\
\text { (y) }\end{array}$ & $\begin{array}{l}\text { Specific IgE } \\
\text { to cod } \\
\text { extracts } \\
\left(k U_{\mathrm{A}} / \mathrm{L}\right)\end{array}$ & $\begin{array}{l}\text { SPT to cod } \\
\text { extracts } \\
\text { (wheal } x \text { flare } \\
\text { in mm) }\end{array}$ & Symptoms \\
\hline 1 & $\mathrm{M}$ & 36 & 0.64 & ND & LE, U, DY, OAS \\
\hline 2 & $\mathrm{~F}$ & 25 & 1.23 & ND & OS, OAS \\
\hline 5 & $\mathrm{M}$ & 33 & 0.44 & ND & OS, U \\
\hline 7 & $\mathrm{M}$ & 41 & 3.14 & ND & $\mathrm{U}, \mathrm{OAS}, \mathrm{CT}$ \\
\hline 10 & $\mathrm{M}$ & 35 & 1.32 & $15 \times 40$ & OS, A, U \\
\hline 12 & $\mathrm{M}$ & 50 & $<0.35$ & $1 \times 40^{*}$ & ES, AE (face, hand) \\
\hline 13 & $\mathrm{~F}$ & 55 & $<0.35$ & $5 \times 20^{*}$ & GI, U, OAS \\
\hline 14 & $\mathrm{~F}$ & 22 & 2.54 & ND & OS, OAS \\
\hline 16 & $\mathrm{~F}$ & 47 & 3.98 & ND & OS, OAS, W, A, C, ES \\
\hline 17 & $\mathrm{~F}$ & 29 & $<0.35$ & $4 \times 15^{\S}$ & $\mathrm{A}, \mathrm{DY}, \mathrm{SY}, \mathrm{AE}$ \\
\hline 18 & $\mathrm{~F}$ & 44 & 0.91 & ND & OS, U, V, DZ \\
\hline 20 & $\mathrm{M}$ & 17 & 14.5 & ND & A, U, OS \\
\hline 21 & $\mathrm{M}$ & 24 & 8.64 & $14 \times 47$ & OAS, DY \\
\hline 22 & $\mathrm{~F}$ & 27 & 8.56 & $8 \times 38$ & $\mathrm{AP}, \mathrm{OAS}$ \\
\hline 23 & $\mathrm{~F}$ & 60 & 0.5 & $7 \times 39$ & $\mathrm{D}, \mathrm{P}, \mathrm{AE}, \mathrm{U}, \mathrm{UR}, \mathrm{RH}, \mathrm{LE}, \mathrm{DY}, \mathrm{N}, \mathrm{V}, \mathrm{DI}$ \\
\hline 24 & $\mathrm{M}$ & 26 & 51.3 & 11.75 (wheal) & LE, N, OAS \\
\hline 25 & $\mathrm{M}$ & 26 & 5.42 & $5 \times 27$ & OAS, DS \\
\hline 26 & $\mathrm{~F}$ & 29 & 14.4 & $17.5 \times 38$ & LE, OAS \\
\hline 27 & $\mathrm{~F}$ & 54 & 12.2 & 4.25 (wheal) & $\mathrm{N}, \mathrm{AP}, \mathrm{DI}, \mathrm{OAS}$ \\
\hline 28 & M & 37 & 1.15 & $13 \times 30.5$ & $\mathrm{P}, \mathrm{NC}, \mathrm{DY}, \mathrm{ES}$ \\
\hline 29 & $\mathrm{~F}$ & 33 & 42.7 & $14 \times 53$ & AE, RH, LE, OAS \\
\hline 30 & $\mathrm{~F}$ & 23 & 5.38 & $9 \times 36$ & OAS \\
\hline 31 & $\mathrm{~F}$ & 42 & 13.6 & $28 \times 50$ & $\mathrm{P}, \mathrm{N}, \mathrm{V}, \mathrm{DI}$ \\
\hline 32 & $\mathrm{M}$ & 43 & 1.01 & $4.75 \times 26$ & $\mathrm{P}, \mathrm{U}, \mathrm{LE}, \mathrm{N}, \mathrm{AP}, \mathrm{OAS}, \mathrm{DY}$ \\
\hline 33 & $\mathrm{~F}$ & 33 & 0.94 & $20 \times 53$ & OAS, DS \\
\hline 34 & M & 4.7 & 3.33 & 2.75 (wheal) & $\mathrm{U}, \mathrm{OAS}$ \\
\hline 35 & $\mathrm{M}$ & 3.8 & 42.7 & ND & NA \\
\hline 36 & $\mathrm{M}$ & 3.3 & 20.8 & ND & NA \\
\hline 37 & $\mathrm{~F}$ & 29 & 19.7 & ND & NA \\
\hline 38 & $\mathrm{M}$ & 4.9 & 15 & ND & NA \\
\hline 39 & $\mathrm{~F}$ & 10 & 25.7 & ND & NA \\
\hline 40 & $\mathrm{~F}$ & 29 & 34.6 & ND & NA \\
\hline 41 & $\mathrm{~F}$ & 5.1 & 22.4 & ND & NA \\
\hline 42 & $\mathrm{M}$ & 28 & 3.48 & $21 \times 45$ & U, P, OAS, AE (oral) \\
\hline 43 & M & 46 & 2.47 & $8 \times 15$ & $\mathrm{OAS}, \mathrm{AD}, \mathrm{AE}$ (oral) \\
\hline 44 & $\mathrm{M}$ & 66 & NA & $5 \times 8$ & OAS, AE (tongue) \\
\hline 45 & $\mathrm{~F}$ & 32 & 1.43 & $13 \times 43$ & $\mathrm{U}, \mathrm{W}$ \\
\hline 46 & $\mathrm{~F}$ & 21 & 0.64 & $10 \times 30$ & UR, NC, R, W, C \\
\hline 47 & $\mathrm{M}$ & 25 & 1.93 & $7 \times 14$ & UR, LE \\
\hline
\end{tabular}

Abbreviations: $F$, female; $M$, male; $S P T$, skin prick test; $N D$, not determined; $N A$; not available; Symptoms ( $A$, anaphylaxis; $A S$, asthma; $A D$, atopic dermatitis; $A E$, angioedema; $A P$, abdominal pain; $C$, cough; $C T$, chest tightness; $D$, dermatitis; $D I$, 
diarrhea; $D S$, dysphagia; $D Y$, dyspnea; $D Z$, dizziness; $E S$, eye swelling; $F$, flushing; $G I$, gastrointestinal symptoms, including nausea, vomiting, diarrhea, abdominal pain; $H$, hoarseness; $H B$, heartburn; $I$, itching; $L E$, Laryngeal edema; $N$, nausea; $N C$, nasal congestion; $O A S$, oral allergy symptoms; $O S$, oropharyngeal swelling; $P$, pruritis; $R H$, rhinorrhea; $S Y$, syncope; $S Z$, sneezing; $T$, tachypnea; $U$, urticaria; $U R$, upper respiratory itching/sneezing; $V$, vomiting; $W$, wheeze).

* Positive SPT to tuna extract $\S$ Positive SPT to salmon extract 
Table 2. Scientific names of fish and frog samples

\begin{tabular}{lll}
\hline Common name & Scientific name & $\begin{array}{l}\text { MW of parvalbumin } \\
\text { [Ref]* }\end{array}$ \\
\hline $\begin{array}{l}\text { American bullfrog } \\
\text { Unsalted herring }\end{array}$ & $\begin{array}{l}\text { Rana catesbeiana } \\
\text { Pilchard }\end{array}$ & \\
Carp & Sardina pilchardus & \\
Northern pike & Cyprinus carpio & 10 and $12 \mathrm{kDa}[37]$ \\
Atlantic cod & Esox lucius & $11.4 \mathrm{kDa}[38]$ \\
Alaskan pollock & Gadus morhua & $11.4 \mathrm{kDa}[39]$ \\
Haddock & Theragra chalcogramma & $11.5 \mathrm{kDa}[40]$ \\
Cusk & Melanogrammus aeglefinus & \\
Hake & Brosme brosme & \\
Bluegill & Urophycis tenuis & \\
Tilapia & Lepomis macrochirus & \\
Mahi-mahi & Oreochromis niloticus & \\
Snapper & Coryphaena hippurus & \\
Hybrid striped bass & Lutjanus guttatus/synagris & \\
Grouper & Morone chrysops saxatilis & \\
Albacore tuna & Epinephelus morio & \\
Chub mackerel & Thunnus alalunga & $11.0 \mathrm{kDa}[41]$ \\
Swordfish & Scomber japonicas & $12 \mathrm{kDa}[32]$ \\
Pacific halibut & Xiphias gladius & \\
American plaice & Hippoglossus stenolepis \\
Yellowtail flounder & Hippoglossoides platessoides & \\
Rainbow trout & Limanda ferruginea \\
Chinook salmon & Oncorhynchus mykiss \\
Catfish & Oncorhynchus tshawytscha \\
Ocean perch & Ictalurus punctatus & \\
\hline
\end{tabular}

Abbreviations: Ref, references.

* MW of parvalbumins reported in published papers 
Table 3. Immunoblot recognition of fish and frog proteins of different MW ranges by sera IgE from 39 fish-allergic subjects

\begin{tabular}{lccccccccc}
\hline Common name & \multicolumn{7}{c}{ \% subjects reacted to proteins between $\mathbf{1 0}$ to $\mathbf{1 0 0}$ kDa } \\
\cline { 2 - 9 } & $\mathbf{1 0 - 1 2}$ & $\mathbf{1 3 - 1 9}$ & $\mathbf{2 0 - 2 5}$ & $\mathbf{2 6 - 4 3}$ & $\mathbf{4 4 - 5 9}$ & $\mathbf{6 0 - 7 0}$ & $\mathbf{7 1 - 8 0}$ & $\mathbf{8 1 - 1 0 0}$ & $>\mathbf{1 0 0}$ \\
\hline American bullfrog & 10 & 3 & 8 & 10 & 5 & 0 & 3 & 3 & 0 \\
Unsalted herring & 56 & 26 & 15 & 13 & 21 & 54 & 13 & 13 & 5 \\
Pilchard & 51 & 0 & 13 & 21 & 54 & 3 & 10 & 3 & 0 \\
Carp & 56 & 3 & 0 & 10 & 21 & 3 & 3 & 5 & 0 \\
Carp parvalbumin & 56 & 0 & 0 & 0 & 0 & 0 & 0 & 0 & 0 \\
Northern pike & 51 & 8 & 0 & 10 & 5 & 3 & 0 & 0 & 0 \\
Atlantic cod & 64 & 26 & 33 & 67 & 64 & 26 & 10 & 3 & 0 \\
Cod parvalbumin & 69 & 0 & 0 & 0 & 0 & 0 & 0 & 0 & 0 \\
Alaskan pollock & 62 & 31 & 13 & 21 & 5 & 3 & 8 & 3 & 0 \\
Haddock & 64 & 10 & 23 & 18 & 38 & 0 & 0 & 10 & 0 \\
Cusk & 77 & 8 & 10 & 41 & 67 & 26 & 13 & 13 & 0 \\
Hake & 62 & 21 & 13 & 51 & 44 & 21 & 5 & 10 & 0 \\
Bluegill & 67 & 23 & 5 & 26 & 18 & 5 & 3 & 3 & 0 \\
Tilapia & 67 & 8 & 3 & 10 & 26 & 0 & 3 & 0 & 0 \\
Mahi-mahi & 13 & 0 & 5 & 15 & 10 & 0 & 0 & 5 & 0 \\
Snapper & 56 & 15 & 15 & 23 & 10 & 0 & 0 & 0 & 0 \\
Hybrid striped bass & 82 & 18 & 5 & 21 & 15 & 0 & 0 & 3 & 3 \\
(Red) Grouper & 72 & 15 & 10 & 18 & 10 & 0 & 3 & 0 & 3 \\
Albacore tuna & 49 & 0 & 3 & 38 & 8 & 5 & 0 & 3 & 3 \\
Chub mackerel & 62 & 8 & 5 & 10 & 8 & 3 & 3 & 0 & 0 \\
Swordfish & 3 & 3 & 3 & 8 & 5 & 0 & 0 & 3 & 0 \\
Pacific halibut & 46 & 21 & 13 & 13 & 10 & 0 & 3 & 5 & 0 \\
American plaice & 77 & 41 & 23 & 15 & 10 & 5 & 0 & 5 & 15 \\
Yellowtail flounder & 54 & 33 & 18 & 10 & 8 & 0 & 3 & 5 & 5 \\
Rainbow trout & 72 & 15 & 54 & 33 & 33 & 26 & 3 & 0 & 3 \\
Chinook salmon & 59 & 13 & 23 & 13 & 26 & 15 & 5 & 3 & 0 \\
Catfish & 85 & 5 & 5 & 13 & 13 & 23 & 8 & 3 & 0 \\
Ocean perch & 54 & 13 & 3 & 10 & 15 & 3 & 0 & 5 & 3 \\
\hline & & & & & & & & & 0 \\
\end{tabular}




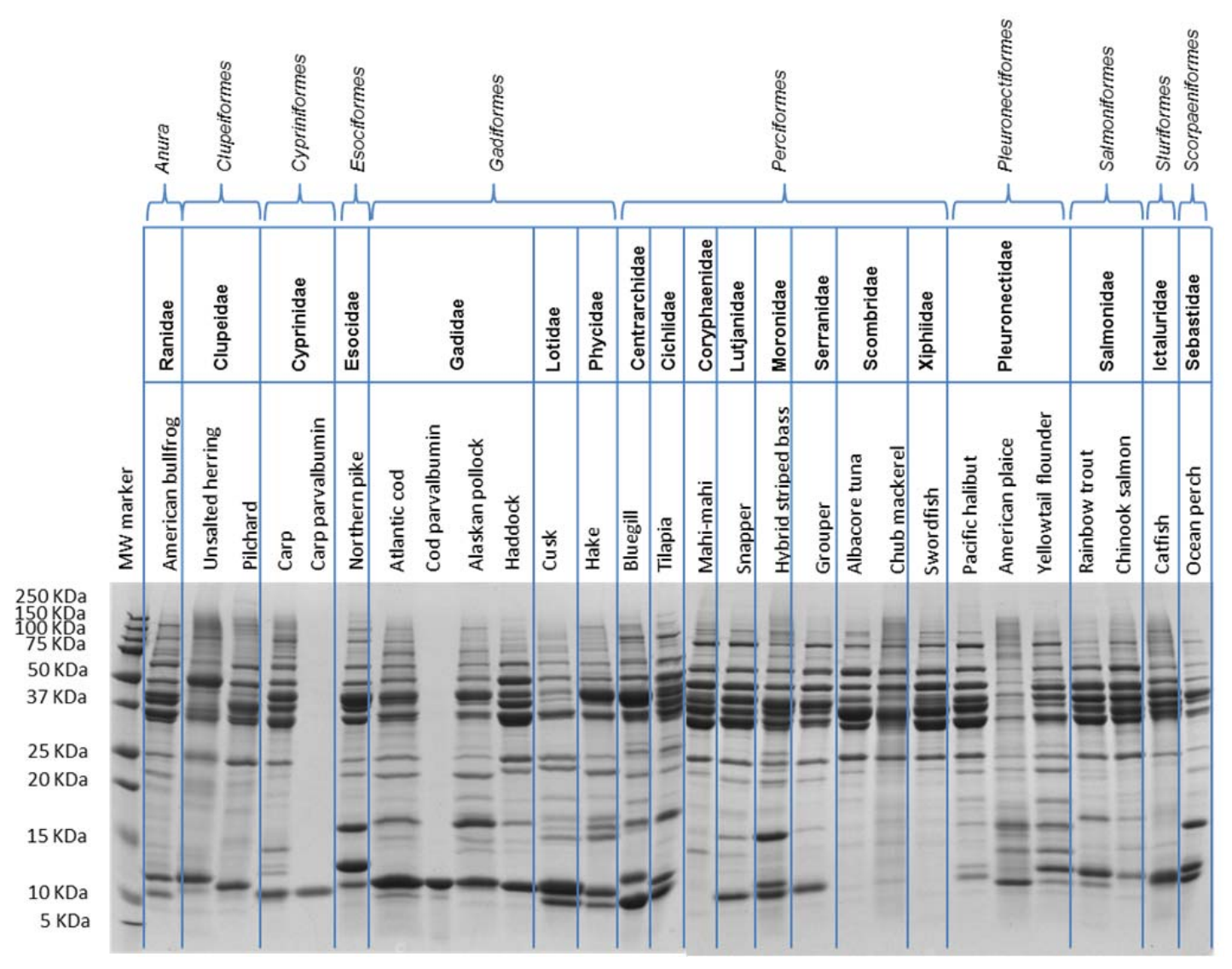

Figure 1. 

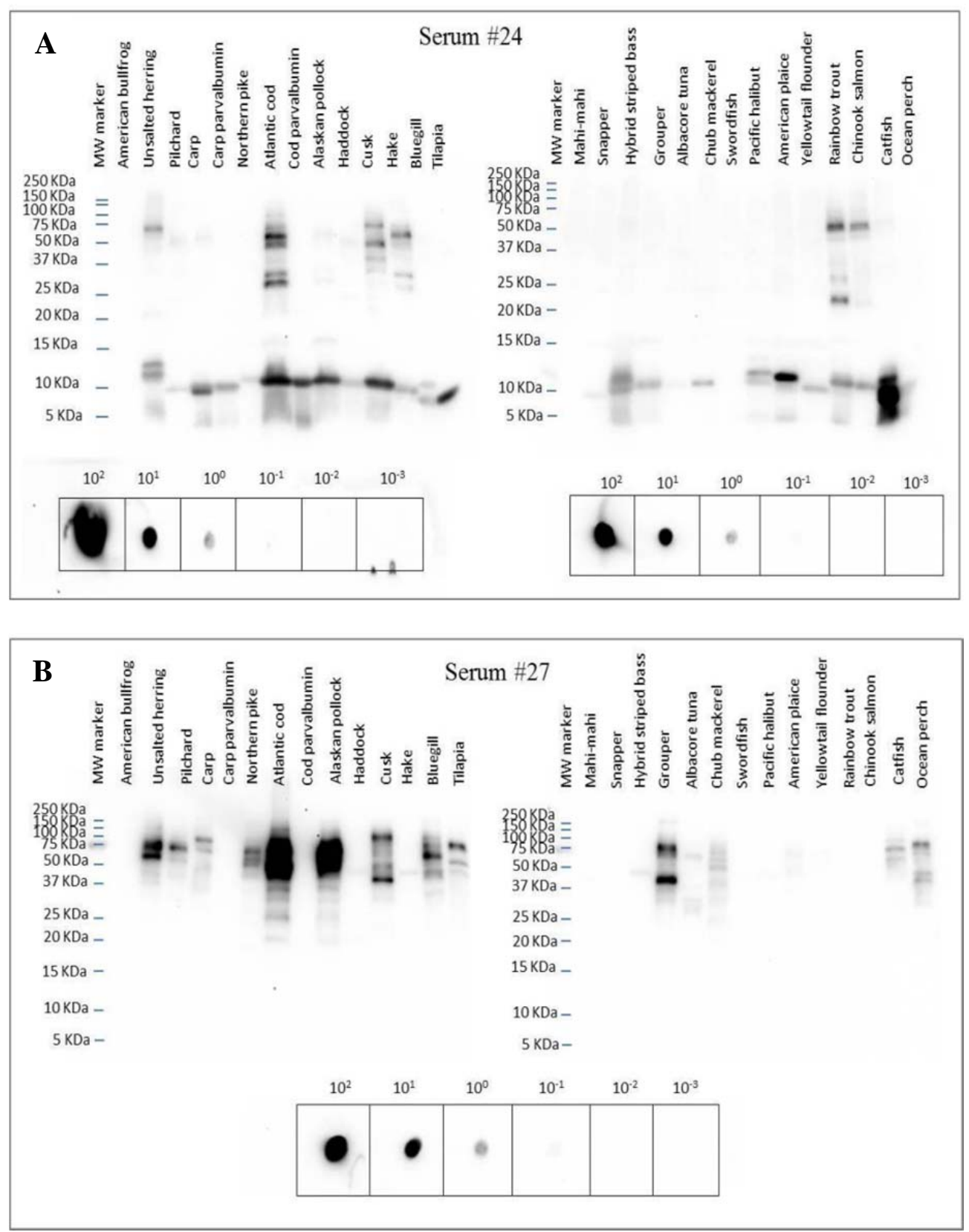

Figure 2. 


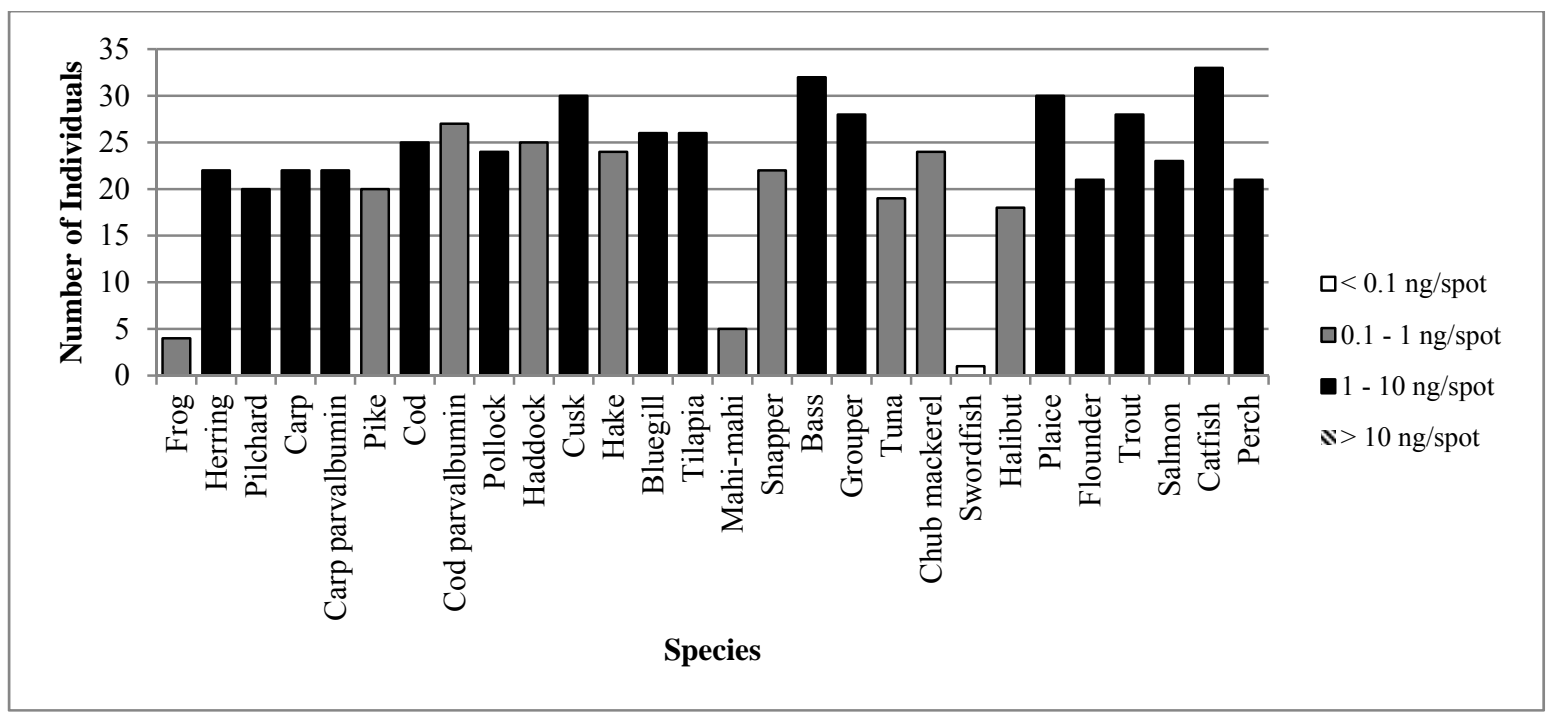

Figure 3. 


\section{CHAPTER 5: IDENTIFICATION OF POTENTIAL ALLERGENS IN COD, CUSK, HERRING, PILCHARD, AND TROUT BY PROTEOMIC APPROACHES}

Poi-Wah Lee ${ }^{1}$, Julie A. Nordlee ${ }^{1}$, Stef J. Koppelman ${ }^{1}$, Joseph L. Baumert ${ }^{1}$ and Steve L. Taylor $^{1}$

${ }^{1}$ Food Allergy Research and Resource Program, University of Nebraska, Lincoln, Nebraska, United States

\section{Correspondence:}

Steve L. Taylor

Food Allergy Research and Resource Program

225 Food Industry Complex

University of Nebraska-Lincoln

Lincoln, NE 68593-0919

E-mail: staylor2@unl.edu

Fax: $+1-402-472-5307$

Abbreviations: APDH, aldehyde phosphate dehydrogenase; BiP, luminal binding protein; GAPDH, glyceraldehyde 3-phosphate dehydrogenase; MLC, myosin light chain 


\section{ABSTRACT}

Scope: Cross-reactivity among fish and frog species is common in fish-allergic individuals. Aside from fish and frog parvalbumins that have been identified as major cross-reactive pan-allergens, non-parvalbumin allergens in specific fish species have also been described are mostly still not well-characterized. In this study, we aimed to identify potential allergens in 5 different fish species using proteomic approaches.

Methods and results: By 1-D immunoblotting, individual sera from 7 fish-allergic subjects showed relatively similar IgE-binding profiles to crude muscle extracts of raw cod, cusk, herring, pilchard, and trout. Sera pooled from these subjects revealed IgE recognition of parvalbumin and its corresponding isoforms in all 5 species using 2-DE and immunoblotting. The pooled sera IgE also reacted to several novel fish allergens that were characterized by LC-MS/MS as $\alpha$ - and $\beta$-actin, desmin, glyceraldehyde 3-phosphate dehydrogenase (GAPDH), fast myosin light chain (MLC), enolase, and creatine kinase proteins.

Conclusion: Further characterization of the novel fish allergens is warranted at the molecular level using larger panels of fish-allergic subjects. The identification of allergens in various fish species will facilitate the elucidation of IgE-binding epitopes and improve the diagnosis and therapy of fish allergy.

Keywords: Fish allergy / IgE antibody / LC-MS/MS / Novel allergens / Parvalbumin / 2$\mathrm{DE}$ 


\section{INTRODUCTION}

Fish has traditionally been an important part of the diet, especially in coastal regions. According to epidemiological studies, increased intake of fish rich in omega-3 fatty acid was associated with a reduced risk of coronary heart diseases, which lead to the recommendation by American Heart Association Dietary Guidelines on consuming at least two servings of fish per week, particularly fatty fish [1]. However, this recommendation does not apply to fish-allergic individuals in whom strict avoidance of all fish species is required, unless otherwise proven to be clinically tolerant to a specific species [2]. Ingestion of fish by fish-allergic individuals could lead to a wide range of symptoms typical of food allergies, including cutaneous, gastrointestinal and respiratory symptoms, or even life-threatening and potentially fatal anaphylaxis [2-4]. Besides fish ingestion, direct skin contact with fish or inhalation of aerosolized proteins generated by cooking fish can also induce symptoms in some allergic subjects $[5,6]$.

Serological and clinical cross-reactivity among fish species have been reported [2, $7,8]$. Individuals allergic to one fish species carry at least a $50 \%$ chance of reacting to a second species [9]. However, a few studies revealed that some fish-allergic individuals are able to consume one or more fish species without experiencing any adverse reactions $[10,11]$. The immunological response to fish species varies between fish-sensitive individuals and could be divided into 3 categories, including cross-reactivity with all fish species, partial tolerance to specific fish species, and monospecific allergy to single fish species [12].

Parvalbumin, a sarcoplasmic calcium-binding protein from fish muscles, has long been implicated as the causative allergen of fish allergy and it has been extensively 
characterized including elucidation of its IgE-binding epitopes [13-16]. Moreover, parvalbumin is classified as pan-allergen involved in the cross-reactivity among fish and frog species [17-19]. Currently, parvalbumin has been isolated and characterized from multiple fish species as the major fish allergen [20-24]. In addition to parvalbumin, other fish proteins such as collagen [25], aldehyde phosphate dehydrogenase (APDH) [26], enolase and creatine kinase [27] have also been described as allergens, but further investigations are necessary for the molecular characterization of some of these allergens and the determination of their role in the cross-reactivity.

In our previous study [28], we demonstrated that individual serum from fishallergic subjects had IgE binding to proteins corresponding to parvalbumins and nonparvalbumin of higher $M_{\mathrm{r}}$ in various fish and frog species. The aim of this study was to utilize proteomic approaches to identify these IgE-reactive proteins in 5 of the fish species previously analyzed, including cod, cusk, herring, pilchard, and trout. The characterization of allergens among fish species will assist in understanding the role of parvalbumin and other novel non-parvalbumin allergens in the monospecific and crossreactive nature of fish allergy. Moreover, the results may facilitate further studies in the elucidation of IgE-binding epitopes on different fish allergens, thus improving the diagnostic and therapeutic strategies for fish allergy.

\section{MATERIALS AND METHODS}

\section{Fish extracts preparation}

Cod (Gadus morhua), cusk (Brosme brosme), herring (Clupea harengus), pilchard (Sardina pilchardus), and trout (Oncorhynchus mykiss) fillets were obtained from 
different fish and seafood distributors in the U.S. and Netherlands. The species identification of the fish samples was performed by Eurofins GeneScan, Inc. (Metairie, LA) using either the Food and Drug Administration (FDA)-validated DNA barcode analysis

(http://www.fda.gov/Food/ScienceResearch/LaboratoryMethods/ucm237391.htm) or nucleotide sequence analysis of the cytochrome $\mathrm{b}$ and $16 \mathrm{~S}$ genes.

For the protein separation by 1-D SDS-PAGE, the grinding, extraction, and protein determination of the fish extracts were performed according to methods described elsewhere [29]. To resolve proteins by 2-DE, the fish fillets were homogenized in rehydration buffer (8M urea, 2\% CHAPS, $50 \mathrm{mM}$ DTT, and $0.5 \%$ ampholyte $\mathrm{pH} 3-10)$. After centrifugation at $3612 \mathrm{~g}$ for 30 minutes at $4^{\circ} \mathrm{C}$, the supernatant was stored at $-80^{\circ} \mathrm{C}$ until use. Protein concentration of the supernatant was estimated by the Bradford assay (Bio-Rad Laboratories, Hercules, CA) using purified bovine serum albumin to generate a standard curve for quantitation.

\section{SDS-PAGE and 2-DE}

Ten micrograms of soluble fish proteins were separated by 1-D SDS-PAGE under reducing conditions as described previously [29]. For 2-DE, $75 \mu \mathrm{g}$ (for staining) and $25 \mu \mathrm{g}$ (for IgE immunoblotting) of fish proteins in $125 \mu 1$ rehydration buffer were applied to immobilized pH gradient strips (ReadyStrip ${ }^{\mathrm{TM}}$, 7-cm, pH 3-10 nonlinear, Bio-Rad Laboratories, Hercules, CA). First dimension IEF was carried out at $20^{\circ} \mathrm{C}$, with an active rehydration step for 12 hours at 50 volts, followed by a conditioning step for 15 minutes at 250 volts, voltage ramping for 2 hours at 4000 volts, and final focusing step of 4000 
volts for 30,000 volt-hours. After equilibrating the strips with equilibration buffer $(8 \mathrm{M}$ urea, $2 \% \mathrm{SDS}, 0.375 \mathrm{M}$ Tris- $\mathrm{HCl}, 20 \%$ glycerol) in the presence of $20 \mathrm{mg} / \mathrm{ml}$ DTT for 15 minutes and then $25 \mathrm{mg} / \mathrm{ml}$ of iodoacetamide for 15 minutes, the second dimension SDSPAGE was carried out using 10-20\% Tris-HCl precast gel (Ready Gel, Bio-Rad Laboratories, Hercules, CA). For $M_{\mathrm{r}}$ and $\mathrm{p} I$ determination, molecular weight markers (Precision Plus Protein ${ }^{\mathrm{TM}}$ Dual Xtra Standards, Bio-Rad Laboratories, Hercules, CA) and 2-D SDS-PAGE standards (Bio-Rad Laboratories, Hercules, CA), respectively, were used. The fish proteins resolved by SDS-PAGE and 2-DE were either stained with Brilliant Blue G-Colloidal Stain (Sigma Chemical Co., St. Louis, MO) or transferred onto a polyvinyl difluoride (PVDF) membrane (Millipore Corporation, Billerica, MA) for IgE immunoblotting.

\section{IgE immunoblotting}

IgE binding to electrophoretically-separated fish proteins was detected as described previously [28]. Fish proteins separated by 1-D SDS-PAGE and 2-DE, respectively, were probed with individual sera of 7 fish-allergic subjects and pooled sera of these subjects. The pooled sera was prepared by mixing 2 parts of serum samples from subjects no. 1-3 and 5-7 with 1 part of serum sample from subject no. 4. IgE-mediated fish allergy was diagnosed on the basis of clinical history and skin prick test and/or specific-IgE test (Pharmacia CAP System FEIA) to cod extract. The diagnostic data are shown in Table 1. Serum from a non-atopic subject tolerating fish was included as control. The use of all serum samples in this study has been reviewed and approved by the Institutional Review Board of the University of Nebraska. 


\section{LC-MS/MS analysis and protein identification}

IgE-binding proteins spots on the stained gel of 2-DE were located by side-byside comparions between the gel and the membrane probed with pooled sera. The positions of molecular weight markers and 2D SDS-PAGE standards further aided the localization of the protein spots. These protein spots were analyzed at the National Jewish Health, Mass Spectrometry Core Facility (Denver, Co) according to the procedures as described [30]. Briefly, protein spots were excised from the 2-DE gel, followed by reduction with DTT and alkylation with iodoacetamide. After digesting the proteins in the excised gel spots with trypsin overnight at $37^{\circ} \mathrm{C}$, the peptides were extracted and speed-vacuumed to reduce volume and remove volatile organic compounds. The resulting peptides were chromatographically resolved on-line using a C18 column and 1200 series HPLC (Agilent Technologies, Palo Alto, CA). For LC-MS/MS analysis, a 6340 LC-MS ion trap or 6510 Quadrupole-TOF LC-MS system (Agilent Technologies, Palo Alto, CA) equipped with a HPLC-chip interface (Agilent Technologies, Palo Alto, CA) were used. Standards were run at the beginning of each day and at the end of a set of analysis for quality control purposes.

The raw data extracted from LC-MS/MS run were subjected to the Spectrum Mill search engine (Rev A.03.03.038 SR1, Agilent Technologies, Palo Alto, CA) for protein identification. Peak picking was performed by applying the following parameters: signalto-noise was set at 5:1, a maximum charge state of 7 was allowed $(z=7)$, and the program was directed to attempt to find a precursor charge state. Collected spectra from cusk and pilchard were searched against all species in the National Center for 
Biotechnology Information (NCBI) protein database, whereas herring, cod, and trout peptide masses were compared to the expected tryptic peptides of each corresponding fish species in the NCBI protein database. Search parameters included carbamidomethylation as a fixed modification, oxidized methionine as a variable modification, a maximum of 2 missed cleavages, precursor ion mass tolerance of \pm 2.5 Da, product ion mass tolerance of $\pm 0.7 \mathrm{Da}$, and maximum ambiguous precursor charge of 4. Protein identifications were considered significant when the following confidence thresholds were fulfilled: (i) minimum of 2 peptides per protein; (ii) protein score $>10$; (iii) individual peptide scores of at least 7; and (iv) scored percent intensity (SPI) of at least $70 \%$. The SPI provides an indication of the percent of the total ion intensity that matches the peptide's MS/MS spectrum. All proteins identified by LC-MS/MS except parvalbumin, were searched against a database of known allergens using the Food Allergy Research and Resource Program (FARRP) AllergenOnline Database version 11 (http://www.allergenonline.org/). Two types of FASTA search were performed using the AllergenOnline database, including an overall full-length search and an 80 amino acids segment search.

\section{RESULTS}

\section{SDS-PAGE and IgE immunoblotting analysis}

One-dimensional SDS-PAGE analysis of the crude muscle extracts of cod, cusk, herring, pilchard, and trout showed different banding patterns for proteins in the molecular weight range of 10 to $250 \mathrm{kDa}$ (Figure 1). All species possessed protein bands migrating between 10 to $13 \mathrm{kDa}$, which corresponded to parvalbumin based on the 
positive immunoreactivity to polyclonal anti-cod parvalbumin antibody as previously reported [28]. Immunoblotting with individual serum IgE from 7 selected fish-allergic subjects showed that all reacted to bands at 10-13 kDa in all 5 fish species analyzed (Figure 1). In addition, IgE reactivity to higher $M_{\mathrm{r}}$ bands at $\geq 20 \mathrm{kDa}$ were also observed in all species. The comparisons of IgE reactivity patterns of each fish species in the immunoblotting were relatively similar among these 7 fish-allergic subjects, although differences exist with regard to the IgE-binding intensity. However, sera from other fishallergic subjects showed differing IgE-binding profiles [28]. These 7 serum samples were pooled for subsequent analysis in the 2-DE. Immunoblotting with serum from a nonatopic subject revealed no IgE-binding proteins in any of the fish species (data not shown).

\section{2-DE, IgE immunoblotting analysis, and protein identification}

Proteins extracted from raw muscles of 5 fish species were separated by 2-DE, followed by Colloidal blue staining (Figure 2A1-2E1) or transferring to PVDF membranes for immunoblotting analysis with pooled sera IgE from 7 fish-allergic subjects (Figure 2A2-2E2). Similar experiments were performed with serum from a nonatopic subject, but no IgE binding was detectable in the immunoblotting (data not shown). Through LC-MS/MS analysis and database searching using Spectrum Mill software, the identities of the IgE-reactive protein spots were determined. Identified proteins with the highest Spectrum Mill protein score for each of the excised spots and their corresponding peptides are displayed in Table 2 and Table 3. 
Several protein spots (spot no. 1 in cod; spot no. 1 and 2 in cusk; spot no. 1 in herring; spot no. 1 and 2 in pilchard; spot no. 1 and 2 in trout) within the $M_{\mathrm{r}}$ range of 10 $13 \mathrm{kDa}$ and $\mathrm{p} I$ range of 4.0-5.5 were present in all 5 fish species, but these spots varied in Colloidal-staining intensity, whether between species or within the same species. Additionally, these protein spots were recognized by the pooled sera IgE of the 7 fishallergic subjects. LC-MS/MS identified these spots as parvalbumin with a significant Spectrum Mill protein score of greater than 10, although in pilchard and cusk, these spots were identified as parvalbumin of other fish species due to the lack of parvalbumin sequences from pilchard (Sardina pilchardus) and cusk (Brosme brosme) in the NCBI protein database (Table 2). Moreover, the $M_{\mathrm{r}}$ and $\mathrm{p} I$ of the protein spots estimated through molecular weight and $\mathrm{p} I$ standards closely matched to the theoretical values, which provide further confirmation of the identities of these protein spots.

In addition to the parvalbumin, the 2-DE and immunoblotting analysis revealed that the IgE from the pooled sera IgE of 7 fish-allergic subjects reacted to multiple novel proteins migrating at higher $M_{\mathrm{r}}$ in all 5 species. To assess the sequence similarity shared between the novel proteins identified by LC-MS/MS and existing allergens with known sequences, a FASTA search against the FARRP AllergenOnline database using the fulllength and 80 amino acids sliding window was conducted. The first 3 proteins with the highest $\mathrm{Z}$ scores showing matches are summarized in Table 4.

According to the LC-MS/MS analysis, spot no. 2 from cod was identified as fast skeletal muscle $\alpha$-actin protein and shared similar $M_{\mathrm{r}}$ and $\mathrm{p} I$ as the theoretical values (Table 2). A FASTA search demonstrated that this spot had $23.2 \%$ identity with luminal binding protein $(\mathrm{BiP})$ from hazel pollen for the full-length alignment, but no matches 
with any putative allergens were found when using the 80-mers sliding window approach (Table 4).

Two different proteins were identified for spot no. 3 from cusk and pilchard, respectively. Spot no. 3 from pilchard was identified as enolase. For spot no. 3 from cusk, the protein was identified as an unnamed protein product from spotted green pufferfish (Tetraodon nigroviridis; GenBank accession no. CAF89801). However, this protein is homologous to enolase, sharing $96 \%$ identity or less with enolase from other fish and non-fish species based on BLASTP (basic local alignment search tool for proteins; http://blast.ncbi.nlm.nih.gov/Blast.cgi) search using the default settings. The experimental and theoretical $M_{\mathrm{r}}$ and $\mathrm{p} I$ were comparable for these 2 spots and the Spectrum Mill protein scores exceeded the threshold for significance (Table 2). The 2 spots shared $66-70 \%$ sequence identity based on full-length FASTA search and as much as $86-87 \%$ sequence identity over 80 amino acids length with enolase 1 allergens from rubber tree and yeast fungus (Table 4).

The pooled sera from the 7 fish-allergic subjects showed specific IgE binding to protein spot no. 4 from cusk that represented GAPDH and protein spots no. 2-6 from herring that corresponded to $\alpha$-actin (Table 2). These spots did not share sequence similarity to any existing allergen, regardless of the high Spectrum Mill score and close matching between the experimental and theoretical values of $M_{\mathrm{r}}$ in spot no. 4 from cusk, and $\mathrm{p} I$ in spots no. 2-6 from herring (Table 2 and 4). Spot no. 5 from cusk identified as unnamed protein from Tetraodon nigroviridis was homologous to desmin protein found in muscle cells based on BLASTP search. The full-length FASTA search revealed that the unnamed protein shared approximately $20 \%$ sequence identity with paramyosin 
allergens from fish parasite and mite. Besides, the unnamed protein also shared $37 \%$ sequence identity with fish parasite allergen over 80-mer residue window (Table 4).

The IgE-reactive spot no. 4 from pilchard was identified as creatine kinase from channel catfish (Ictalurus punctatus) with a high Spectrum Mill score and good agreement between experimental and theoretical values of $M_{\mathrm{r}}$ and $\mathrm{p} I$ (Table 2). The FASTA search of creatine kinase returned identity matches with arginine kinase allergens from crustacean shellfish and moth, with identities of $46 \%$ over full-length sequence and 61-65\% over 80 amino acid residues (Table 4). Through LC-MS/MS analysis, spot no. 3 from trout was identified as a protein corresponding to fast MLC 2 and was shown to possess similar experimental $M_{\mathrm{r}}$ and $\mathrm{p} I$ as the theoretical values (Table 2). This spot appeared to share sequence homology to MLC allergens (EF-hand protein) from crustacean shellfish, cypress and tree pollen, displaying $<35 \%$ identity in full-length alignment and $<42 \%$ in 80 -mers window. Spot no. 4 from trout identified as $\beta$-actin displayed low sequence identity with a novel allergen from timothy grass over its fulllength sequence (Table 2 and 4). Furthermore, no matches resulted from the 80 amino acids sliding window search of the $\beta$-actin.

\section{DISCUSSION}

Fish is one of the important animal foods capable of inducing IgE-mediated food hypersensitivity in allergic individuals. To date, only parvalbumin has been identified and well-characterized as a major fish allergen. Clinical and serological cross-reactivity among multiple fish species has been reported and was attributed to the parvalbumin molecule. Previously, we identified parvalbumin as the IgE-reactive proteins in 25 fish 
species including cod, cusk, herring, pilchard, and trout based on 1-D and immunoblotting with sera from 39 fish-allergic individuals. In the present study we confirmed that parvalbumin is a major allergen in all 5 of these fish species using 1-D and 2-DE immunoblotting in conjunction with LC-MS/MS analysis. These results suggested parvalbumin as major cross-reactive allergens among fish species, which is in line with the previous observations $[17,28]$. Studies have shown that adult fish and amphibians are capable of expressing multiple parvalbumin isoforms that are speciesspecific in the skeletal muscles. These parvalbumin isoforms can be divided into 2 lineages, namely $\beta$-parvalbumin $(\mathrm{p} I<5.0)$ and $\alpha$-parvalbumin $(\mathrm{p} I>5.0)[19,20]$. Similarly, we demonstrated the presence of at least two IgE-reactive protein spots at 10$13 \mathrm{kDa}$ and $\mathrm{p} I$ range of 4.0-5.5 in cusk, pilchard, and trout that corresponded to parvalbumin isoforms. Very recently, Perez-Gordo et al. elucidated the IgE epitopes in two isoforms of Atlantic salmon and concluded that the isoforms may differ in their allergenic behavior [31]. Likewise, we observed differences in the IgE-binding intensity to parvalbumin isoforms within the same species in the 2-DE immunoblotting, such as pilchard (Figure 2D2).

In our previous study [28], several additional IgE-reactive non-parvalbumin protein bands of higher $M_{\mathrm{r}}$ were identified from immunoblotting of 1-D gels; these IgEreactive protein bands in herring, pilchard, cod, cusk, hake, and trout were recognized by greater than $50 \%$ of the serum samples from 39 fish-allergic subjects. Current study showed that these IgE-binding proteins from 5 of the fish species were recognized by pooled sera IgE from 7 fish-allergic individuals in the 1-D and 2-DE immunoblotting. Identities of these IgE-reactive proteins were determined by LC-MS/MS analysis. To 
assess the potential allergenicity, the sequence identities between these novel IgE-binding proteins and existing allergens were compared in the FARRP AllergenOnline database using the FASTA program. An identity match $>50 \%$ over full-length alignment and/or identities $>35 \%$ over 80 amino acids alignment indicates a potential risk of allergenic cross-reactivity (http://www.allergenonline.org/).

Surprisingly, despite the fact that actin is a highly conserved protein with sequence identity close to $100 \%$ between human and other animal species [32], spot no. 2 from cod and spot no. 2-6 from herring which were bound by IgE from fish-allergic subjects, were identified as $\alpha$-actin, while spot no. 4 from trout was identified as $\beta$-actin. Actin is a globular protein (G-actin) that polymerizes to form filaments, known as Factin, which is the main component of the cytoskeleton [33]. In addition to maintaining cytoskeletal structure, actin is important in other cellular processes, including cell motility, cell division, and intracellular movements [33, 34]. Six different isoforms of actin are expressed in mammals: two cytoplasmic actins in nonmuscle cells ( $\beta$ and $\gamma$ ), two striated muscle actins ( $\alpha$-skeletal and $\alpha$-cardiac) and two smooth muscle actins ( $\alpha$-aortic and $\alpha$-enteric) [34]. In teleosts, at least nine isoforms of muscle-type $\alpha$-actins and cytoplasmic-type $\beta$-actins have been isolated [35]. Thus far, there are no reports on the allergenicity of actin, apart from a study of allergenic proteins involved in meat allergy, which revealed that children with meat allergy had $\operatorname{IgE}$ antibodies reacted with bovine actin in immunoblotting, but no positive skin prick test responses to bovine actin were observed [32]. This finding was attributed to the antigenic disparity of various actin forms in the tests; actin is mainly present as monomeric form (G-actin) in immunoblotting, whereas the polymeric form of actin (F-actin) is found in the skin prick 
test extract. An overall FASTA alignment revealed that $\operatorname{cod} \alpha$-actin and trout $\beta$-actin shared low sequence identity $(<25 \%)$ with BiP from hazel pollen (designated as Cor a 10) and a novel mutant allergen from timothy grass, respectively. However, the comparatively low degree of sequence identity suggests that these fish actin proteins are not very likely to be implicated as cross-reacting allergens with hazel or timothy grass pollen. Overall, the significance of fish actin as a fish allergen requires further clinical confirmation.

Spot no. 5 from cusk was identified as a desmin protein with $20-21 \%$ sequence identity with paramyosin. Desmin is a main component of the intermediate filaments that transversely connect individual myofibrils together at the Z-line [36, 37]. Paramoysin is a highly conserved protein among invertebrates that interacts with myosin and forms the core of the thick filaments of muscles $[38,39]$. The full-length FASTA search demonstrated that the sequence identities between desmin and paramyosin allergens from fish parasite and mite were sufficiently low that the potential for allergenic crossreactivity is likely minimal. Moreover, desmin as expressed in human and fish possess highly conserved sequences during evolution [40]. Thus, the allergenicity of cusk desmin requires additional clinical confirmation. No allergenicity is reported for desmin from other biological sources.

Spot no. 4 from cusk was identified as GAPDH, which is a key enzyme in the glycolytic pathway for energy production. Despite the lack of identity match between GAPDH and any of the existing allergens in the AllergenOnline database, a recent study revealed that a $36 \mathrm{kDa}$ allergen in pilchard, identified as GAPDH, was recognized by mice sensitized with raw pilchard extract and the sera from fish processing workers who 
had specific IgE against pilchard, suggesting that this novel allergen is likely to be important in occupational sensitization to fish [41]. In addition, a $41 \mathrm{kDa}$ IgE-reactive protein purified from the crude extracts of raw cod was identified to be homologous to APDH (or GAPDH) [26, 42]. The $41 \mathrm{kDa}$ protein was proposed to share low sequence similarity with the acidic residues of the calcium-binding domains in parvalbumin due to its recognition by an anti-parvalbumin monoclonal antibody. According to the study, 4 of 13 cod-allergic patients had specific IgE to human APDH. Additionally, IgE crossreactivity between APDH from human erythrocytes and cod muscle was detected in the IgE inhibiton-radioimmunoassay, whereas pork and chicken APDH showed no crossreactivity [26]. Although APDH is a well conserved protein in evolution between cod and human, the in vivo reactivity of anti-fish APDH IgE with human enzyme is unlikely to occur as the native APDH protein is sequestered in the cell [26].

Spot no. 3 from trout was identified as fast MLC 2 protein that shared $39-45 \%$ sequence identity with shrimp MLC allergen (Lit v 3 ) and tree pollen allergens (Cup a 4 and Jun o 2) in an 80-mers sliding window search. Similar to parvalbumin, these allergens are calcium-binding proteins that belong to the EF-hand superfamily [43-45]. Examples of calcium-binding allergens that possess variable EF-hand motifs include cockroach and shrimp MLC (Bla g 8, Lit v 3), cod parvalbumin (Gad m 1), shrimp sarcoplasmic calcium-binding proteins (Lit v 4), and cockroach troponin C (Bla g 6). Calcium-binding allergens have also been identified in plants, including tree pollens (Bet v 3, Bet v 4, Ole e 3, Ole e 8, Jun o 2), grass pollens (Cyn d 7, Phl p 7), and rapeseed (Bra n 1, Bra n 2, Bra r 1, Bra r 2) [46]. In general, we identified GAPDH and MLC proteins as potential novel fish allergens. However, it is questionable whether the degree of 
sequence identity with shrimp or tree pollen allergens would be sufficient to elicit crossreactivity. Further investigation is needed to establish the clinical relevance of these novel allergens.

Both spots no. 3 from cusk and pilchard were determined as proteins corresponding to enolase, while spot no. 4 from pilchard was identified as creatine kinase. The identification of enolase and creatine kinase as putative allergens agreed with a recent study that identified these proteins as potential allergens in blunt snout bream [27]. However, in contrast to our study, none of the 11 patients allergic to blunt snout bream in that study had IgE reactivity to parvalbumin from blunt snout bream according to 1-D and 2-DE immunoblotting [27]. Enolase (2-phospho-D-glycerate hydrolase) is a key glycolytic and gluconeogenic enzyme responsible for the reversible conversion of 2phospho-D-glycerate to phosphoenolpyruvate [47]. Enolase has been recognized as an important allergen of molds and latex and IgE cross-reactivity between these allergens has been demonstrated [47]. On the other hand, creatine kinase catalyzes the transfer of a high-energy phosphoryl group from ATP to creatine, yielding ADP and phosphocreatine and vice versa. Phosphocreatine is a form of metabolically inert phosphagens that serve as an intermediate storage and transport form of energy in cells with high rates of ATP turnover, such as muscle and brain [48]. This enzyme shows sequence homology to the arginine kinase allergen identified in shrimp (Lit v 2 and Pen $\mathrm{m}$ 2) and moth (Plo i 1). Arginine kinase and creatine kinase evolve from a common ancestor and share a similar metabolic role, although creatine kinase and phosphocreatine are present in vertebrates and some invertebrate species, while arginine kinase and phosphoarginine are found only in invertebrates and certain protozoa [48-50]. 
In conclusion, parvalbumin is identified as the cross-reacting allergen among cod, cusk, herring, pilchard, and trout. Fish muscle proteins other than parvalbumin that bound sera IgE from fish-allergic subjects were identified as $\alpha$ - and $\beta$-actin, desmin, GAPDH, fast MLC 2, enolase, and creatine kinase. Among these IgE-reactive novel proteins, only $\alpha$-actin and enolase were shown as likely to be cross-reactive with the same protein among fish species based upon their identification as $\operatorname{IgE}$-reactive proteins in more than one fish species. The actins and desmin seem unlikely possibilities as fish allergens because of the degree of sequence similarity to the same proteins in humans. Enolase and creatine kinase have previously been identified as IgE-binding proteins in blunt snout bream but we have now demonstrated the presence of enolase as an IgE-binding protein in pilchard and cusk and creatine kinase as an IgE-binding protein in pilchard. It should be noted however, that further studies are warranted to characterize these novel allergens at the molecular level using sera from a larger group of fish-allergic subjects and to confirm the clinical significance of these IgE-binding proteins as allergens using skin prick testing or basophil activation tests. Although parvalbumin remains as the major fish allergen, a diversity of other fish proteins are able to bind IgE from the sera of some fishallergic individuals. Further efforts to identify and evaluate these proteins are needed. The identification of allergens responsible for the species-specific and cross-reactive nature of fish allergy will facilitate further studies in the elucidation of IgE-binding epitopes and improve the diagnosis and therapy of fish allergy.

\section{ACKNOWLEDGEMENTS}


Financial support was provided by the Food Allergy Research and Resource Program at the University of Nebraska. Sera were obtained from Allergy, Asthma and Immunology Associates (Lincoln and Omaha, NE) and University Medical Center (Utrecht, The Netherlands). We would like to thank Richard Norland (Norland Products Inc.) for providing some of the fish samples, E. Pearce Smith (Eurofins GeneScan, Inc.) and Rakhi Panda (University of Nebraska) for technical assistance, and the National Jewish Health Mass Spectrometry facility for analysis of the samples. Funding for the ion trap mass spectrometer was provided by NCRR S10RR023703.

\section{REFERENCES}

[1] Kris-Etherton, P. M., Harris, W. S., Appel, L. J., Fish consumption, fish oil, omega3 fatty acids, and cardiovascular disease. Arterioscler. Thromb. Vasc. Biol. 2003, 23, e20-e30.

[2] Helbling, A., Haydel, R. Jr., McCants, M. L., Musmand, J. J. et al., Fish allergy: is cross-reactivity among fish species relevant? Double-blind placebo-controlled food challenge studies of fish allergic adults. Ann. Allergy Asthma Immunol. 1999, 83, $517-523$.

[3] Taylor, S. L., Kabourek, J. L., Hefle. S. L., Fish allergy: fish and products thereof. J. Food Sci. 2004, 69, 175-180.

[4] Yunginger, J. W., Sweeney, K. G., Sturner, W. Q., Giannandrea, L. A. et al., Fatal food-induced anaphylaxis. JAMA. 1988, 260, 1450-1452.

[5] Domínguez, C., Ojeda, I., Crespo, J. F., Pascual, C. et al., Allergic reactions following skin contact with fish. Allergy Asthma Proc. 1996, 17, 83-87. 
[6] Rodríguez, J., Reaño, M., Vives, R., Canto, C. et al., Occupational asthma caused by fish inhalation. Allergy 1997, 52, 866-869.

[7] de Martino, M., Novembre, E., Galli, L., de Marco, A., et al., Allergy to different fish species in cod-allergic children: in vivo and in vitro studies. J. Allergy Clin. Immunol. 1990, 86, 909-914.

[8] Hansen, T. K., Bindslev-Jensen, C., Skov, P. S., Poulsen, L. K., Codfish allergy in adults: IgE cross-reactivity among fish species. Ann. Allergy Asthma Immunol. 1997, 78, 187-194.

[9] Sicherer, S. H., Sampson, H. A., Food allergy. J. Allergy Clin. Immunol. 2010, 125, S116-S125.

[10] Aas, K. Studies of hypersensitivity of fish - allergological and serological differentiation between various species of fish. Int. Arch. Allergy Appl. Immunol. $1966,30,257-267$

[11] Bernhisel-Broadbent, J., Scanlon, S. M., Sampson, H. A., Fish hypersensitivity. I. in vitro and oral challenge results in fish-allergic patients. J. Allergy Clin. Immunol. 1992, 89, 730-737.

[12] Pascual, C. Y., Reche, M., Fianodor, A., Valbuena, T., et al., Fish allergy in childhood. Pediatr. Allergy Immunol. 2008, 19, 573-579.

[13] Elsayed, S., Aas, K., Isolation of purified allergens (cod) by isoelectric focusing. Int. Arch. Allergy Appl. Immunol. 1971, 40, 428-438.

[14] Elsayed, S., Apold, J., Immunochemical analysis of cod fish Allergen M: locations of the immunoglobulin binding sites as demonstrated by the native and synthetic peptides. Allergy 1983, 38, 449-459. 
[15] Untersmayr, E., Szalai, K., Riemer, A. B., Hemmer, W., et al., Mimitopes identify conformational epitopes on parvalbumin, the major fish allergen. Mol. Immunol. 2006, 43, 1454-1461.

[16] Yoshida, S., Ichimura, A., Shiomi, K., Elucidation of a major IgE epitopes of Pacific mackerel parvalbumin. Food Chem. 2008, 111, 857-861.

[17] Van Do, T., Elsayed, S., Florvaag, E., Hordvik, I., Endresen, C., Allergy to fish parvalbumins: studies on the cross-reactivity of allergens from 9 commonly consumed fish. J. Allergy Clin. Immunol. 2005, 116, 1314-1320.

[18] James, J. M., Helm, R. M., Burks, A. W., Lehrer, S. B., Comparison of pediatric and adult IgE antibody binding to fish proteins. Ann. Allergy Asthma Immunol. 1997, 79, 131-137.

[19] Hilger, C., Thill, T., Grigioni, F., Lehners, C., et al., IgE antibodies of fish allergic patients cross-react with frog parvalbumin. Allergy 2004, 59, 653-660.

[20] Lindstrøm, C. D., van Dô, T., Hordvik, I., Endresen, C., Elsayed, S., Cloning of two distinct cDNAs encoding parvalbumin, the major allergen of Atlantic salmon (Salmo salar). Scand. J. Immunol. 1996, 44, 335-344.

[21] Shiomi, K., Hayashi, S., Ishikawa, M., Shimakura, K., Nagashima, Y., Identification of parvalbumin as an allergen in horse mackerel. Fish. Sci. 1998, 64, $300-304$.

[22] Van Do, T., Hordvik, I., Endresen, C., Elsayed, S., Characterization of parvalbumin, the major allergen in Alaska Pollack and comparison with codfish Allergen M. Mol. Immunol. 2005, 42, 345-353. 
[23] Swoboda, I., Bugajska-Schretter, A., Verdino, P., Keller, W., et al., Recombinant carp parvalbumin, the major cross-reactivity fish allergen: a tool for diagnosis and therapy of fish allergy. J. Immunol. 2002, 168, 4576-4584.

[24] Hamada, Y., Tanaka, H., Ishizaki, S., Ishida, M., et al., Purification, reactivity with IgE and cDNA cloning of parvalbumin as the major allergen of mackerel. Food Chem. Toxicol. 2003, 41, 1149-1156.

[25] Hamada, Y., Nagashima, Y., Shiomi, K., Identification of collagen as a new fish allergen. Biosci. Biotechnol. Biochem. 2001, 65, 285-291.

[26] Das Dores, S., Chopin, C., Romano, A., Galland-Irmouli, A.-V., et al., IgE-binding and cross-reactivity of a new $41 \mathrm{kDa}$ allergen of codfish. Allergy 2002, 57(Suppl 72), 84-87.

[27] Liu, R., Krishnan, H. B., Xue, W., Liu, C., Characterization of allergens isolated from freshwater fish blunt snout bream (Megalobrama amblycephala). J. Agric. Food Chem. 2011, 59, 458-463.

[28] Lee, P. W., Nordlee, J. A., Koppelman, S. J., Baumert, J. L., Taylor, S. L., Screening of purified parvalbumins and muscle proteins of 25 fish species by human IgE immunoblotting. 2012, (submitted for publication).

[29] Lee, P. W., Nordlee, J. A., Koppelman, S. J., Baumert, J. L., Taylor, S. L., Evaluation and comparison of the species-specificity of 3 antiparvalbumin IgG antibodies. J. Agric. Food Chem. 2011, 59, 12309-12316.

[30] Mukherjee, A., Reisdorph, N., Guda, C., Pandey, S., Roy, S. K., Changes in ovarian protein expression during primordial follicle formation in the hamster. Mol. Cell Endrocrinol. 2012, 348, 87-94. 
[31] Perez-Gordo, M., Lin, J., Bardina, L., Pastor-Vargas, C., et al., Epitope mapping of Atlantic salmon major allergen by peptide microarray immunoassay. Int. Arch. Allergy Immunol. 2012, 157, 31-40.

[32] Restani, P., Fiocchi, A., Beretta, B., Velonà, T., et al., Meat allergy: III-proteins involved and cross-reactivity between different animal species. J. Am. Coll. Nutr. 1997, 16, 383-389.

[33] Hennessey, E. S., Drummond, D. R., Sparrow, J. C., Molecular genetics of actin function. Biochem. J. 1993, 291, 657-671.

[34] Kim, S., Karsi, A., Dunham, R. A., Liu, Z., The skeletal muscle a-actin gene of channel catfish (Ictalurus punctatus) and its association with piscine specific SINE elements. Gene 2000, 252, 173-181.

[35] Venkatesh, B., Tay, B. H., Elgar, G., Brenner, S., Isolation, characterization and evolution of nine pufferfish (Fugu rubripes) actin gene. J. Mol. Biol. 1996, 259, $655-665$.

[36] Verrez-Bagnis, V., Noel, J., Sautereau, C., Fleurence, J., Desmin degradation in postmortem fish muscle. J. Food Sci. 1999, 64, 240-242.

[37] Ashie, I. N. A., Simpson, B. K., Proteolysis in food myosystems - a review. J. Food Biochem. 1997, 21, 91-123.

[38] Pérez-Pérez, J., Fernández-Caldas, E., Marañón, F., Sastre, J. et al., Molecular cloning of paramyosin, a new allergen of Anisakis simplex. Int. Arch. Allergy Immunol. 2000, 123, 120-129. 
[39] Ramos, J. D. A., Nge, C., Wah, L. B., Yan, C. K., cDNA cloning and expression of Blo t 11, the Blomia tropicalis allergen homologous to paramyosin. Int. Arch. Allergy Immunol. 2001, 126, 286-293.

[40] Nelson, W. J., Traub, P., Intermediate $(10 \mathrm{~nm})$ filament proteins and the $\mathrm{Ca}^{2+}$ activated proteinase specific for vimentin and desmin in the cells from fish to man: an example of evolutionary conservation. J. Cell Sci. 1982, 57, 25-49.

[41] van der Ventel, M., Nieuwenhuizen, N. E., Kirstein, F., Hikuam, C., et al., Differential responses to natural and recombinant allergens in a murine model of fish allergy. Mol. Immunol. 2011, 48, 637-646.

[42] Galland, A. V., Dory, D., Pons, L., Chopin, C., et al., Purification of a 41 kDa codallergenic protein. J. Chromatrogr. B. Biomed. Sci. Appl. 1998, 706, 63-71.

[43] Ayuso, R., Grishina, G., Bardina, L., Carrillo, T., et al., Myosin light chain is a novel shrimp allergen, Lit v 3. J. Allergy Clin. Immunol. 2008, 122, 795-802.

[44] Pico de Coaña, Y., Parody, N., Fuertes, M. Á., Carnés, J., et al., Molecular cloning and characterization of Cup a 4, a new allergen from Cupressus arizonica. Biochem. Biophys. Res. Commun. 2010, 401, 451-457.

[45] Tinghino, R., Barletta, B., Palumbo, S., Afferni, C., et al., Molecular characterization of a cross-reactive Juniperus oxycedrus pollen allergen, Jun o 2: a novel calcium-binding allergen. J. Allergy Clin. Immunol. 1998, 101, 772-777.

[46] Valenta, R., Hayek, B., Seiberler, S., Bugajska-Schretter, A., et al., Calciumbinding allergens: from plants to man. Int. Arch. Allergy Immunol. 1998, 117, 160166. 
[47] Wagner, S., Breiteneder, H., Simon-Nobbe, B., Susani, M., et al., Hev b 9, an enolase and a new cross-reactive allergen from Hevea latex and molds. Purification, characterization, cloning and expression. Eur. J. Biochem. 2000, 267, 7006-7014.

[48] Wallimann, T., Wyss, M., Brdiczka, D., Nicolay, K., Eppenberger, H. M., Intracellular compartmentation, structure and function of creatine kinase isoenzymes in tissues with high and fluctuating energy demands: the 'phosphocreatine circuit' for cellular energy homeostasis. Biochem. J. 1992, 281, $21-40$

[49] García-Orozco, K. D., Aispuro-Hernández, E., Yepiz-Plascencia, G., Calderón-dela-Barca, A. M., Sotelo-Mundo, R. R. Molecular characterization of arginine kinase, an allergen from the shrimp Litopenaeus vannamei. Int. Arch. Allergy Immunol. 2007, 144, 23-28.

[50] Uda, K., Fujimoto, N., Akiyama, Y., Mizuta, Y., et al., Evolution of the arginine kinase gene family. Comp. Biochem. Physiol. Part D Genomics Proteomics. 2006, 1, 209-218. 


\section{FIGURE CAPTIONS}

Figure 1. Colloidal-stained 1-D SDS-PAGE profiles (lane 1) and the corresponding immunoblot analysis of cod (A), cusk (B), herring (C), pilchard (D), and trout (E) using individual serum from 7 fish-allergic subjects (lanes 2-8).

Figure 2. Colloidal-stained 2-DE profiles of cod (A1), cusk (B1), herring (C1), pilchard (D1), and trout (E1) and the corresponding immunoblot analysis of cod (A2), cusk (B2), herring (C2), pilchard (D2), and trout (E2) using pooled sera from 7 fish-allergic subjects. The IgE-reactive spots excised for further identification by LC-MS/MS are circled and numbered. 
Table 1. Clinical and serological characteristics of the fish-allergic subjects

\begin{tabular}{|c|c|c|c|c|c|}
\hline $\begin{array}{l}\text { Subject } \\
\text { no. }\end{array}$ & Gender & Age (y) & $\begin{array}{l}\text { sIgE to cod } \\
\left(\mathbf{k} \mathbf{U}_{\mathrm{A}} / \mathbf{L}\right)\end{array}$ & $\begin{array}{l}\text { SPT }^{\mathrm{a}} \text { to cod } \\
\text { (wheal } x \text { flare in } \mathrm{mm} \text { ) }\end{array}$ & Symptoms $^{\mathrm{c}}$ \\
\hline 1 & $\mathrm{~F}$ & 22 & 2.54 & $\mathrm{ND}^{\mathrm{b}}$ & OS, OAS \\
\hline 2 & M & 17 & 14.5 & ND & $\mathrm{A}, \mathrm{U}, \mathrm{OS}$ \\
\hline 3 & $\mathrm{~F}$ & 27 & 8.56 & $8 \times 38$ & $\mathrm{AP}, \mathrm{OAS}$ \\
\hline 4 & M & 26 & 51.3 & 11.75 (wheal) & LE, N, OAS \\
\hline 5 & M & 26 & 5.42 & $5 \times 27$ & OAS, DS \\
\hline 6 & $\mathrm{~F}$ & 42 & 13.6 & $28 \times 50$ & $\mathrm{P}, \mathrm{N}, \mathrm{V}, \mathrm{DI}$ \\
\hline 7 & $\mathrm{M}$ & 4.7 & 3.33 & 2.75 (wheal) & $\mathrm{U}, \mathrm{OAS}$ \\
\hline
\end{tabular}

${ }^{a}$ SPT, skin prick test.

${ }^{\mathrm{b}} \mathrm{ND}$, not determined.

${ }^{\text {c }}$ Symptoms (A, anaphylaxis; AP, abdominal pain; DI, diarrhea; DS, dysphagia; LE,

Laryngeal edema; N, nausea; OAS, oral allergy symptoms; OS, oropharyngeal swelling;

P, pruritis; U, urticaria; V, vomiting). 
Table 2. Identification of IgE-reactive spots excised from 2-DE by LC-MS/MS analysis

\begin{tabular}{|c|c|c|c|c|c|c|c|}
\hline \multirow{2}{*}{$\begin{array}{l}\text { Fish, } \\
\text { Spot no. }\end{array}$} & \multirow[t]{2}{*}{ Protein / Species / Accession no. } & \multicolumn{2}{|c|}{ Theoretical } & \multicolumn{2}{|c|}{ Experimental } & \multicolumn{2}{|c|}{ MS/MS analysis } \\
\hline & & $\begin{array}{c}M_{\mathrm{r}} \\
(\mathrm{kDa})\end{array}$ & $\mathrm{p} I$ & $\begin{array}{c}M_{\mathrm{r}} \\
(\mathrm{kDa})\end{array}$ & $\begin{array}{c}\mathrm{p} I \\
\text { range }\end{array}$ & $\begin{array}{c}\text { Coverage } \\
(\%)\end{array}$ & Score \\
\hline Cod, 1 & $\begin{array}{l}\text { Parvalbumin beta / Gadus morhua / } \\
\text { AAK63086 }\end{array}$ & 11.5 & 4.56 & 10 & $4.0-4.5$ & 60 & 123.92 \\
\hline Cod, 2 & $\begin{array}{l}\text { Fast skeletal muscle alpha-actin / Gadus } \\
\text { morhua / AAM } 21702\end{array}$ & 42.0 & 5.23 & 47 & $5.5-5.9$ & 5 & 23.57 \\
\hline Cusk, 1 & $\begin{array}{l}\text { Parvalbumin / Hypomesus transpacificus / } \\
\text { ACP30426 }\end{array}$ & 11.6 & 4.43 & 10 & $4.0-4.5$ & 17 & 23.16 \\
\hline Cusk, 2 & $\begin{array}{l}\text { Parvalbumin beta, Gad m } 1 \text { / Gadus } \\
\text { morhua / Q90YK9 }\end{array}$ & 11.6 & 4.58 & 12 & $4.0-5.0$ & 28 & 96.05 \\
\hline Cusk, 3 & $\begin{array}{l}\text { Unnamed protein / Tetraodon nigroviridis } \\
\text { / CAF89801 }\end{array}$ & 47.1 & 5.99 & 49 & $5.5-5.9$ & 22 & 154.65 \\
\hline Cusk, 4 & $\begin{array}{l}\text { Glyceraldehyde 3-phosphate } \\
\text { dehydrogenase / Gadus morhua / } \\
\text { AAL05892 }\end{array}$ & 36.1 & 7.73 & 36 & $5.1-5.6$ & 26 & 127.74 \\
\hline Cusk, 5 & $\begin{array}{l}\text { Unnamed protein / Tetraodon nigroviridis } \\
\text { / CAG09263 }\end{array}$ & 77.7 & 5.57 & 57 & $5.1-5.6$ & 8 & 64.33 \\
\hline Herring, 1 & $\begin{array}{l}\text { Parvalbumin / Clupea harengus / } \\
\text { CAQ72970 }\end{array}$ & 11.7 & 4.98 & 12 & $4.0-5.0$ & 69 & 229.09 \\
\hline Herring, 2 & $\begin{array}{l}\text { Alpha actin / Clupea harengus / } \\
\text { ABP49171 }\end{array}$ & 42.0 & 5.18 & 52 & $4.5-5.1$ & 38 & 179.9 \\
\hline Herring, 3 & $\begin{array}{l}\text { Alpha actin / Clupea harengus / } \\
\text { ABP49171 }\end{array}$ & 42.0 & 5.18 & 56 & $5.1-5.5$ & 31 & 187.61 \\
\hline Herring, 4 & $\begin{array}{l}\text { Alpha actin / Clupea harengus / } \\
\text { ABP } 49171\end{array}$ & 42.0 & 5.18 & 53 & $5.1-5.5$ & 15 & 84.6 \\
\hline Herring, 5 & $\begin{array}{l}\text { Alpha actin / Clupea harengus / } \\
\text { ABP49171 }\end{array}$ & 42.0 & 5.18 & 45 & $5.1-5.5$ & 46 & 227.2 \\
\hline Herring, 6 & $\begin{array}{l}\text { Alpha actin / Clupea harengus / } \\
\text { ABP49171 }\end{array}$ & 42.0 & 5.18 & 38 & $5.1-5.5$ & 9 & 46.37 \\
\hline Pilchard, 1 & $\begin{array}{l}\text { Parvalbumin / Clupea harengus / } \\
\text { CAQ72972 }\end{array}$ & 11.8 & 5.16 & 10 & $4.5-5.0$ & 8 & 12.64 \\
\hline Pilchard, 2 & $\begin{array}{l}\text { Parvalbumin / Sardinop sagax / } \\
\text { CAQ68366 }\end{array}$ & 11.9 & 6.07 & 11 & $4.5-5.5$ & 17 & 40.33 \\
\hline Pilchard, 3 & $\begin{array}{l}\text { Enolase } 3 \text { / Xenopus laevis / } \\
\text { NP_001080346 }\end{array}$ & 47.4 & 6.44 & 45 & $5.9-6.6$ & 15 & 113.46 \\
\hline Pilchard, 4 & $\begin{array}{l}\text { Creatine kinase / Ictalurus punctatus / } \\
\text { AAO25755 }\end{array}$ & 42.8 & 6.32 & 41 & $5.9-6.6$ & 19 & 147.31 \\
\hline Trout, 1 & $\begin{array}{l}\text { Parvalbumin-2 / Oncorhynchus mykiss / } \\
\text { NP_001182340 }\end{array}$ & 11.4 & 4.41 & 10 & $4.0-4.5$ & 41 & 38.7 \\
\hline Trout, 2 & $\begin{array}{l}\text { Parvalbumin isoform 1d / Oncorhynchus } \\
\text { mykiss / NP_001182339 }\end{array}$ & 11.9 & 5.09 & 11 & $4.5-5.0$ & 47 & 80.81 \\
\hline Trout, 3 & $\begin{array}{l}\text { Fast myosin light chain } 2 \text { / Oncorhynchus } \\
\text { mykiss / NP_001118151 }\end{array}$ & 18.9 & 4.66 & 17 & $4.5-5.0$ & 51 & 166.04 \\
\hline Trout, 4 & $\begin{array}{l}\text { Actin beta / Oncorhynchus mykiss / } \\
\text { NP_001117707 }\end{array}$ & 41.8 & 5.30 & 67 & $5.5-5.7$ & 9 & 54.52 \\
\hline
\end{tabular}


Table 3. Summary of peptides identified for IgE-reactive spots by LC-MS/MS analysis

\begin{tabular}{|c|c|c|}
\hline $\begin{array}{l}\text { Fish, } \\
\text { Spot no. }\end{array}$ & Protein / Species / Accession no. & Position / Sequence \\
\hline Cod, 1 & $\begin{array}{l}\text { Parvalbumin beta / Gadus morhua / } \\
\text { AAK63086 }\end{array}$ & $\begin{array}{l}18 \text { / (K)ACEAAESFSYK(A) } \\
47 \text { / (K)AFFVIDQDK(S) } \\
56 \text { / (K)SGFIEEDELK(L) } \\
66 \text { / (K)LFLQVFK(A) } \\
77 \text { / (R)ALTDAETK(A) } \\
89 \text { / (K)AGDSDGDGAIGVDEWAVLVK(A) }\end{array}$ \\
\hline Cod, 2 & $\begin{array}{l}\text { Fast skeletal muscle alpha-actin / Gadus } \\
\text { morhua / AAM } 21702\end{array}$ & $\begin{array}{l}21 /(\mathrm{K}) \operatorname{AGFAGDDAPR}(\mathrm{A}) \\
31 /(\mathrm{R}) A \operatorname{VFPSIVGRPR}(\mathrm{H})\end{array}$ \\
\hline Cusk, 1 & $\begin{array}{l}\text { Parvalbumin / Hypomesus transpacificus / } \\
\text { ACP30426 }\end{array}$ & 47 / (K)AFFIIDQDKSGFIEEDELK(L) \\
\hline Cusk, 2 & $\begin{array}{l}\text { Parvalbumin beta, Gad m } 1 \text { / Gadus } \\
\text { morhua / Q90YK9 }\end{array}$ & $\begin{array}{l}46 \text { / (K)KVFEIIDQDKSDFVEEDELK(L) } \\
47 \text { / (K)VFEIIDQDK(S) } \\
47 \text { / (K)AFFVIDQDK(S) } \\
47 \text { / (K)VFEIIDQDKSDFVEEDELK(L) } \\
56 \text { / (K)SDFVEEDELK(L) } \\
66 \text { / (K)LFLQNFSAGAR(A) }\end{array}$ \\
\hline Cusk, 3 & $\begin{array}{l}\text { Unnamed protein / Tetraodon nigroviridis } \\
\text { / CAF89801 }\end{array}$ & $\begin{array}{l}10 \text { / (R)EILDSRGNPTVEVDLWTAK(G) } \\
16 \text { / (R)GNPTVEVDLWTAK(G) } \\
42 \text { / (K)NFSVVDQEK(I) } \\
90 \text { / (K)IDKFmLELDGTENK(S) } \\
163 \text { / (K)LAmQEFmILPVGAANFHEAMR(I) } \\
184 \text { / (R)IGAEVYHNLK(S) } \\
200 \text { / (K)YGKDATNVGDEGGFAPNILENNEALELLK(S) } \\
203 \text { / (K)DATNVGDEGGFAPNILENNEALELLK(S) } \\
234 \text { / (K)AGYPDKIIIGMDVAASEFYR(S) } \\
240 \text { / (K)IIGGDVAASEFYR(S) } \\
264 \text { / (K)DATNVGDEGGFAPNILENKEALELLK(S) } \\
331 \text { / (R)YITPDQLADLYK(S) }\end{array}$ \\
\hline Cusk, 4 & $\begin{array}{l}\text { Glyceraldehyde 3-phosphate } \\
\text { dehydrogenase / Gadus morhua / } \\
\text { AAL05892 }\end{array}$ & $\begin{array}{l}161 \text { / (K)VIHDNFGIVEGLmSTVHAITATQK(T) } \\
196 \text { / (R)DGRGASQNIIPASTGAAK(A) } \\
199 \text { / (R)GASQNIIPASTGAAK(A) } \\
233 \text { / (R)VPTPNVSVVDLTVR(L) } \\
233 \text { / (R)VPTPNVSVVDLTVRLEKPAK(Y) } \\
308 \text { / (K)LVTWYDNEFGYSNR(V) } \\
322 \text { / (R)VIDLmAHMSCKE(-) }\end{array}$ \\
\hline Cusk, 5 & $\begin{array}{l}\text { Unnamed protein / Tetraodon nigroviridis } \\
\text { / CAG09263 }\end{array}$ & $\begin{array}{l}56 \text { / (R)MQYEGIAAK(N) } \\
289 \text { / (R)TYSGEKLDFNLADAmNQDFLNTR(T) } \\
312 \text { / (R)TNEKAELQHLNDR(F) } \\
420 \text { / (R)ADVDNATLAR(L) }\end{array}$ \\
\hline Herring, 1 & $\begin{array}{l}\text { Parvalbumin / Clupea harengus / } \\
\text { CAQ72970 }\end{array}$ & $\begin{array}{l}9 \text { / (K)GADIDAALK(A) } \\
9 \text { / (K)GADIDAALKACEAK(D) } \\
9 \text { / (K)GADIDAALKACEAKDSFK(H) } \\
23 \text { / (K)DSFKHKDFFAK(I) } \\
27 \text { / (K)HKDFFAK(I) } \\
34 \text { / (K)IGLATK(S) } \\
40 \text { / (K)SAADLKK(A) } \\
47 \text { / (K)AFEIIDQDK(S) } \\
47 \text { / (K)AFEIIDQDKSGFIEEEELK(L) }\end{array}$ \\
\hline
\end{tabular}




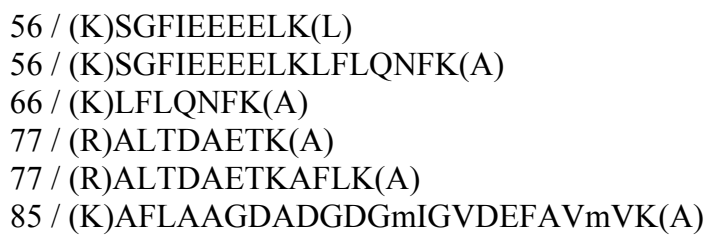

$56 /(\mathrm{K})$ SGFIEEEELK(L)

$56 /$ (K)SGFIEEEELKLFLQNFK(A)

$66 /(\mathrm{K})$ LFLQNFK(A)

77 / (R)ALTDAETK(A)

77 / (R)ALTDAETKAFLK(A)

85 / (K)AFLAAGDADGDGmIGVDEFAVmVK(A)

Herring, 2 Alpha actin / Clupea harengus / ABP49171

Herring, 3 Alpha actin / Clupea harengus / ABP49171

Herring, 4 Alpha actin / Clupea harengus / ABP49171

Herring, 5 Alpha actin / Clupea harengus / ABP49171

Herring, 6 Alpha actin / Clupea harengus / ABP49171

Pilchard, 1 Parvalbumin / Clupea harengus / CAQ72972

Pilchard, 2 Parvalbumin / Sardinop sagax /
21 / (K)AGFAGDDAPR(A)

31 / (R)AVFPSIVGRPR(H)

53 / (K)DSYVGDEAQSK(R)

53 / (K)DSYVGDEAQSKR(G)

150 / (R)TTGIVLDAGDGVTHNVPVYEGYALPHAImR(L)

$186 /$ (R)DLTDYLmK(I)

199 / (R)GYSFVTTAER(E)

218 / (K)LCYVALDFENEmATAASSSSLEK(S)

$241 /$ (K)SYELPDGQVITIGNER(F)

318 / (K)EITALAPSTmK(I)

362 / (K)DEYEEAGPSIVHR(K)

$21 /$ (K)AGFAGDDAPR(A)

$31 /$ (R)AVFPSIVGRPR(H)

53 / (K)DSYVGDEAQSKR(G)

$180 /$ (R)LDLAGRDLTDYLmK(I)

186 / (R)DLTDYLmK(I)

199 / (R)GYSFVTTAER(E)

218 / (K)LCYVALDFENEmATAASSSSLEK(S)

$241 /$ (K)SYELPDGQVITIGNER(F)

318 / (K)EITALAPSTmK(I)

362 / (K)DEYEEAGPSIVHR(K)

$21 /$ (K)AGFAGDDAPR(A)

$31 /$ (R)AVFPSIVGRPR(H)

$199 /$ (R)GYSFVTTAER(E)

$241 /$ (K)SYELPDGQVITIGNER(F)

318 / (K)EITALAPSTmK(I)

$21 /$ (K)AGFAGDDAPR(A)

$31 /$ (R)AVFPSIVGRPR(H)

42 / (R)HQGVmVGmGQK(D)

53 / (K)DSYVGDEAQSKR(G)

64 / (K)RGILTLK(Y)

150 / (R)TTGIVLDAGDGVTHNVPVYEGYALPHAImR(L)

$180 /$ (R)LDLAGR(D)

186 / (R)DLTDYLmK(I)

199 / (R)GYSFVTTAER(E)

218 / (K)LCYVALDFENEmATAASSSSLEK(S)

$241 /$ (K)SYELPDGQVITIGNER(F)

287 / (K)CDIDIRK(D)

287 / (K)CDIDIR(K)

318 / (K)EITALAPSTmK(I)

362 / (K)DEYEEAGPSIVHR(K)

199 / (R)GYSFVTTAER(E)

$241 /$ (K)SYELPDGQVITIGNER(F)

318 / (K)EITALAPSTmK(I)

47 / (K)AFEIIDQDK(S)

47 / (K)AFAIIDQDKSGFIEEEELK(L) 


\section{CAQ68366}

Pilchard, 3 Enolase 3 / Xenopus laevis /

NP_001080346

Pilchard, 4 Creatine kinase / Ictalurus punctatus / AAO25755

Trout, 1 Parvalbumin-2 / Oncorhynchus mykiss / NP_001182340

Trout, 2 Parvalbumin isoform 1d / Oncorhynchus mykiss / NP_001182339

Trout, 3 Fast myosin light chain 2 / Oncorhynchus mykiss / NP_001118151
56 / (K)SGFIEEEELK(L)

$16 /$ (R)GNPTVEVDLYTAK(G)

65 / (K)AVDHVNKDIAPK(L)

82 / (K)FSVVEQEKIDK(F)

106 / (K)FGANAILGVSLAVCK(A)

163 / (K)LAmQEFmILPVGASNFHEAmR(I)

163 / (K)LAmQEFmILPVGASNFHEAMR(I)

163 / (K)LAMQEFmILPVGASNFHEAmR(I)

163 / (K)LAMQEFmILPVGASNFHEAMR(I)

184 / (R)IGAEVYHNLK(A)

203 / (K)DATNVGDEGGFAPNILENKEALELLK(T)

234 / (K)AGYPDKIIIGMDVAASEFYR(S)

$240 /(\mathrm{K}) \mathrm{IIIGMDVAASEFYR(S)}$

240 / (K)IIIGMDVAASEFYR(S)

254 / (R)GGKYDLDFKSPDDPAR(H)

257 / (K)YDLDFKSPDDPAR(H)

344 / (K)VNQIGSVTESIQACK(L)

359 / (K)mAQSAGWGVmVSHR(S)

359 / (K)mAQSAGWGVMVSHR(S)

359 / (K)MAQSAGWGVMVSHR(S)

413 / (R)IEEELGDKAK(F)

413 / (R)IEEELGDK(A)

87 / (K)DLLDPIISDR(H)

87 / (K)DLFDPIISDR $(\mathrm{H})$

$105 /$ (K)HSTDLNFENLK(G)

108 / (K)TDLNFENLK(G)

$139 /$ (K)GYTLPPHNSR(G)

139 / (K)GYALPPHNSR(A)

156 / (K)LSIEALASLDGEFK(G)

157 / (K)LSVEALNSLDGEFKGK(Y)

157 / (K)LSVEALNSLDGEFK(G)

320 / (K)RGTGGVDTASVGGVFDISNADR(I)

321 / (R)GTGGVDTASVGGVFDISNADR(I)

341 / (R)LGSSEVAQVQMVVDGVK(L)

364 / (K)KLEKGESIDDmIPAQK(C)

366 / (K)KLEKGEAIDSmIPAQK(-)

366 / (K)KLEKGEAIDSMIPAQK(-)

368 / (K)GESIDDmIPAQK(C)

370 / (K)GEAIDSmIPAQK(-)

46 / (K)AFYVIDQDK(S)

$65 /(\mathrm{K})$ LFLQNFSASAR(A)

84 / (K)AFLADGDKDGDGmIGVDEFAAmIKG(-)

$21 /$ (K)AADSFNFK(T)

29 / (K)TFFHTIGFASK(S)

$50 /(\mathrm{K})$ VIDQDASGFIEVEELK(L)

$66 /(\mathrm{K})$ LFLQNFCPK(A)

77 / (R)VLTDAETK(A)

10 / (R)GAAAEGGSSNVFSmFEQSQIQEYK(E)

50 / (K)DDLRDVLASmGQLNVKNEELEAmVK(E)

54 / (R)DVLASmGQLNVK(N)

54 / (R)DVLASmGQLNVKNEELEAmVK(E)

$66 /(\mathrm{K}) \mathrm{NEELEAmVK}(\mathrm{E})$

108 / (K)VLDPDATGFIKK(D)

$108 /(\mathrm{K})$ VLDPDATGFIK(K) 
$120 /$ (K)DFLQELLTTQCDR(F)

157 / (K)QICYVITHGEEKEE(-)

Trout, 4 Actin beta / Oncorhynchus mykiss / NP_001117707
19 / (K)AGFAGDDAPR(A)

29 / (R)AVFPSIVGRPR(H) 239 / (K)SYELPDGQVITIGNER(F) 
Table 4. Sequence homology shared between IgE-reactive proteins identified by LCMS/MS and known allergens, as determined by FASTA search

\begin{tabular}{|c|c|c|c|c|c|}
\hline \multirow{2}{*}{$\begin{array}{l}\text { Fish, } \\
\text { Spot no. }\end{array}$} & \multirow{2}{*}{$\begin{array}{l}\text { LC-MS/MS } \\
\text { Protein }\end{array}$} & \multicolumn{4}{|c|}{ FASTA search $^{\mathrm{a}}$} \\
\hline & & Protein / Species / Accession no. / Allergen & $\begin{array}{l}\text { Full-length } \\
\text { identity }(\%)\end{array}$ & $\begin{array}{c}\text { 80-mers } \\
\text { identity }(\%)\end{array}$ & $\begin{array}{l}\text { EF- } \\
\text { hand }^{\mathrm{b}}\end{array}$ \\
\hline Cod, 2 & $\begin{array}{l}\text { Fast skeletal } \\
\text { muscle alpha- } \\
\text { actin }\end{array}$ & $\begin{array}{l}\text { Putative luminal binding protein / Corylus } \\
\text { avellana / CAC14168 / Hazel pollen } \\
\text { allergen }\end{array}$ & 23.2 & No match & No \\
\hline \multirow[t]{3}{*}{ Cusk, 3} & $\begin{array}{l}\text { Unnamed } \\
\text { protein }\end{array}$ & $\begin{array}{l}\text { Enolase } 1 \text { / Hevea brasiliensis / Q9LEJ0 / } \\
\text { Hev b 9, latex allergen }\end{array}$ & 69.0 & 86.3 & No \\
\hline & & $\begin{array}{l}\text { Enolase } 2 \text { / Hevea brasiliensis / Q9LEI9 / } \\
\text { Hev b 9, latex allergen }\end{array}$ & 68.8 & 86.3 & No \\
\hline & & $\begin{array}{l}\text { Enolase } 1 \text { / Candida albicans SC5314 / } \\
\text { P30575 / Fungal allergen }\end{array}$ & 66.1 & 76.2 & No \\
\hline Cusk, 4 & $\begin{array}{l}\text { Glyceraldehyde } \\
\text { 3-phosphate } \\
\text { dehydrogenase }\end{array}$ & No match & No match & No match & No \\
\hline \multirow[t]{3}{*}{ Cusk, 5} & $\begin{array}{l}\text { Unnamed } \\
\text { protein }\end{array}$ & $\begin{array}{l}\text { Paramyosin / Anisakis simplex / Q9NJA9 / } \\
\text { Ani s 2, fish parasite allergen }\end{array}$ & 20.7 & NM & No \\
\hline & & $\begin{array}{l}\text { Paramyosin allergen / Blomia tropicalis / } \\
\text { AAM83103 / Mite allergen }\end{array}$ & 21.2 & $\mathrm{NM}$ & No \\
\hline & & $\begin{array}{l}\text { Paramyosin isoform, partial / Anisaki } \\
\text { simplex / AAF75225 / Fish parasite allergen }\end{array}$ & 20.5 & 37.0 & No \\
\hline Herring, 2-6 & Alpha actin & No match & No match & No match & No \\
\hline \multirow[t]{3}{*}{ Pilchard, 3} & Enolase 3 & $\begin{array}{l}\text { Enolase } 1 \text { / Hevea brasiliensis / Q9LEJ0 / } \\
\text { Hev b 9, latex allergen }\end{array}$ & 70.4 & 87.5 & No \\
\hline & & $\begin{array}{l}\text { Enolase } 2 \text { / Hevea brasiliensis / Q9LEI9 / } \\
\text { Hev b 9, latex allergen }\end{array}$ & 70.1 & 87.5 & No \\
\hline & & $\begin{array}{l}\text { Enolase } 1 \text { / Candida albicans SC5314 / } \\
\text { P30575/ Fungal allergen }\end{array}$ & 66.3 & 78.7 & No \\
\hline \multirow[t]{3}{*}{ Pilchard, 4} & Creatine kinase & $\begin{array}{l}\text { Arginine kinase / Litopenaeus vannamei / } \\
\text { ABI98020 / Crustacean allergen }\end{array}$ & 46.3 & 65.0 & No \\
\hline & & $\begin{array}{l}\text { Allergen Pen m } 2 \text { / Penaeus monodon / } \\
\text { AAO15713 / Crustacean allergen }\end{array}$ & 46.0 & 65.0 & No \\
\hline & & $\begin{array}{l}\text { Arginine kinase / Plodia interpunctella / } \\
\text { CAC85911 / Moth allergen }\end{array}$ & 46.3 & 61.3 & No \\
\hline \multirow[t]{3}{*}{ Trout, 3} & $\begin{array}{l}\text { Fast myosin } \\
\text { light chain } 2\end{array}$ & $\begin{array}{l}\text { Lit v } 3 \text { allergen myosin light chain / } \\
\text { Litopenaeus vannamei / ACC76803 / } \\
\text { Crustacean allergen }\end{array}$ & 33.5 & 42.1 & Yes \\
\hline & & $\begin{array}{l}\text { Putative Cup a } 4 \text { allergen / Cupressus } \\
\text { arizonica / ACY01951 / Cypress pollen } \\
\text { allergen }\end{array}$ & 33.1 & 40.0 & Yes \\
\hline & & $\begin{array}{l}\text { Polcalcin Jun o } 2 \text { / Juniperus oxycedrus / } \\
\text { O64943 / Tree pollen allergen }\end{array}$ & 35.4 & 38.8 & Yes \\
\hline Trout, 4 & Actin beta & $\begin{array}{l}\text { Unnamed protein product, partial / Phleum } \\
\text { pratetense / CAD } 38397 \text { / Novel mutant } \\
\text { allergen }\end{array}$ & 24.7 & No match & No \\
\hline
\end{tabular}

${ }^{\mathrm{a}}$ Only the first 3 proteins with the highest $\mathrm{Z}$ score were listed.

${ }^{\mathrm{b}}$ Protein with EF-hand domains. 
A

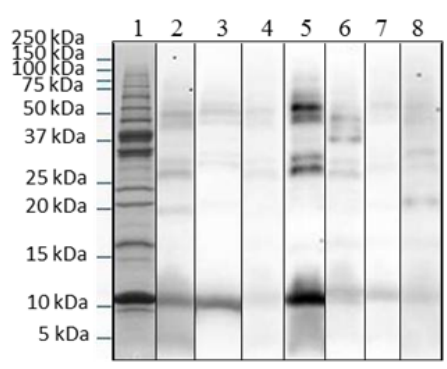

B

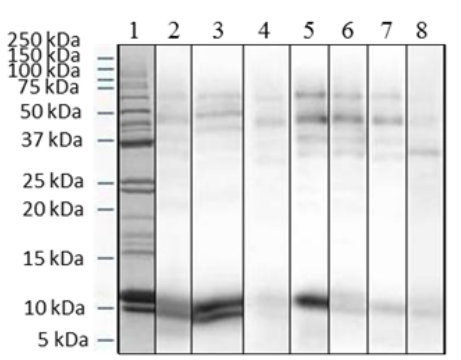

C

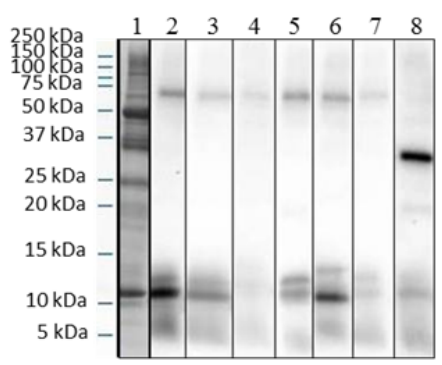

D

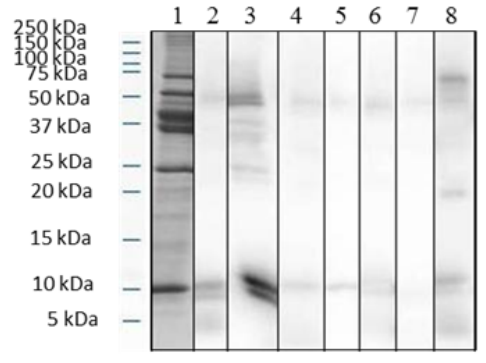

E

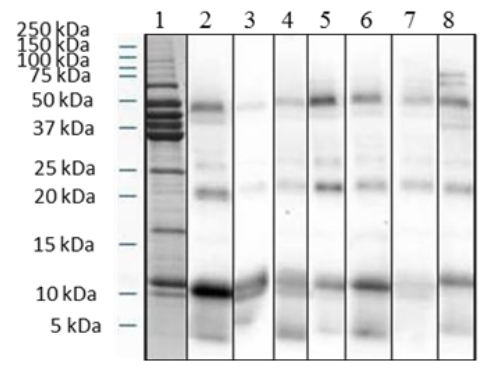

Figure 1. 


\section{A1}

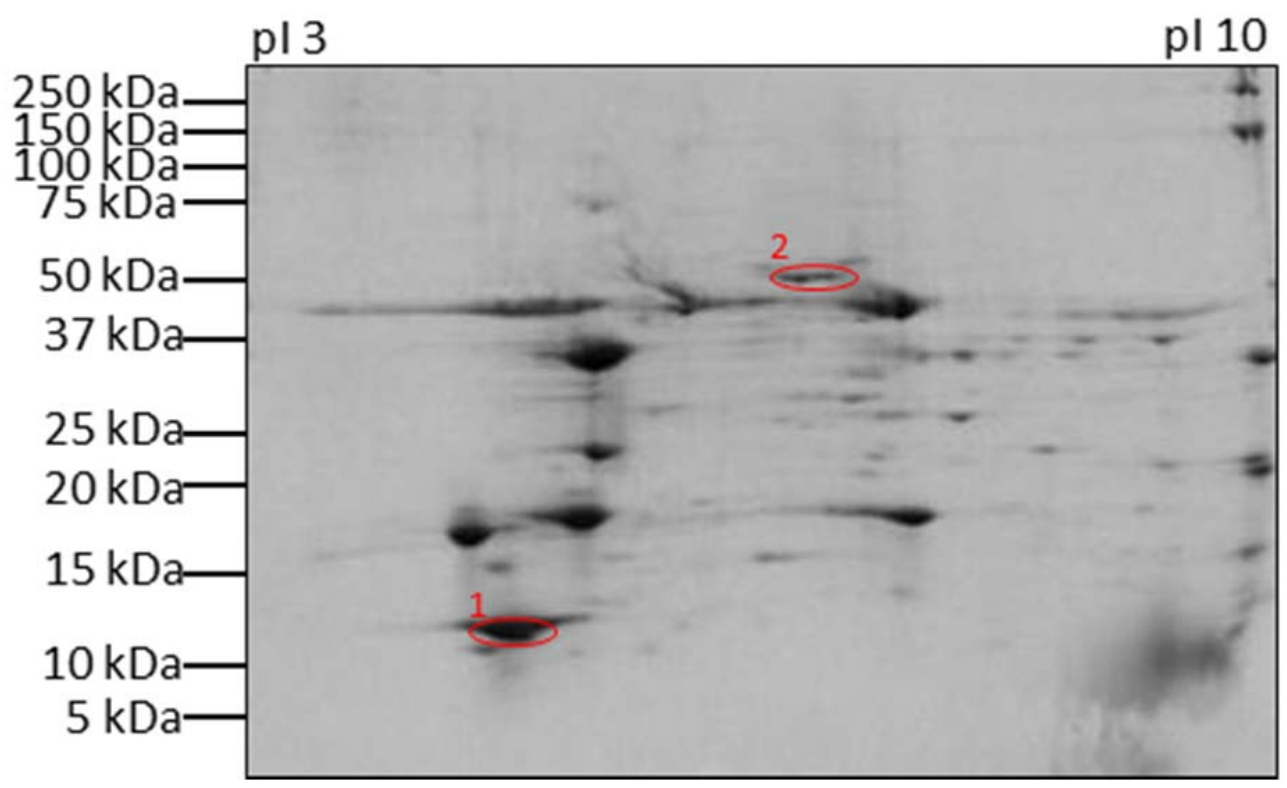

A2

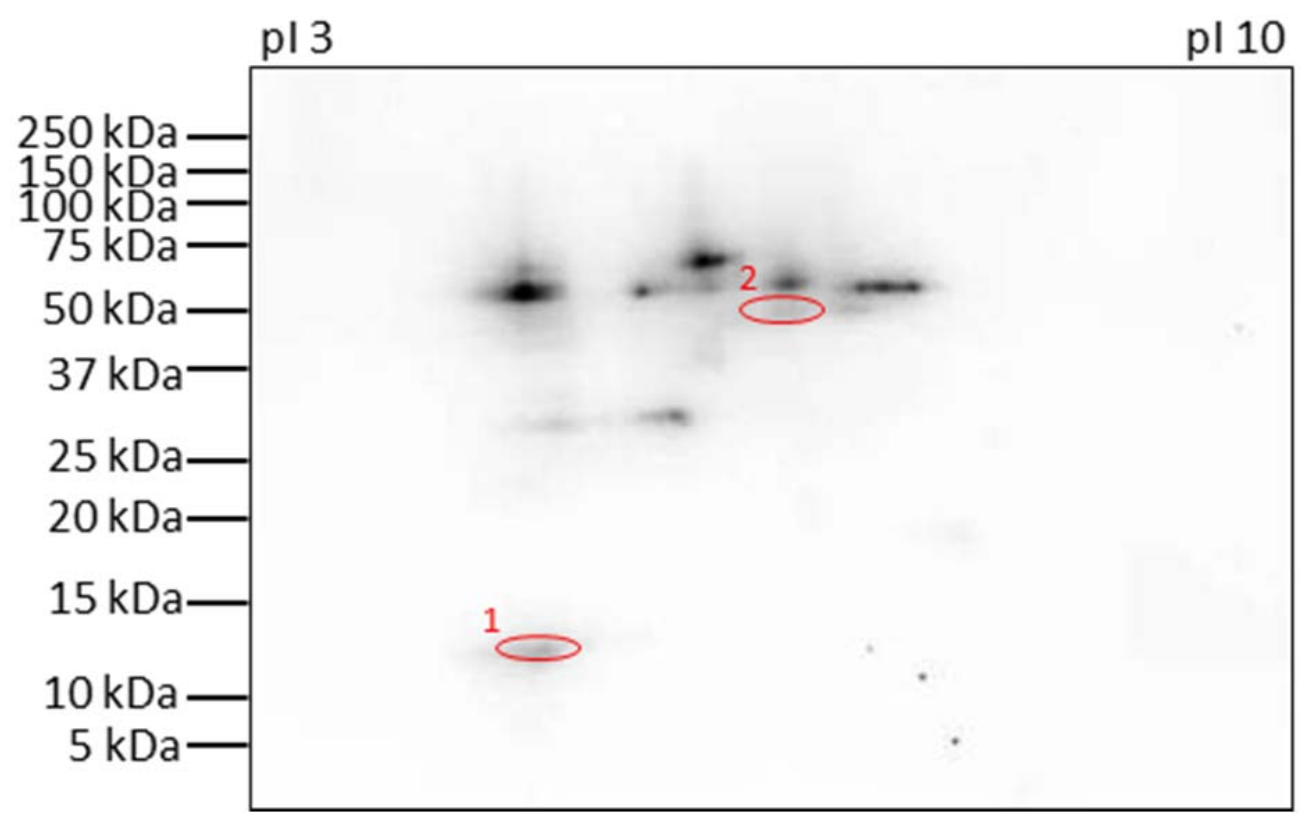




\section{B1}

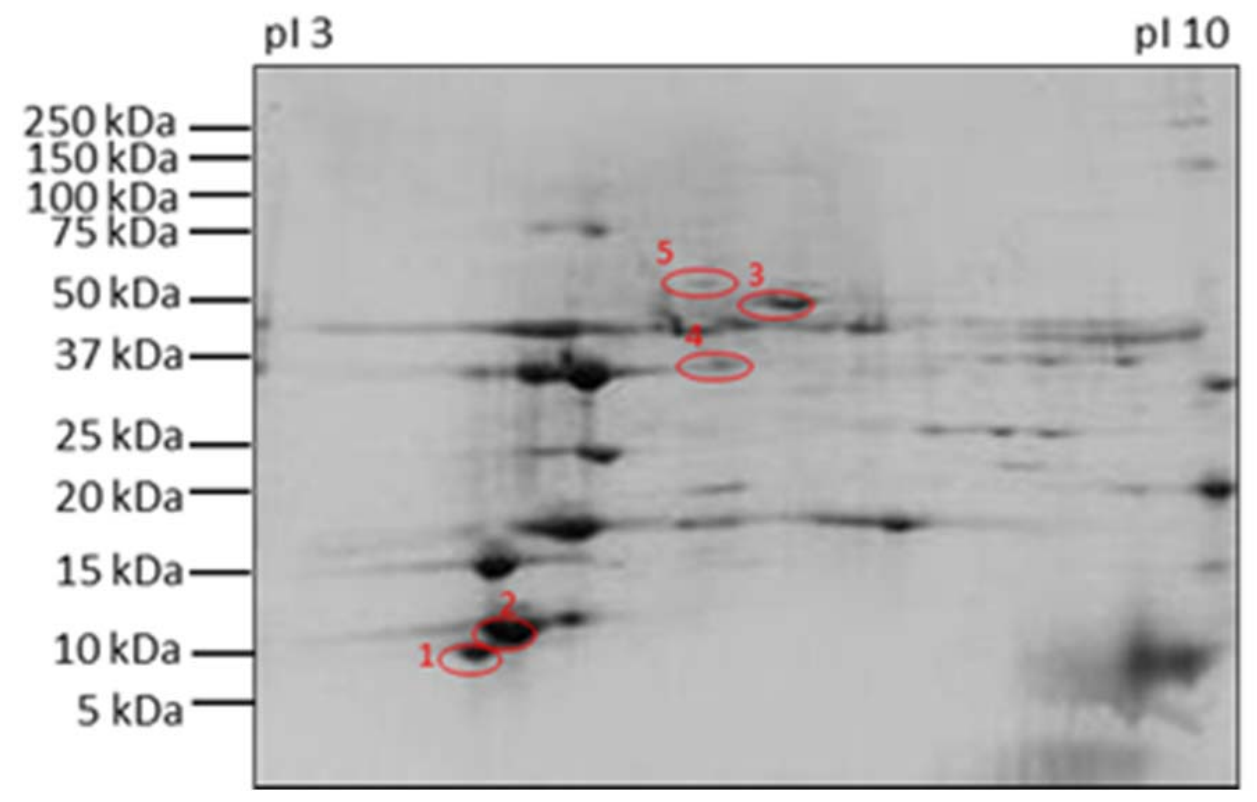

\section{B2}

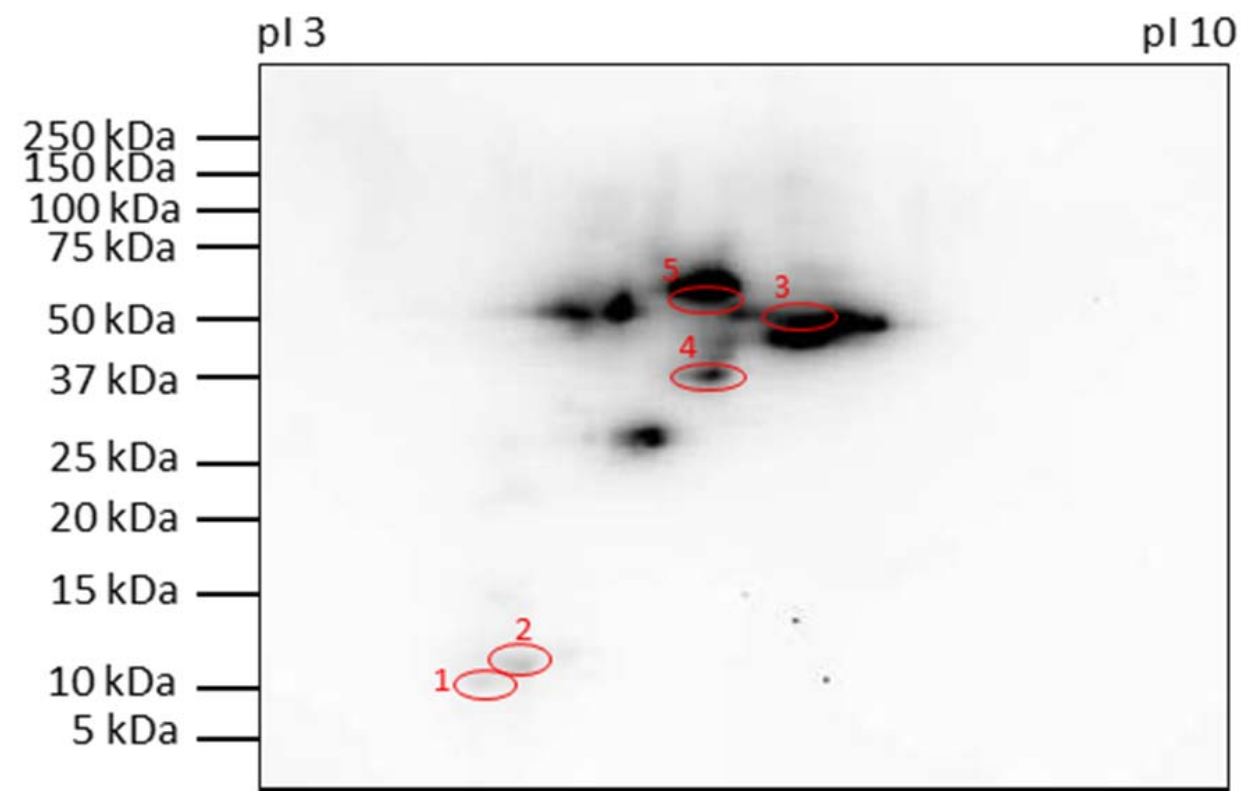




\section{C1}

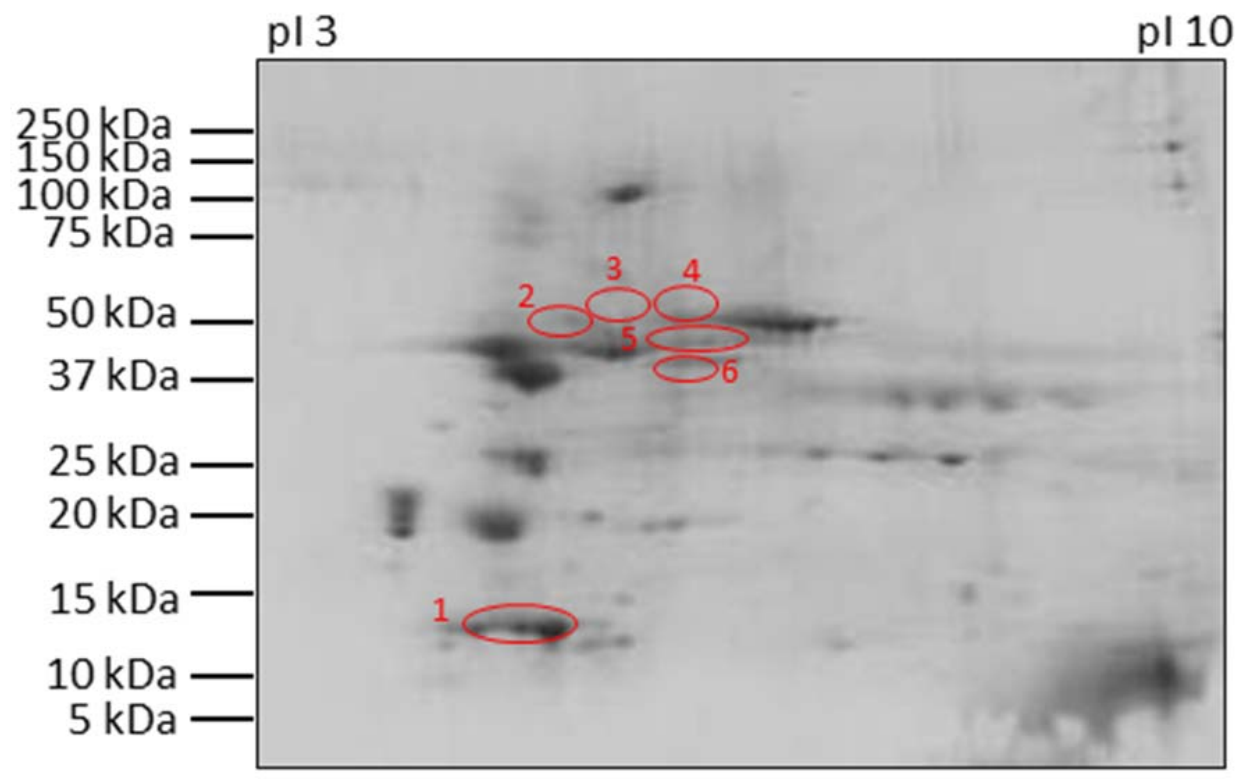

C2

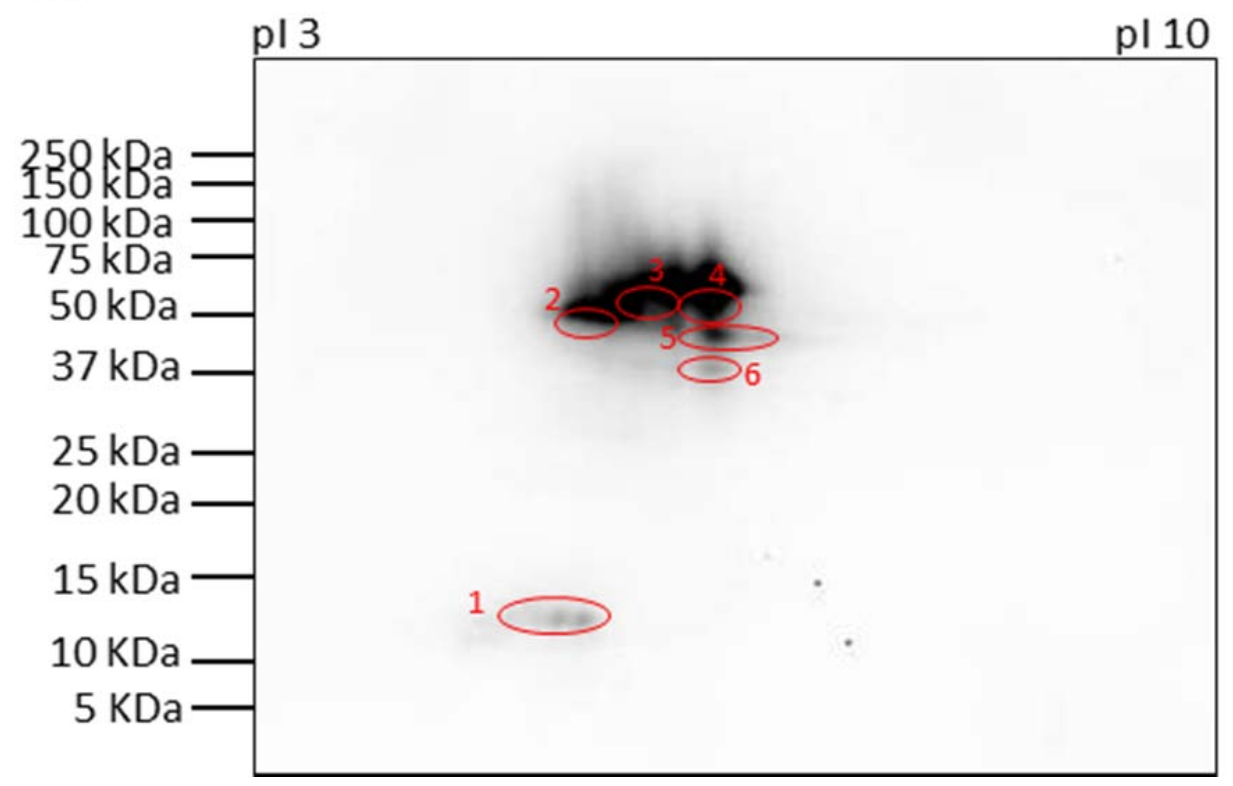




\section{D1}

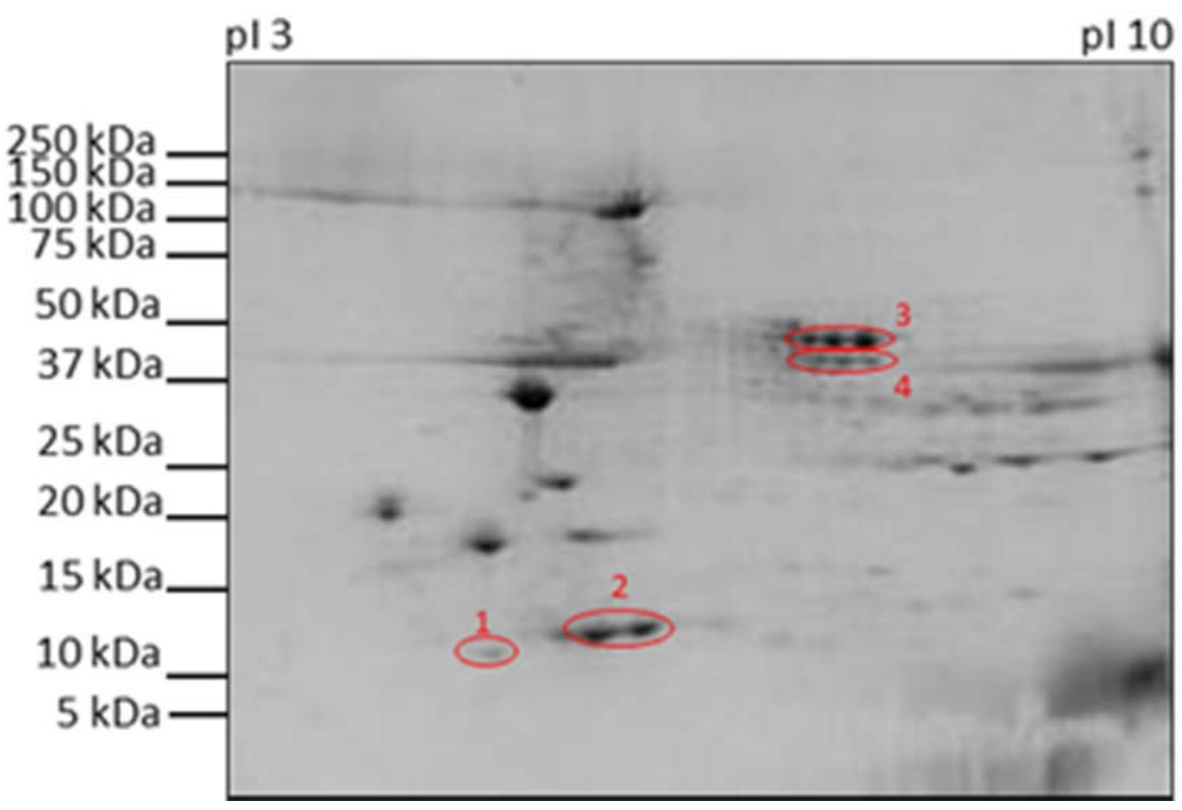

\section{D2}

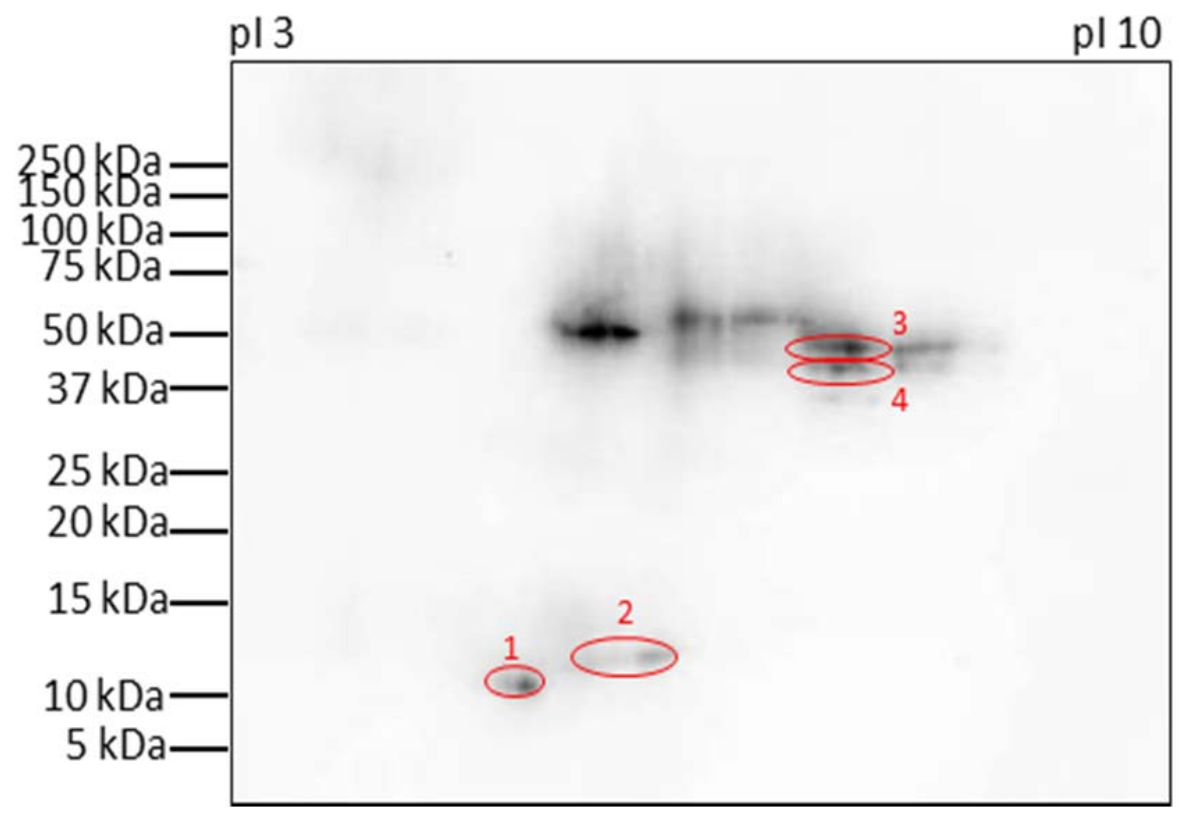




\section{E1}

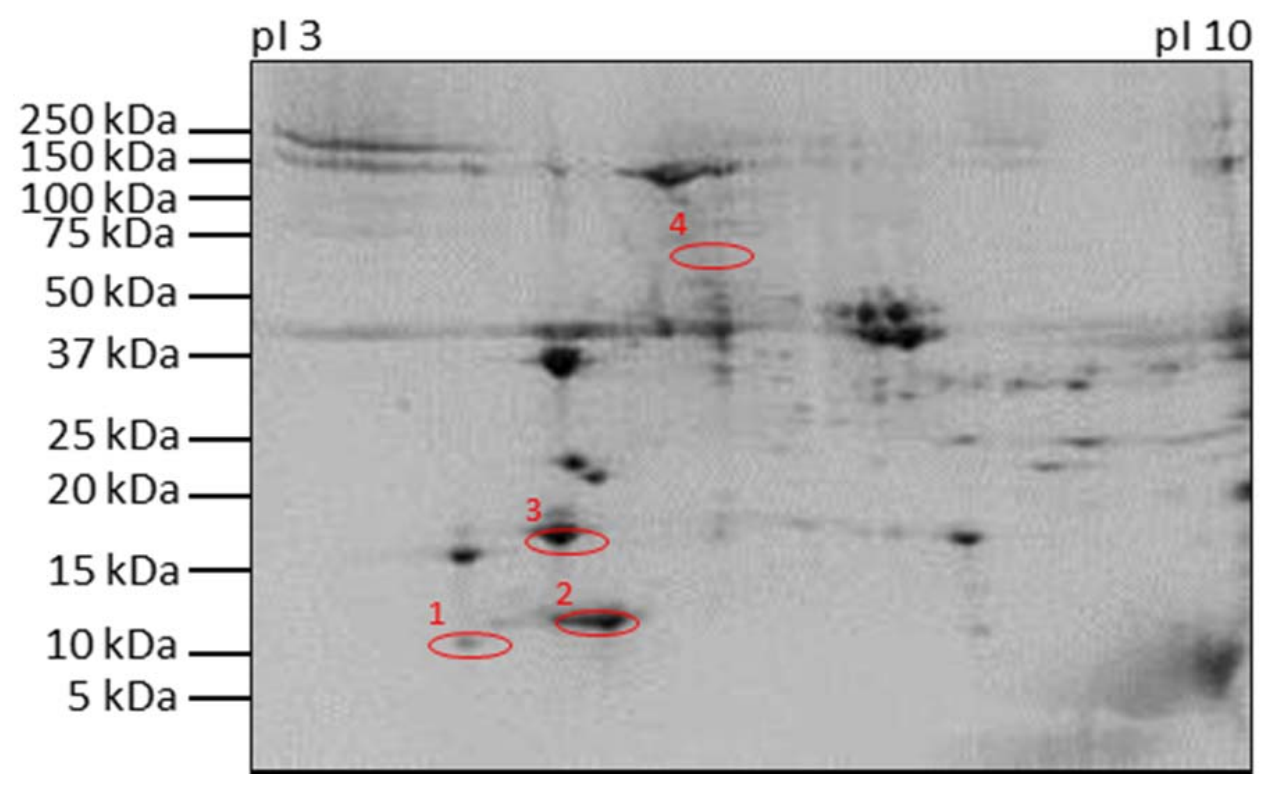

\section{E2}

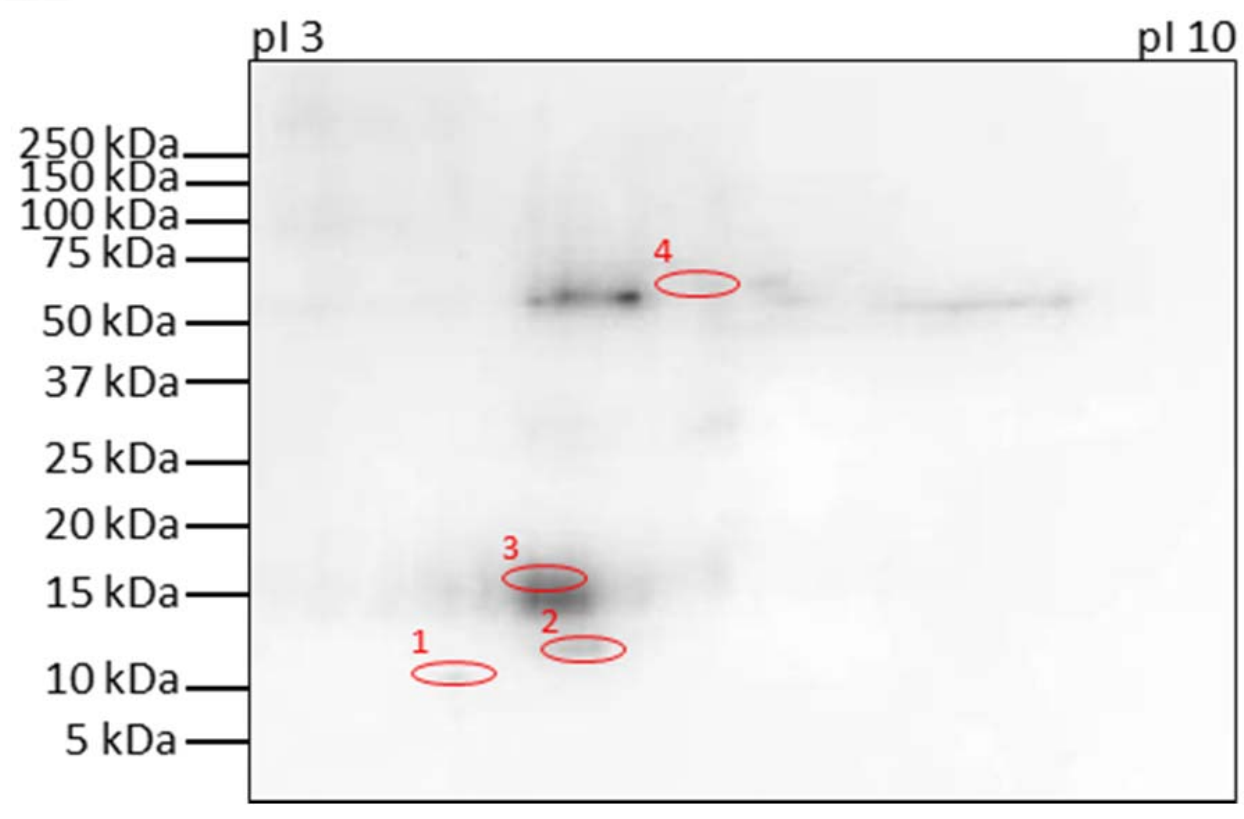

Figure 2. 
CHAPTER 6: EFFECTS OF HEATING, CALCIUM, AND MAILLARD REACTIONS ON THE IgE AND IgG BINDING TO FISH PARVALBUMINS

Poi-Wah, Lee ${ }^{1}$, Julie A. Nordlee ${ }^{1}$, Stef J. Koppelman ${ }^{1}$, Joseph L. Baumert ${ }^{1}$, and Steve L. Taylor $^{1 *}$

${ }^{1}$ Food Allergy Research and Resource Program, University of Nebraska, Lincoln, NE, United States

* Corresponding author. Tel: +1-402-472-2833; Fax: +1-402-472-5307; Email: staylor2@unl.edu 


\begin{abstract}
Parvalbumin is the major pan-allergen in fish and frog. By competitive-inhibition enzyme-linked immunosorbent assay (ELISA), 3 antiparvalbumin IgG antibodies showed variable binding to cooked fish muscles, depending on fish species and detection antibodies. In the absence of calcium, the $3 \mathrm{IgG}$ antibodies had lower binding to fish muscle extracts, regardless of heating. Purified cod parvalbumin (cod PV) that was glycated for 24 hours and heated significantly showed reduced binding to anticarp parvalbumin monoclonal antibody. Contrarily, anticod parvalbumin polyclonal antibody (anticod PV PoAb) had enhanced binding to glycated cod PV, but significantly lower reactivity with cod PV that was heated in the absence of calcium. Of 3 antiparvalbumin IgG antibodies, anticod PV PoAb is more suitable to detect fish residues in foods as the binding was less affected by heating and Maillard reaction. IgE binding to cod PV was reduced by both Maillard and heat treatments and the effects were more pronounced in the absence of calcium, suggesting that these treatments might reduce the allergenicity of cod PV.
\end{abstract}

Keywords: Fish allergy; fish parvalbumins; heating; calcium; Maillard reaction; IgE; $\mathrm{IgG}$ 


\section{INTRODUCTION}

Fish is widely consumed and represents an important food commodity in international trade (1). On the other hand, fish is also one of the most frequently implicated foods causing IgE-mediated type I hypersensitivity reactions (2). The major allergen known to induce allergic reactions was first isolated from cod and was identified as parvalbumin (Gad c 1) (3). Parvalbumin is a calcium-binding sarcoplasmic protein involved in muscle relaxation that belongs to the EF-hand superfamily (4). Subsequent studies revealed that parvalbumins isolated from multiple fish and frog species are a major cross-reactive allergen for these species $(5-7)$. Gad $\mathrm{c} 1$ is a very stable allergen. Studies have shown that the allergenicity of Gad c 1 was not significantly affected by extreme $\mathrm{pH}$, heat denaturation, and chemical modifications (denaturation, reduction, and alkylation), suggesting that the allergenic activity of Gad c 1 is primarily dependent on the primary structure rather than on the molecular conformation (8). Nevertheless, steric conformation also affects the allergenicity of fish parvalbumins, as several studies revealed that calcium-depleted parvalbumins exhibit a loss of IgE reactivity due to conformational changes induced in the absence of calcium $(7,9,10)$.

Various thermal and non-thermal processing techniques for foods are known to induce protein unfolding, denaturation, and aggregation that lead to alterations in IgGand IgE-binding epitopes as well as the creation of neo-epitopes or unmasking of existing ones. As a result, the antigenicity and allergenicity of the proteins may be modified $(11-14)$. Fish is a highly perishable food and deteriorates rapidly after catch due to spoilage caused by enzymatic, bacterial and chemical actions. To extend the storage life and develop desirable sensory properties, fish are often preserved by canning, salting, 
drying, and smoking, among others. These treatments may alter the structures and allergenic properties of fish allergens, including parvalbumins. In fact, BernhiselBroadbent et al. (15) reported that the extensively heat-treated fish such as canned tuna and salmon were less allergenic than fresh fish. Furthermore, Chatterjee et al. (16) revealed that frying and boiling of the fish muscle abolished the IgE binding to the allergenic proteins in 2 Indian fishes, hilsa and pomfret. Sletten et al. (17) demonstrated that smoked fish had increased IgE binding to fish proteins, whereas chemically processed fish, such as lye-treated, sugar-cured, fermented, and pickled fish had reduced or abolished IgE binding. A recent study by de Jongh et al. (18) implied that the Maillardtreated cod PV possessed lower aggregation propensity compared to its native counterpart, thus affecting the digestibility of parvalbumin and possibly the $\operatorname{IgG}$ and $\operatorname{IgE}$ binding to parvalbumin that are yet to be studied.

The aim of this study was to investigate the influence of heating, calcium, and Maillard reaction on $\operatorname{IgG}$ and $\operatorname{IgE}$ binding to parvalbumins. The results will aid in determining the usefulness of the IgG antibodies for detecting allergenic fish residues in processed foods using immunoassays methods. The results may also provide insights into the allergenic potential of parvalbumin after food processing treatments as the specific $\operatorname{IgE}$ binding to allergens is a prerequisite for the elicitation an allergic reaction (11).

\section{MATERIALS AND METHODS}

\section{Materials}

Sardine (Sardina pilchardus), carp (Cyprinus carpio), pike (Esox lucius), Atlantic cod (Gadus morhua), tilapia (Oreochromis niloticus), and catfish (Ictalurus punctatus) 
fillets were obtained from different fish and seafood distributors in the U.S. and the species identification was authenticated by Eurofins GeneScan, Inc. (Metairie, LA) using polymerase chain reaction (PCR), either the U.S. Food and Drug Administration (FDA)validated DNA barcode analysis (19) or nucleotide sequence analysis of the cytochrome b and $16 \mathrm{~S}$ genes. Cod parvalbumin (cod PV) was purified from cod fillets by a combination of diafiltration and chromatography steps as described elsewhere (18). Mouse antifrog parvalbumin monoclonal antibody (antifrog PV MoAb; clone PARV-19) was purchased from Sigma-Aldrich (St. Louis, MO), mouse anticarp parvalbumin monoclonal antibody (anticarp PV MoAb; clone PV 235) was from Swant, Inc. (Switzerland), and rabbit anticod parvalbumin polyclonal antibody (anticod PV PoAb) was developed using purified cod parvalbumin as the antigen with an immunization protocol that has been previously described (20). All other chemicals used in this study were of analytical grade.

\section{Human Serum}

Serum samples were obtained from 16 subjects whose diagnostic characteristics are summarized in Table 1. All individuals had a convincing history of fish allergy and positive skin prick test (SPT) and/or specific-IgE test (Immuno-CAP FEIA) with values > $0.35 \mathrm{kU}_{\mathrm{A}} / \mathrm{L}$ to cod extract. An equal volume of human serum samples were pooled for the competitive-inhibition IgE-ELISA experiment. The use of all serum samples in this study has been reviewed and approved by Institutional Review Board of the University of Nebraska. 


\section{Preparation and Extraction of Raw and Cooked Fish Muscles}

Raw fish fillets were ground to a uniform consistency using a commercial food processor. Cooked muscle was prepared by heating the ground fish muscle at $99^{\circ} \mathrm{C}$ in a shaking water bath for 20 min, followed by mincing with metal spatula. Soluble proteins from the ground raw and cooked fish muscle samples were extracted overnight with gentle rocking at $4^{\circ} \mathrm{C}$ and at a sample-to-buffer ratio of 1:10 in 4 different extraction buffers: (i) 0.01 M phosphate buffered saline (PBS; $0.002 \mathrm{M} \mathrm{NaH}_{2} \mathrm{PO}_{4}, 0.008 \mathrm{M}$ $\mathrm{Na}_{2} \mathrm{HPO}_{4}$, and $0.85 \% \mathrm{NaCl}, \mathrm{pH} 7.4$ ); (ii) Tris buffer (20 mM Tris, $100 \mathrm{mM} \mathrm{NaCl}, \mathrm{pH}$ 8.1); (iii) Tris buffer containing $10 \mathrm{mM} \mathrm{CaCl}_{2}$; and (iv) Tris buffer containing $10 \mathrm{mM}$ ethylenediaminetetraacetic acid (EDTA). After centrifuging the extracts at $3612 g$ in a tabletop centrifuge at $4^{\circ} \mathrm{C}$ for $30 \mathrm{~min}$, the supernatant solution was filtered through a 5$\mu \mathrm{m}$ Versapor ${ }^{\circledR}$ membrane syringe filter (Pall Corporation, Ann Arbor, MI). Later, a portion of the filtered raw fish muscle extracts was heated at $99^{\circ} \mathrm{C}$ in a shaking water bath for $20 \mathrm{~min}$, followed by centrifugation. Insoluble material was discarded and the supernatant solution was referred to as "heated raw muscle extracts". The protein content of all solutions was determined by the Lowry method (21).

\section{Preparation of Glycation and Heated Cod PV}

Cod PV was glycated according to the procedures described by de Jongh et al. (18), with the following modifications. Five milligrams of lyophilized cod PV was dissolved in $0.5 \mathrm{~mL}$ of deionized water ( $\mathrm{pH} 8.0$ ), followed by addition of $25 \mathrm{mg}$ of Dglucose. After adjusting the $\mathrm{pH}$ of the solution to 8.0 by adding $0.2 \mathrm{M} \mathrm{NaOH}$, the solution was mixed and lyophilized. The dried material was then incubated for 10 and 24 hours at 
$60^{\circ} \mathrm{C}$ under a $\mathrm{NaNO}_{3}$ saturated atmosphere with a relative humidity $(\mathrm{RH})$ of $65 \%$. Subsequently, the dried material was dissolved in $0.5 \mathrm{~mL}$ of deionized water containing 5 $\mathrm{mM} \mathrm{CaCl}_{2}$ (pH 8.0), extensively dialyzed (3.5 kDa molecular weight cutoff) against deionized water containing $5 \mathrm{mM} \mathrm{CaCl}_{2}\left(\mathrm{pH} \mathrm{8.0)}\right.$ at $4{ }^{\circ} \mathrm{C}$ to remove non-reacted Dglucose, lyophilized to form dry powder, and re-dissolved in $0.5 \mathrm{~mL}$ of deionized water containing either $5 \mathrm{mM} \mathrm{CaCl}_{2}$ or EDTA ( $\mathrm{pH}$ 8.0). Control samples were prepared using the same materials and procedures, but without the addition of D-glucose or with the addition of sucrose. For the heat treatment, $1 \mathrm{mg} / \mathrm{mL}$ of native and glycated cod PV were heated at $95^{\circ} \mathrm{C}$ for $15 \mathrm{~min}$ in a water bath, and then cooled in ice. The protein content of all cod PV samples was estimated based on UV absorption measurement at $280 \mathrm{~nm}$ and the calculated extinction coefficient of 0.620 for cod PV (Swiss-Prot/TrEMBL accession number: A5I873).

\section{Measurement of Available Lysine Content}

A chromogenic ortho-phthaldialdehyde (OPA) method described by de Jongh et al. (18) was used to measure the available non-glycated lysines in cod PV. The free primary amino groups react with OPA in the presence of N,N-dimethyl-2mercaptoethylammonium-chloride (DMA), forming alkyl-iso-indole derivatives that are detectable by absorbance at $340 \mathrm{~nm}$ in spectrophotometer (22). Briefly, the OPA reagent was prepared by mixing $40 \mathrm{mg}$ OPA in $1 \mathrm{~mL}$ methanol, followed by the addition of 25 mL 0.1 M borax buffer (pH 9.4), 200 mg DMA, 5 mL 10\% SDS solution, and enough deionized water to bring the final volume to $50 \mathrm{~mL}$. L-leucine diluted in deionized water to $0.01,0.03,0.1,0.3,1,2,3$, and $4 \mathrm{mM}$ was used as the standard to generate a 
calibration curve. Standards and sample protein solutions at $35 \mu \mathrm{L}$ were mixed with 0.7 $\mathrm{mL}$ of OPA reagent in a quartz cuvette for $2 \mathrm{~min}$, followed by absorbance measurement at $340 \mathrm{~nm}$. The absorbance of the blank (OPA reagent alone) was subtracted from all readings.

\section{Competitive-inhibition IgG-ELISA}

Polystyrene microtiter plates (Nagle Nunc International, Rochester, NY) were coated with $100 \mu \mathrm{L} /$ well of either raw fish muscle extracts ( 1 or $10 \mu \mathrm{g} / \mathrm{mL}$ ) or native, unheated cod PV $(1 \mu \mathrm{g} / \mathrm{mL})$ in coating buffer $\left(0.015 \mathrm{M} \mathrm{Na}_{2} \mathrm{CO}_{3}, 0.035 \mathrm{M} \mathrm{NaHCO}_{3}\right.$, and $0.02 \% \mathrm{NaN}_{3}, \mathrm{pH} 9.6$ ) and incubated overnight at $4^{\circ} \mathrm{C}$. Following incubation, the plates were washed with buffer (0.01 M PBS containing $0.05 \%$ Tween 20 , pH 7.4), then incubated for 2 hours at $37^{\circ} \mathrm{C}$ with $350 \mu \mathrm{L} /$ well of blocking buffer consisting of $0.1 \%$ porcine skin gelatin (Sigma-Aldrich, St. Louis, MO) in $0.01 \mathrm{M}$ PBS, pH 7.4. In a separate polypropylene plate, 3 different antiparvalbumin antibodies diluted to 1:7500 in conjugate buffer [Tris buffer containing $0.1 \%$ bovine serum albumin (BSA; AffymetrixUSB, Cleveland, $\mathrm{OH}$ ), $\mathrm{pH}$ 8.1] were incubated with various concentrations of the serially diluted inhibitors, depending on the fish species (as shown in Table 2) at an antibody-toinhibitor volumetric ratio of $1: 1$ for 2 hours at $37^{\circ} \mathrm{C}$. For ELISA plates coated with raw fish muscle extracts, the inhibitors consisted of raw, cooked, and heated raw muscle extracts that were diluted in their respective extraction buffers. For ELISA plates coated with cod PV, the inhibitors consisted of heated and unheated forms of either native or glycated cod PV diluted in conjugate buffer. After blocking, the plates were washed and $100 \mu \mathrm{L} /$ well of the antibody-inhibitor mixture was added to the plates for 2 hours at $37^{\circ} \mathrm{C}$. 
Next, the plates were washed and incubated with $100 \mu \mathrm{L} /$ well of rabbit antimouse IgG (diluted 1:5000 and 1:1000 respectively in conjugate buffer for antifrog and anticarp PV MoAb) and goat antirabbit IgG (diluted 1:4500 in conjugate buffer for anticod PoAb) labeled with alkaline phosphatase enzyme for 1 hour at $37^{\circ} \mathrm{C}$. Binding was visualized with $p$-nitrophenyl phosphate substrate (Sigma Fast, Sigma-Aldrich, St. Louis, MO), and the color developed was measured at $405 \mathrm{~nm}$. Each of the fish muscle samples was extracted on 2 separate days and analyzed in duplicate. The OD of the blank wells (no antibody-inhibitor mixture) was subtracted from all other ODs. Percentage inhibition was calculated as follows: $\left[\left(\mathrm{OD}_{405}\right.\right.$ without inhibitor- $\mathrm{OD}_{405}$ with inhibitor $) / \mathrm{OD}_{405}$ without inhibitor] $\mathrm{x} 100$. The inhibitor concentration that resulted in 50\% inhibition of $\operatorname{IgG}$ binding to coated wells $\left(\mathrm{IC}_{50}\right)$ was determined from the percent inhibition curve.

\section{Competitive-inhibition IgE-ELISA}

Competitive-inhibition IgE-ELISA was performed according to the methods as described above in the "competitive-inhibition IgG-ELISA" section with the following modifications. In brief, microtiter plates were coated with $100 \mu \mathrm{L} /$ well of native, unheated cod PV $(1 \mu \mathrm{g} / \mathrm{mL})$ in the same coating buffer without $0.02 \% \mathrm{NaN}_{3}$ overnight at $4^{\circ} \mathrm{C}$. After washing, the plates were blocked for 1 hour at $37^{\circ} \mathrm{C}$ with $350 \mu \mathrm{L} /$ well of blocking/conjugate buffer [Tris buffer containing 1\% BSA]. On a separate plate, pooled human serum diluted 1:5 was incubated with various concentrations of inhibitors at an antibody-to-inhibitor ratio of $1: 1$ for 2 hours at $37^{\circ} \mathrm{C}$. The inhibitors, consisting of heated and unheated forms of either native or glycated cod PV, were diluted five-fold (0.00016 $0.1 \mu \mathrm{g} / \mathrm{mL}$ ) in blocking/conjugate buffer. Following blocking, the plates were washed 
and $100 \mu \mathrm{L} /$ well of the antibody-inhibitor mixture was added to plates for 2 hours at $37^{\circ} \mathrm{C}$. Next, the plates were washed and incubated with $100 \mu \mathrm{L} /$ well of mouse antihuman IgE (diluted 1:1000 in blocking/conjugate buffer) labeled with horseradish peroxidase for 1 hour at $37^{\circ} \mathrm{C}$. Binding was visualized with 3,3',5,5'-tetramethylbenzidine substrate (Sigma-Aldrich, St. Louis, MO) and the color developed was measured at $450 \mathrm{~nm}$. Each cod PV sample was analyzed in duplicate wells in 2 independent ELISA trials. Percentage inhibition and $\mathrm{IC}_{50}$ values were calculated as described above using $\mathrm{OD}_{450}$.

\section{Statistics}

Differences in the $\mathrm{IC}_{50}$ values between samples were determined using ANOVA followed by Dunnett's test (SAS programs, SAS Institute Inc., Cary, NC). A $p$ value $<$ 0.05 was considered statistically significant.

\section{RESULTS AND DISCUSSION}

\section{Effects of Heating and Calcium on IgG Binding to Fish Muscle Extracts}

The binding of the 3 antiparvalbumin IgG antibodies against raw, cooked, and heated raw muscle extracts in the presence or absence of calcium was assessed by competitive-inhibition IgG-ELISA. For each fish species, the effects of heating and calcium on the $\mathrm{IgG}$ binding were determined by comparing the $\mathrm{IC}_{50}$ values between the extracts of fish muscle treated with heat/calcium/EDTA and the raw muscle extracted in PBS (Figure 1). Initially, we used PBS as an extraction buffer for the fish muscle samples. However, calcium phosphate precipitate formed when calcium was added to PBS, and thus $\mathrm{CaCl}_{2}$ and EDTA were added to the Tris buffer to study the effects of 
calcium. The comparisons of the $\mathrm{IC}_{50}$ values between the PBS- and Tris-extracted fish samples revealed comparable results when detected by all 3 antiparvalbumin antibodies, indicating that the extraction behavior of parvalbumins in PBS and Tris buffers was similar.

Heat-induced protein denaturation could lead to the aggregation and precipitation of proteins, and thus result in a decrease in protein solubility (23). Although parvalbumin is shown to be resistant to heat denaturation $(8,24)$, the solubility of parvalbumin in the crude fish muscle extracts after heat treatment and the ability of the antiparvalbumin IgG antibodies to detect parvalbumin after heating remains largely unexplored. In the current study, we demonstrated that the effects of heating on IgG binding varies depending on the fish species analyzed and the types of antiparvalbumin antibodies used for detection in the ELISA. Of 4 fish species tested (cod was excluded due to lack of binding with antifrog PV MoAb), heating did not affect the binding of antifrog PV MoAb to cooked carp, tilapia, and catfish (Figure 1A). However, the antibody binding to both cooked sardine and pike were significantly reduced regardless of the extraction buffers, as indicated by an increase in $\mathrm{IC}_{50}$ values in comparisons to the PBS-extracted raw muscles of each corresponding fish species. The detection of raw and cooked fish muscle extracts by anticarp PV MoAb revealed that heating significantly increased the antibody binding to cooked carp, pike, and tilapia, as shown by decreased $\mathrm{IC}_{50}$ values, whereas the reactivity of the antibody to cooked cod was significantly reduced after heating (Figure 1B). In contrast, the binding of anticarp PV MoAb to cooked sardine and catfish muscle extracts was unaffected by heating. For the anticod PV PoAb, heating did not alter the antibody binding to cooked sardine and pike that were extracted in PBS and Tris buffers 
(Figure 1C). While heating significantly increased the reactivity of anticod PV PoAb to cooked carp, tilapia, and catfish, heating significantly diminished antibody binding to cooked cod compared to its raw counterparts, but the reduction was minimal. Similarly, Chatterjee et al. (16) demonstrated that the changes in IgE reactivity of fish proteins varied among 4 Indian fishes; IgE binding of pomfret and hilsa muscle extracts was markedly reduced following boiling or frying, whereas IgE binding to the allergenic proteins in bhetki and mackerel were unaffected by heat treatments. Therefore, no common trend exists in the effects of thermal treatments on the immunogenicity of allergenic proteins from different fish species as probed by $\operatorname{IgE}$ binding (16). Our results demonstrated that anticod PV PoAb appears to be more suitable for the detection of allergenic fish residues compared to antifrog and anticarp PV MoAb as thermal processing has lesser effects on the anticod PV PoAb immunoreactivity, which is probably attributed to the polyclonal nature of the anticod PV PoAb that is capable of recognizing multiple epitopes on parvalbumins in fish muscle extracts.

To exclude the possible difficulties in extracting parvalbumin from cooked fish muscles, raw muscle extracts subjected to heat treatment (specified as "heated raw ext." in Figure 1) were evaluated in the ELISA. Compared to both raw and cooked fish muscle extracts, heated raw muscle extracts had overall lower $\mathrm{IC}_{50}$ values when detected by all 3 antiparvalbumin IgG antibodies, although the decrease was not statistically significant for all fish species. The increased in IgG binding to heated raw muscle extracts was probably due to the heat-induced precipitation and removal of fish proteins that could potentially interfere with the binding of antiparvalbumin antibodies to fish parvalbumins in the ELISA. Moreover, heating of raw fish extracts also possibly rendered further 
precipitation and insolubility of additional fish proteins, and thus concentrating parvalbumin in the soluble fraction of the extracts.

Parvalbumin is a calcium-binding muscle protein involved in the muscle relaxation process. Studies have shown that the IgG and IgE binding to parvalbumin could be affected by the presence or absence of calcium $(9,10,25-27)$. Here, we showed that the presence of calcium generally did not improve the reactivity of 3 antiparvalbumin IgG antibodies to raw or heat-treated fish muscle extracts when comparing between fish samples that were given similar treatments. However, the presence of EDTA completely abolished the binding of antifrog and anticarp PV MoAb to the fish extracts in both the unheated or heated forms of fish muscles, regardless of fish species. Although the presence of EDTA did not entirely eliminate the binding of anticod PV PoAb to the fish extracts, the pronounced reduction in the slope of the inhibition ELISA curves (data not shown) suggested that the antibody had decreased parvalbumin-binding capacity. Therefore, for fish samples extracted in Tris buffer containing EDTA, the $\mathrm{IC}_{50}$ values were unreliable and could not be compared with the remaining fish samples. Our findings were in disagreement with the results obtained by Gajewski and Hsieh (27) who observed an increase in the reactivity of antifrog PV MoAb and anti-heated catfish monoclonal antibody to cooked fish extracts after calcium depletion. The differences in results might be due to the use of different ELISA formats and the addition of EDTA when incubating inhibitors with IgG antibodies in our study, whereas in the study by Gajewski and Hsieh, EGTA was added when coating ELISA plates with fish extracts. EDTA salt is a direct food additive that has been approved for used as preservatives, processing aids and color stabilizers in a variety of foods (28). Consequently, the effects of calcium depletion on 
IgG binding to parvalbumin may have an impact on the detection of allergenic fish residues in processed foods in cases where EDTA is used as an ingredient.

\section{Effects of Heating, Calcium, and Maillard Reactions on IgG and IgE Binding to Cod PV}

Maillard reaction is a non-enzymatic browning reaction that is initiated by the condensation between the carbonyl groups of reducing sugars (like glucose) and the free amino group of proteins (mainly the $\varepsilon$-amino group of lysine, but also the $\alpha$-amino group of N-terminal amino acids), forming $\mathrm{N}$-substituted glycosylamine, which rearranges to form Amadori products (29). The Maillard reactions occur during the smoking and drying of fish and contributes to the color and flavor development (30). In this study, cod PV was subjected to the initial stages of the Maillard reaction by reacting cod PV with glucose at $60^{\circ} \mathrm{C}$ and $65 \% \mathrm{RH}$ for 10 and 24 hours. The degree of glycation was estimated by measuring the lysine content by assessing the free primary amino groups in the glycated cod PV using the OPA method. Accordingly, cod PV dissolved in water containing calcium or EDTA showed a marked reduction in the available lysine after heating in the presence of glucose; the amount of glycated lysine in cod PV was estimated at $54-65 \%$ and $82-84 \%$, respectively after incubating with glucose for 10 and 24 hours (data not shown). The available lysine content remained unchanged when cod PV was incubated in the presence of sucrose (data not shown).

To gain insights into the influence of heat processing, calcium, and Maillard reactions on $\mathrm{IgG}$ binding to cod PV, we evaluated the treated and untreated samples by competitive-inhibition IgG-ELISA using anticarp PV MoAb and anticod PV PoAb, but 
not antifrog PV MoAb due to the lack of immunoreactivity with cod PV. The $\mathrm{IC}_{50}$ values obtained from the inhibition curves were compared between the native, unheated cod PV in the presence of calcium and the remaining cod PV samples (Figure 2A). Neither heating nor the presence of calcium and EDTA affected the binding of anticarp PV MoAb to the native cod PV. Additionally, the antibody binding was unaffected when cod PV was glycated for 10 hours, regardless of the presence or absence of calcium. A similar result occurred for the native cod PV that was glycated for 24 hours in the presence of calcium. Nevertheless, cod PV that was glycated for 24 hours in the presence of EDTA but unheated and cod PV that was glycated for 24 hours in the presence of calcium and EDTA, followed by heating had significantly lower binding to anticarp PV MoAb, as compared to the native cod PV. In the case of anticod PV PoAb, native cod PV that was heat-treated in the presence of EDTA had significantly lower antibody binding capacity, whereas the effects of both heating and EDTA were not detected in the glycated cod PV (Figure 2B). Interestingly, compared to the native cod PV, both unheated and heated forms of the glycated cod PV in the presence or absence of calcium (with the exception cod PV that was glycated for 24 hours in the presence of EDTA and then heated) demonstrated higher reactivity to anticod PV PoAb, but the difference did not reach statistical significance. The results revealed that heating and the Maillard reaction had little effect on the immunoreactivity of anticod PV PoAb with cod PV when compared to anticarp PV MoAb, probably owing to the recognition of multiple epitopes on cod PV by the anticod PV PoAb.

Alterations in the allergenic or IgE-binding properties of food proteins as a result of the Maillard reaction have been addressed in a few studies. Gruber et al. (31) 
demonstrated that the Maillard reaction reduced the allergenicity of cherry allergen (Pru av 1). Recent reports on the shellfish allergens revealed that the Maillard reaction enhanced and reduced, respectively, the allergenicity of scallop and squid tropomyosins $(32,33)$. Nonenzymatic browning due to the Maillard reaction occurred in dried and smoked fish products. However, studies evaluating the changes in IgE-binding capacity of fish parvalbumin after the Maillard reaction are lacking. Therefore, we evaluated the influence of heating, calcium, and the Maillard reaction on the IgE-binding potency of cod PV by competitive-inhibition IgE-ELISA using pooled serum IgE from fish-allergic individuals (Figure 3). The comparisons of $\mathrm{IC}_{50}$ values between samples revealed that the IgE reactivity to native cod PV was unaffected by heat treatment and the presence or absence of calcium. Although not confirmed, this finding is likely attributed to the conformational stability of purified cod PV after heating and calcium-depletion, as indicated by far-UV circular dichroism spectra in previous study (34). Additionally, de Jong et al. (18) demonstrated that the presence or absence of calcium ions did not affect the secondary structure of cod PV, but had impact on the tertiary structure due to the formation of less condensed globular structures in the calcium-depleted cod PV. In contrast to cod PV, Bugajska-Schretter et al. (9) reported that the calcium-depleted carp parvalbumin formed a random coil conformation after heating and failed to refold upon cooling. Furthermore, it has been shown that the IgE reactivity to the calcium-depleted parvalbumins from mackerel (Sco j 1) and carp (Cyp c 1) were markedly reduced (26, 35). The mutants of Sco j 1 and Cyp c 1 with modifications on either 1 or both the calcium binding sites exhibited similarly reduced IgE-binding capacity $(26,35)$. Tomura et al. (26) proposed that the dissimilarities observed between Gad c 1 and Sco j 1/Cyp c 1 
were due to the dependence of IgE binding on conformational epitopes on Sco $\mathrm{j} 1$ and Cyp c 1 rather than linear epitopes on Gad c 1.

Regardless of the heat treatment, cod PV that was glycated for 10 and 24 hours in the presence of calcium had reduced IgE binding, with the exception of the cod PV glycated for 24 hours and heated, but the decrease was not significant. A similar result was occurred for cod PV that was glycated for 10 hours in the presence of EDTA but unheated. However, cod PV that was glycated for 24 hours and then heated in the presence of calcium had significantly lower IgE binding capacity compared to the native cod PV. Moreover, in the presence of EDTA, 10 hours-glycated cod PV that was heated and 24 hours-glycated cod PV that was unheated or heated showed significantly diminished IgE binding, indicating that the Maillard reaction combined with heating in the absence of calcium significantly reduced IgE binding to cod PV. Despite the fact that glycated- and calcium-depleted cod PV after heat treatment had lower IgE-binding capacity, the digestion stability of the cod PV remains to be elucidated as de Jongh et al. (18) reported that cod PV incubated with glucose for 5 hours under Maillard conditions, followed by heat treatment was more susceptible to pepsin-digestion in in vitro experiments, as compared to the native forms. This observation can likely be attributed to the lower aggregation propensity of the glycated cod PV after heating that allows for easy access of the pepsin enzymes to the cleavage sites on cod PV.

In conclusion, inconsistent effects on the immunoreactivity of 3 antiparvalbumin IgG antibodies to crude fish extracts resulted in response to heat treatment. The binding of these $\operatorname{IgG}$ antibodies to cooked fish muscle extracts varies, depending on the fish species and the type of antibodies used for detection in the competitive-inhibition ELISA. 
This result may be due to the differences in the heat-induced unfolding, denaturation and aggregation state of the fish proteins among various species, leading to the variation in extraction efficiency of parvalbumin and the binding by IgG antibodies. Therefore, to determine whether the antiparvalbumin IgG antibodies are suitable for detecting residues of allergenic fish proteins, extensive verifications are required using various thermallyprocessed fish species. Furthermore, the 3 antibodies had reduced binding capacity to the fish extracts in the absence of calcium, while the presence of calcium did not improve the reactivity of the 3 antibodies to the fish extracts. In the present study, the effects of heating, calcium, and Maillard reactions on the immunoreactivity of $\operatorname{IgG}$ and $\operatorname{IgE}$ antisera with cod PV were also evaluated. In general, parvalbumin that was glycated for 24 hours, followed by heating displayed significantly reduced binding to the anticarp PV MoAb, regardless of the presence or absence of calcium. Native cod PV that was heated in the presence of EDTA had lower binding to anticod PV PoAb, whereas glycation of cod PV increased the binding of the anticod PV PoAb, as compared to the native cod PV. Of 3 antiparvalbumin IgG antibodies, the anticod PV PoAb is the most suitable for use in immunoassays for the detection of fish residues in processed foods because the antigen binding of this antiserum was reduced to a lesser extent than the two MoAb, following thermal processing and the Maillard reaction. However, the results of IgE binding assays using a restricted number of fish allergic sera to bind to cod PV demonstrated reduced binding by the combination of Maillard and heat treatments. These combined treatments had more pronounced effects when EDTA was present. However, the digestibility of heated, Maillard-treated and calcium-depleted cod PV remains to be investigated. 


\section{ACKNOWLEDGEMENTS}

Financial support was provided by the Food Allergy Research and Resource Program at the University of Nebraska. Sera were obtained from Allergy, Asthma and Immunology Associates (Lincoln and Omaha, NE), University Hospital (Zurich Switzerland), and University Medical Center (Utrecht, The Netherlands). We thank Dr. Devin Rose, Nyambe Lisulo Mkandawire, and Junyi Yang (University of Nebraska) for use of the freeze dryer and their technical assistance.

\section{REFERENCES}

(1) Food and Agriculture Organization of the United Nations (FAO), Fisheries and Aquaculture Department. The state of world fisheries and aquaculture 2010. http://www.fao.org/fishery/sofia/en (accessed February 24, 2012).

(2) Sicherer, S. H.; Sampson, H. A. Food allergy. J. Allergy Clin. Immunol. 2006, 117, S470-S475.

(3) Elsayed, S.; Aas, K. Isolation of purified allergen (cod) by isoelectric-focusing. Int. Arch. Allergy Appl. Immunol. 1971, 40, 428-438.

(4) Permyakov, S. E.; Bakunts, A. G.; Denesyuk, A. I.; Knyazeva, E. L.; Uversky, V. N.; Permyakov, E. A. Apo-parvalbumin as an intrinsically disordered protein. Proteins 2008, 15, 822-836.

(5) Van Do, T.; Hordvik, I.; Endresen, C.; Elsayed, S. Characterization of parvalbumin, the major allergen in Alaska Pollack and comparison with codfish Allergen M. Mol. Immunol. 2005, 42, 345-353. 
(6) Van Do, T.; Elsayed, S.; Florvaag, E.; Hordvik, I.; Endresen, C. Allergy to fish parvalbumins: studies on the cross-reactivity of allergens from 9 commonly consumed fish. J. Allergy Clin. Immunol. 2005, 116, 1314-1320.

(7) Hilger, C.; Thill, L.; Grigioni, F.; Lehners, C.; Falagiani, P.; Ferrara, A.; Romano, C.; Stevens, W.; Hentges, F. IgE antibodies of fish allergic patients cross-react with frog parvalbumin. Allergy 2004, 59, 653-660.

(8) Elsayed, S.; Aas, K. Characterization of a major allergen (cod). Observations on effect of denaturation on the allergenic activity. J. Allergy 1971, 47, 283-291.

(9) Bugajska-Schretter, A.; Grote, M.; Vangelista, L.; Valent, P.; Sperr, W. R.; Rumpold, H.; Pastore, A.; Reichelt, R.; Valenta, R.; Spitzauer, S. et al. Purification, biochemical, and immunological characterization of a major food allergen: different immunoglobulin E recognition of the apo- and calciumbound forms of carp parvalbumin. Gut 2000, 46, 661-669.

(10) Swoboda, I.; Bugajska-Schretter, A.; Verdino, P.; Keller, W; Sperr, W. R.; Valent, P.; Valenta, R.; Spitzauer, S. Recombinant carp parvalbumin, the major cross-reactivity fish allergen: a tool for diagnosis and therapy of fish allergy. $J$. Immunol. 2002, 168, 4576-4584.

(11) Thomas, K.; Herouet-Guicheney, C.; Ladics, G.; Bannon, G.; Cockburn, A.; Crevel, R.; Fitzpatrick, J.; Mills, C.; Privalle, L.; Vieths, S. Evaluating the effect of food processing on the potential human allergenicity of novel proteins: international workshop report. Food Chem. Toxicol. 2007, 1116-1122.

(12) Sathe, S. K.; Sharma, G. M. Effects of food processing on food allergens. Mol. Nutr. Food Res. 2009, 53, 970-978. 
(13) Besler, M.; Steinhart, H.; Paschke, A. Stability of food allergens and allergenicity of processed foods. J. Chromatogr. B 2001, 756, 207-228.

(14) Davis, P. J.; Smales, C. M.; James, D. C. How can thermal processing modify the antigenicity of proteins? Allergy 2001, 56, 56-60.

(15) Bernhisel-Broadbent, J.; Scanlon, S. M.; Sampson. H. A. Fish hypersensitivity. II. Clinical relevance of altered fish allergenicity caused by various preparation methods. J. Allergy Clin. Immunol. 1992, 90, 622-629.

(16) Chatterjee, U.; Mondal, G.; Chakraborti, P.; Patra, H. K.; Chatterjee. B. P. Changes in the allergenicity during different preparations of pomfret, hilsa, bhetki and mackerel fish as illustrated by enzyme-linked immunosorbent assay and immunoblotting. Int. Arch. Allergy Immunol. 2006, 141, 1-10.

(17) Sletten, G.; Van Do, T.; Lindvik, H.; Egaas, E.; Florvaag, E. Effects of industrial processing on the immunogenicity of commonly ingested fish species. Int. Arch. Allergy Immunol. 2010, 151, 223-236.

(18) de Jongh, H. H.; Taylor, S. L.; Koppelman, S. J. Controlling the aggregation propensity and thereby digestibility of allergens by Maillardation as illustrated for cod fish parvalbumin. J. Biosci. Bioeng. 2011, 111, 204-211.

(19) Handy, S. M.; Deeds, J. R.; Ivanova, N. V.; Hebert, P. D. N.; Hanner, R.; Ormos, A.; Weigt, L. A.; Moore, M. M.; Hellberg, R. S.; Yancy H. F. Single laboratory validated method for DNA-barcoding for the species identification of fish for FDA regulatory compliance, 2011. http://www.fda.gov/Food/ScienceResearch/LaboratoryMethods/ucm237391.ht $\underline{\text { m }}$ (accessed February 24, 2012). 
(20) Koppelman, S. J.; Nordlee, J. A.; Lee, P.-W.; Happe, R. P.; Hessing, M.; Norland, R.; Manning, T.; Deschene, R.; de Jong, G. A. H.; Taylor, S. L. Parvalbumin in fish skin-derived gelatin. Food Additives Contaminants, submitted for publication, 2012.

(21) Lowry, O. H.; Rosebrough, N. J.; Farr, A. L.; Randall, R. J. Protein measurement with the Folin phenol reagent. J. Biol. Chem. 1951, 193, 265-275.

(22) van Teeffelen, A. M.; Broersen, K.; de Jongh, H. H. Glucosylation of $\beta$ lactoglobulin lowers the heat capacity change of unfolding; a unique way to affect protein thermodynamics. Protein Sci. 2005, 14, 2187-2194.

(23) Mills, E. N.; Sancho, A. I.; Rigby, N. M.; Jenkins, J. A.; Mackie, A. R. Impact of food processing on the structural and allergenic properties of food allergens. Mol. Nutr. Food Res. 2009, 53, 963-969.

(24) Griesmeier, U.; Bublin, M.; Radauer, C.; Vázquez-Cortés, S.; Ma, Y.; Fernández-Rivas, M.; Breiteneder, H. Physicochemical properties and thermal stability of Lep w 1, the major allergen of whiff. Mol. Nutr. Food Res. 2010, 54, 861-869.

(25) Bugajska-Schretter, A.; Elfman, L.; Fuchs, T.; Kapiotis, S.; Rumpold, H.; Valenta, R.; Spitzauer, S. Parvalbumin, a cross-reactive fish allergen, contains IgE-binding epitopes sensitive to periodate treatment and $\mathrm{Ca}^{2+}$ depletion. $J$. Allergy Clin. Immunol. 1998, 101, 67-74.

(26) Tomura, S.; Ishizaki, S.; Nagashima, Y.; Shiomi, K. Reduction in the IgE reactivity of Pacific mackerel parvalbumin by mutations at $\mathrm{Ca}^{2+}$ binding sites. Fish. Sci. 2008, 74, 411-417. 
(27) Gajewski, K. G.; Hsieh, Y. H. Monoclonal antibody specific to a major fish allergen: parvalbumin. J. Food Prot. 2009, 72, 818-825.

(28) Heimbach, J.; Rieth, S.; Mohamedshah, F.; Slesinski, R.; Samuel-Fernando, P.; Sheehan, T.; Dickmann, R.; Borzelleca, J. Safety assessment of iron EDTA [Sodium Iron $\left(\mathrm{Fe}^{3+}\right)$ ethylenediaminetetraacetic acid]: summary of toxicological, fortification and exposure data. Food Chem. Toxicol. 2000, 38, 99-111.

(29) Martins, S. I. F. S.; Jongen, W. M. F.; van Boekel, M. A. J. S. A review of Maillard reaction in food and implications to kinetic modeling. Trends Food Sci. Tech. 2001, 11, 364-373.

(30) Sikorski, Z.; Haard, N.; Motohiro, T.; Pan, B. S. Quality. In Fish drying \& smoking: production and quality; Doe, P. E., Eds.; CRC Press, LLC: Boca Raton, FL, 1998; pp. 89-116.

(31) Gruber, P.; Vieths, S.; Wangorsch, A.; Nerkamp, J.; Hofmann, T. Maillard reaction and enzymatic browning affect the allergenicity of Pru av 1, the major allergen from cherry (Prunus avium). J. Agric. Food Chem. 2004, 52, 40024007.

(32) Nakamura, A.; Watanabe, K.; Ojima, T.; Ahn, D-H.; Saeki, H. Effect of Maillard reaction on allergenicity of scallop tropomyosin. J. Agric. Food Chem. 2005, 53, 7559-7564.

(33) Nakamura, A.; Sasaki, F.; Watanabe, K.; Ojima, T.; Ahn, D-H.; Saeki, H. Changes in allergenicity and digestibility of squid tropomyosin during the Maillard reaction with ribose. J. Agric. Food Chem. 2006, 54, 9529-9534. 
(34) Ma, Y.; Griesmeier, U.; Susani, M.; Radauer, C.; Briza, P.; Erler, A.; Bublin, M.; Alessandri, S.; Himly, M.; Vàzquez-Cortés, S.; et al. Comparison of natural and recombinant forms of the major fish allergen parvalbumin from cod and carp. Mol. Nutr. Food Res. 2008, 52, S196-S207.

(35) Swoboda, I.; Bugajska-Schretter, A.; Linhart, B.; Verdino, P.; Keller, W.; Schulmeister, U.; Sperr, W. R.; Valent, P.; Peltre, G.; Quirce, S.; et al. A recombinant hypoallergenic parvalbumin mutant for immunotherapy of IgEmediated fish allergy. J. Immunol. 2007, 178, 6290-6296. 


\section{FIGURE CAPTIONS}

Figure 1. Inhibitors concentrations at $50 \%$ inhibition $\left(\mathrm{IC}_{50}\right)$ of antifrog $\mathrm{PV} \mathrm{MoAb}(\mathbf{A})$, anticarp PV MoAb (B), and anticod PV PoAb (C) binding to PBS-extracted raw muscle proteins coated on plate, as determined by competitive-inhibition IgG-ELISA; the inhibitors constituted of raw fish muscle extracts (grey bar), cooked fish muscle extracts (white bar), and heated raw fish muscle extracts (black bar) in PBS and Tris buffer alone, and Tris buffer containing either $10 \mathrm{mM} \mathrm{CaCl}_{2}$ or $10 \mathrm{mM}$ EDTA. Each $\mathrm{IC}_{50}$ value is the average of 4 readings and the error bar represents the standard error of the mean. The asterisk denotes significant difference from the $\mathrm{IC}_{50}$ of PBS-extracted raw muscle of each corresponding fish species $(p<0.05)$.

Figure 2. Inhibitors concentrations at 50\% inhibition ( $\left.\mathrm{IC}_{50}\right)$ of anticarp PV $\mathrm{MoAb}(\mathbf{A})$, and anticod PV PoAb (B) binding to native cod PV coated on plate, as determined by competitive-inhibition IgG-ELISA; the inhibitors constituted of cod PV dissolved in water containing $5 \mathrm{mM} \mathrm{CaCl}_{2}$ (white bar) or $5 \mathrm{mM} \mathrm{EDTA} \mathrm{(black} \mathrm{bar)} \mathrm{that} \mathrm{were} \mathrm{either}$ unheated, heated, glycated for $10 \mathrm{~h}$, glycated for $10 \mathrm{~h}$ but heated, glycated for $24 \mathrm{~h}$, or glycated for $24 \mathrm{~h}$ but heated. Each $\mathrm{IC}_{50}$ value is the average of 4 readings and the error bar represents the standard error of the mean. The asterisk denotes significant difference from the $\mathrm{IC}_{50}$ of unheated cod PV dissolved in water containing $5 \mathrm{mM} \mathrm{CaCl}_{2}(p<0.05)$.

Figure 3. Inhibitors concentrations at 50\% inhibition $\left(\mathrm{IC}_{50}\right)$ of $\mathrm{IgE}$ binding to native cod $\mathrm{PV}$ coated on plate, as determined by competitive-inhibition IgE-ELISA; the inhibitors constituted of cod PV dissolved in water containing $5 \mathrm{mM} \mathrm{CaCl}_{2}$ (white bar) or $5 \mathrm{mM}$ 
EDTA (black bar) that were either unheated, heated, glycated for $10 \mathrm{~h}$, glycated for $10 \mathrm{~h}$ but heated, glycated for $24 \mathrm{~h}$, or glycated for $24 \mathrm{~h}$ but heated. Each $\mathrm{IC}_{50}$ value is the average of 4 readings and the error bar represents the standard error of the mean. The asterisk denotes significant difference from the $\mathrm{IC}_{50}$ of unheated cod $\mathrm{PV}$ dissolved in water containing $5 \mathrm{mM} \mathrm{CaCl}_{2}(p<0.05)$. 
Table 1. Characteristics of fish-allergic subjects and in vitro diagnosis

\begin{tabular}{|c|c|c|c|c|c|c|}
\hline $\begin{array}{l}\text { Subjects no. } \\
\text { (Locations) }\end{array}$ & Sex $^{a}$ & $\begin{array}{l}\text { Age } \\
\text { (y) }\end{array}$ & $\begin{array}{l}\text { Specific } \\
\text { IgE to } \\
\text { cod } \\
\text { extracts } \\
\left(k U_{A} / L\right)\end{array}$ & $\begin{array}{l}\text { SPT }^{b} \text { to cod } \\
\text { extracts } \\
\text { (wheal } x \\
\text { flare in } \\
\text { mm) }\end{array}$ & Symptoms $^{c}$ & Specific fish avoided \\
\hline 2 (USA) & $\mathrm{F}$ & 25 & 1.23 & $\mathrm{ND}^{d}$ & OS, OAS & None \\
\hline 7 (USA) & $\mathrm{M}$ & 41 & 3.14 & ND & $\mathrm{U}, \mathrm{OAS}, \mathrm{CT}$ & Cod, flounder, halibut, tuna \\
\hline 14 (USA) & $\mathrm{F}$ & 22 & 2.54 & ND & OS, OAS & Salmon \\
\hline 16 (USA) & $\mathrm{F}$ & 47 & 3.98 & ND & $\begin{array}{l}\text { OS, OAS, W, A, C, } \\
\text { ES }\end{array}$ & Perch \\
\hline 20 (USA) & $\mathrm{M}$ & 17 & 14.5 & ND & A, U, OS & Cod \\
\hline 21 (Netherlands) & $\mathrm{M}$ & 24 & 8.64 & $14 \times 47$ & OAS, DY & $\begin{array}{l}\text { Cod, salmon, tilapia, } \\
\text { pangasius }\end{array}$ \\
\hline 22 (Netherlands) & $\mathrm{F}$ & 27 & 8.56 & $8 \times 38$ & AP, OAS & $\begin{array}{l}\text { Cod, tuna, herring, salmon, } \\
\text { sardines, eel }\end{array}$ \\
\hline 24 (Netherlands) & $\mathrm{M}$ & 26 & 51.3 & 11.75 (wheal) & LE, N, OAS & $\begin{array}{l}\text { Cod, tuna, herring, salmon, } \\
\text { tilapia, pollack, mackerel, } \\
\text { sardine, hake, eel, pangasius, } \\
\text { swordfish, eurpoean plaice }\end{array}$ \\
\hline 25 (Netherlands) & $\mathrm{M}$ & 26 & 5.42 & $5 \times 27$ & OAS, DS & $\begin{array}{l}\text { Cod, tuna, herring, salmon, } \\
\text { tilapia, hake }\end{array}$ \\
\hline 26 (Netherlands) & $\mathrm{F}$ & 29 & 14.4 & $17.5 \times 38$ & LE, OAS & Cod \\
\hline 29 (Netherlands) & $\mathrm{F}$ & 33 & 42.7 & $14 \times 53$ & AE, RH, LE, OAS & Trout \\
\hline 30 (Netherlands) & $\mathrm{F}$ & 23 & 5.38 & $9 \times 36$ & OAS & Cod, tuna, salmon \\
\hline 31 (Netherlands) & $\mathrm{F}$ & 42 & 13.6 & $28 \times 50$ & $\mathrm{P}, \mathrm{N}, \mathrm{V}, \mathrm{DI}$ & $\begin{array}{l}\text { Cod, herring, mackerel, sail, } \\
\text { sardine, eel }\end{array}$ \\
\hline 34 (Netherlands) & $\mathrm{M}$ & 4.7 & 3.33 & 2.75 (wheal) & U, OAS & Cod, salmon \\
\hline 43 (Switzerland) & M & 46 & 2.47 & $8 \times 15$ & OAS, AD, AE (oral) & $\begin{array}{l}\text { All fish except tuna, cod, } \\
\text { canned sardines and canned } \\
\text { tuna }\end{array}$ \\
\hline 45 (Switzerland) & $\mathrm{F}$ & 32 & 1.43 & $13 \times 43$ & $\mathrm{U}, \mathrm{W}$ & None \\
\hline
\end{tabular}

${ }^{a} F$, female; $M$, male.

${ }^{b} S P T$, skin prick test.

${ }^{c}$ Symptoms ( $A$, anaphylaxis; $A S$, asthma; $A D$, atopic dermatitis; $A E$, angioedema; $A P$,

abdominal pain; $C$, cough; $C T$, chest tightness; $D I$, diarrhea; $D S$, dysphagia; $D Y$, dyspnea;

$E S$, eye swelling; $L E$, laryngeal edema; $N$, nausea; $O A S$, oral allergy symptoms; $O S$, oropharyngeal swelling; $P$, pruritis; $R H$, rhinorrhea; $U$, urticaria; $V$, vomiting; $W$, wheeze).

${ }^{d} N D$, not determined. 
Table 2. Experimental conditions for competitive-inhibition IgG-ELISA

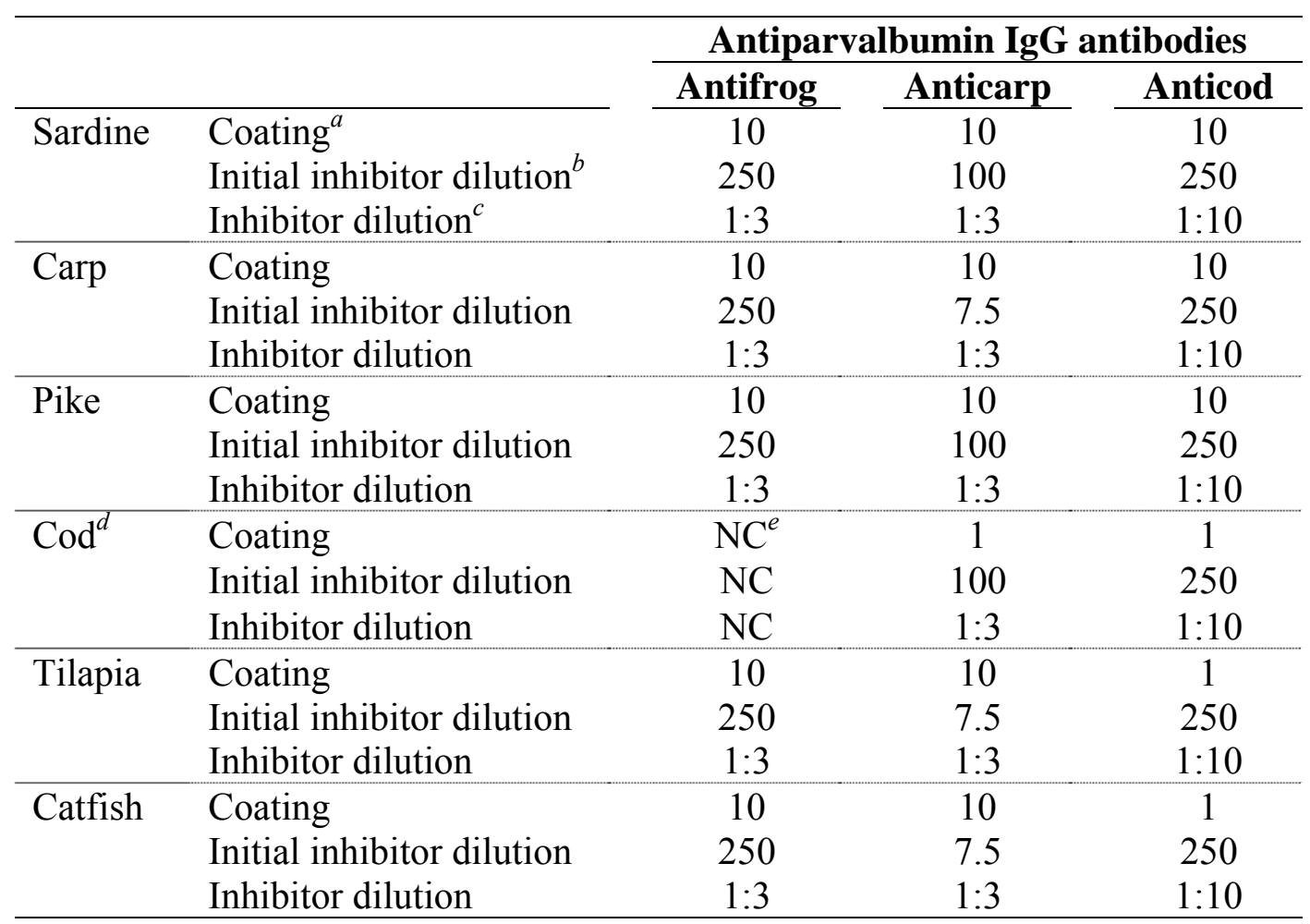

${ }^{a}$ Concentrations of raw fish muscle extracts for coating microtiter plates $(\mu \mathrm{g} / \mathrm{mL})$

${ }^{b}$ Starting concentrations of the inhibitors $(\mu \mathrm{g} / \mathrm{mL})$

${ }^{c}$ Serial dilutions of the inhibitors (v/v)

${ }^{d}$ The conditions applied to plates coated with either raw cod muscle extract or cod PV

${ }^{e}$ Not conducted due to the lack of antifrog PV MoAb binding to cod 

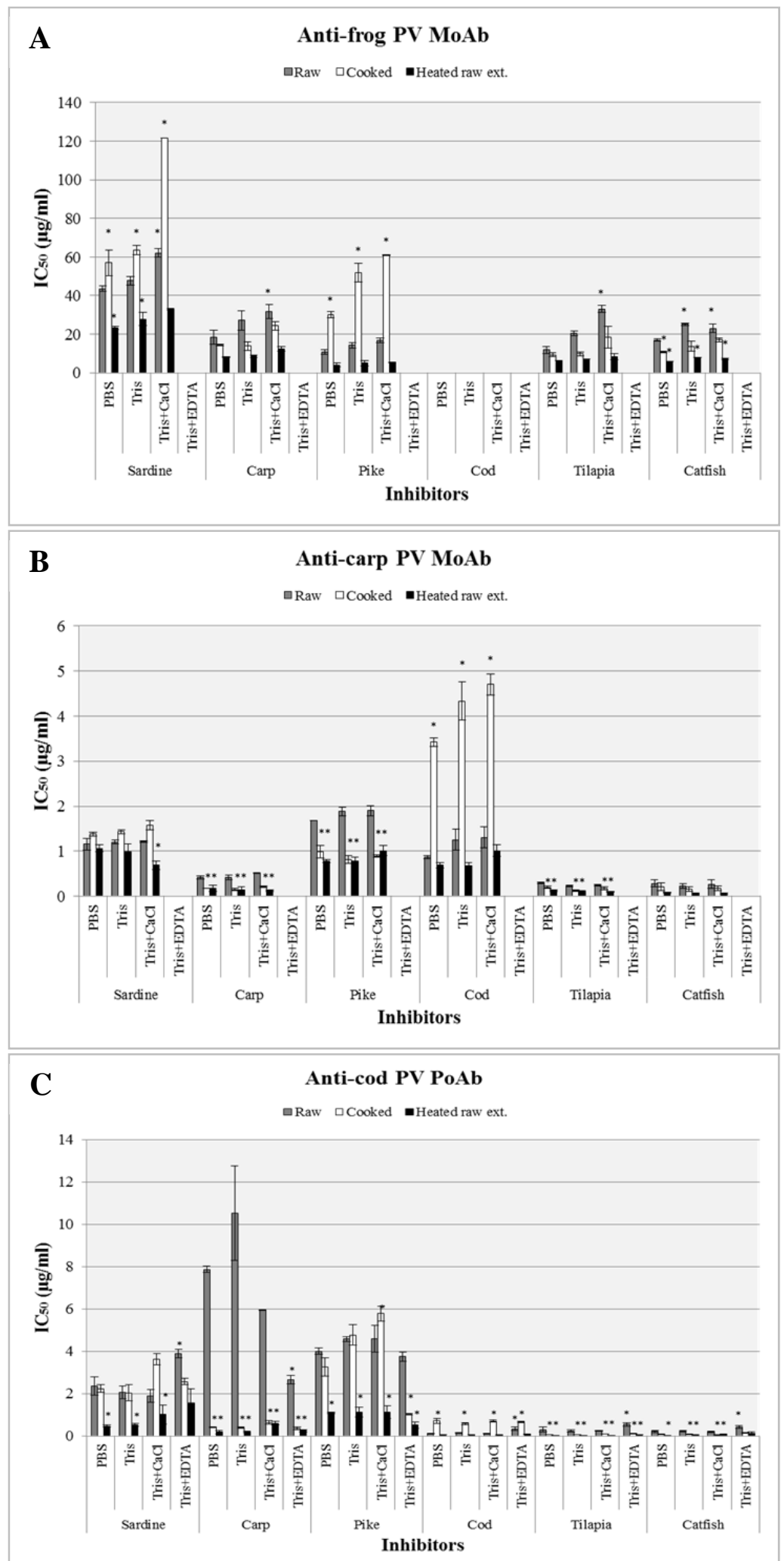

Figure 1. 

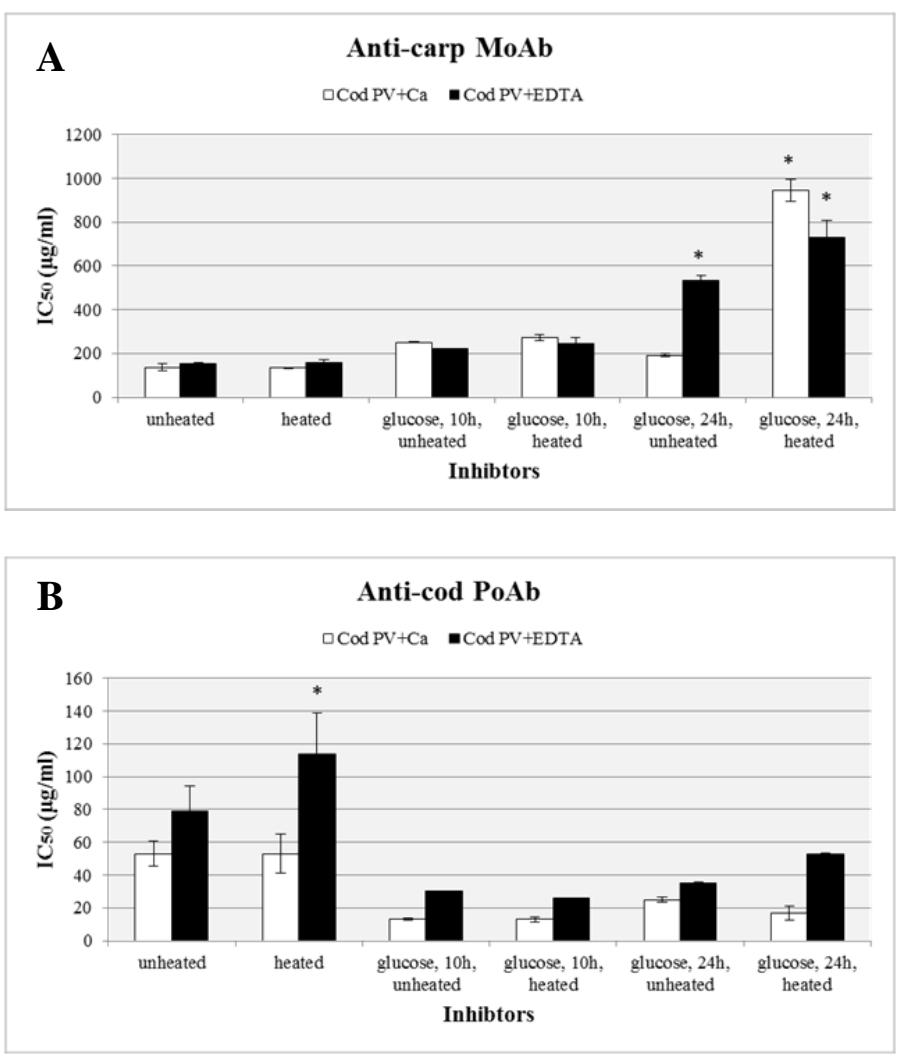

Figure 2. 


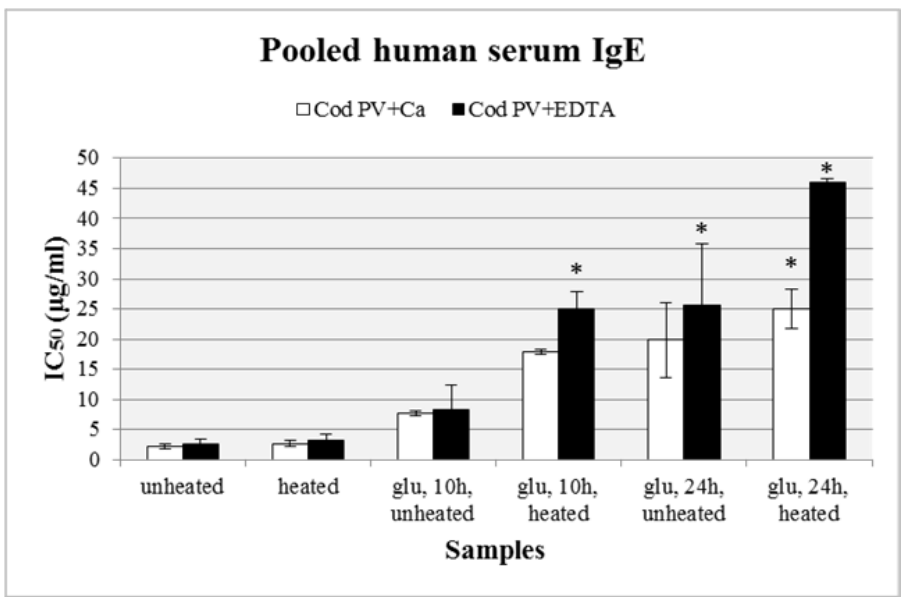

Figure 3. 


\section{CHAPTER 7: EVALUATION OF THE EVOLUTIONARY RELATIONSHIP OF PARVALBUMINS}

\section{ABSTRACT}

Despite the widespread distribution of parvalbumins in all vertebrates, including humans, this protein has been identified as a cross-reactive allergen of many fish and a few edible frog species. The degree of cross-reactivity between different fish species varies greatly among fish-allergic individuals, yet factors underlying the variable crossreactivity remain unclear. The objective of this study was to investigate the evolutionary relationship and interspecies variation of the parvalbumin sequences between fish (species that are members of the class Actinopterygii) and non-fish species (species that are not members of the class Actinopterygii) to provide insights into the role of primary structure in the cross-reactivity among fish. Multiple sequence alignment and sequence identity computation of the entire parvalbumin sequence and the regions corresponded to IgE-binding epitopes of Gad c 1 was achieved by the CLUSTAL W program. A phylogenetic tree of parvalbumins was reconstructed using the PHYLIP program. The sequence alignment showed that the parvalbumin among ray-finned fish shared higher sequence identity compared to non-fish species. Both calcium-binding loops representing the $\operatorname{IgE}$ epitopes of Gad c 1 were conserved among fish and non-fish species, except human $\beta$-parvalbumin. Parvalbumin possesses 3 EF-hand motifs, namely $\mathrm{AB}, \mathrm{CD}$, and EF domains, which consist of two alpha-helices flanking a central loop in each domain. Low sequence identity in the $\mathrm{AB}$ domain and the junction between the $\mathrm{AB} / \mathrm{CD}$ domains of fish parvalbumins may have an important role in the variable cross-reactivity among 
fish. The phylogenetic analysis revealed that parvalbumins of all ray-finned fish but zebrafish and pike were closely related. The $\beta$-parvalbumins of teleosts were more closely related to the $\beta$-parvalbumins of amphibians and reptiles than mammals. Moreover, the teleost $\beta$-parvalbumins are divergent from the $\alpha$-parvalbumin in mammalian and non-mammalian species. Further studies characterizing both sequential and conformational IgE-binding epitopes of parvalbumins from multiple fish species are necessary to better understand the cross-reactivity.

\section{INTRODUCTION}

Parvalbumins are cytoplasmic calcium-binding proteins of approximately $12 \mathrm{kDa}$ in molecular weight, which are broadly distributed in vertebrates, including humans (Permyakov, 2006). Parvalbumin is absent in invertebrates, but instead another form of soluble sarcoplasmic calcium-binding protein that displays properties distinct from the parvalbumin is present in invertebrates (Wnuk and Jauregui-adell, 1983). Parvalbumin belongs to the EF-hand superfamily listed in the Pfam database. EF-hand superfamily is a group of calcium-binding proteins that bind divalent ions with different affinities and is involved in maintaining the intracellular free calcium concentrations for normal cell functioning (Nakayama and Kretsinger, 1994; Permyakov, 2006). Examples of EF-hand proteins include parvalbumin, calmodulin, calbindin, troponin $\mathrm{C}$, and myosin light chain, among others (Wopfner et al., 2007). The EF-hand proteins can be divided into two groups: sensor (trigger) proteins and buffer proteins (non-trigger). Sensor proteins such as calmodulin and troponin $\mathrm{C}$ undergo conformational changes upon calcium binding and regulate the activity of a large number of proteins. Buffer proteins such as parvalbumin 
and calbindin maintain proper calcium homeostasis by taking up and transporting calcium in cells (Hoffman-Sommergruber and Mills, 2009; Permyakov, 2006). A common structural property shared among EF-hand proteins is the conserved EF-hand motif. Each motif is 30 amino acid residues in length, consisting of two alpha-helices flanking a central loop that coordinates the divalent ions, particularly calcium and magnesium (Permyakov et al., 2008; Valenta et al., 1998). Parvalbumin possess 3 EFhand motifs, referred to as $\mathrm{AB}, \mathrm{CD}$, and $\mathrm{EF}$ domains (Kretsinger and Nockolds, 1973). Only the $\mathrm{CD}$ and $\mathrm{EF}$ domains are functional in chelating divalent ions, whereas the $\mathrm{N}$ terminal $\mathrm{AB}$ domain lost its capacity to bind calcium during evolution, but functions as a cap covering the hydrophobic surface of both the CD and EF domains (Swoboda et al., 2007).

Two separate lineages of parvalbumin have been described, designated as $\alpha$ - and $\beta$-parvalbumins (Goodman and Pechère, 1977). The features that distinguish these 2 lineages are the isoelectric points $(\alpha>5, \beta<4.5)$, sequence characteristics ( $\alpha$ contains an additional amino acid residue in the $\mathrm{C}$-terminal helix), affinities for calcium and magnesium ( $\beta$ has greater affinity for calcium and magnesium ions than $\alpha$ ), crystal structure (metal-free forms of $\beta$ shows greater flexibility in protein conformation than metal-bound forms, when compared to the $\alpha$ ), cell-type specific expression, chromosomal localization (the genes for $\alpha$ and $\beta$, respectively, are located on chromosome 22 and 7 in human), and physiologic functions (Arif, 2009; Föhr et al., 1993; Pauls et al., 1996; Permyakov, 2006). Parvalbumin is present at millimolar concentrations in certain muscle tissues, such as the sarcoplasm of fast contracting/relaxing muscles of vertebrates. Parvalbumin can also be found in non-muscle tissues, including testis, endocrine glands, 
skin, and neurons (Pauls et al., 1996). The proposed function of parvalbumin is acting as a soluble relaxation factor by facilitating the calcium translocation within the sarcoplasm and accelerating the relaxation process of muscles (Pauls et al., 1996; Permyakov, 2006).

Despite the widespread distribution of parvalbumin in all vertebrates including humans, this protein has been identified as a cross-reactive allergen only in fish and frog species (Hilger et al., 2004; Van Do et al., 2005). Although parvalbumin is not the dominant protein in fish, it has been identified as the major allergen in fish due to its recognition by serum $\operatorname{IgE}$ from $>90 \%$ of individuals with fish hypersensitivity in some populations (Untersmayr et al., 2006). The clinically relevant and serological crossreactivity among fish has been documented but the degree of cross-reactivity between different fish species varies greatly among fish-allergic individuals as demonstrated by blinded oral food challenges (Bernhisel-Broadbent et al., 1992; Helbling et al., 1999). The factors underlying the wide cross-reactivity between fish and frogs remain unclear. The objective of this study was to investigate the evolutionary relationships of the allergenic fish parvalbumins and the non-allergenic homologs from non-fish species to provide a clearer understanding of the potential factors contributing to the allergenicity of fish parvalbumins. The interspecies variation of the parvalbumin sequence, specifically regions corresponding to the previously identified IgE-binding epitopes was also analyzed to understand the role of primary structure in the cross-reactivity among fish species.

\section{MATERIAL AND METHODS}

\section{Sequence Alignment}


The sequences of parvalbumin homologs from fish, amphibians, mammals, reptiles and birds were obtained from National Center for Biotechnology Information (NCBI; http://www.ncbi.nlm.nih.gov/protein/). Multiple sequence alignment of the parvalbumins were performed using the CLUSTAL W version 2 program (Larkin et al., 2007) accessed at the European Molecular Biology Laboratory's European Bioinformatics Institute website (EMBL-EBI; http://www.ebi.ac.uk/Tools/msa/clustalw2/). The alignment was run using the following default parameters: Gonnet protein weight matrix, gap opening penalty of 10 , and gap extension penalty of 0.2 . The sequence identity, expressed as percent identity (\% ID), of either the entire length of the parvalbumin sequence or the sequence regions corresponded to the previously described IgE-binding epitopes of $\beta$-parvalbumin ( $\mathrm{Gad} \mathrm{c}$ 1) from Baltic cod (Elsayed and Apold, 1983) was computed by the Clustal W program.

\section{Phylogenetic Analysis}

Parvalbumin sequences were aligned by the CLUSTAL X program (Thompson et al., 1997), followed by analysis using the Phylogeny Inference Package (PHYLIP) software version 3.67 (Felsenstein, 1993). First, the pairwise evolutionary distances for the aligned sequences were computed using the Jones-Taylor-Thornton substitution matrix (Jones et al., 1992) in the PROTDIST program. A phylogenetic tree predicting the evolutionary relationship between parvalbumins was then reconstructed by the neighborjoining method (Saitou and Nei, 1987). The confidence limit for the inferred relationship shown in the tree was assessed by bootstrap analysis of 1000 replicates using the SEQBOOT and CONSENSE programs. The tree was viewed and edited by the FigTree 
version 1.3.1 (http://tree.bio.ed.ac.uk/software/figtree/). Parvalbumin from thornback rays was selected as an outgroup based on the evolutionary study by Goodman and Pechèrer (1977). Outgroup is a lineage in phylogenetic analysis that does not belong to the clade being studied, but is closely related to it.

\section{RESULTS AND DISCUSSION}

\section{Sequence Alignment}

The parvalbumin sequences of both $\alpha$ - and $\beta$-lineages were obtained from the NCBI database (Table 1). Fish and amphibians have been shown to express multiple isotypes of parvalbumin, ranging from two to five in skeletal muscles (Permyakov, 2006). For these species, only the isoform that displayed the lowest percent identity with Gad c 1 was selected for the alignment in order to reduce the number of aligned sequences and to include the parvalbumin isoform that is most divergent from Gad c 1 . Figure 1 shows the alignment of 61 parvalbumin sequences with highest similarities corresponding to the 2 calcium-binding regions in all fish and non-fish species. Sequences outside of the calcium-binding domains are highly variable among species, especially amino acids within the AB domain of the parvalbumin.

Studies conducted by Elaysed and Apold (1983) identified several IgE-binding epitopes based on immunological reactivity of serum IgE from fish-allergic patients to trypsin-digested peptide fragments and synthetic peptides of Gad c 1. Figure 2 displays the 5 epitopes identified in Gad c 1, including residues 13-32 (AB domain), 33-44 (axis joining $\mathrm{AB}$ and $\mathrm{CD}$ domains), 49-64 (calcium-binding loop of $\mathrm{CD}$ domain), 65-74 (axis joining $\mathrm{CD}$ and EF domains), and 88-96 (calcium-binding loop of EF domain). To 
characterize the relatedness of the parvalbumins among fish and non-fish species, the \% ID of the entire parvalbumin sequences were computed subsequent to the sequence alignment. Additionally, the \% ID of peptides corresponding to the $5 \operatorname{IgE}$ epitopes of Gad c 1 was estimated to determine whether these peptides are highly conserved among fish species that renders them liable for the immunological cross-reactivity among different fish and frog species. Moreover, the \% ID of these peptides also provides information concerning the degree of identity shared between parvalbumins of fish and non-fish species, especially human. The epitopes from Gad c 1 was used as a reference in $\%$ ID comparisons as Gad c 1 represents a major pan-allergen in fish and frog species (Hilger et al., 2004; Van Do et al., 2005).

Figure 3A-G shows the \% ID calculated for the parvalbumin sequences from fish and non-fish species. The comparison of whole parvalbumin sequences among ray-finned fish belonging to the class Actinopterygii revealed a wide \% ID ranging from $43 \%$ $98 \%$, with an average of $69 \%$ (Table 2). Previous observations have led to the supposition that allergic cross-reactivity typically requires more than $70 \%$ amino acid identity between protein allergens, while proteins with identity matches of less than $50 \%$ are typically not cross-reactive (Aalberse, 2000). Fish that consistently showed low \% ID $(<70 \%)$ with the rest of the ray-finned fish included $\beta$-parvalbumins from Baltic cod, zebrafish, and $\alpha$-parvalbumin from Northern pike (Figure 3A). Compared to the $\%$ ID of the entire parvalbumin sequence among different ray-finned fish, ray-finned fish and nonfish species shared lower \% ID ranging from $39 \%-79 \%$ and an average of $54 \%$. The $\beta$ parvalbumins from ray-finned fish demonstrated higher identities to $\beta$-parvalbumins from all frog species, salamander, boa snake, map turtle and coelacanth, compared to other 
non-fish species. Hilger et al. (2004) previously demonstrated that sera from fish-allergic individuals may bind to frog (Rana esculenta) parvalbumin by in vitro assays. IgE immunoblotting demonstrated that 3/13 (23\%) and 11/12 (92\%) fish-allergic individuals had $\operatorname{IgE}$ antibodies that reacted to the $\alpha$ - and $\beta$-parvalbumins of frog, respectively. These individuals also had a positive reaction to recombinant frog parvalbumin in skin prick tests, implying the presence of shared IgE-binding epitopes in fish and frog parvalbumins. Comparisons of human $\alpha$ - and $\beta$-parvalbumin sequences to those of different ray-finned fish parvalbumins revealed sequence identities between human $\alpha$ parvalbumin and fish parvalbumins in the range of $49-62 \%$ with an average of $53 \%$, whereas the average $\%$ ID was only $47 \%$ (ranging from $39-58 \%$ ) between human $\beta$ parvalbumin and fish parvalbumins.

In comparison to the IgE-binding epitopes in $\mathrm{CD}$ and $\mathrm{EF}$ domains, the parvalbumin sequence located within the $\mathrm{AB}$ domain and the junction between the $\mathrm{AB}$ and CD domains appeared to be the least conserved among various ray-finned fish (Figure 3B and 3C). Table 2 shows that both the $\mathrm{AB}$ domain and $\mathrm{AB} / \mathrm{CD}$-domains junction of different ray-finned fish had an average $\%$ ID of $62 \%$ and a wide range of $\%$ ID ( $25-100 \%$ for $\mathrm{AB}$ domain and $33-92 \%$ for $\mathrm{AB} / \mathrm{CD}$ domains junction), indicating that the amino acid sequences within these regions are highly variable among different fish species. Ray-finned fish and non-fish species shared even lower \% ID for sequences around the $\mathrm{AB}$ domain, with an average $\%$ ID less than $52 \%$. The sequence alignments of $\mathrm{AB}$ domain and $\mathrm{AB} / \mathrm{CD}$-domain junction showed lower average \% ID between fish and human $\beta$-parvalbumin (39\% and 44\%) than between fish and human $\alpha$-parvalbumin ( $47 \%$ and $67 \%$ ). Because the $\mathrm{AB}$ domain between ray-finned fish showed low sequence 
identities, this region may contain important IgE epitopes that would not be predicted to be fully cross-reactive between fish species. Two recent studies have identified the AB region to contain IgE-binding sites based on epitope mapping of overlapping parvalbumin-derived peptides. Yoshida et al. (2008) reported a peptide corresponding to amino acid 21 - 40 (AGSFDHKKFFKACGLSGKST) of Pacific mackerel, Scomber japonicus parvalbumin (Sco j 1) as an IgE-binding epitope within Sco j 1. No substantial $\operatorname{IgE}$ reactivity was observed in this region for parvalbumins from 7 other fish species (sardine, Japanese eel, cod, horse mackerel, crimson sea bream, skipjack and flounder), probably due to the replacement of 1 to 6 amino acids important for IgE-binding. PerezGordo et al. (2012) identified 3 IgE-binding epitopes on the parvalbumin isoform of Atlantic salmon (Salmon salar), Sal s 1 beta 1. These epitopes included peptides corresponding to amino acids 1-18 (Epitope 1: MACAHLCKEADIKTALEA), 28-45 (Epitope 2: KTFFHTIGFASKSADDVK), and 61-81 (Epitope 3:

VEELKLFLQNFCPKARELTDA). Interestingly, Perez-Gordo et al. (2012) found an association between the symptoms experienced by fish-allergic patients and epitopes recognized by their serum IgE antibodies. Patients who recognized only epitope 1 had mild symptoms such as urticaria, whereas patients who recognized epitope 3 had more symptoms, including some are serious ones such as asthma. Although the 3 epitopes are widely separated based on linear sequence, they are in close proximity in the 3dimensional model. Epitope 1 and 2 of Sal s 1 beta 1 were partially located within the AB domain previously described as IgE epitopes on Gad c 1. Interestingly, IgE epitopes could not be identified in another parvalbumin isoform of the Atlantic salmon, Sal s 1 beta 2 , probably due to the crucial amino acid substitutions in primary structure and the 
flat conformation in Sal s beta 2 (Perez-Gordo et al., 2012). Our current Clustal analysis revealed that SalmonB2 (Sal s 1 beta 2) had overall lower sequence identities than salmonB1 (Sal s beta 1) when comparing the parvalbumin sequences between salmon and other ray-finned fish (Figure 3A).

The sequence identity for axis joining $\mathrm{CD}$ and $\mathrm{EF}$ domains of fish and non-fish parvalbumins is displayed in Figure 3E. The sequence in this region showed an average $\%$ ID of $73 \%$ when comparing different ray-finned fish that belong to the taxanomic class of Actinopterygii, whereas the average \% ID between fish and non-fish species was only $48 \%$ (Table 2). In contrast to the $\mathrm{AB}$ domain and $\mathrm{AB} / \mathrm{CD}$-domain junctions, the average $\% \mathrm{ID}$ for $\mathrm{CD} / \mathrm{EF}-$ domains junctions between fish and non-fish species was significantly lower than between different ray-finned fish, indicating that the sequences within the $\mathrm{CD} / \mathrm{EF}$-domain junctions are more conserved between ray-finned fish. In addition, the average $\%$ ID for the CD/EF-domain junction was low between fish and human $\alpha$ parvalbumin (37\%) or human $\beta$-parvalbumin (57\%). Perez-Gordo et al. (2012) revealed that the epitope 3 of Sal s 1 beta 1 overlapped with the epitope on the $\mathrm{CD} / \mathrm{EF}$ junction of Gad c 1.

The calcium-binding loops of both the $\mathrm{CD}$ and $\mathrm{EF}$ domains of parvalbumins were relatively conserved across the majority of fish and non-fish species, showing an average $\%$ ID $\geq 70 \%$ (Figure 3D, 3F, 3G, and Table 2). The sequence identities within these 2 calcium-binding sites were higher between fish and human $\alpha$-parvalbumin ( $\%$ ID $\geq 70 \%$ ) than between fish and human $\beta$-parvalbumin ( $\%$ ID $\geq 58 \%$ ). Although the 2 calciumbinding segments of fish parvalbumins displayed high sequence conservation with other vertebrate parvalbumins, the parvalbumins that are found in mammals, including human, 
are not allergenic. One explanation may be the suppression of the immune response to parvalbumins of mammals to prevent autoimmune diseases (Jenkins et al., 2007). Interestingly, the calcium-binding loops of both $\mathrm{CD}$ and $\mathrm{EF}$ domains in Gad c 1 and the calcium-binding loop of the EF domain in carp parvalbumin have been identified as IgEbinding epitopes (Elsayed and Apold, 1983; Untersmayr et al., 2006). Jenkins et al. (2007) proposed that the replacement of lysine 91 in human $\alpha$-parvalbumin with serine in fish parvalbumin could possibly inhibit fish-specific IgE from recognizing the human parvalbumin, but this anecdotal suggestion has not been systematically-studied. Similar speculation may be applied to the calcium-binding CD-loop, in which the majority of fish $\beta$-parvalbumin differs from the $\alpha$-parvalbumin of human and other mammals at position 52 (glutamine in fish versus lysine in human). In contrast, the epitope mapping studies conducted by Yoshida et al. (2008) and Perez-Gordo et al. (2012) did not identify both calcium-binding loops as IgE-binding epitopes on Sco 1 and Sal s beta 1, and thus the presence IgE epitopes within these calcium-binding regions of fish parvalbumins requires further confirmation.

Based on the sequence alignment results, it was tempting to speculate that fishallergic individuals with cross-reactivity to a broad range of fish species were likely to react to the epitopes within the two conserved calcium-binding regions and $\mathrm{CD} / \mathrm{EF}$ domains junction in fish parvalbumin, whereas fish-allergic individuals showing reactivity to several specific fish species were more likely to have IgE antibodies recognizing the $\mathrm{AB}$ domains and $\mathrm{AB} / \mathrm{CD}$-domain junctions on parvalbumin. However, the relationship between the primary or conformational structures of fish parvalbumins 
and the widespread, yet unpredictable allergenic cross-reactivity among fish species remains to be investigated.

\section{Phylogenetic Analysis}

The evolutionary relationship of parvalbumins from fish and non-fish species is shown in Figure 4. Alpha-parvalbumin of the cartilaginous fish (thornback ray) was separated from the remaining parvalbumins of fish and non-fish species that were further divided into groups consisting of $\alpha$-parvalbumin $(\mathrm{pI} \geq 5)$ and $\beta$-parvalbumin $(\mathrm{pI} \leq 4.5)$. The $\alpha$ - and $\beta$-lineages of parvalbumins appears to have arisen from gene duplication of a common $\alpha \beta$ parvalbumin gene (Goodman and Pechère, 1977). The $\beta$-parvalbumins of teleosts, amphibians, reptiles and mammals are not clustered. Instead, the $\beta$-parvalbumins of teleosts (except zebrafish), amphibians, and reptiles were evolutionarily more closely related and were grouped together independently of the $\beta$-parvalbumins of mammals (pig, human, mouse, rat) and zebrafish. While the $\beta$-parvalbumin in fish muscles has been identified as an allergen, humans generally lack $\beta$-parvalbumin in muscles (Jenkins et al., 2007). The $\beta$-parvalbumin of mammals, also known as oncomodulin, was previously identified as an oncofetal protein that is absent from normal adult tissues of mammals. The oncomodulin expression is primarily confined to neoplastic tissues, placental cytotrophoblasts, and pre-implantation embryos (Permyakov, 2006). Later studies revealed that oncomodulin is also expressed by the outer hair cells of the Corti organ in rodents, which is the sole expression site for $\beta$-parvalbumin in adult mammals (Sakaguchi et al., 1998). The physiological role of oncomodulin is largely unknown, but proposed functions include acting like calmodulin in the signal transduction pathways or 
counteracting the actions of calmodulin in an antagonistic fashion (Pauls et al., 1996).

Figure 4 shows that the $\alpha$-parvalbumins of Actinopterygii (pike), Sarcopterygii (coelacanth), Chondrichthyes (shark), and Amphibia (frog and salamander) species are clustered together and are distantly related to the $\alpha$-parvalbumins of mammals and birds. The $\alpha$-parvalbumin is expressed abundantly in the fast twitch skeletal muscle of fish and amphibians, but less so in the fast twitch muscle of mammals and birds (Jenkins et al., 2007). The concentrations of parvalbumin in skeletal muscles differ markedly between human and rodent. Human muscle contains $\leq 0.001 \mathrm{~g}$ parvalbumin $/ \mathrm{kg}$ wet tissue, while rat muscle contains $2.4-3.3 \mathrm{~g}$ parvalbumin/kg wet tissue (Föhr et al., 1993). The expression pattern of $\alpha$-parvalbumin also differs between humans and other vertebrates; $\alpha$-parvalbumin is found in both extrafusal and intrafusal muscle fibers in rat, whereas the expression of $\alpha$-parvalbumin in restricted to the intrafusal fibers in human. The low volume ratio of intrafusal to extrafusal fibers, estimated at 1:5000 - 10000, is responsible for the minute amounts of parvalbumin in human muscles (Föhr et al., 1993). Stronger expression of $\alpha$-parvalbumin occurs in human cerebellum and kidney than muscle, thymus, lung, heart, and diaphragm. In contrast to chicken that expresses $\alpha$-parvalbumin in muscle and $\beta$-parvalbumin (avian thymic hormone) in thymus, human expresses exclusively $\alpha$-parvalbumin in thymus and muscle (Föhr et al., 1993). Currently, no report has indicated the allergenicity of $\alpha$-parvalbumin in fish and non-fish species other than frog (Jenkins et al., 2007).

\section{CONCLUSIONS}


Because fish-allergic individuals are prone to react only to parvalbumins from fish and frog, the conclusion that can be drawn from the present study is that the low sequence identity in the $\mathrm{AB}$ domains and the junctions between $\mathrm{AB}$ and $\mathrm{CD}$ domains of fish parvalbumins compared to parvalbumins from other species probably contributes to the wide cross-reactivity between fish species. Both calcium-binding motifs of Gad c 1 have been identified as IgE-binding epitopes despite the high sequence identities between fish and non-fish species within these regions. Therefore, the clinical significance of these epitopes would be predicted to be lower and remains to be validated. Further studies involving the simultaneous elucidation of either sequential or conformational $\operatorname{IgE}$ epitopes of multiple fish species using sera from fish-allergic individuals diagnosed with clinical cross-reactivity to the corresponding fish species would assist in understanding the variable cross-reactivity.

\section{REFERENCES}

Aalberse, R. C. 2000. Structural biology of allergens. J. Allergy Clin. Immunol. 106: 228-238.

Arif, S. H. 2009. A Ca2 ${ }^{+}$-binding protein with numerous roles and uses: parvalbumin in molecular biology and physiology. Bioessays 31: 410-421.

Bernhisel-Broadbent, J., S. M. Scanlon, and H. A. Sampson. 1992. Fish hypersensitivity. I. In vitro and oral challenge results in fish-allergic patients. J. Allergy Clin. Immunol. 89: 730-737.

Elsayed, S., and J. Apold. 1983. Immunochemical analysis of cod fish Allergen M: locations of the immunoglobulin binding sites as demonstrated by the native and synthetic peptides. Allergy 38: 449-459.

Felsenstein, J. 1993. PHYLIP (phylogeny inference package), version 3.67. Available at: http://evolution.genetics.washington.edu/phylip.html. Accessed December 5, 2011. 
Föhr, U. G., B. R. Weber, M. Müntener, W. Staudenmann, G. J. Hughes, S. Frutiger, et al. 1993. Human $\alpha$ and $\beta$ parvalbumin: structure and tissue-specific expression. Eur. J. Biochem. 215: 719-727.

Goodman, M., and J. F. Pechère. The evolution of muscular parvalbumins investigated by the maximum parsimony method. J Mol Evol. 9:131-58.

Hilger, C., L. Thill, F. Grigioni, C. Lehners, P. Falagiani, A. Ferrara, C. Romano, W. Stevens, and F. Hentges. 2004. IgE antibodies of fish allergic patients cross-react with frog parvalbumin. Allergy 59: 653-660.

Hoffmann-Sommergruber, and K., E. N. C. Mills. 2009. Food allergen protein families and their structural characteristics and application in component-resolved diagnosis: new data from the EuroPrevall project. Anal. Biol. Chem. 395: 25-35.

Jenkins, J. A., H. Breiteneder, and E. N. Mills. 2007. Evolutionary distance from human homologs reflects allergenicity of animal food proteins. J. Allergy Clin. Immunol. 120: 1399-1405.

Jones, D. T., W. R. Taylor, and J. M. Thornton. 1992. The rapid generation of mutation data matrices from protein sequences. Comput. Appl. Biosci. 8 (3): 275-282.

Kretsinger, R. H., and C. E. Nockolds. 1973. Carp muscle calcium-binding protein. II. Structure determination and general description. J. Biol. Chem. 248: 3313-3326.

Larkin, M. A., G. Blackshields, N. P. Brown, R. Chenna, P. A. McGettigan, H. McWilliam, et al. 2007. Clustal W and Clustal X version 2.0. Bioinformatics 23: 29472948.

Nakayama, S., and R. H. Kretsinger. 1994. Evolution of the EF-hand family of proteins. Annu. Rev. Biophys. Biomol. Struct. 23: 473-507.

Pauls, T. L., J. A. Cox, and M. W. Berchtold. 1996. The $\mathrm{Ca}^{2+}$-binding proteins parvalbumin and oncomodulin and their genes: new structural and functional findings. Biochim. Biophys. Acta 1306: 39-54.

Perez-Gordo, M., J. Lin, L. Bardina, C. Pastor-Vargas, B. Cases, F. Vivanco, et al. 2012. Epitope mapping of Atlantic salmon major allergen by peptide microarray immunoassay. Int. Arch. Allergy Immunol. 157: 31-40.

Permyakov, E. A. 2006. Parvalbumin. In V. N. Uversky (eds.), Molecular Anatomy and Physiology of Protein Series. Nova Science Publishers, Inc., New York, NY. pp. 5-52, 101-144. 
Permyakov, S. E., A. G. Bakunts, A. I. Denesyuk, E. L. Knyazeva, V. N. Uversky, and E. A. Permyakov. 2008. Apo-parvalbumin as an intrinsically disordered protein. Proteins 15: 822-836.

Saitou, N., and M. Nei. 1987. The neighbor-joining method: a new method for reconstructing phylogenetic trees. Mol. Biol. Evol. 4: 406-425.

Sakaguchi, N., M. T. Henzl, L. Thalmann, R. Thalmann, and B. A. Schulte. 1998. Oncomodulin is expressed exclusively by outer hair cells in the organ of Corti. J. Histochem. Chytochem. 46: 29-40

Swoboda, I., A. Bugajska-Schretter, B. Linhart, P. Verdino, W. Keller, U. Schulmeister, et al. 2007. A recombinant hypoallergenic parvalbumin mutant for immunotherapy of IgE-mediated fish allergy. J. Immunol. 178: 6290-6296.

Thompson, J. D., T. J. Gibson, F. Plewniak, F. Jeanmougin, and D. G. Higgins. 1997. The CLUSTAL_X Windows interface: flexible strategies for multiple sequence alignment aided by quality analysis tools. Nucleic Acids Res. 25: 4876-4882.

Valenta, R., B. Hayek, S. Seiberler, A. Bugajska-Schretter, V. Niederberger, A. Twardosz, et al. 1998. Calcium-binding allergens: from plants to man. Int. Arch. Allergy Immunol. 117: 160-166.

Van Do, T, S. Elsayed, E. Florvaag, I. Hordvik, and C. Endresen. 2005. Allergy to fish parvalbumins: studies on the cross-reactivity of allergens from 9 commonly consumed fish. J. Allergy Clin. Immunol. 116: 1314-1320.

Wopfner, N., O. Dissertori, F. Ferreira, and P. Lackner. 2007. Calcium-binding proteins and their role in allergic diseases. Immunol. Allergy Clin. N. Am. 27: 29-44.

Wnuk, W., and J. Jauregui-adell. 1983. Polymorphism in high-affinity calcium-binding proteins from crustacean sarcoplasm. Eur. J. Biochem. 131: 177-182.

Untersmayr, E., K. Szalai, A. B. Riemer, W. Hemmer, I. Swoboda, B. Hantusch, et al. 2006. Mimotopes identify conformational epitopes on parvalbumin, the major fish allergen. Mol. Immunol. 43: 1454-1461.

Yoshida, S., A. Ichimura, and K. Shiomi. 2008. Elucidation of a major IgE epitopes of Pacific mackerel parvalbumin. Food Chem. 111: 857-861. 
Table 1.Detailed information on the parvalbumin sequences from fish and non-fish species, including biological classifications for the source organisms of the parvalbumin sequences, sequence identification numbers (GI), and protein names. These parvalbumin sequences were used in the multiple sequence alignment and reconstruction of the phylogenetic tree.

\begin{tabular}{|c|c|c|c|c|c|c|c|}
\hline Class & Order & Family & Genus \& Species & Common name & $\mathbf{G I}^{\mathbf{1}}$ & Protein name & $\begin{array}{l}\text { Abbreviation }^{2} \\
\end{array}$ \\
\hline \multirow[t]{31}{*}{ Actinopterygii } & Gadiformes & Gadidae & Gadus morhua & Atlantic cod & 32363376 & parvalbumin beta (Gad m 1) & AtlCodB \\
\hline & & & Gadus callarias & Baltic cod & 131112 & parvalbumin beta (Gad c I) & BalCodB \\
\hline & & & Merlangius merlangus & Whiting & 3287979 & parvalbumin beta & whitingB \\
\hline & & & Theragra chalcogramma & Alaska pollock & 32363375 & parvalbumin beta (The c 1) & pollockB \\
\hline & & Merlucciidae & Merluccius merluccius & European hake & 131116 & parvalbumin beta & EuroHakeB \\
\hline & & & Merluccius bilinearis & Silver hake & 3024436 & parvalbumin beta & SilHakeB \\
\hline & Anguilliformes & Anguillidae & Anguilla japonica & Japanese eel & 165905303 & Parvalbumin & eel \\
\hline & Batrachoidiformes & Batrachoididae & Opsanus tau & Oyster toadfish & 131118 & parvalbumin beta (IIIF) & toadfishB \\
\hline & Clupeigoformes & Clupeidae & Sardinops melanostictus & Japanese pilchard & 165905301 & Parvalbumin & pilchard \\
\hline & Cypriniformes & Cyprinidae & Cyprinus carpio & Common carp & 131110 & Parvalbumin beta & carpB \\
\hline & & & & & 124012139 & Parvalbumin alpha (A1) & CarpA \\
\hline & & & Leuciscus cephalus & European chub & 131115 & parvalbumin beta $(\mathrm{V})$ & chubB \\
\hline & & & Danio rerio & Zebrafish & 33636707 & parvalbumin 9 & zebrafish \\
\hline & Cyprinodontiformes & Rivulidae & Rivulus marmoratus & Mangrove rivulus & 50953783 & parvalbumin 2 & Mangrove2 \\
\hline & & & & & 50953781 & parvalbumin 1 & mangrove 1 \\
\hline & Esociformes & Esocidae & Esox lucius & Northern pike & 131111 & parvalbumin beta & pikeB \\
\hline & & & & & 131097 & parvalbumin alpha & PikeA \\
\hline & Perciformes & Carangidae & Trachurus japonicus & Japanese jack mackerel & 77799798 & white muscle parvalbumin & J.mackerel \\
\hline & & Cichlidae & Oreochromis mossambicus & Mozambique tilapia & 71897458 & Parvalbumin & tilapia \\
\hline & & Latidae & Lates calcarifer & Barramundi perch & 56553755 & parvalbumin beta- 2 & perchB \\
\hline & & Lutjanidae & Lutjanus argentimaculatus & Mongrove red snapper & 148535026 & Parvalbumin & redsnapper \\
\hline & & Scombridae & Katsuwonus pelamis & Skipjack tuna & 165905307 & Parvalbumin & tuna \\
\hline & & & Scomber japonicus & Chub mackerel & 32363220 & Parvalbumin beta & CmackerelB \\
\hline & & Sparidae & Evynnis japonica & Crimson seabream & 165905305 & Parvalbumin & seabream \\
\hline & Pleuronectiformes & Paralichthyidae & Paralichthys olivaceus & Bastard halibut & 63029130 & Parvalbumin & halibut \\
\hline & Salmoniformes & Salmonidae & Coregonus clupeaformis & Lake whitefish & 169160074 & parvalbumin beta & whitefisB \\
\hline & & & Salmo salar & Atlantic salmon & 18281421 & parvalbumin beta $2($ Sal s 1$)$ & SalmonB2 \\
\hline & Gymnotiformes & Gymnotidae & Electrophorus electricus & Electric eel & 225027 & parvalbumin II & E.eel \\
\hline & & & Salvelinus alpinus & Arctic char & 22901922 & parvalbumin beta 542 & charB \\
\hline & Scorpaeniformes & Sebastidae & Sebastes inermis & Japanese stingfish & 87130759 & Parvalbumin & stingfish \\
\hline & Siluriformes & Ictaluridae & Ictalurus punctatus & Channel catfish & 27883551 & Parvalbumin & catfish \\
\hline
\end{tabular}

${ }^{1} \mathrm{GI}$ is the sequence identification number assigned consecutively to each sequence record processed by NCBI

2 The abbrevations for naming the source of the parvalbumin sequence in the sequence alignment and phylogenetic tree.

The capital letter A and B at the end of the abbreviations represent alpha and beta-parvalbumin, respectively. Parvalbumins that are known to be allergenic are represented in bold characters. 
Table 1. (cont.)

\begin{tabular}{|c|c|c|c|c|c|c|c|}
\hline Class & Order & Family & Genus \& Species & Common name & $\overline{\text { GI I }^{\mathbf{1}}}$ & Protein name & $\overline{\text { Abbreviation }}^{2}$ \\
\hline \multirow[t]{9}{*}{ Amphibia } & Anura & Pipidae & Xenopus tropicalis & "Western clawed frog & 62859433 & Parvalbumin & "WC.frog \\
\hline & & & Xenopus laevis & African clawed frog & 131120 & parvalbumin beta & AC.frogB \\
\hline & & Ranidae & Limnonectes macrodon & Fanged River Frog & 148356695 & Parvalbumin & FR.frog \\
\hline & & & Rana catesbeiana & Bullfrog & 27923002 & parvalbumin beta & BullfrogB \\
\hline & & & & & 27923000 & parvalbumin alpha & bullfrogA \\
\hline & & & Rana esculenta & Edible frog & 131119 & parvalbumin beta & e.frogB \\
\hline & & & & & 131106 & parvalbumin alpha & E.frogA \\
\hline & Caudata & Amphiumidae & Amphiuma means & Two-toed salamander & 131095 & parvalbumin alpha & Salamand.A \\
\hline & & & & & 131108 & parvalbumin beta & salamand.B \\
\hline Aves & Galliformes & Phasianidae & Gallus gallus & Chicken & 239564 & Parvalbumin & chicken \\
\hline \multirow[t]{2}{*}{ Chondrichythyes } & Carcharhiniformes & Triakidae & Triakis Semifasciata & Leopard shark & 266850 & parvalbumin alpha & sharkA \\
\hline & Rajiformes & Rajidae & Raja clavata & Thornback ray & 131104 & parvalbumin alpha & T.rayA \\
\hline \multirow[t]{13}{*}{ Mammalia } & Artiodactyla & Bovidae & Bos taurus & Cattle & 118573127 & parvalbumin alpha & cattleA \\
\hline & Carnivora & Felidae & Felis catus & Cat & 118600941 & parvalbumin alpha & catA \\
\hline & Rodentia & Caviidae & Cavia porcellus & Domestic guinea pig & 1709811 & parvalbumin alpha & PigA \\
\hline & & & & & 3122578 & oncomodulin (parvalbumin beta) & pigB \\
\hline & Lagomorpha & Leporidae & Oryctolagus cuniculus & European Rabbit & 118600944 & parvalbumin alpha & rabbitA \\
\hline & Primates & Cercopithecidae & Macaca fuscata & Japanese Macaque & 118600943 & parvalbumin alpha & macaqueA \\
\hline & & Hominidae & Homo sapiens & Human & 131100 & parvalbumin alpha & humanA \\
\hline & & & & & 417401 & oncomodulin (parvalbumin beta) & HumanB \\
\hline & Rodentia & Muridae & Mus musculus & House mouse & 3334478 & parvalbumin alpha & mouseA \\
\hline & & & & & 1709467 & oncomodulin (parvalbumin beta) & MouseB \\
\hline & & & Rattus norvegicus & Norwegian rat & 11968064 & Parvalbumin & rat \\
\hline & & & & & 129169 & oncomodulin (parvalbumin beta) & RatB \\
\hline & & & Gerbillus sp. & Gerbil & 118600942 & parvalbumin alpha & gerbilA \\
\hline \multirow[t]{2}{*}{ Reptilia } & Squamata & Boidae & Boa constrictor & Boa snake & 131109 & parvalbumin beta & snakeB \\
\hline & Testudines & Emydidae & Graptemys geographica & Map turtle & 131113 & parvalbumin beta & turtleB \\
\hline \multirow[t]{2}{*}{ Sarcopterygii } & Coelacanthiformes & Latimeriidae & Latimeria chalumnae & Coelacanth & 131114 & parvalbumin beta & Coelacan.B \\
\hline & & & & & 131101 & parvalbumin alpha & Coelacan.A \\
\hline
\end{tabular}

${ }^{1} \mathrm{GI}$ is the sequence identification number assigned consecutively to each sequence record processed by NCBI

${ }^{2}$ The abbrevations for naming the source of the parvalbumin sequence in the sequence alignment and phylogenetic tree.

The capital letter A and B at the end of the abbreviations represent alpha and beta-parvalbumin, respectively. Parvalbumins

that are known to be allergenic are represented in bold characters. 


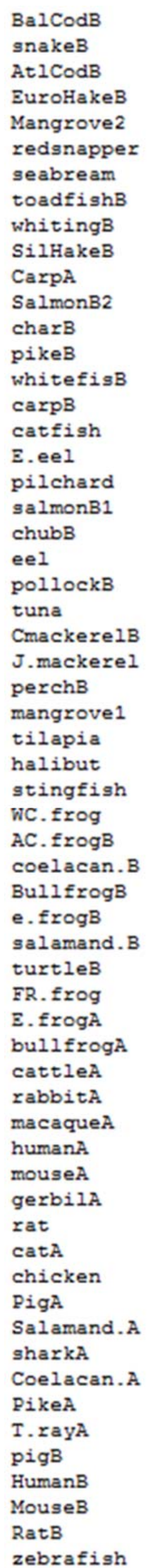

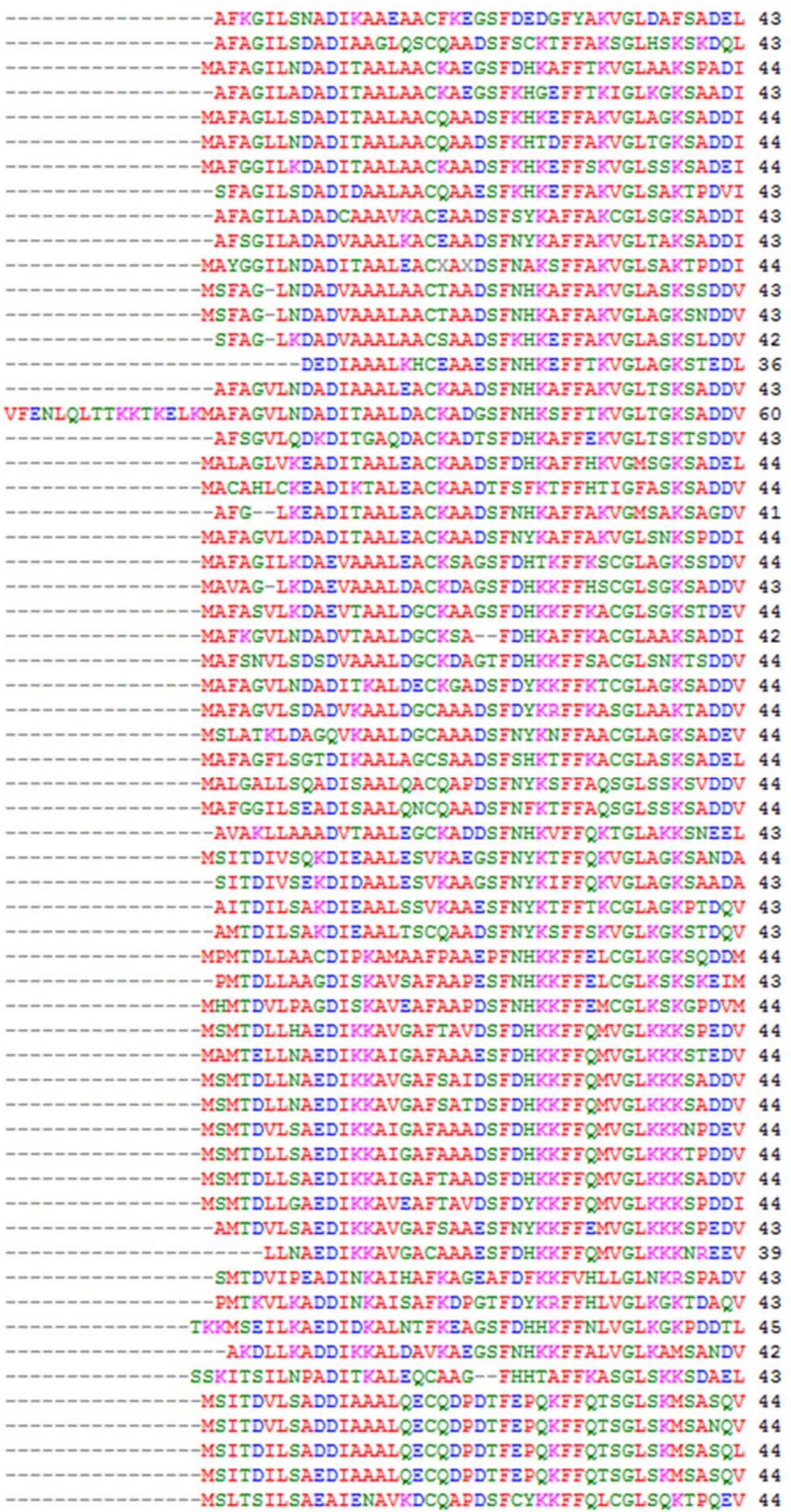




\begin{tabular}{|c|c|c|c|c|c|}
\hline BalCodB & KKLE: & & FAADLRALTDAETKAFLKAC & DSDGDGKIGVDE & 目EG 10 \\
\hline snakeB & TKVIG & DRDKSGYIEEDE & LKKFLQNFDGKARDITDKETAEFLKE & DTDGDGKIGVEB & AIV 1 \\
\hline$t 1$ CodB & 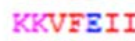 & DQDKSDEVEEDE & LFLQNESAGARALSDAETKVFLKAd & DSDGDGKIGVDE & 目EG \\
\hline uroHakeB & WFGII & PQDKSDFVEEDE & LKLFLQNESAGARALTDAETATFLKAO & DSDGDGKIGVE: & FA 1 \\
\hline angrove 2 & 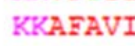 & PQDKSGEIESDE & LKLFLQNFSASARALTDAETKTFLKAC & DSDGDGKIGVDE & FA 1 \\
\hline edsnapper & KAFAVI & PQDKSGEIEEDE & LKLFLQNFKGGARALTDDETKTFLKAd & DTDGDGKIGA. & FA 1 \\
\hline bream & & DQDKSGEIEEDE & LKLFLQNFKAGARALTDEETKKFLKAD & DSDGDGKIGA. & $2 \mathrm{~A}$ \\
\hline padfish $B$ & KAFYVI & PQDKSGIIEDA & LKLFLQNFASSARALTDKETETFLKA & DSDGDGKIGI & FA 10 \\
\hline witingB & KAFVEI & PQDRSGEIEEDE & LKLFLQVFKAGARALTDAETKAFLKA & DSDGDGAIGV & gr 10 \\
\hline SilHakeB & KAFF & PQDKSGEIEEI & LKLFLQVFSAGARALTDAETKAFLKAC & DSDGDGAIGVDE & 可 10 \\
\hline CarpA & CAFA & DQDKSGEIEEDE & LKLFLQNESAGARALTDAETKAFLKAd & DSDGDGKIGVDE & 目FA 10 \\
\hline SalmonB2 & KAFYVI & PQDKSGEIEEDA & LKLFLQNESASARALTDAETKAFLAD & DKDGDGMIGVDE & 目FA 10 \\
\hline $\operatorname{char} \mathrm{B}$ & KAAFYVI & PQDRSGFIESDE & LKLFLQNESASARALTDAETKAFLAD & DKDGDGMIGV & EA 10 \\
\hline pikeB & KAFY & PQDKSGEIEEI & LKLFLQNISPSARALTDAETKAFLAD & DKDGDGMIGV & 目 10 \\
\hline hitefisB & KAFY & PQDKSGEIEEI & LKLFLQTFSAGARALTDKETKAFLAAC & DVDGDGMIGVDE & 目A 96 \\
\hline $\operatorname{arpB}$ & KAFA & PQDKSGEIEEDE & LKLFLQNFKADARALTDGETKTFLKA & DSDGDGKIGV & 目I 10 \\
\hline catfish & KAFA & DODKSGFIEED & LKLFLQNEKSSARALTDAETKTFLKA & DTDGDGKIGV & EA 12 \\
\hline E.eel & KKAFA & DEDKSGFIEEI & LKLFLQNFKDGGRALTDAETKAVMAQ & DKDGDGKIGVEB & 目S 10 \\
\hline ilchard & zSTA & DQDKSGEIEEES & LKLFLQNFCKKARALTDGETKNFLKAd & DTDGDGKIGI & FN 10 \\
\hline salmonB1 & KAFK & PQDASGIIEVEA & LKLFLQNFCPKARELTDAETKAFLKA & DADGDGMIGI & 目A 10 \\
\hline chubB & KAFE & DEDKSGFIEEES & LKLFLQNFKAGARALTDAETKIFLKAO & DADGDGKIGI & 目 10 \\
\hline eel & KAIS & DQDKSGEIEE: & LKLFLQNFSKGARALTDKETKAFLQAC & DTDGDGKIGIDE & 目FA 10 \\
\hline $0110 c k B$ & 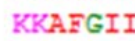 & PQDQSDEIEEES & LKLFLQNESASARALSDAETKAFLKAC & DSDGDGKIGV & 目FA 10 \\
\hline Euna & KKAFA & PQDKSGEIEEES & LKLFLQNFKSSARALSDAETKAFLIAC & DSDGDGKIGVDE & 目FA 10 \\
\hline CmackerelB & KKAFA & DQDKSGFIEEES & LKLFLQNFKAGARALSDAETKAFLKAC & DSDGDGKIGIDE & 目A 10 \\
\hline ckerel & KAFA & PQDKSGEIEEDE & LKLFLQNFCAGARALSDAETKAFLKAC & DSDGDGKIGV & 目A 10 \\
\hline perchB & -1 & DQDKSGEIEEES & LKLFLQNFKADARVLTDVETSTFLKAd & DTDGDGKIG: & EI 10 \\
\hline langrove 1 & KKAFAII & PQDKSGEIEEDE & LKLFLQNFSGGARALTDAETKAFLKAO & DSDGDGKIGA. & 目FA 10 \\
\hline tilapia & CKAFKII & DQDNSGFIEESE & LKLFLQNESAGARALTDKETKAFLSAC & DSDGDGKIGI & 目A 10 \\
\hline halibut & VAFGVI & PQDGSGEIES: & LKLFLQNESAGARALTDKETKEFLAAC & DSDGDGKIGVE: & 目F 10 \\
\hline stingfish & KAFAII & DQDNSAYIEEES & LKLFLQNFAAGARALTDKETKTFLAAC & DSDGDGKI & FI 10 \\
\hline wc. frog & RNAFAII & PQDKSGIIEEDE & LKLFLQNESAGARALIDAETKAFLNAC & DSDGDGKIGVDE & 目Q 10 \\
\hline$A C . f r o g B$ & RNVEAII & PQDRSGFIEEES & LKLFLQNFSASARALTDAETKAFLAAC & DSDGDGKIGVEZ & 目殒 10 \\
\hline coelacan. B & BAIFKII & PQDKSGEIEDEA & LELFLQNESAGARTLTKTETETFLKAd & DSDGDGKIGV & 目E 10 \\
\hline BullfrogB & KVFEII & DRDRSGFIEEED & LCLFLQNFKSNARALSSAETAAFLKAO & DSDGDGKIGVEA & 目Q 10 \\
\hline e. $f r o g B$ & CKVEEII & PRDKSGFIEQDE & LGLFLNFRASARVLSDAETSAFLKAC & DSDGDGKIGVE: & 取 10 \\
\hline salamand. B & KKVFDII & PQDKSGYIEEDE & LQLFLKNICSSARSLSNAETKAFLFAd & DSDGDGKIGVDE & 目EQ 10 \\
\hline turtleB & KKIFGII & DQDKS & LQLFLNESSTARALTAAETKAFMAAC & DTDGDGKIG & A $E Q \quad 10$ \\
\hline FR.frog & KVFHMI & DKDQSGEIIKDE & LALILKGETPEGRDLSDKETTALLAAd & DKDGDGKIGV & 目F 10 \\
\hline E. frogA & QKVFHVI & PQDQSGFIEKEE & LCLILKGFTPEGRSLSDKETTALLAAC & DKDGDGKIGVDE & 目FV 10 \\
\hline bullfrogA & KQVEGII & PQDRSGEIEEDE & LCLMLKGFTPNARSLSVKETTALLAAd & DKDGDGKIGMDE & 目FV 10 \\
\hline cattleA & KKVFHII & PKDKSGFIEEES & LGFILKGFSPDARDLSVKETKTLLAAd & DKDGDGKIGP. & FS 10 \\
\hline rabbitA & KVVFHII & DKDKSGEIEEES & LGFILKGFSPDARDLSVKETKTLMAAd & DKDGDGKIGADE & 目S 10 \\
\hline macaqueA & KKVFHII & PKDKSGIIEEDE & LGEILKGESPDARDISAKETKILMAAC & DKDGDGKIGV & 目S 10 \\
\hline humanA & KKVFHMI & DKDKS & LGFILKGESPDARDLSAKETKMLMAAC & DKDGDGKI & 目S 10 \\
\hline mouseA & KKVEHII & DKDKSGFIEE: & LGSILKGESSDARDLSAKETKTLLAAC & DKDGDGKIGVEE & 目S 10 \\
\hline gerbilA & KVFHII & DKDKSGEIEEDE & LGFILKGFSSDARDLSAKETKILLAAd & DKDGDGKIGVEE & 目S 10 \\
\hline rat & KKVEHII & DKDKSGEIESDE & LGSILKGFSSDARDLSAKETKTLMAAd & DKDGDGKIGVEA & 目S 10 \\
\hline $\operatorname{cat} A$ & KKVFHII & DKDKSGEIEEDE & LGEILKGFYPDARDLSVKETKMLMAAd & DKDGDGKIDV & 国F 10 \\
\hline chicken & KKVFHII & DKDRSGFIEEED & LKFVLKGTTPDGRDLSDKETKALLAAC & DKDGDGKIGA. & FA 10 \\
\hline PigA & KMVEQII & DKDKSGEIEEEZ & LKEILKGFSADARDLSDTETKRMMAAC & DKDGDGKIGA & --95 \\
\hline Salamand. A & TKAFHII & DKDRSGYIEIEZ & LQIILKGFSKEGRELTDKETKDLIIKA & DKDGDGKIGV & 目F 10 \\
\hline sharkA & KEVIEII & DKDQSGEIEEIE & LKGVLKGESAHGRDLNDTETKALLAAd & DSDHDGKIGADE & 国F 10 \\
\hline Coelacan.A & KEVEGII & DQDKSGYIEEEZ & LKFVLKGFAAGGRELTANETKALLKA & DQDGDDKIGVDE & IIT 10 \\
\hline PikeA & KKVEKAI & DADASGEIEEEZ & LKFVLKSFAADGRDLTDAETKAFLKAD & DKDGDGKIGIDE & 目FE 10 \\
\hline T. rayA & AEIENVI & DGDQSGYIEVE & LKNFLKCFSDGARVLNDKETSNFLAAC & DSDGDHKIGVDE & 目F 10 \\
\hline pigB & KDVEREI & DNDQSGYLDEEZ & LKEFLQKFESGARELTESETKSLMAAA & DNDGDGKIGADE & FQ 10 \\
\hline HumanB & KDVEREI & DNDQSGYLDEEB & LKFFLQKFESGARELTESETKSLMAAA & DNDGDGKIGAEB & 目Q 10 \\
\hline MouseB & KDIFQEI & DNDQSGYLDEDE & LKYFLQRFQSDARELTESETKSLMDAI & DNDGDGKIGA & 目浭 10 \\
\hline RatB & KDIFREI & DNDQSGYLDGDE & LKYFLQKEQSDARELTESETKSLMDAP & DNDGDGKIGADE & 目政 10 \\
\hline ebraf & KDVERII & DEDNSGEIEEAD & LKEFLQREFPGARTLTEKEIKSLITAA & DDDSDGRIGV & \\
\hline & & $t+\ldots:=:$ & $++\ldots+$ : &.++++ & \\
\hline
\end{tabular}




\begin{tabular}{|c|c|c|}
\hline BalCodB & ALVDKWGAKG & 113 \\
\hline snakeB & VLVTKG---- & 109 \\
\hline AtlCodB & AMIKA----- & 109 \\
\hline EuroHakeB & AMVKG----- & 108 \\
\hline Mangrove 2 & ALVKG----- & 109 \\
\hline redsnapper & AMVKA---- & 109 \\
\hline seabream & BMVKV----- & 109 \\
\hline toadfishB & DLVKEA---- & 109 \\
\hline whitingB & ALVKA----- & 108 \\
\hline SilHakeB & ALVKA----- & 108 \\
\hline CarpA & ALVKA----- & 109 \\
\hline SalmonB2 & AMIKG----- & 108 \\
\hline charB & AMIKG---- & 108 \\
\hline pikeB & AMIKA----- & 107 \\
\hline whitefisB & TLVKA----- & 101 \\
\hline $\operatorname{carpB}$ & ALVKA----- & 108 \\
\hline catfish & SLVKA----- & 125 \\
\hline E.eel & ALVKA---- & 108 \\
\hline pilchard & HLVKH----- & 109 \\
\hline salmonB1 & VLVKQ----- & 109 \\
\hline chubB & ALVKA----- & 106 \\
\hline eel & AVVKA----- & 109 \\
\hline pollockB & AMVKA----- & 109 \\
\hline tuna & ALVKKH----- & 108 \\
\hline CmackerelB & AMIKG----- & 109 \\
\hline J.mackerel & AMVKH----- & 107 \\
\hline perch $B$ & ALVKP----- & 109 \\
\hline mangrove 1 & VMVKA----- & 109 \\
\hline tilapia & ALVKA----- & 109 \\
\hline halibut & ALVKA----- & 109 \\
\hline stingfish & ALVKA----- & 109 \\
\hline พC.frog & ALVKA----- & 109 \\
\hline$A C . f r o g B$ & SLVKR----- & 109 \\
\hline coelacan. B & KLVKA----- & 108 \\
\hline BullfrogB & ALVKA----- & 109 \\
\hline e. $f r o g B$ & ALVKA----- & 108 \\
\hline galamand. B & ALVRS----- & 108 \\
\hline turtleB & ALVKA----- & 108 \\
\hline FR.frog & KLVSEC---- & 110 \\
\hline E. $f r o g A$ & TLVSES---- & 109 \\
\hline bullfrogA & TLVSES---- & 110 \\
\hline cattleA & TLVAES---- & 110 \\
\hline rabbitA & TLVSES---- & 110 \\
\hline macaqueA & TLVAES---- & 110 \\
\hline humanA & TLVAES---- & 110 \\
\hline mouseA & TLVAES---- & 110 \\
\hline gerbilA & TLVSES---- & 110 \\
\hline rat & TLVAES---- & 110 \\
\hline catA & SLVAKS---- & 110 \\
\hline chicken & TMVAES---- & 109 \\
\hline PigA & ------- & \\
\hline Salamand.A & SLVAES---- & 109 \\
\hline sharkA & KMVAQA---- & 109 \\
\hline Coelacan.A & NLVKAA---- & 111 \\
\hline PikeA & TLVHEA---- & 108 \\
\hline T.rayA & SMAKMT---- & 109 \\
\hline pigB & BMVHS----- & 109 \\
\hline HumanB & BMVHS----- & 109 \\
\hline MouseB & BMVHS----- & 109 \\
\hline RatB & EMVHS--- & 109 \\
\hline zebraf & TMVSS----- & 109 \\
\hline
\end{tabular}


Figure 1. Multiple alignment of the parvalbumin sequences from fish and non-fish species using Clustal W program. The amino acid residues are color-coded according to their physicochemical properties: small and hydrophobic amino acids (AVFPMILW) are red; acidic amino acids (DE) are blue; basic amino acids (RK) are magenta; amino acids with hydroxyl, sulfhydryl, and amine groups, and glycine (STYHCNGQ) are green; unusual amino or imino acids are grey. The symbols shown below the alignments denote the degree of conservation observed in each column: an asterisk ' $*$ ' indicates identical residue in all sequences; a colon ':' indicates highly conserved sequences; a period '.' indicates weakly conserved sequences. The numbers at the end of each sequence correspond to the position of last residues in each row, and the sequences in brackets correspond to the 2 conserved calcium-binding regions in parvalbumins. Gaps are indicated by hypens. The capital letter A and B at the end of the organism names represent alpha- and beta-parvalbumin, respectively. 
BalCodB AFKGILSNADIKAAEAACFKEGSFDEDGFYAKVGLDAFSADELKKLFKIADEDKEGFIEEDELK 64

BalCodB LFLIAFAADLRALTDAETKAFLKAGDSDGDGKIGVDEFGALVDKWGAKG 113

Figure 2. Sequence of $\beta$-parvalbumin from Baltic cod $(\operatorname{Gad} \mathrm{c} 1)$. The red brackets indicate linear IgE-binding epitopes, and the underlined residues indicate calcium-binding motifs. 
Nercems idemithy

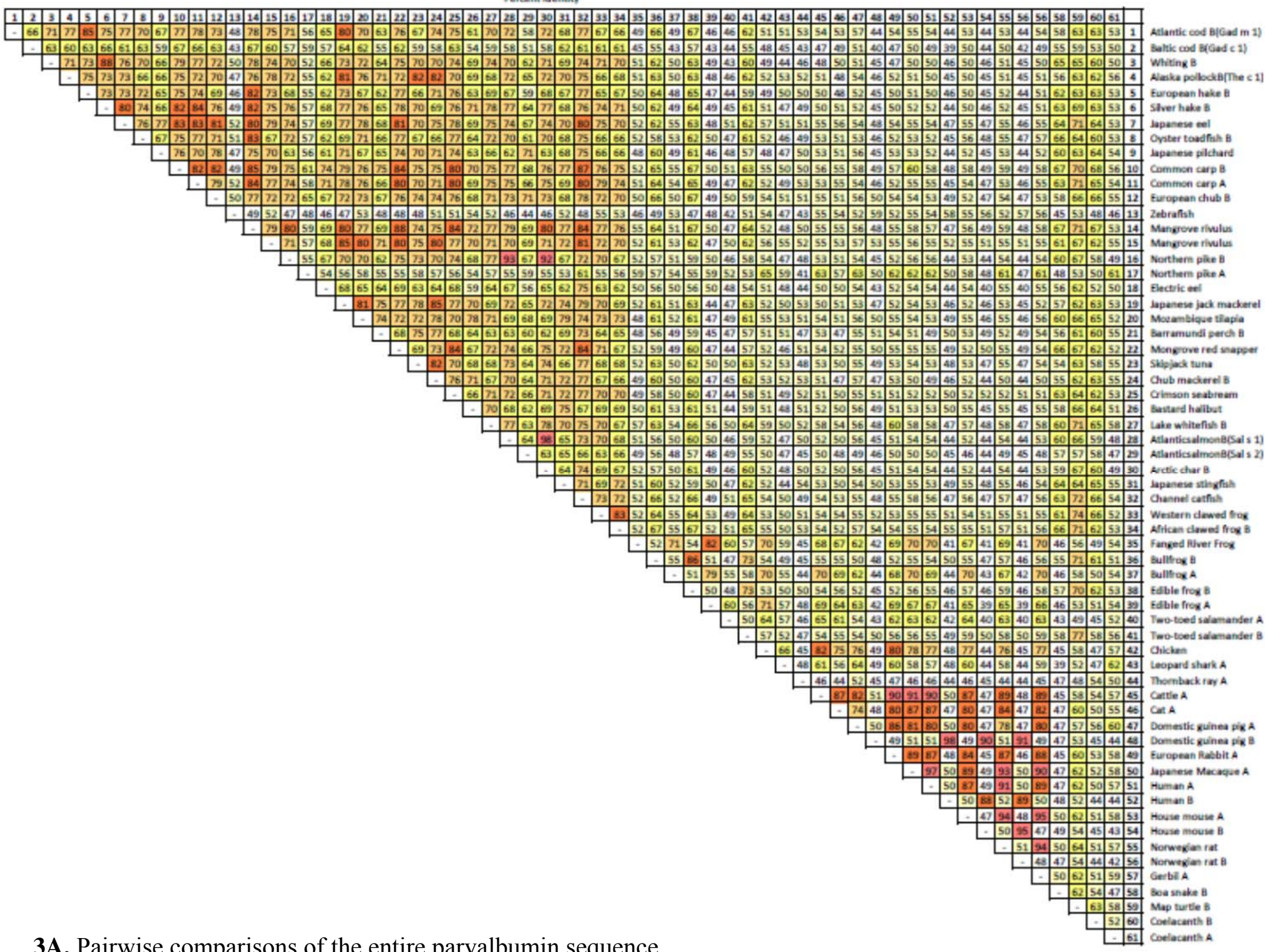




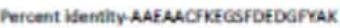

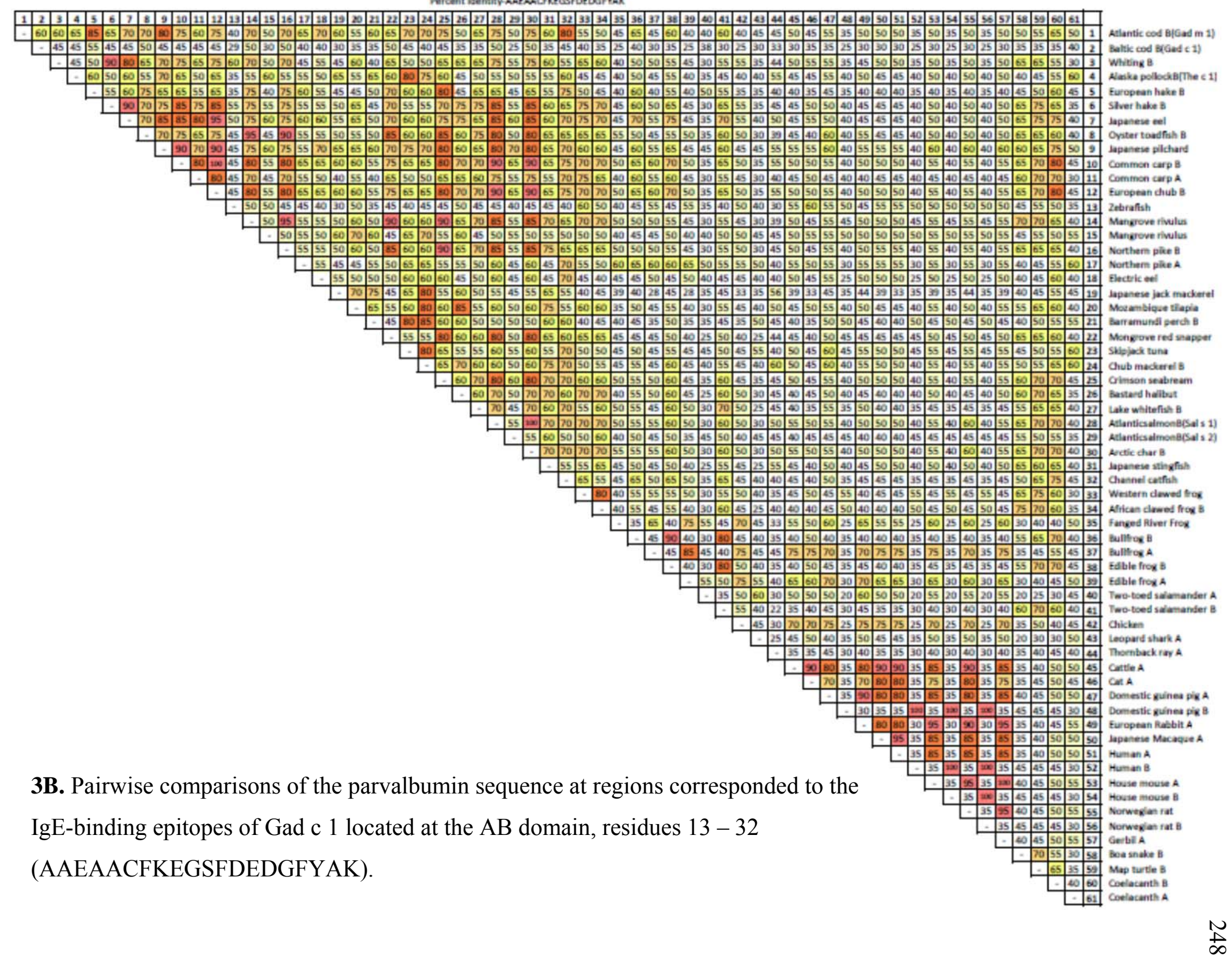


Percent identity VGKoAPSADELK

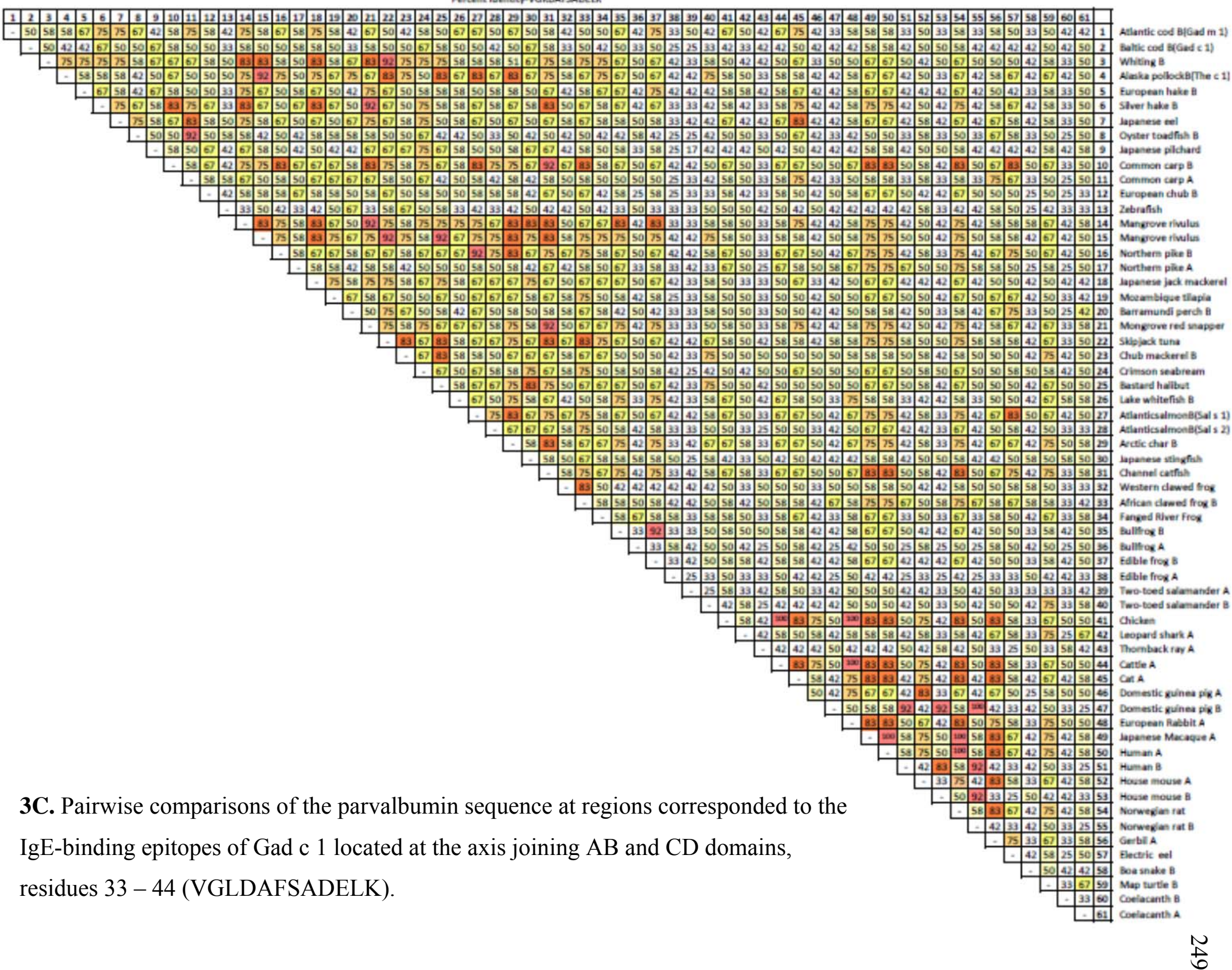


Percent WSentity-LADEDKEGFEFDELK




Percent Uemity LFUAFAMOL

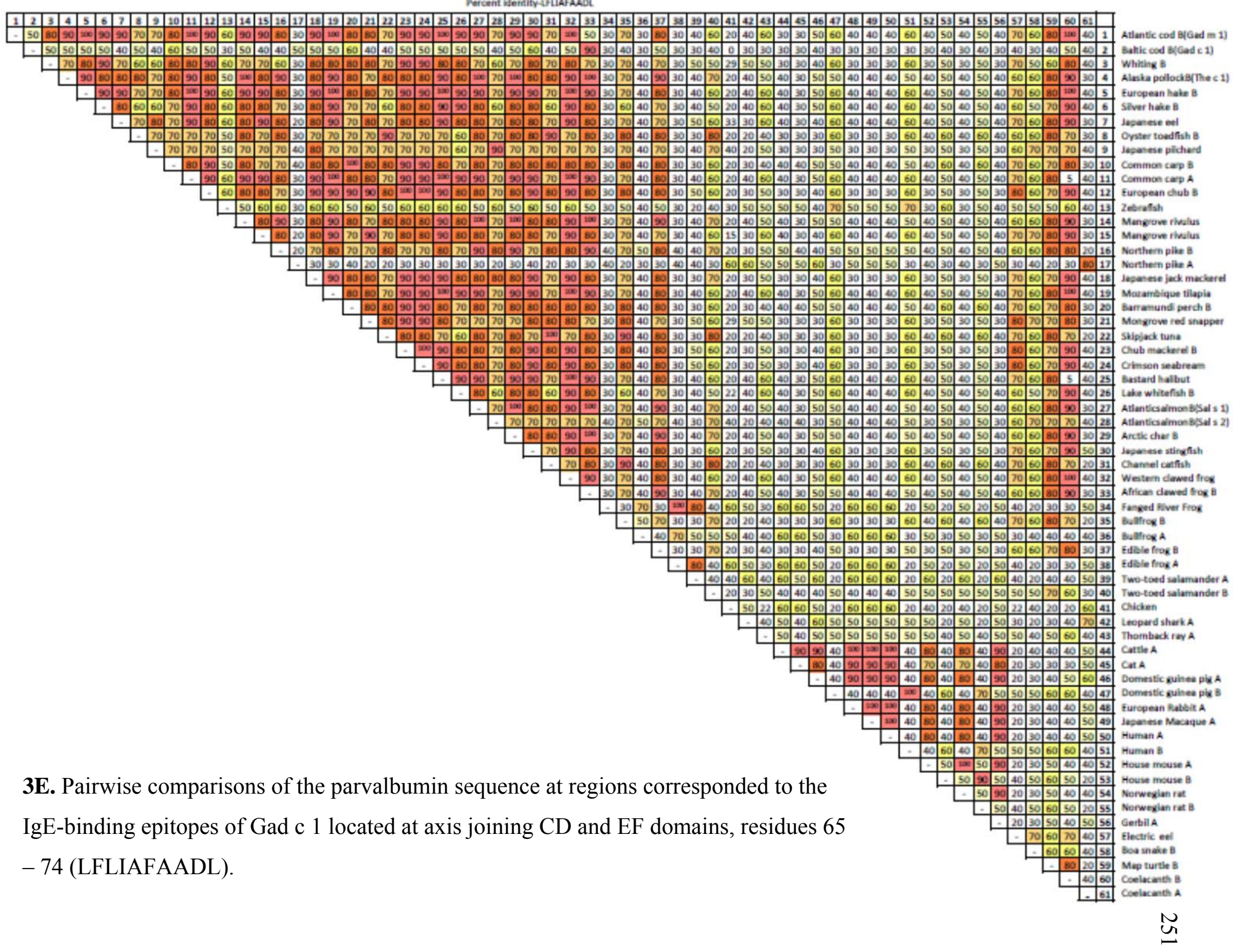


Peicent idenetity AGDSDGDOK

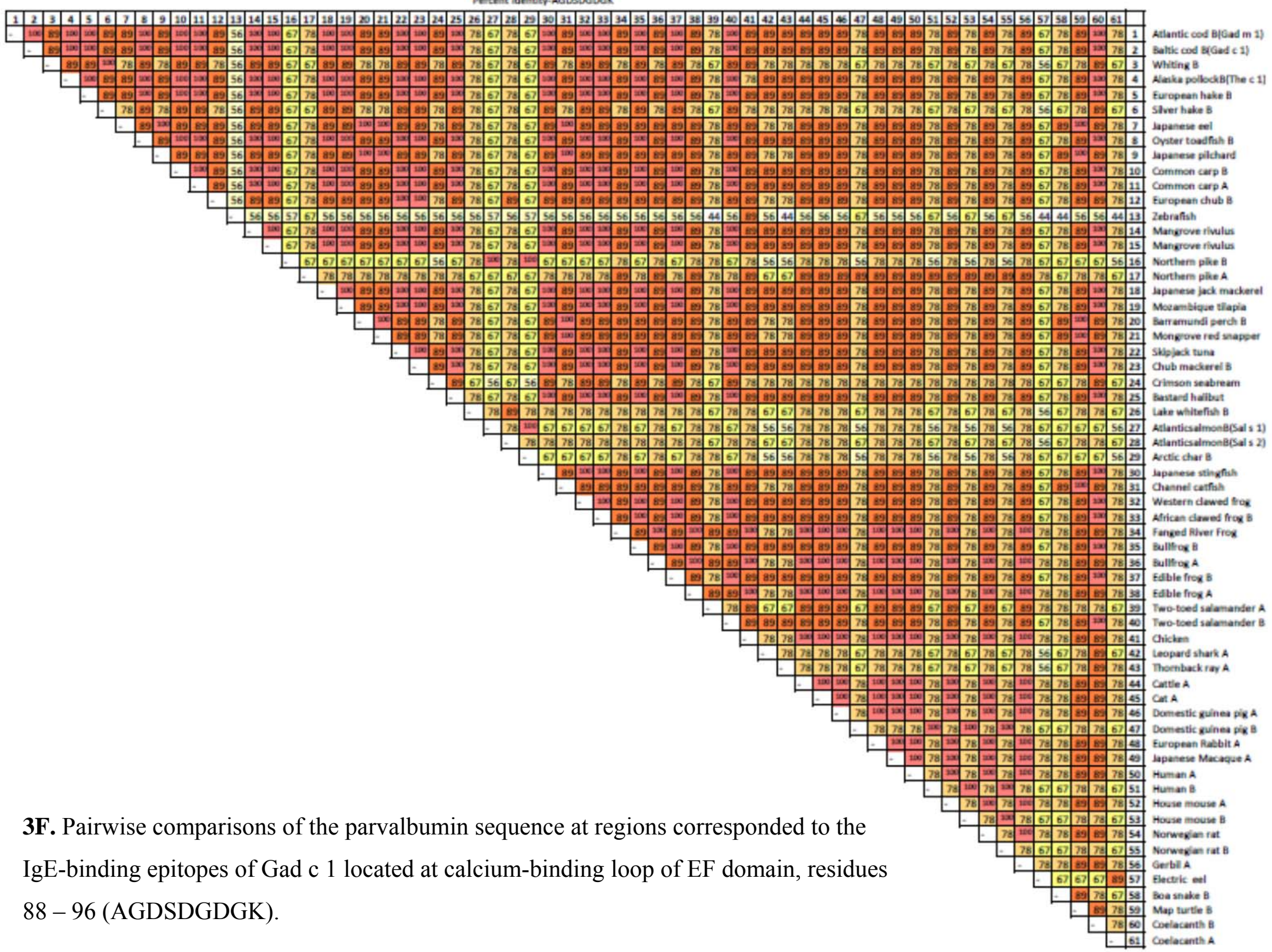


Percent idemity-AGOSOGDGoOvDEFC

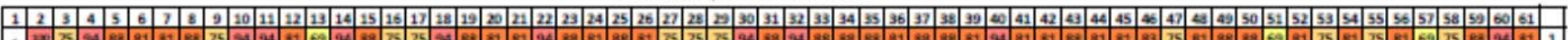
\begin{aligned}-75 \\ \hline\end{aligned}

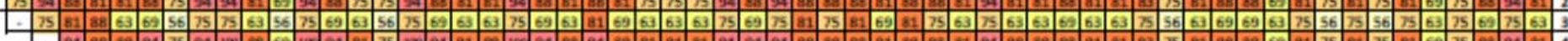

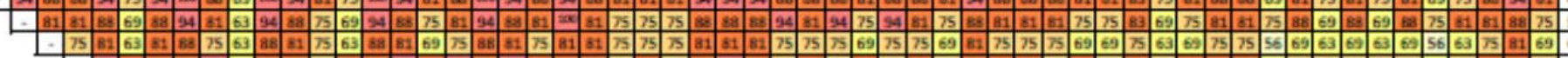

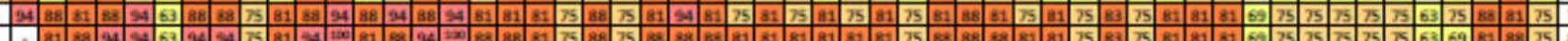

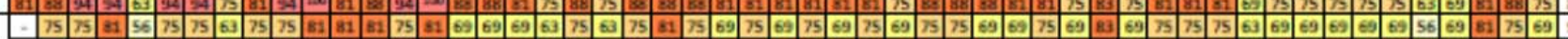

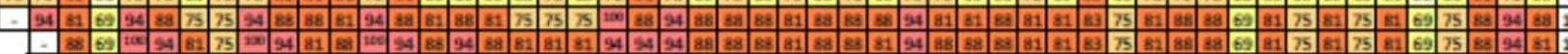

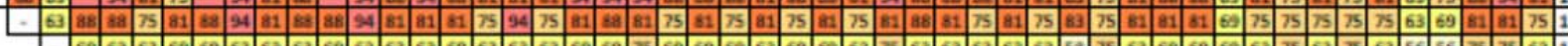

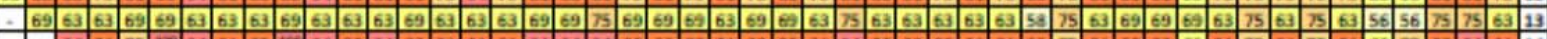

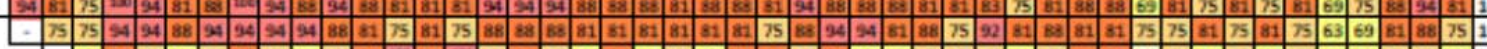

\begin{tabular}{l}
69 \\
\hline
\end{tabular}

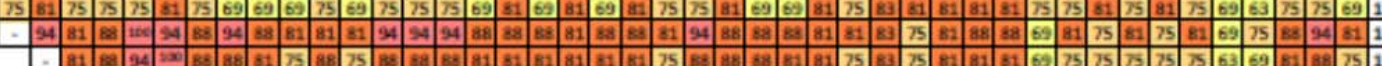

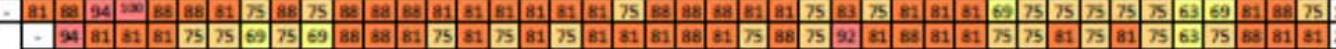

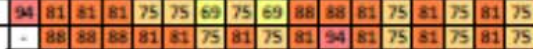

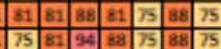

$\mathrm{ses}$

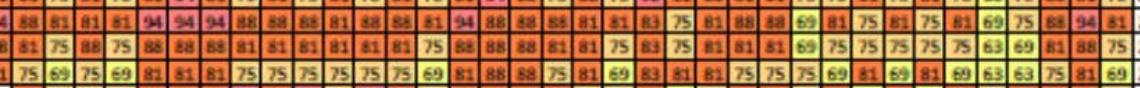

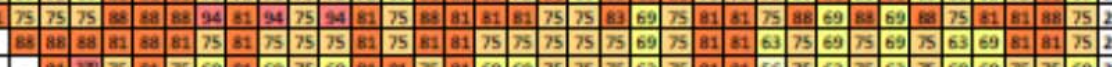

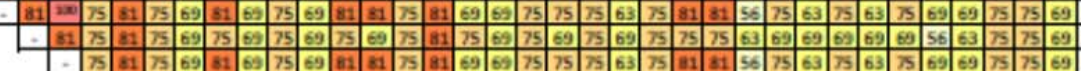

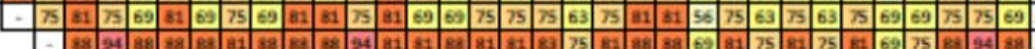

\begin{aligned}-4 \\ \hline\end{aligned}

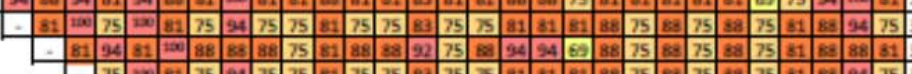

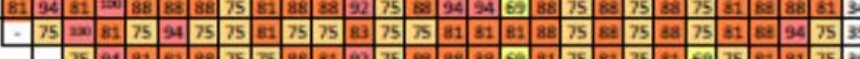

75

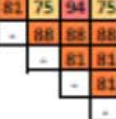

3G. Pairwise comparisons of the parvalbumin sequence at regions corresponded to the

IgE-binding epitopes of Gad c 1 located at calcium-binding loop of EF domain, residues

88 - 103 (AGDSDGDGKIGVDEFG). 
Figure 3. Pairwise comparisons of the parvalbumin sequences between fish and non-fish species. Numbers on the top row and the outer right-hand side of column represent numbers assigned to parvalbumin sequences from different organisms. The remaining numbers in the color-coded boxes correspond to the percent identity (\% ID) computed from the alignment of parvalbumin sequences that encompass the entire sequence length (3A), and 6 different regions corresponded to IgE-binding epitopes of Gad c 1, including AAEAACFKEGSFDEDGFYAK (3B), VGLDAFSADELK (3C), IADEDKEGFIEEDELK (3D), LFLIAFAADL (3E), AGDSDGDGK (3F), and AGDSDGDGKIGVDEFG (3G). The boxes are colored according to the $\%$ ID: $<49 \%$ is white; $50-59 \%$ is light yellow; $60-69 \%$ is dark yellow; $70-79 \%$ is light orange; $80-89 \%$ is dark orange; $90-100 \%$ is dark pink. The capital letter A and B at the end of the organism names represent alpha- and beta-parvalbumin, respectively. 
Table 2. Comparisons of the \% ID of parvalbumin sequences among fish species in the class of Actinopterygii, and non-fish species, specifically human $\alpha$ - or $\beta$-parvalbumin

\begin{tabular}{|c|c|c|c|c|c|}
\hline \multirow{2}{*}{\multicolumn{2}{|c|}{ Parvalbumin sequence }} & \multicolumn{4}{|c|}{ Percent identity (\% ID) } \\
\hline & & \multirow{2}{*}{$\begin{array}{c}\text { Among } \\
\text { Actinopteryii } \\
43 \%-98 \%^{2} \\
69 \%{ }^{3} \\
\end{array}$} & \multirow{2}{*}{$\begin{array}{c}\begin{array}{c}\text { Actinopteryii } \\
\text { versus Others }\end{array} \\
39 \%-79 \% \\
54 \% \\
\end{array}$} & \multirow{2}{*}{$\begin{array}{c}\text { Actinopterygii } \\
\text { versus human } \\
\text { a-parvalbumin } \\
49 \%-62 \% \\
53 \%\end{array}$} & \multirow{2}{*}{$\begin{array}{c}\text { Actinopterygii } \\
\text { versus human } \\
\text { B-parvalbumin } \\
39 \%-58 \% \\
47 \% \\
\end{array}$} \\
\hline & Entire sequence & & & & \\
\hline \multirow{6}{*}{$\begin{array}{l}\text { IgE- } \\
\text { binding } \\
\text { epitopes } \\
\text { located at }\end{array}$} & $\begin{array}{c}\text { AB domain } \\
\text { (residues 13-32) }\end{array}$ & $\begin{array}{c}25 \%-100 \% \\
62 \%\end{array}$ & $\begin{array}{c}25 \%-80 \% \\
48 \%\end{array}$ & $\begin{array}{c}30 \%-50 \% \\
47 \%\end{array}$ & $\begin{array}{c}25 \%-50 \% \\
39 \%\end{array}$ \\
\hline & $\begin{array}{l}\text { Axis joining AB and CD domain } \\
\text { (residues 33-44) }\end{array}$ & $\begin{array}{c}33 \%-92 \% \\
62 \%\end{array}$ & $\begin{array}{c}25 \%-83 \% \\
52 \%\end{array}$ & $\begin{array}{c}42 \%-83 \% \\
67 \%\end{array}$ & $\begin{array}{c}33 \%-67 \% \\
44 \%\end{array}$ \\
\hline & $\begin{array}{c}\mathrm{Ca}^{2+} \text {-binding loop of CD domain } \\
\text { (residues 49-64) }\end{array}$ & $\begin{array}{c}56 \%-100 \% \\
85 \% \\
\end{array}$ & $\begin{array}{c}44 \%-94 \% \\
70 \% \\
\end{array}$ & $\begin{array}{c}50 \%-75 \% \\
70 \% \\
\end{array}$ & $\begin{array}{c}44 \%-63 \% \\
58 \% \\
\end{array}$ \\
\hline & $\begin{array}{l}\text { Axis joining CD and EF domain } \\
\text { (residues 65-74) }\end{array}$ & $\begin{array}{c}20 \%-100 \% \\
73 \%\end{array}$ & $\begin{array}{c}15 \%-100 \% \\
48 \%\end{array}$ & $\begin{array}{c}20 \%-50 \% \\
37 \%\end{array}$ & $\begin{array}{c}30 \%-70 \% \\
55 \%\end{array}$ \\
\hline & $\begin{array}{l}\mathrm{Ca}^{2+} \text {-binding loop of EF domain } \\
\text { (residues 88-96) }\end{array}$ & $\begin{array}{c}44 \%-100 \% \\
83 \% \\
\end{array}$ & $\begin{array}{c}44 \%-100 \% \\
83 \% \\
\end{array}$ & $\begin{array}{c}56 \%-89 \% \\
85 \% \\
\end{array}$ & $\begin{array}{c}56 \%-89 \% \\
74 \% \\
\end{array}$ \\
\hline & $\begin{array}{l}\mathrm{Ca}^{2+} \text {-binding loop of EF domain } \\
\text { (residues } 88-103 \text { ) }\end{array}$ & $\begin{array}{c}56 \%-100 \% \\
82 \% \\
\end{array}$ & $\begin{array}{c}56 \%-94 \% \\
78 \%\end{array}$ & $\begin{array}{l}69 \%-88 \% \\
82 \% \\
\end{array}$ & $\begin{array}{c}56 \%-75 \% \\
68 \% \\
\end{array}$ \\
\hline
\end{tabular}

${ }^{1}$ Others include organisms in the class of Amphibia, Aves, Chondrichythyes, Mammalia, Reptilia, and Sarcopterygii ${ }^{2}$ Range of $\%$ ID

${ }^{3}$ Average of $\%$ ID 


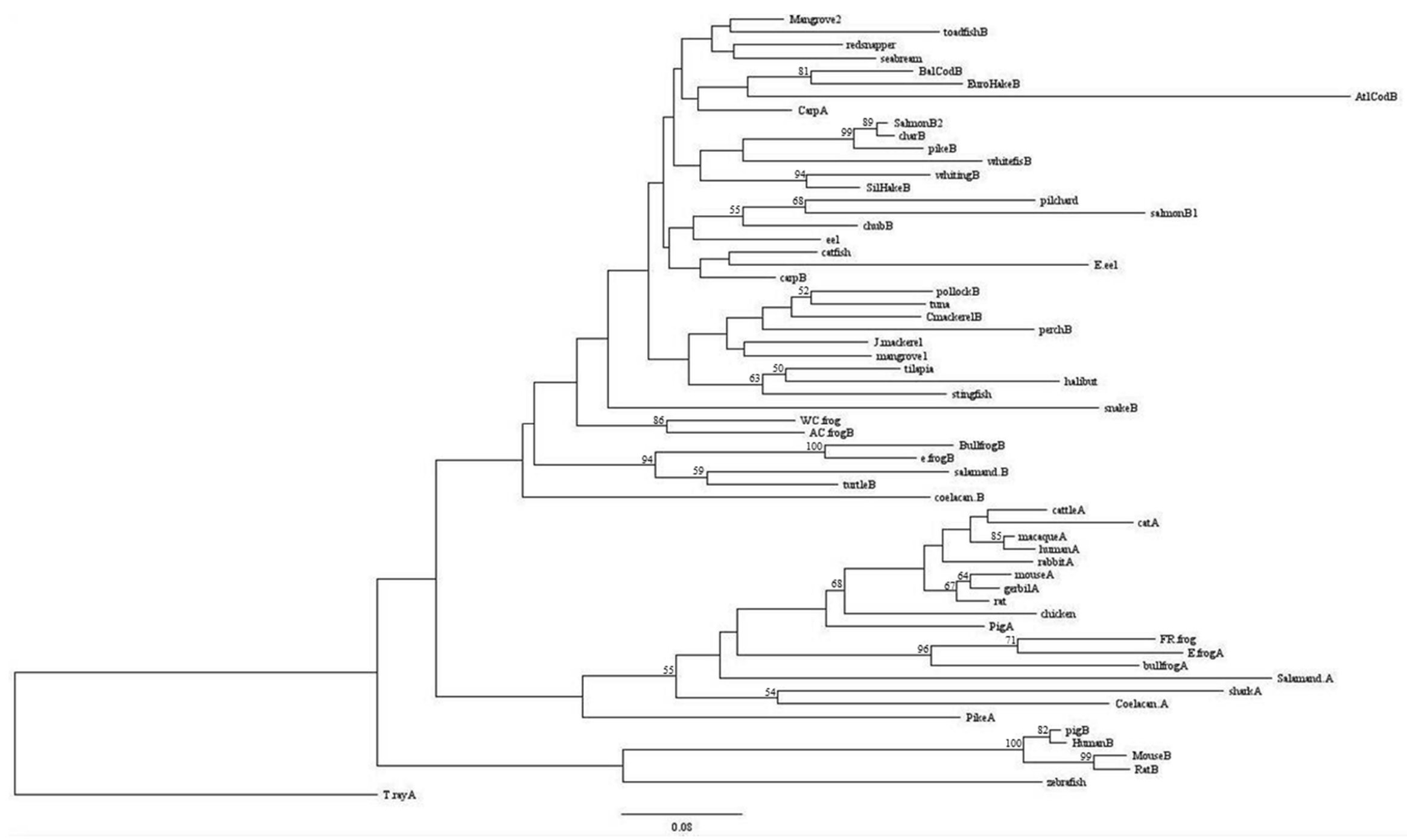

Figure 4. Phylogenetic relationship of the parvalbumins from fish and non-fish species. The scale represents 0.08 amino acid substitutions per site. Bootstrap values above $50 \%$ are displayed in numbers at nodes. 


\section{Appendix A. Characteristics of fish-allergic subjects and in vitro diagnosis}

\begin{tabular}{|c|c|c|c|c|c|c|c|c|c|c|c|c|c|c|c|c|c|c|c|c|c|c|}
\hline 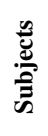 & 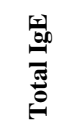 & 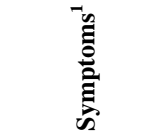 & & & & & & & & & & के & 苞 & & & & & & & & & \\
\hline & & & $\overline{0}$ & 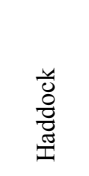 & 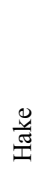 & $\begin{array}{l}\text { ü } \\
\stackrel{0}{0} \\
\overline{0}\end{array}$ & 昜 & 总 & 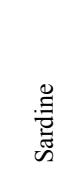 & $\begin{array}{l}\overline{\tilde{\Xi}} \\
\stackrel{\Xi}{0} \\
\dot{\Xi}\end{array}$ & 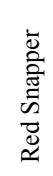 & $\underset{\xi}{\leftrightarrows}$ & 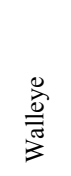 & 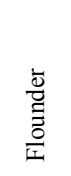 & 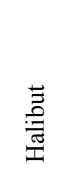 & 范 & 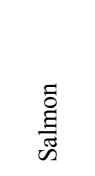 & $\vec{\Xi}$ & $\begin{array}{l}\frac{5}{0} \\
\overline{0} \\
2 \\
\tilde{\Xi} \\
0 \\
0 \\
0\end{array}$ & 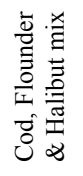 & 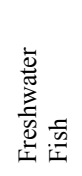 & 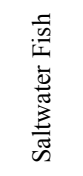 \\
\hline 1 & 121 & $\begin{array}{c}\text { LE,U,DY,OA } \\
\text { S }\end{array}$ & 0.64 & & & & & & & & & $\frac{6 \times 30}{0.6} ;$ & & & & & $\frac{5 \times 20}{0.36}$ & & & & & \\
\hline 2 & 59 & OS,OAS & 1.23 & $\frac{\text { Score 4; }}{3.08}$ & & $\frac{\text { Score 4; }}{1.5}$ & & $\frac{\text { Score 4; }}{1.51}$ & $\frac{\text { Score 4; }}{1.47}$ & & & $\frac{\text { Score 2; }}{4.35}$ & & & & $\frac{\text { Score 4; }}{0.44}$ & $\frac{\text { Score 4; }}{3.52}$ & & & & & \\
\hline 3 & 120 & $\begin{array}{c}\text { OAS,OS,DS, } \\
\text { U }\end{array}$ & $<0.35$ & & & & & & & & & $<0.35$ & & & & & $\begin{array}{c}20 \times 20 ; \\
<0.35\end{array}$ & & & $\underline{7 \times 7}$ & & \\
\hline 4 & 158 & OS,OAS & $<0.35$ & & & & & & & & & $\frac{3 \times 15}{<0.35}$ & $<0.1$ & $<0.1$ & $<0.35$ & & $\frac{2 \times 10 ;}{<0.35}$ & & & $\underline{3 \times 3}$ & & \\
\hline 5 & 374 & $\mathrm{OS}, \mathrm{U}$ & 0.44 & & & & & & & & & $\frac{4 \times 5}{<0.35}$ & & 0.11 & $<0.35$ & & $\frac{0 \times 2 ;}{<0.35}$ & & & $\underline{12 \times 20}$ & & \\
\hline 6 & 229 & $\mathrm{AS}, \mathrm{U}, \mathrm{W}$ & $<0.35$ & & & & & & & & & $\frac{3 \times 5 ;}{<0.35}$ & & $<0.1$ & $<0.35$ & & $\frac{3 \times 10 ;}{<0.35}$ & & & $\underline{2 \times 5}$ & & \\
\hline 7 & 1204 & $\mathrm{U}, \mathrm{OAS}, \mathrm{CT}$ & 3.14 & & & & & & & & & $\frac{4 \times 10}{2.43}$ & & 2.56 & 2.62 & & & & & $\underline{7 \times 20}$ & & \\
\hline 8 & 68 & OS,DY,OAS & $<0.35$ & & & & & & & & & & & & & & $\frac{2 \times 10 ;}{<0.35}$ & & & & & \\
\hline 9 & 222 & H,DY,HB,F & $<0.35$ & & & & & & & & & $\frac{3 \times 10 ;}{<0.35}$ & & $<0.1$ & $<0.35$ & & & & & $\underline{1 \times 4}$ & & \\
\hline 10 & 239 & $\mathrm{OS}, \mathrm{A}, \mathrm{U}$ & $\frac{15 \times 40}{1.32}$ & & & & & & & & & 1.19 & & & & & $\frac{12 \times 30}{1.24}$ & $\underline{15 \times 20}$ & & & & \\
\hline 11 & 179 & $\mathrm{NC}, \mathrm{T}$ & $<0.35$ & & & $\frac{\text { Score 3; }}{<0.1}$ & & & & $<0.1$ & $<0.1$ & & & & & & $\frac{\text { Score 1; }}{<0.35}$ & & & & & \\
\hline 12 & 46 & $\begin{array}{l}\text { ES,AE(face, } \\
\text { hand) }\end{array}$ & $<0.35$ & & & & & & & & & $\frac{1 \times 40 ;}{<0.35}$ & & $<0.1$ & $<0.35$ & & & & & $\underline{2 \times 40}$ & & \\
\hline 13 & 245 & GI,U,OAS & $<0.35$ & & & & & & & & & $\frac{5 \times 20}{<0.35}$ & & & & & $\frac{2 \times 5 ;}{<0.35}$ & & & & & \\
\hline 14 & 457 & OS,OAS & 2.54 & $\frac{\text { Score 4; }}{3.51}$ & & $\frac{\text { Score 4; }}{3.33}$ & & $\frac{\text { Score 4; }}{3.96}$ & $\frac{\text { Score 4; }}{3.2}$ & & & \pm canned & & & & $\frac{\text { Score 4; }}{2.76}$ & $\frac{\text { Score 4; }}{3.32}$ & & & & & \\
\hline 15 & 58 & OS,OAS & $<0.35$ & & & & & & & & & & & $<0.1$ & $<0.35$ & & & & & & & \\
\hline 16 & 84 & $\begin{array}{c}\text { OS,OAS,W,A } \\
\text {,C,ES }\end{array}$ & 3.98 & 3.27 & & & & & & & & 1.83 & 8.49 & & & & 3.21 & 4.16 & $\frac{\text { Score } 4}{3.39}$ & & $\underline{\text { Score } 4}$ & $\underline{\text { Score } 3}$ \\
\hline 17 & 216 & $\mathrm{~A}, \mathrm{DY}, \mathrm{SY}, \mathrm{AE}$ & $<0.35$ & & & & & & & & & $\frac{2 \times 3 ;}{0.35}$ & & & & & $\frac{4 \times 15}{<0.35}$ & & & & & \\
\hline 18 & 2302 & $\mathrm{OS}, \mathrm{U}, \mathrm{V}, \mathrm{DZ}$ & 0.91 & & & & & & & & & $\frac{7 \times 10}{<0.35}$ & & 0.52 & 0.54 & & $\frac{2 \times 10}{0.48}$ & & & $\underline{5 \times 10}$ & & \\
\hline 19 & 43 & OS,SZ,I & $<0.35$ & & & & & & & & & $\frac{3 \times 4 ;}{<0.35}$ & & $<0.35$ & $<0.35$ & & $\frac{0 \times 3}{0.48}$ & & & $\underline{6 \times 8}$ & & \\
\hline 20 & 540 & $\mathrm{~A}, \mathrm{U}, \mathrm{OS}$ & 14.5 & & & & & & & & & $\frac{7 \times 50}{11}$ & & 12.1 & 14.8 & & $\frac{13 \times 60}{14.9}$ & & & $\underline{13 \times 60}$ & & \\
\hline
\end{tabular}

${ }^{1} \mathrm{~A}=$ anaphylaxis; $\mathrm{AS}=$ asthma; $\mathrm{AD}=$ atopic dermatitis; $\mathrm{AE}=$ angioedema; $\mathrm{AP}=$ abdominal pain; $\mathrm{C}=$ cough; $\mathrm{CT}=$ chest tightness; $\mathrm{D}=\mathrm{dermatitis} ; \mathrm{DI}=\mathrm{diarrhea} ; \mathrm{DS}=\mathrm{dysphagia} ;$

$\mathrm{DY}=$ dyspnea; $\mathrm{DZ}=$ dizziness; $\mathrm{ES}=$ eye swelling; $\mathrm{F}=$ flushing; $\mathrm{GI}=$ gastrointestinal symptoms (nausea, vomiting, diarrhea, abdominal pain); $\mathrm{H}=$ hoarseness; $\mathrm{HB}=$ heartburn; $\mathrm{I}=\mathrm{itching}$; $\mathrm{LE}=$ Laryngeal edema; $\mathrm{N}=$ nausea; $\mathrm{NC}=$ nasal congestion; $\mathrm{OAS}=$ oral allergy symptoms; $\mathrm{OS}=$ oropharyngeal swelling; $\mathrm{P}=$ pruritis; $\mathrm{RH}=$ rhinorrhea; $\mathrm{SY}=$ syncope; $\mathrm{SZ}=$ sneezing;

$\mathrm{T}=$ tachypnea; $\mathrm{U}=$ urticaria; $\mathrm{UR}=$ =upper respiratory itching/sneezing; $\mathrm{V}=$ vomiting; $\mathrm{W}=$ wheeze 
Appendix A. (cont.)

\begin{tabular}{|c|c|c|c|c|c|c|c|c|c|c|c|c|c|c|c|c|c|c|c|c|c|c|}
\hline 这 & 菢 & 音 & & & & & & & & & & 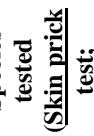 & 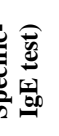 & & & & & & & & & \\
\hline & & & $\overline{0}$ & $\begin{array}{l}\frac{י}{0} \\
\frac{0}{0} \\
\frac{\pi}{\pi}\end{array}$ & 莺 & $\begin{array}{l}\frac{4}{0} \\
\frac{0}{0} \\
0\end{array}$ & 兽 & 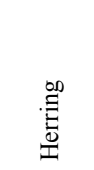 & 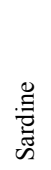 & $\begin{array}{l}\overline{\mathrm{o}} \\
\bar{\Xi} \\
\dot{0}\end{array}$ & 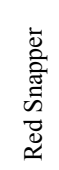 & $\stackrel{\Xi}{\Xi}$ & 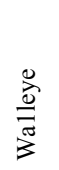 & 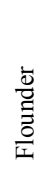 & $\begin{array}{l}\overline{\#} \\
\text { 言 } \\
\text { 胥 }\end{array}$ & $\frac{0}{0}$ & 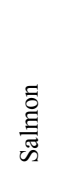 & 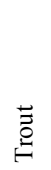 & 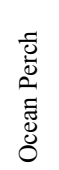 & 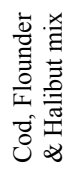 & 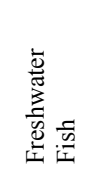 & 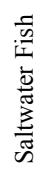 \\
\hline 21 & NA & OAS,DY & $\frac{14 \times 47}{8.64}$ & & $\underline{12 \times 44}$ & & $\underline{14 \times 36}$ & $\underline{9.5 \times 47}$ & & & & $\underline{8.5 \times 22}$ & & & & & & & & & $\underline{7 \times 37}$ & \\
\hline 22 & NA & AP,OAS & $\frac{8 \times 38}{8.56}$ & & $\underline{10 \times 34}$ & & $\underline{11 \times 29}$ & $\underline{11 \times 36}$ & & & & $\underline{8 \times 29}$ & & & & & & & & & $\underline{18 \times 43}$ & \\
\hline 23 & NA & $\begin{array}{c}\text { D,P,AE,U,UR } \\
\text {,RH,LE,DY } \\
\text { N,V,DI }\end{array}$ & $\underline{7 \times 39} ; 0.5$ & & $\underline{14 \times 48}$ & & $\underline{9 \times 35}$ & $7.5 \times 34$ & & & & $\underline{4 \times 18}$ & & & & & & & & & $8.5 \times 31$ & \\
\hline 24 & NA & LE,N,OAS & $\frac{11.75(\mathrm{w})}{51.3}$ & & $\underline{13(\mathrm{w})}$ & & $\underline{8.25(\mathrm{w})}$ & $\underline{15(\mathrm{w})}$ & & & & $\underline{5.5(\mathrm{w})}$ & & & & & & & & & $11.75(\mathrm{w})$ & \\
\hline 25 & NA & OAS,DS & $\frac{5 \times 27}{5.42}$ & & $\frac{9.25 x}{26}$ & & $\underline{8 \times 25}$ & $\underline{5.5 \times 24}$ & & & & $\underline{2.25 \times 23}$ & & & & & & & & & $\underline{8.5 \times 26}$ & \\
\hline 26 & NA & LE,OAS & $\frac{17.5 \times 38}{14.4}$ & & $\underline{24 \times 44}$ & & $\underline{14 \times 38}$ & $\underline{14 \times 38}$ & & & & $\underline{3.5 \times 13}$ & & & & & & & & & $\underline{15 \times 35}$ & \\
\hline 27 & NA & $\begin{array}{c}\mathrm{N}, \mathrm{AP}, \mathrm{DI}, \mathrm{OA} \\
\mathrm{S}\end{array}$ & $\frac{4.25(\mathrm{w})}{12.2}$ & & $\underline{5(\mathrm{w})}$ & & $\underline{4.5(\mathrm{w})}$ & $\underline{4.74(\mathrm{w})}$ & & & & $\underline{4.5(\mathrm{w})}$ & & & & & & & & & $\underline{4.25(\mathrm{w})}$ & \\
\hline 28 & NA & P,NC,DY,ES & $\frac{13 \times 30.5 ;}{1.15}$ & & $\underline{11 \times 18}$ & & $\underline{11 \times 19}$ & $\underline{9(w)}$ & & & & $3.25 \times 16$ & & & & & & & & & $9.25 \times 21$ & \\
\hline 29 & NA & $\begin{array}{c}\text { AE,RH,LE,O } \\
\text { AS }\end{array}$ & $\frac{14 \times 53}{42.7}$ & & $\underline{13 \times 48}$ & & $\underline{13 \times 50}$ & $\underline{9 \times 49}$ & & & & $\underline{9 \times 37}$ & & & & & & & & & $\underline{12 \times 50}$ & \\
\hline 30 & NA & OAS & $\frac{9 \times 36 ;}{5.38}$ & & $\underline{13 \times 28}$ & & $\underline{4.25 \times 35}$ & $\underline{14 \times 35}$ & & & & $\underline{2.75 \times 13}$ & & & & & & & & & $\underline{8 \times 35}$ & \\
\hline 31 & NA & $\mathrm{P}, \mathrm{N}, \mathrm{V}, \mathrm{DI}$ & $\frac{28 \times 50}{13.6}$ & & $\underline{22 \times 50}$ & & $\underline{28 \times 52}$ & $\underline{15 \times 22}$ & & & & $\underline{12 \times 26}$ & & & & & & & & & $\underline{23 \times 31}$ & \\
\hline 32 & NA & $\begin{array}{c}\text { P,U,LE,N,AP, } \\
\text { OAS,DY }\end{array}$ & $\frac{4.75 \times 26 ;}{1.01}$ & & $\underline{4 \times 24}$ & & $\underline{6 \times 22}$ & $\underline{4 \times 15}$ & & & & $\underline{3.75 \times 20}$ & & & & & & & & & $\underline{3.5 \times 19}$ & \\
\hline 33 & NA & OAS,DS & $\frac{20 \times 53}{0.94}$ & & $\underline{8 \times 35}$ & & $\underline{13 \times 52}$ & $\underline{5.25 \times 33}$ & & & & $\underline{6.25 \times 42}$ & & & & & & & & & $\underline{12 \times 42}$ & \\
\hline 34 & NA & U,OAS & $\frac{2.75(\mathrm{w})}{3.33}$ & & $\underline{9 \times 32}$ & & $\underline{8 \times 29}$ & $\underline{3.75(w)}$ & & & & $\underline{2.75(\mathrm{w})}$ & & & & & & & & & $\underline{3.75(\mathrm{w})}$ & \\
\hline 35 & NA & & 42.7 & & & & & & & & & 20 & & & & & & & & & & \\
\hline 36 & NA & & 20.8 & & & & & & & & & 14.2 & & & & & & & & & & \\
\hline 37 & NA & & 19.7 & & & & & & & & & & & & & & 12.8 & & & & & \\
\hline 38 & NA & & 15 & & & & & & & & & & & & & & & & & & & \\
\hline 39 & NA & & 25.7 & & & & & & & & & & & & & & & & & & & \\
\hline 40 & NA & & 34.6 & & & & & & & & & & & & & & 22.2 & & & & & \\
\hline 41 & NA & & 22.4 & & & & & & & & & & & & & & & & & & & \\
\hline 42 & NA & $\begin{array}{c}\text { U, P, OAS, } \\
\text { AE (oral) }\end{array}$ & $\frac{21 \times 45 ;}{3.48}$ & & & & & & & & & & & & & & & & & & & \\
\hline 43 & NA & $\begin{array}{l}\text { OAS, AD, } \\
\text { AE (oral) }\end{array}$ & $\frac{8 \times 15 ;}{2.47}$ & & & & & & & & & & & & & & & & & & & \\
\hline
\end{tabular}




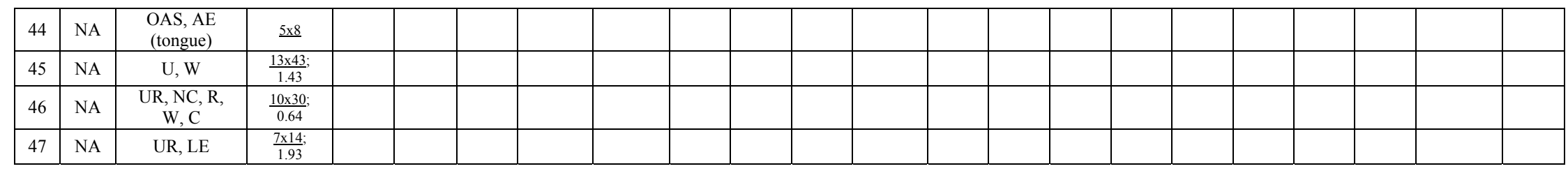

${ }^{1} \mathrm{~A}=$ anaphylaxis; $\mathrm{AS}=$ asthma; $\mathrm{AD}=$ atopic dermatitis; $\mathrm{AE}=$ angioedema; $\mathrm{AP}=$ abdominal pain; $\mathrm{C}=$ cough; $\mathrm{CT}=$ chest tightness; $\mathrm{D}=$ dermatitis; $\mathrm{DI}=$ diarrhea; $\mathrm{DS}=$ dysphagia;

$\mathrm{DY}=$ dyspnea; $\mathrm{DZ}=$ dizziness; $\mathrm{ES}=$ eye swelling; $\mathrm{F}=$ flushing; $\mathrm{GI}=$ gastrointestinal symptoms (nausea, vomiting, diarrhea, abdominal pain); $\mathrm{H}=$ hoarseness; $\mathrm{HB}=$ heartburn; $\mathrm{I}=\mathrm{itching}$;

$\mathrm{LE}=$ Laryngeal edema; $\mathrm{N}=$ nausea; $\mathrm{NC}=$ nasal congestion; $\mathrm{OAS}=$ oral allergy symptoms; $\mathrm{OS}=$ oropharyngeal swelling; $\mathrm{P}=$ pruritis; $\mathrm{RH}=$ rhinorrhea; $\mathrm{SY}=$ syncope; $\mathrm{SZ}=$ sneezing;

$\mathrm{T}=$ tachypnea; $\mathrm{U}=$ urticaria; $\mathrm{UR}=$ upper respiratory itching/sneezing; $\mathrm{V}=$ vomiting; $\mathrm{W}=$ wheeze 
Appendix B. Immunoblot analysis of IgE binding from non-atopic, atopic, and 47 fish-allergic subjects (serum \#1 - \#47) to purified cod and carp parvalbumins, and crude extracts of fish and frog muscles.
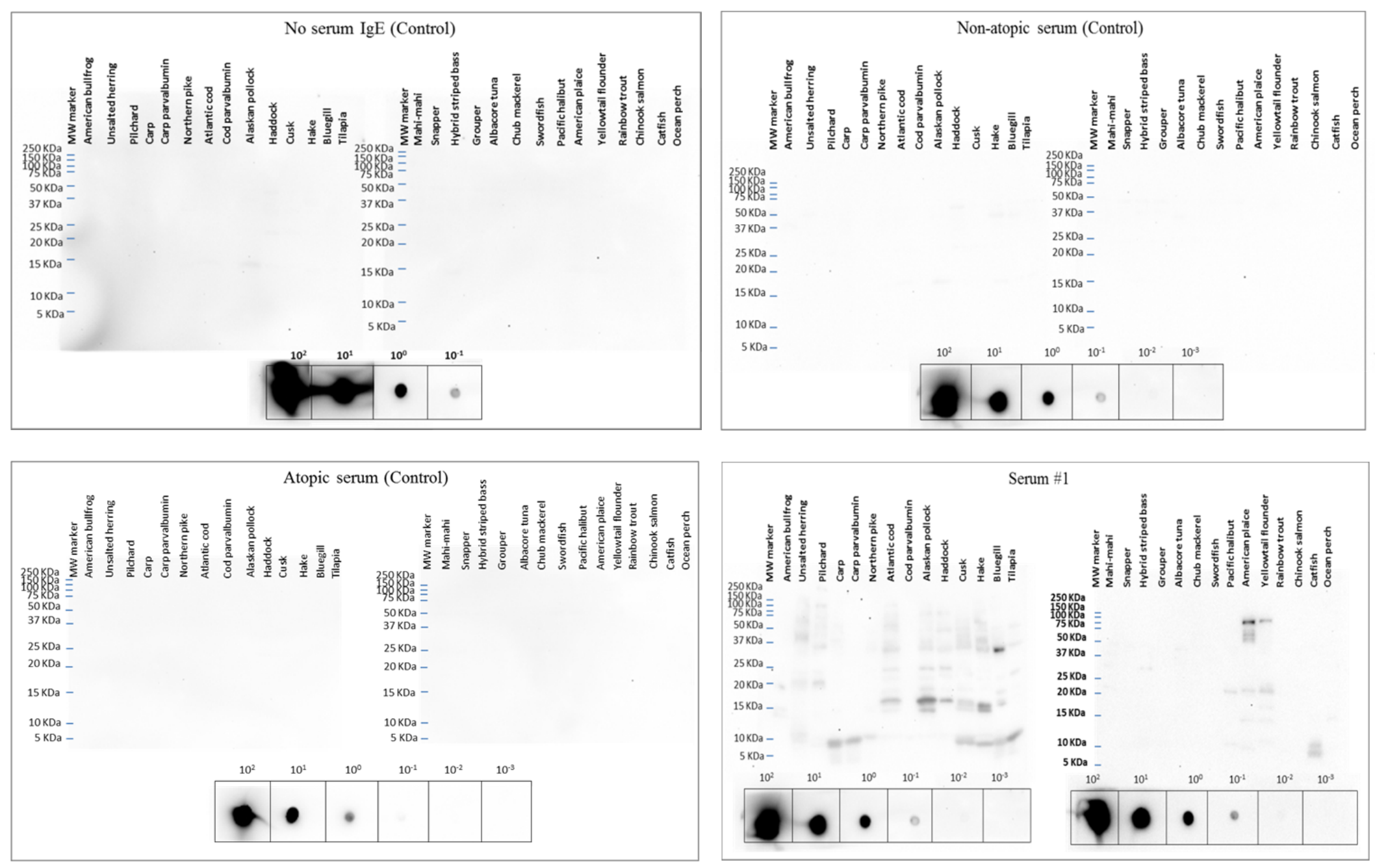

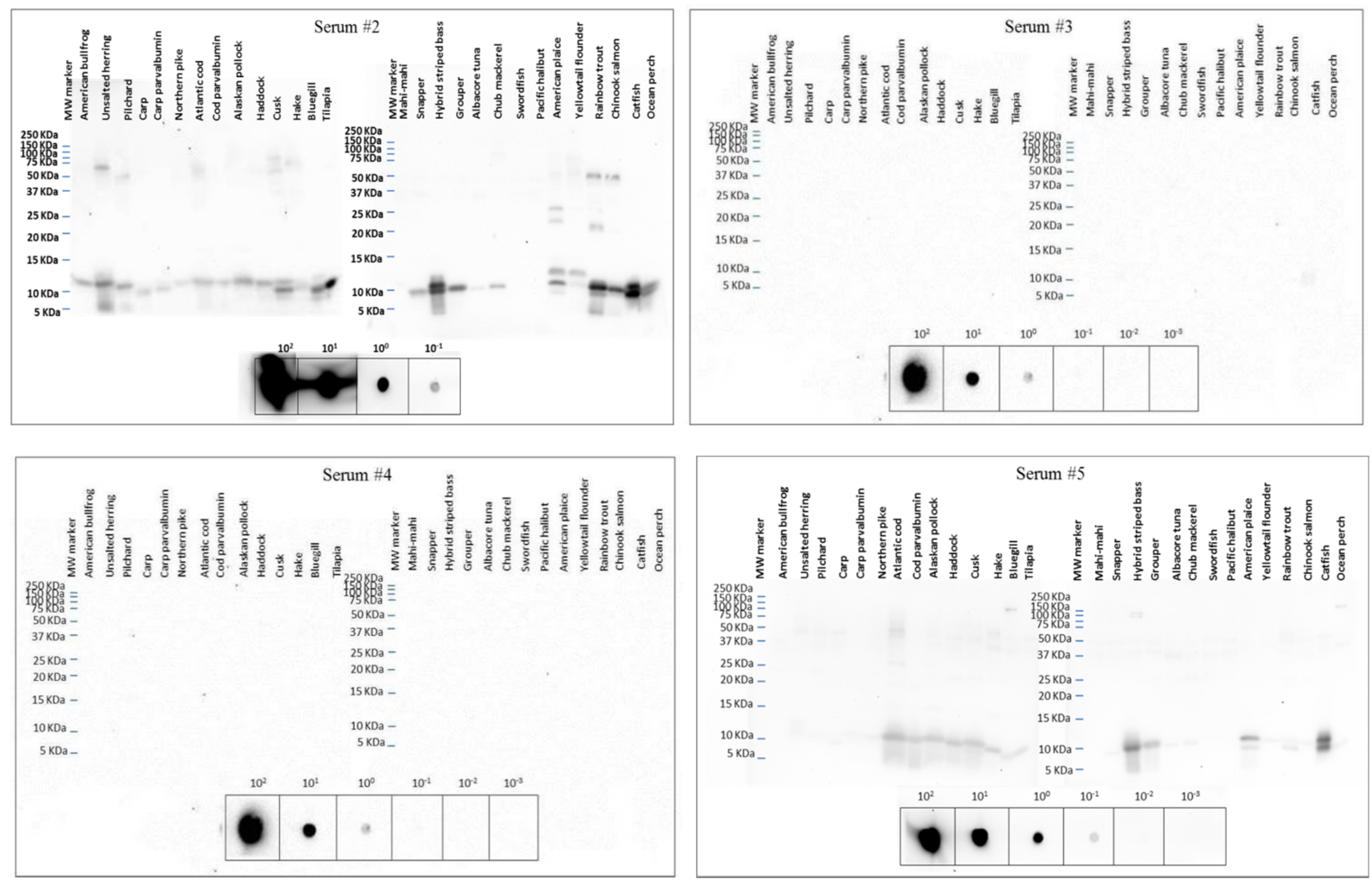

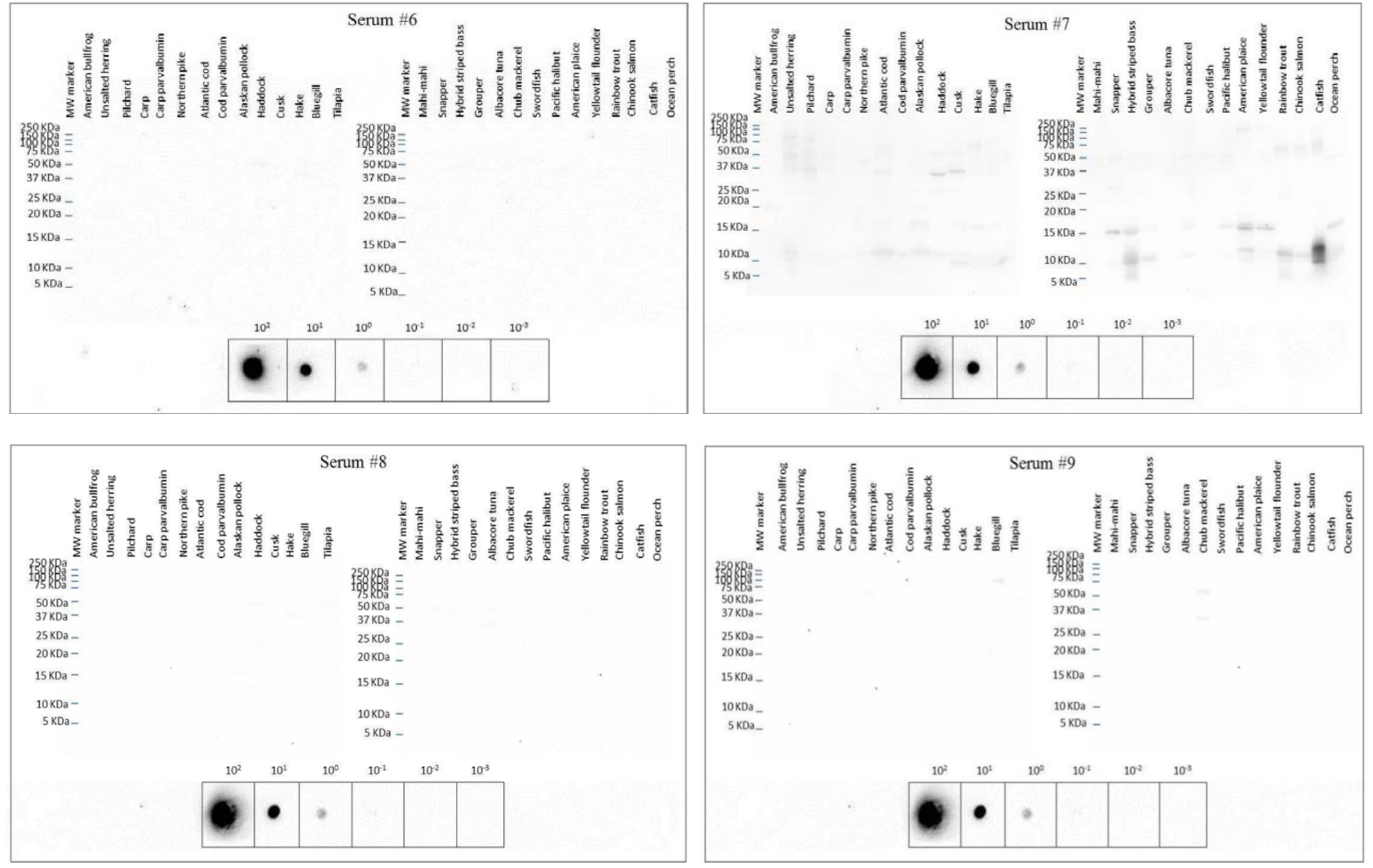

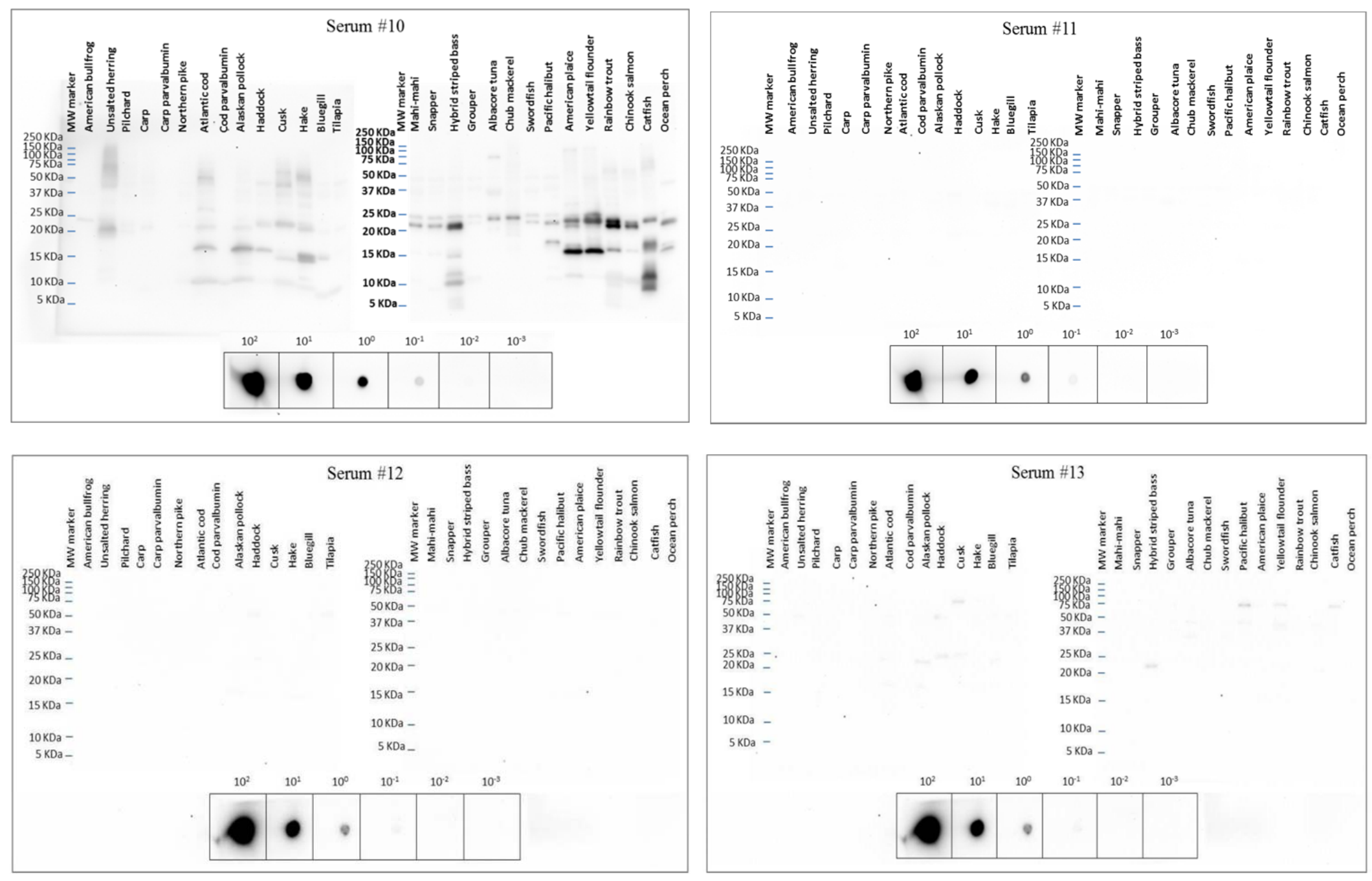

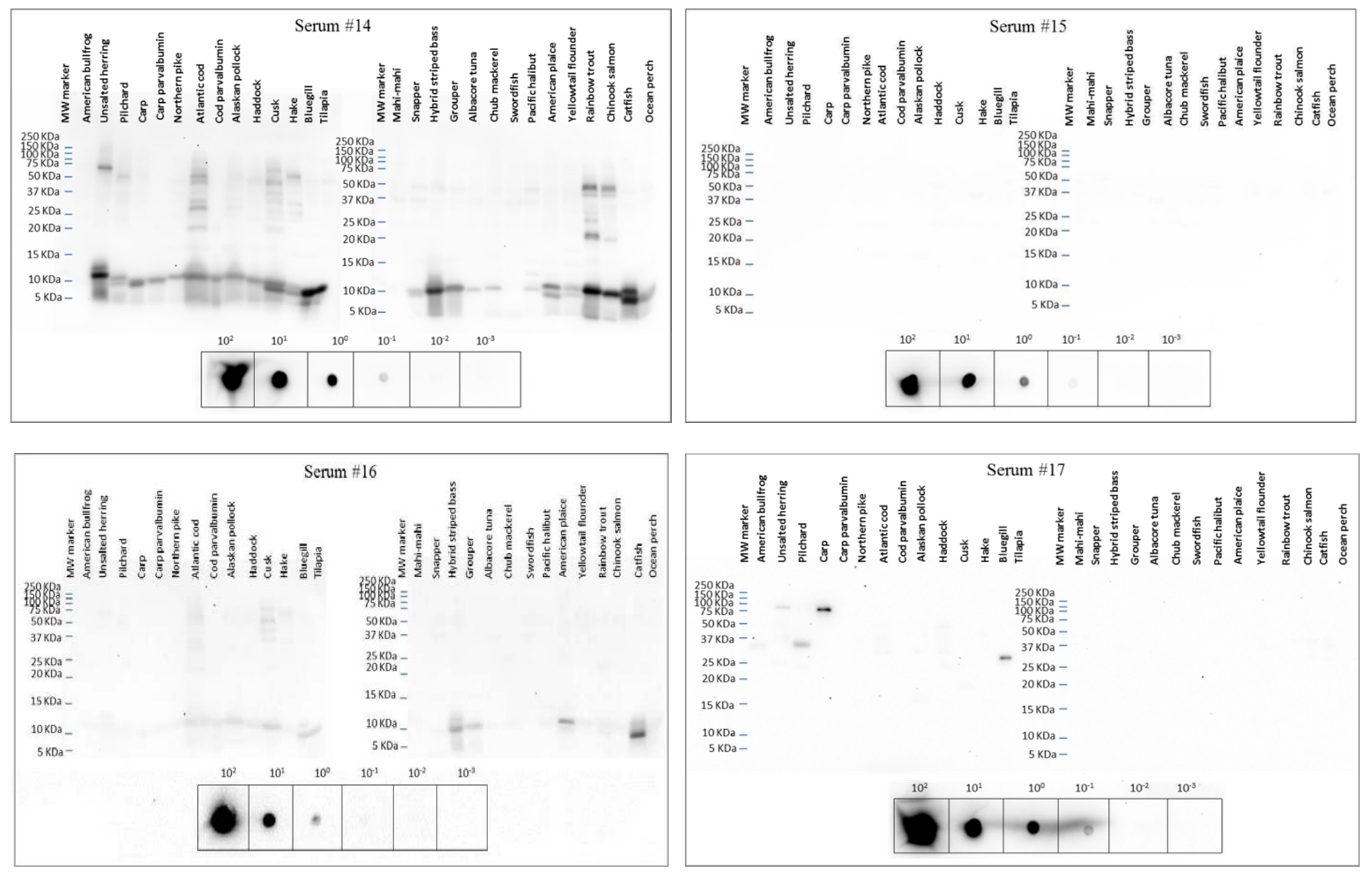

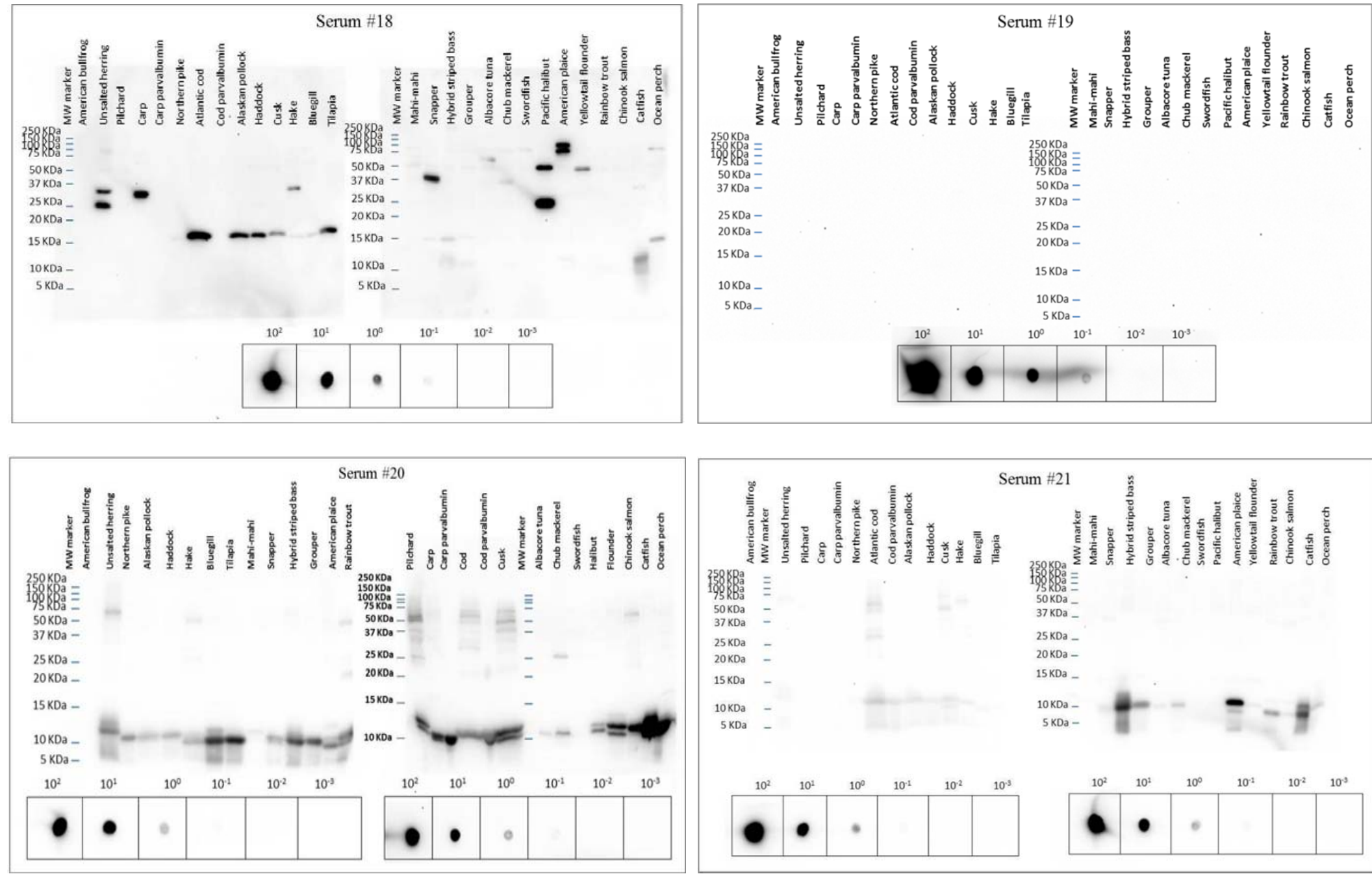

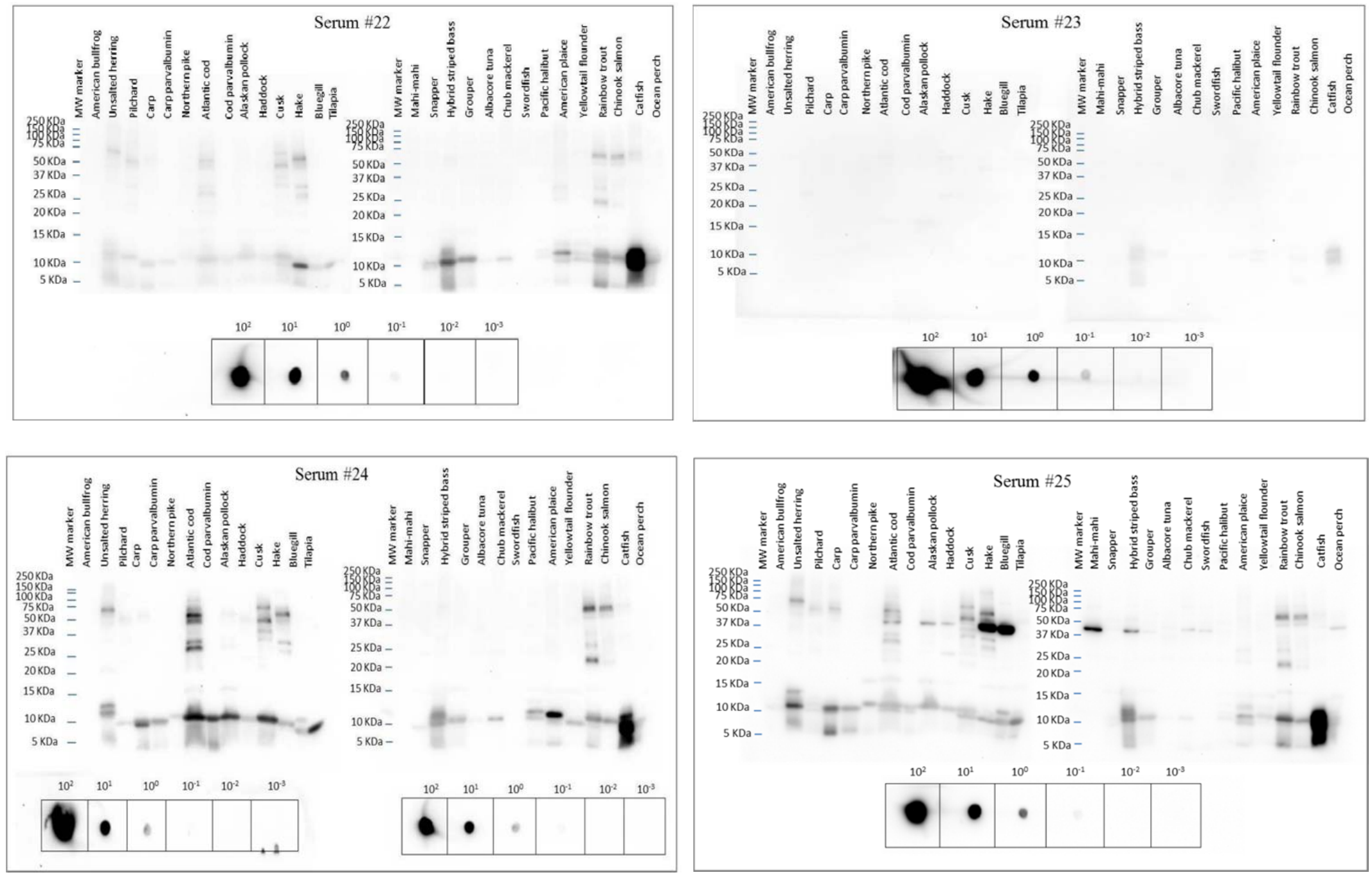

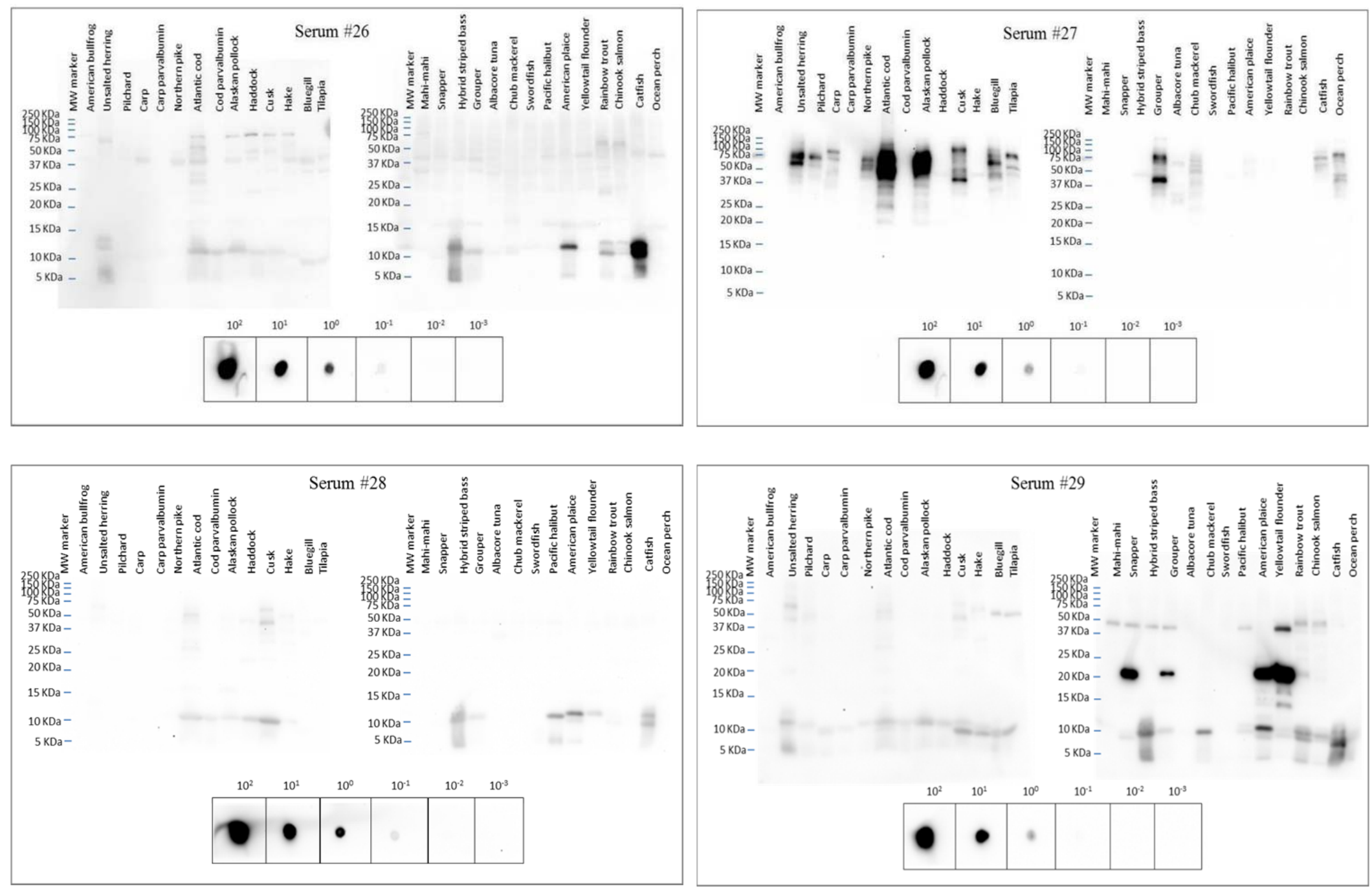

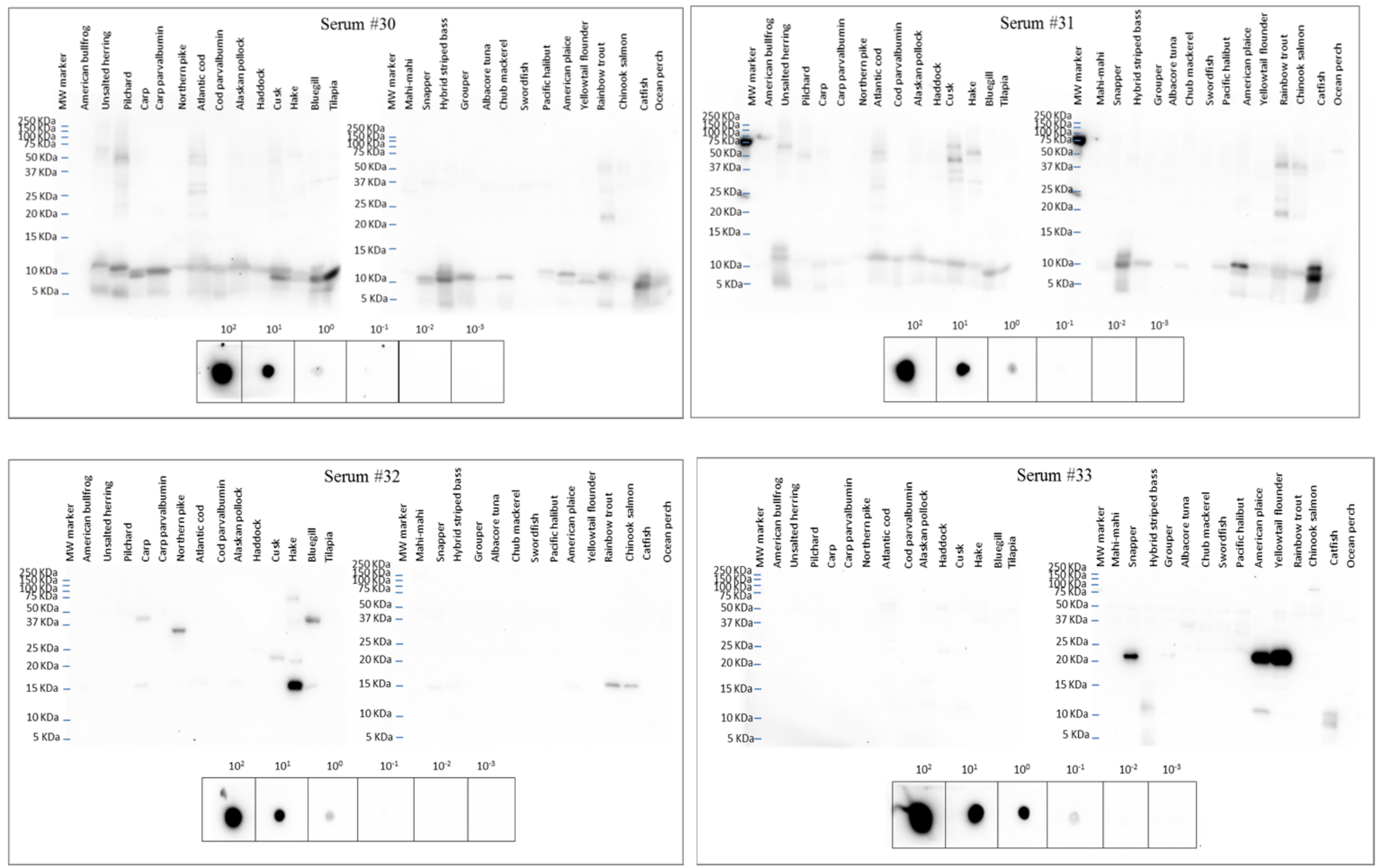

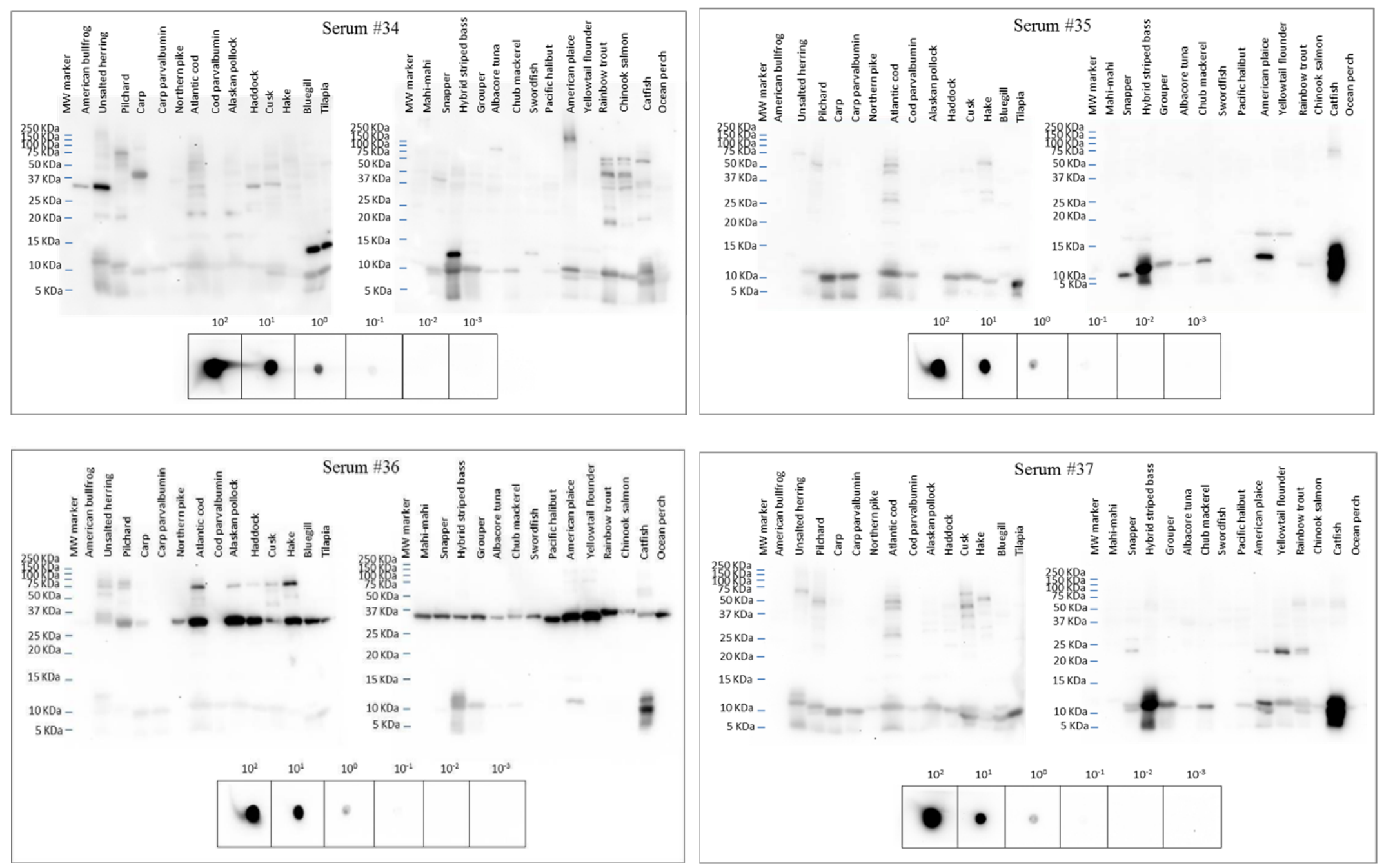

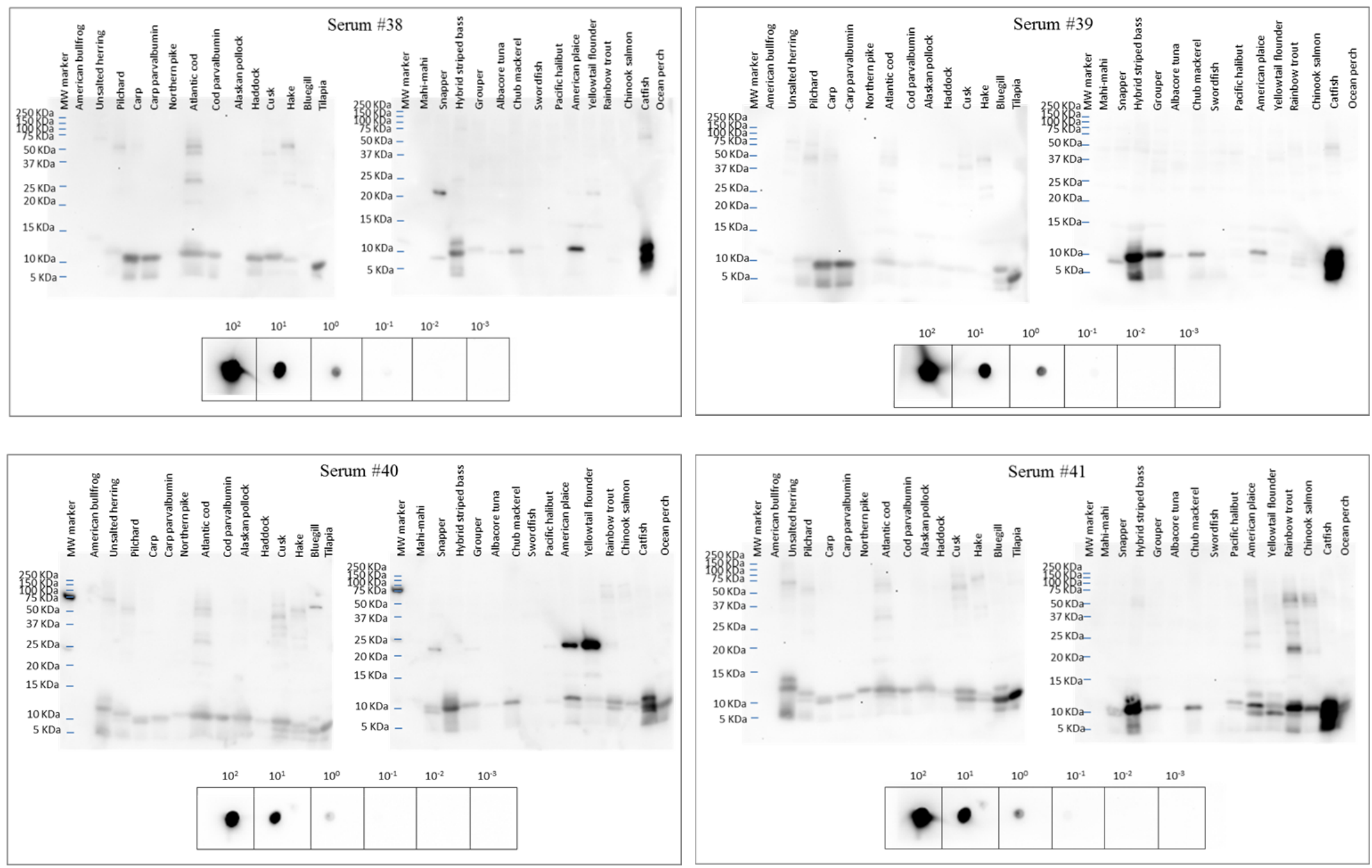

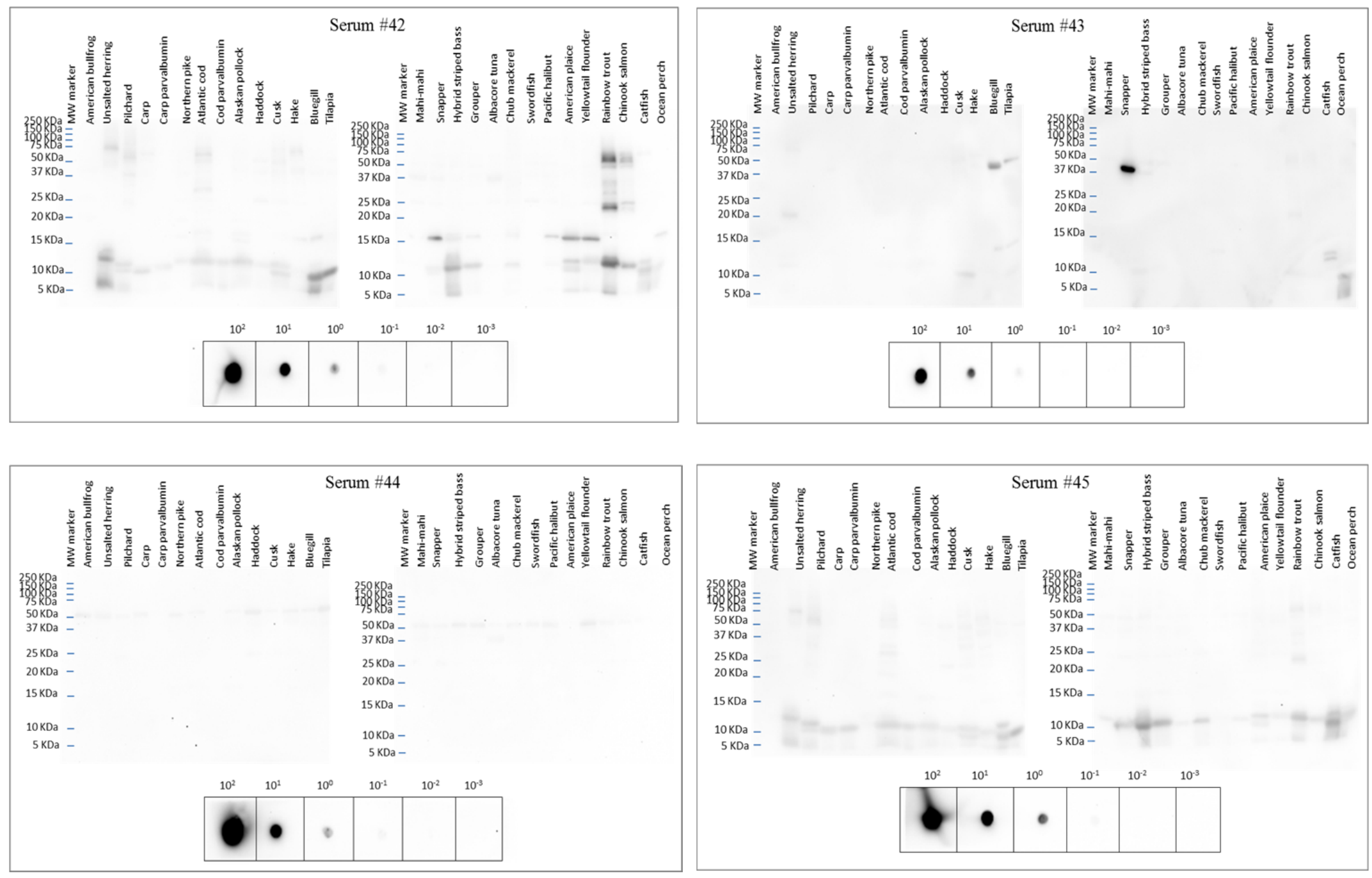

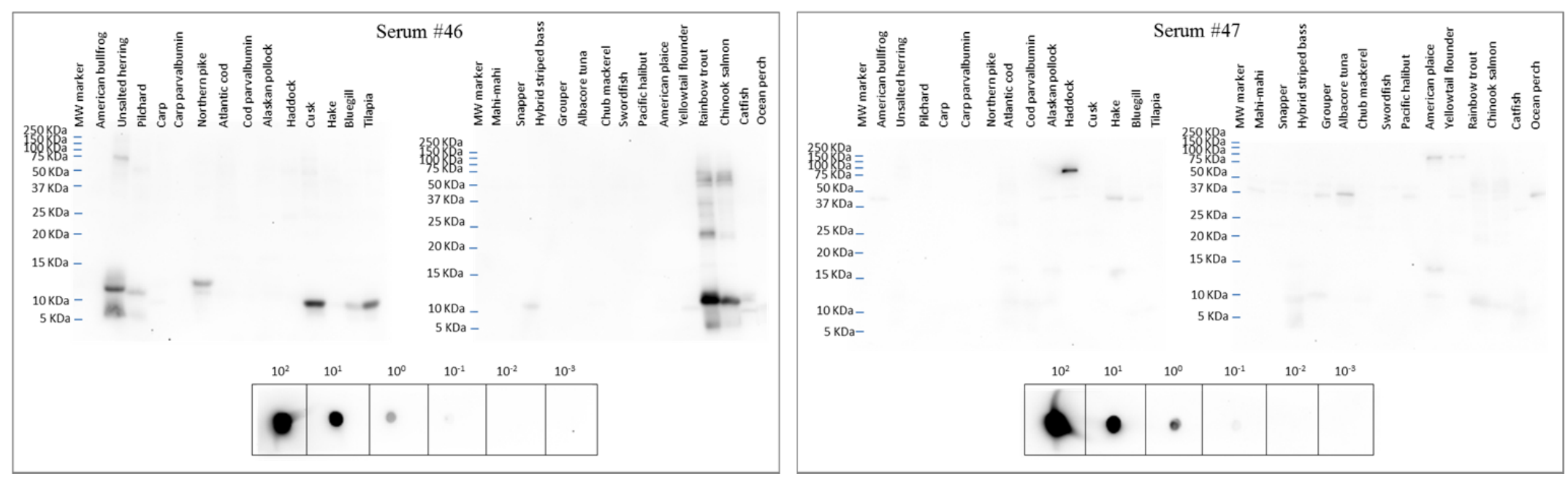

Dot blotting of the serially-diluted human IgE proteins $\left(10^{2}-10^{-3} \mathrm{ng} /\right.$ spot $)$ are shown in square boxes. 
Appendix C. Frequency and mean IgE-binding intensity of sera from 39 fish-allergic subjects to fish and frog proteins of different molecular weights ranges on immunoblots.

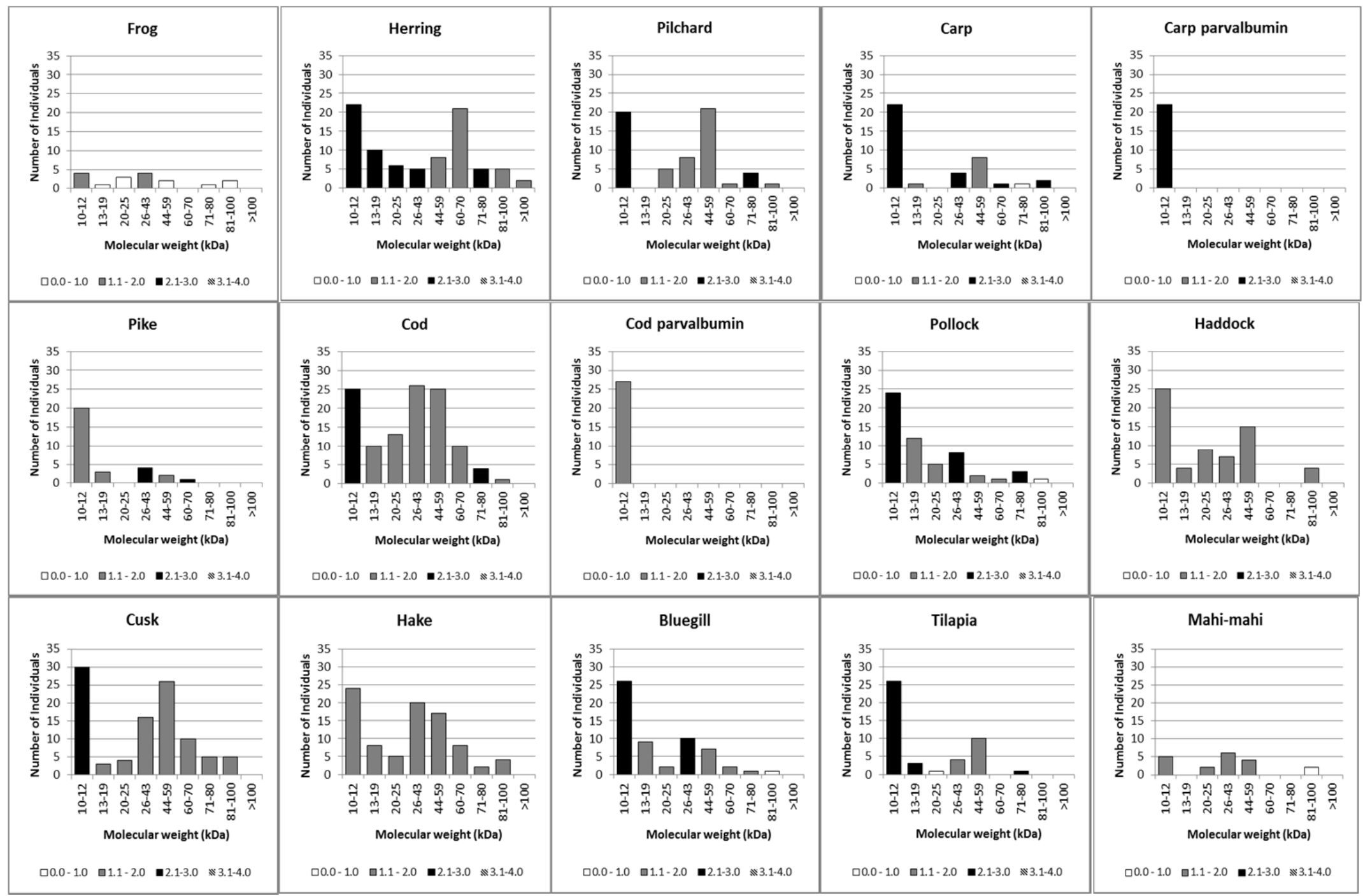




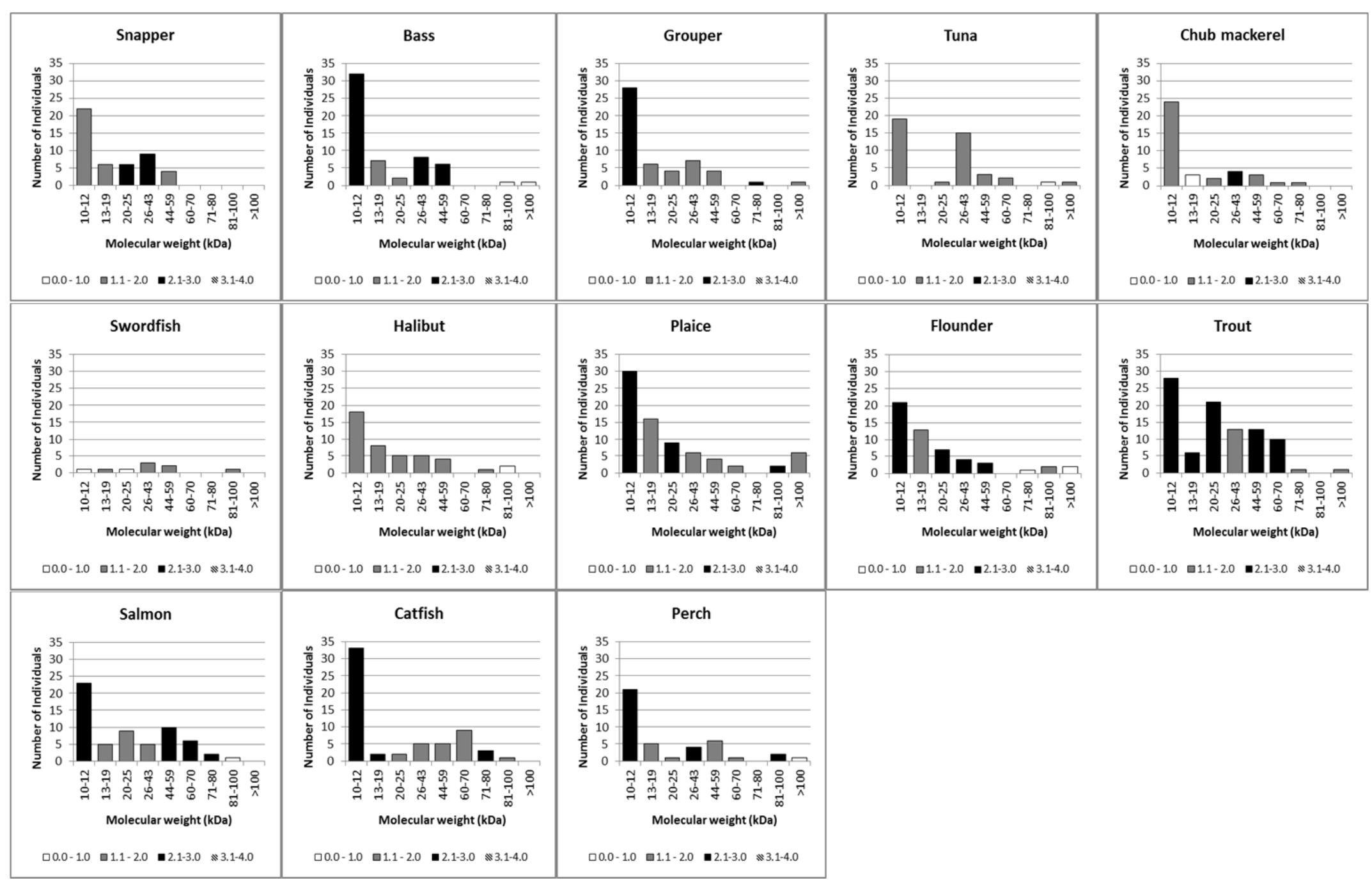

The degree of IgE-binding intensity shown in the figure legends ranged from extremely strong (3.1 - 4.0), strong (2.1 - 3.0), medium (1.1 - 2.0), and low (0.0 - 1.0) intensity. The intensity of the IgE-binding corresponded to the relative amounts of human IgE proteins on dot blots: extremely strong $\left(>10^{2} \mathrm{ng} / \mathrm{spot}\right)$, strong $\left(10^{1}-10^{\circ} \mathrm{ng} / \mathrm{spot}\right)$, medium $\left(10^{0}-10^{-1} \mathrm{ng} / \mathrm{spot}\right)$, and low $\left(<10^{-1} \mathrm{ng} /\right.$ spot $)$ intensity. 